\title{
Coal/Biomass Gasification at the Colorado School of Mines
}

\author{
Final Scientific/Technical Report
}

Reporting Period Start Date: August 12, 2008

Reporting Period End Date: February 28, 2011

\section{Principal Authors:}

Terry Parker, Provost and Executive Vice President Robert Braun, Assistant Professor, Engineering Division Chris Dreyer, Associate Research Professor, Engineering Division

Anthony Dean, Professor, Chemical Engineering Mark Eberhart, Professor, Chemistry

Robert Kee, Professor, Engineering Division Jason Porter, Assistant Professor, Engineering Division

Ivar Reimanis, Professor, Metallurgical Engineering

Nigel Sammes, Professor, Metallurgical Engineering

Date Report Issued: November 2011 DOE Award Number DE-NT0005202

\author{
Submitted by: \\ Colorado School of Mines \\ 1500 Illinois Street \\ Golden, CO 80401
}




\section{Disclaimer:}

This report was prepared as an account of work sponsored by an agency of the United States Government. Neither the United States Government nor any agency thereof, nor any of their employees, makes any warranty, express or implied, or assumes any legal liability or responsibility for the accuracy, completeness, or usefulness of any information, apparatus, product, or process disclosed, or represents that its use would not infringe privately owned rights. Reference herein to any specific commercial product, process, or service by trade name, trademark, manufacturer, or otherwise does not necessarily constitute or imply its endorsement, recommendation, or favoring by the United States Government or any agency thereof. The views and opinions of authors expressed herein do not necessarily state or reflect those of the United States Government or any agency thereof. 


\begin{abstract}
:
This program was a 2.5 year effort focused on technologies that support coal and biomass gasification. Two primary tasks were included in the effort: 1) Coal/Biomass gasification and system optimization (organized as three subtasks) and 2) development of high temperature micro channel ceramic heat exchangers. This program integrates effort from faculty, students, and staff in Engineering, Chemical Engineering, Metallurgical Engineering, and Chemistry at the Colorado School of Mines. Short descriptions for the tasks and the primary task outcomes are included in the summary below. A more complete reporting of the activity for each task is contained in the body of the report.
\end{abstract}

\title{
Task I: Coal/Biomass gasification and system optimization
}

This task focuses on three subtasks: 1) syngas characterization as a function of fuel and operating parameters, 2) investigation of tar reduction methods, and 3) system modeling and optimization.

\section{I-A: Syngas Characterization as a Function of Fuel and Operating Parameters}

This effort has focused on design, assembly, and initial testing of a laboratory-scale, highpressure gasification reactor. Key elements for this reactor are: production of a system that has demonstrated temperatures and pressures typical of industrial gasifiers but at the university laboratory scale providing a cost effective testbed for gasification; operational flexibility that allows control of parameters such as temperature, pressure, residence time, and variable feedrates for gas-phase reactants and solids (coal and/or biomass); and real-time analysis of major gas-phase species at the gasifier outlet.

The CSM gasifier is a compact one-meter flow reactor capable of temperatures to $1650^{\circ} \mathrm{C}$ and pressures to $41 \mathrm{~atm}$. Particulate feeding is accomplished using an auger-type feeder contained in a separate pressure vessel capable of feeding particulate matter up to approximately $100 \mu \mathrm{m}$ mean diameter. The completed gasifier has been operated at a temperature of $1450^{\circ} \mathrm{C}$ and has demonstrated successful coal gasification at pressures of 2.5 atm and $8.5 \mathrm{~atm}$. Syngas concentrations of nearly $50 \%$ in an argon entrainment flow have been demonstrated, with higher concentrations expected in future testing.

\section{I-B: Investigation of Tar Reduction Methods}

This study included a combined experimental and modeling investigation to determine the effect of oxygen addition to a synthesis gas stream that contains methane and/or ethylene as representative hydrocarbons. This study focused on the removal of organic compounds from a synthesis gas stream that could lead to deposit formation in downstream units (e.g., solid-oxide fuel cells or gas-to-liquids catalysts). The objectives of this work were to explore the potential for gas-phase partial oxidation reactions to remove deposit precursors, develop a suitable partial oxidation kinetic model to identify optimum conditions for this process, and assess the potential to increase the concentration of good fuels such as methane, hydrogen, and carbon monoxide in 
the gasifier stream. A detailed kinetic model was developed that indicated such selective oxidation could be achieved under certain conditions. These conditions were then verified in a series of experiments. The good agreement between the model predictions and our experimental data also allowed us to interrogate the model to understand the reasons for the surprisingly selective oxidation. This research on selective oxidation of ethylene was been documented in a paper published in the Journal of Physical Chemistry A. Another manuscript is in preparation describing our research on selective oxidation of propylene. We presented aspects of this research at the International Conference on Chemical Kinetics held in July 2011 at MIT.

\section{I-C: Systems Modeling and Optimization}

In this task, a system-level modeling efforts were carried out that focused on two primary areas of investigation: (1) integration of existing energy conversion technologies to achieve highlyefficient IGFC systems with optional carbon capture, and (2) evaluating carbon capture strategies for IGFC hybrid power systems using emerging membrane separation technologies. IGFC system studies were carried out in Focus Area (1) at the 140-150 MW scale for plants integrated with an entrained-flow, dry-fed, oxygen-blown, slagging coal gasifier and a combined cycle in the form of a gas turbine and either steam or organic Rankine cycle (ORC) bottoming power generator. The results of the study indicate that hybrid SOFC-GT-ORC systems could achieve electric efficiencies approaching $48 \%$ (LHV) and reach as high as $51 \%$ with CCS if optimal SOFC operating parameters are selected.

Focus Area (2) carried out techno-economic analyses that evaluated concepts that employed either hydrogen or oxygen transfer membrane technologies strategically located upstream or downstream of the SOFC power block. In particular, the analysis focused on examination of pre-SOFC and post-SOFC CCS concepts. The best system configuration results when water-gas shift membrane reactor technology is employed in a Pre-SOFC CCS system. The system achieves a $\sim 3 \%$ decrease in capital cost and $2.1 \%$ increase in overall efficiency to $49.8 \%$-LHV.

One journal paper derived from Focus Area (1) has been published in the ASME Journal of Gas Turbines and Power. Another journal paper derived from Focus Area (2) is in draft. The results for both focus areas have been presented in three different talks given at the ASME International Colloquium on Environmentally Preferred Advanced Generation (ICEPAG) in 2010 and 2011.

\section{Task II: High Temperature microchannel exchangers}

This effort was focused on the model-based design and experimental performance evaluation of an all-ceramic compact counterflow microchannel heat exchanger. A unique fabrication process called Pressure Laminated Integrated Structures (PLIS) facilitated low-cost manufacturing. The fabricated heat exchangers were tested using inlet air heated up to $750^{\circ} \mathrm{C}$ on the hot side, roomtemperature inlet air on the cold side, and flow rates up to $3 \times 10^{-3} \mathrm{~kg} \mathrm{~s}^{-1}$ (150 standard liters per minute of air). The paper reports measured performance of single units at the kilowatt scale for which heat-exchanger effectiveness up to $70 \%$ has been achieved. 


\section{Table of Contents}

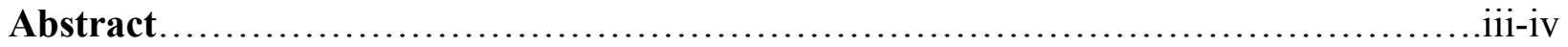

Task I: Coal/Biomass gasification and system optimization

I-A: Syngas Characterization as a Function of Fuel and Operating Parameters........ I-A, p. 1-11

I-B: Cleanup of Gasifier Output.............................................. p. 1-19

I-C: Systems Modeling and Optimization........................................ p. 1-84

Task II: High temperature microchannel exchangers.........................II, p. 1-23 


\title{
Design, assembly, and initial testing of a laboratory-scale gasification reactor
}

\author{
Sub-task I-A
}

Final Report

T. Parker, J. Porter, M. Jakulewicz

1610 Illinois Street

Engineering Division

Colorado School of Mines

Golden, CO 80401

Prepared for:

The U.S. Department of Energy

National Energy Technology Laboratory

626 Cochrans Mill Road

Pittsburgh, PA

Under contract no.: DE-NT0005202

1 October 2011

\section{COLORADOSCHOOLOFMINES}




\section{Table of Contents}

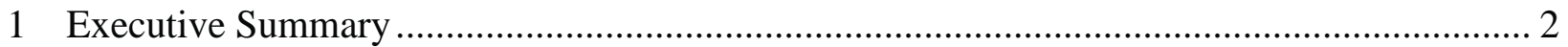

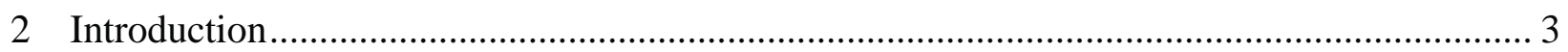

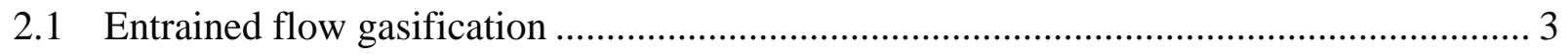

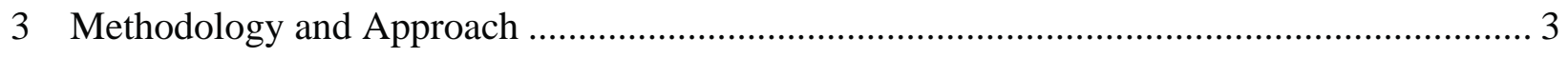

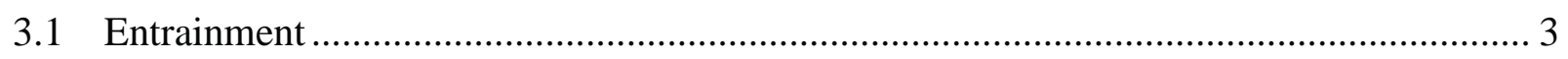

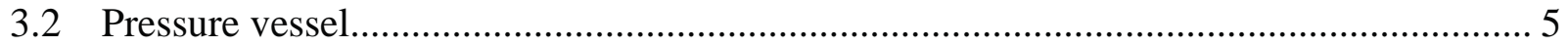

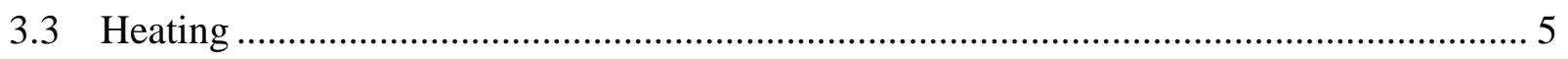

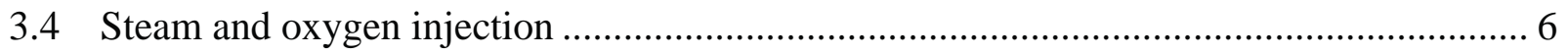

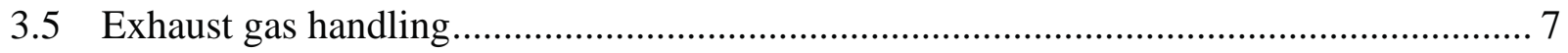

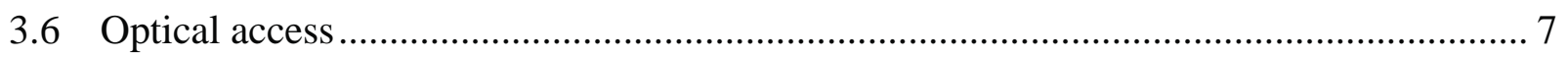

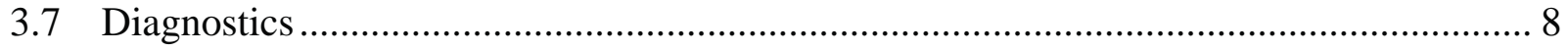

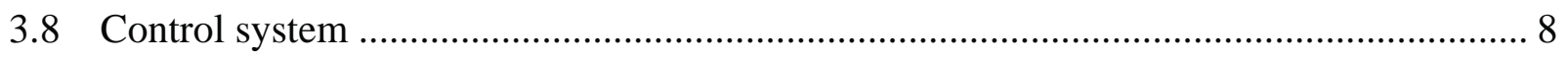

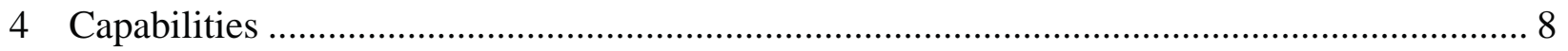

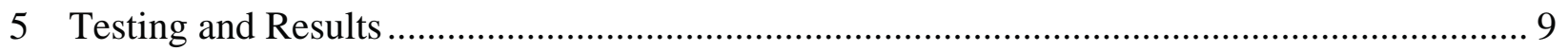

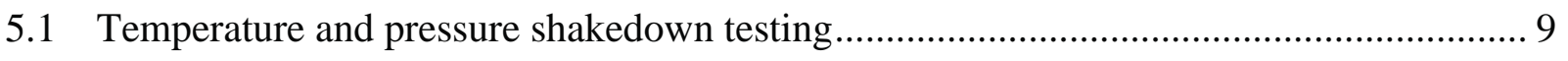

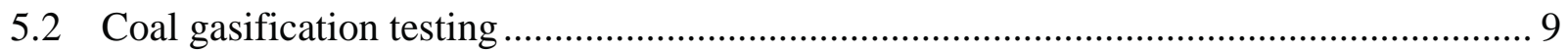

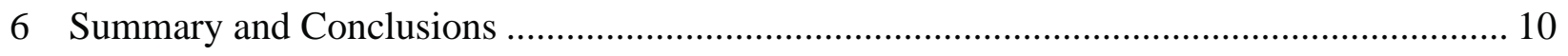

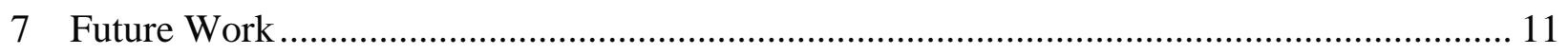

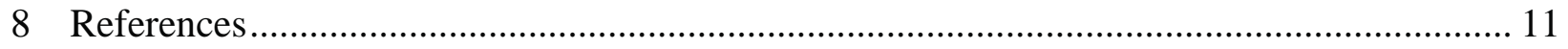




\section{Executive Summary}

Sub-task I.A focuses on the design, assembly, and initial testing of a laboratory-scale, highpressure gasification reactor. The project's research objective was to design and build a compact, fuel flexible system to study the high-temperature and high-pressure reaction kinetics of coal and biomass. During the design phase of the project, researchers at the Colorado School of Mines studied several existing high-pressure entrained flow research gasifiers ${ }^{[1][2][3][4]}$ before arriving at the CSM design. Fabrication and initial shakedown testing of the reactor were completed in February 2011. The CSM reactor is a compact one-meter flow reactor capable of temperatures to $1650^{\circ} \mathrm{C}$ and pressures to $41 \mathrm{~atm}$. Particulate feeding is accomplished using an auger-type feeder contained in a separate pressure vessel, which is capable of feeding particulate matter up to approximately $100 \mu \mathrm{m}$ mean diameter. All product gases flow through a temperature controlled extraction probe capable of cooling product gases to any desired temperature between $650^{\circ} \mathrm{C}$ and $10^{\circ} \mathrm{C}$. Gas analysis is performed using gas chromatography and mass spectrometry. Initial testing has demonstrated successful coal gasification at a temperature of $1450^{\circ} \mathrm{C}$ and pressures of $2.5 \mathrm{~atm}$ and $8.5 \mathrm{~atm}$.
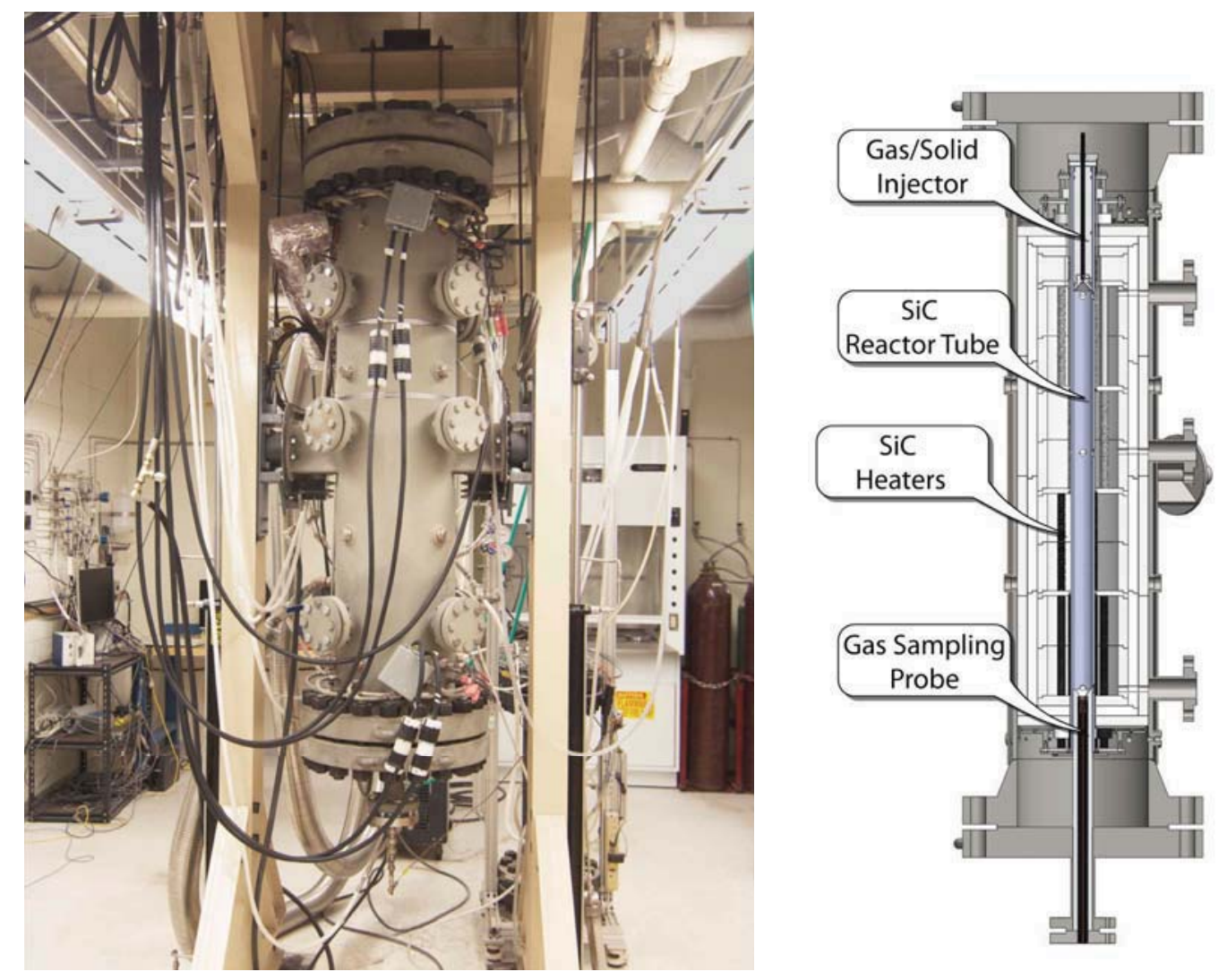

Figure 1. Photograph of the Colorado School of Mines gasifier with cutaway drawing showing internal structure. 


\section{Introduction}

The size and cost of gasification systems and the difficulty researchers face getting access to industrial gasifiers at a reasonable cost are major hurdles for experimental gasification research. The CSM gasifier is a fuel-flexible and affordable alternative for academic and industrial researchers interested in experimental gasification studies. The wide range of operating temperatures and pressures make the CSM gasifier applicable to a host of operating conditions and feedstocks, allowing researchers to produce synthesis gas of varying composition. Capabilities for varying residence time, particulate size, and in-situ diagnostics make the CSM gasifier ideal for high quality gasification kinetics studies.

\subsection{Entrained flow gasification}

An entrained flow reactor design was chosen for the CSM gasifier for two reasons: first, it is a popular choice for industrial gasifiers, and second, it offers many advantages for studying gasification in the laboratory. The majority of modern coal gasifiers and IGCC applications use the entrained flow design and typically operate above $1400^{\circ} \mathrm{C}$ and between 20 and $70 \mathrm{~atm}^{[5]}$. The main advantages of entrained flow gasifiers are the production of a cleaner synthesis gas and operation above the ash melting point (higher carbon conversion and less gas cleanup required). The main disadvantage is a higher consumption of oxygen. As a research tool, an entrained flow reactor allows for fuel flexibility (different varieties of coal and biomass), a well-characterized residence time and temperature, and the small particle size $(\leq 100 \mu \mathrm{m})$ is conducive with the small footprint required for laboratory research. In addition, there are established techniques for gas sampling and in situ optical investigation ${ }^{[4]}$.

\section{Methodology and Approach}

Successful operation of a research gasifier requires several key technologies to work together: metering of solids, gases, and liquids into the gasifier; sufficient power to maintain high temperatures at elevated pressure; gas sampling and analysis; and active control of feed rates, temperatures, and pressures. In addition to adapting design principles from existing research gasifiers, several aspects of the CSM gasifier required significant research and development. The resulting gasifier has several unique features that will provide opportunities for world-class gasification research. Major features of the gasification design are discussed below.

\subsection{Entrainment}

Reliably feeding particulates at pressure is a major challenge in studying gasification. The small sizes required for entrained flow gasification result in significant static attraction, agglomeration, and bridging (in the case of biomass). Several commercial feeders were tested, but each failed to meet the requirement for steady feeding of coal and biomass over a range of feed rates. To accomplish reliable feeding at pressure an auger was designed to operate within a secondary pressure vessel. The auger has a primary screw drive and secondary agitation arms to prevent 
bridging within the feeder. Particulates metered from the auger are aerodynamically mixed in an eductor into an argon entrainment gas and piped to the injector assembly through $1 / 8$ " tubing.

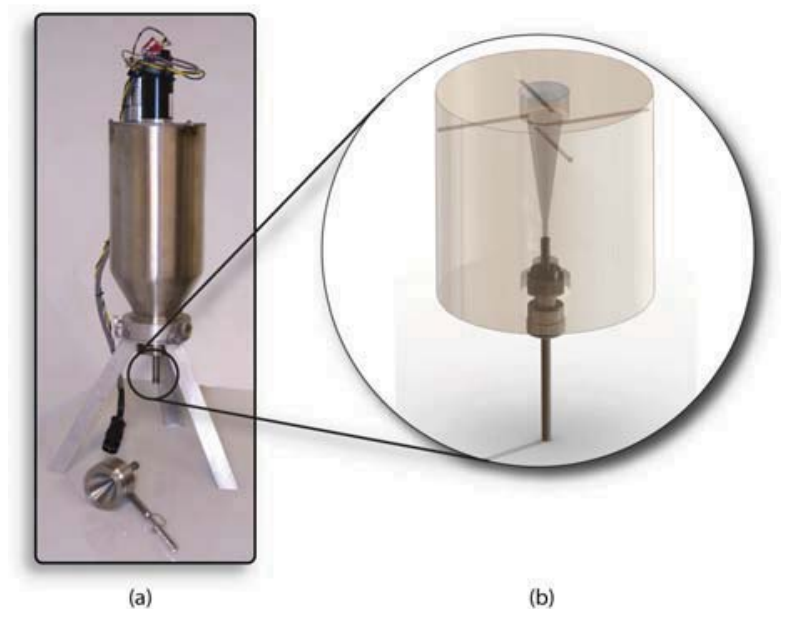

Figure 2. Feeder vessel (a) with schematic of coal/argon eductor (b).

The eductor is fabricated from polycarbonate and a remote camera system monitors the solid feeding. Several designs were evaluated until a reliable and steady feed was achieved. The resulting system is capable of feeding between $0.5 \mathrm{~g} / \mathrm{min}$ and $100 \mathrm{~g} / \mathrm{min}$ of coal into an argon entrainment flow between 1 and 50 SLPM. Coal feed-rates have been tested over current operating ranges and show exceptional linearity (Figure 3).

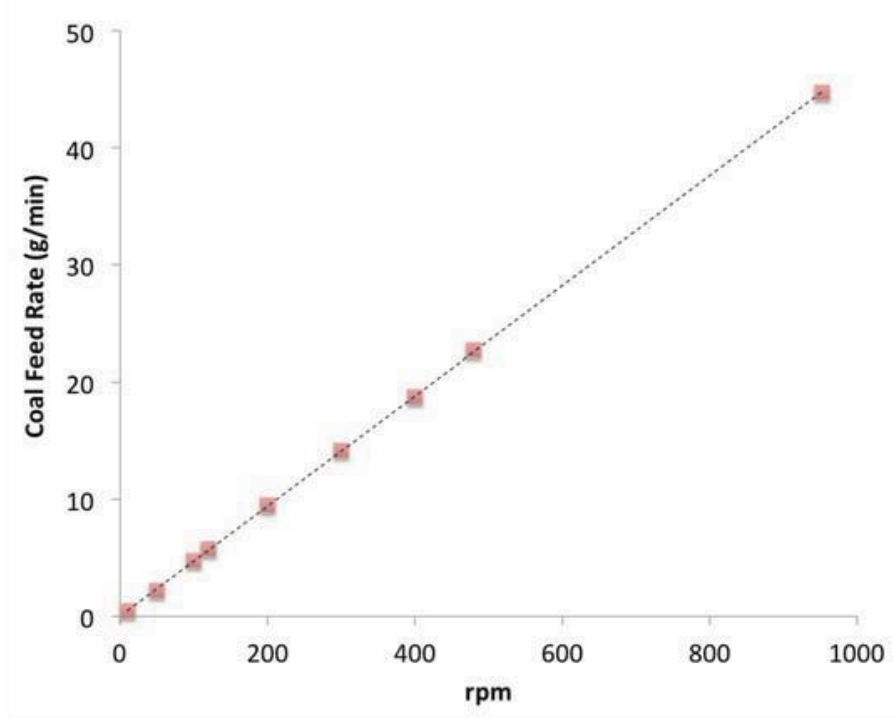

Figure 3. Measured coal feed rate versus auger rotation rate. Measurements made at 1 atm without eductor. 


\subsection{Pressure vessel}

Significant effort was dedicated to design a pressure vessel capable of high pressure and high temperature while minimizing footprint and cost. The ASME certified pressure vessel fabricated for the reactor has a built-in oil jacket that enables high temperatures in the core of the reactor while maintaining the outer wall temperature well below the ASME temperature limit of $315^{\circ} \mathrm{C}$. Another unique aspect of the reactor is the addition of optical access ports at three axial locations providing optical access for both line-of-sight diagnostics (e.g. absorption) and orthogonal collection (e.g. LIF, emission). The pressure vessel is mounted to a support frame that allows for vertical translation and rotation (Figure 4). This configuration allows the reactor to be lifted, so that the translational extraction probe can traverse the full length of the reactor tube, and rotated for convenient maintenance.

\subsection{Heating}

The CSM gasifier has five heating zones: a gas preheater surrounding the injection section, and four baffled heating zones along the axis of the reactor. Each heating zone is individually controlled by five Spang phase-angle fired power controllers. The four main heating zones provide up to $3.5 \mathrm{~kW}$ of electrical heating per zone. The gas preheater provides up to 2 $\mathrm{kW}$. Type $\mathrm{C}$ thermocouples inserted in each heater zone are used for control using the National

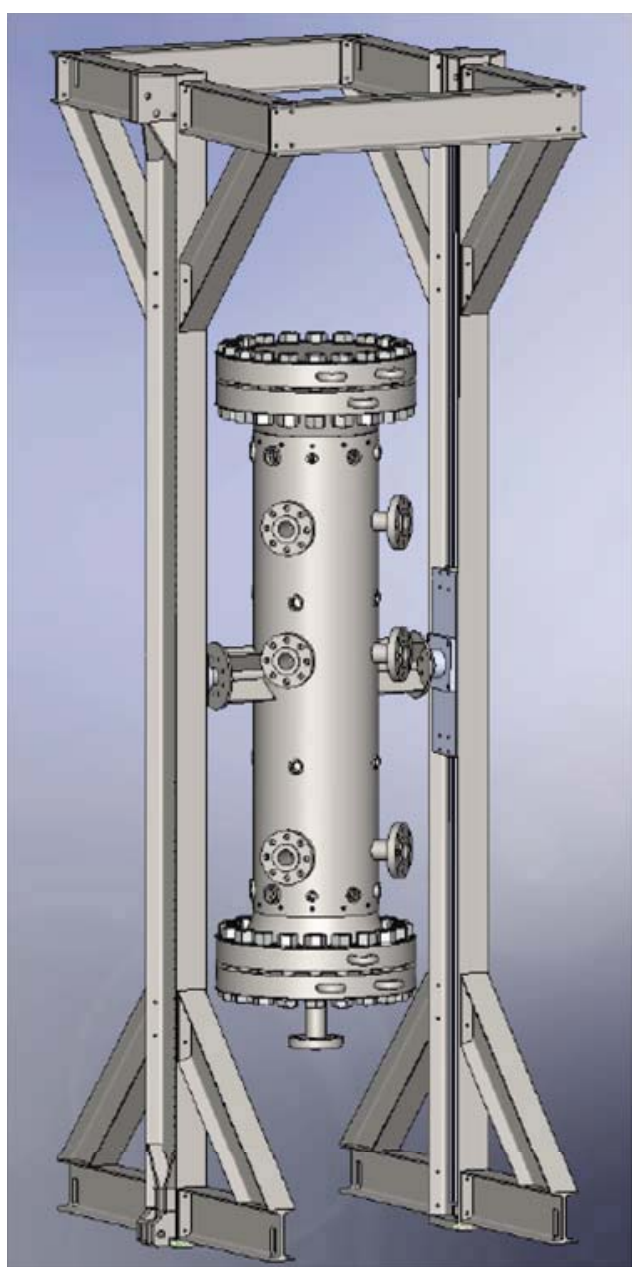

Figure 4. Pressure vessel and support frame. Instruments Real-Time controller PXI data acquisition system. In order to ensure adequate heating of the core at elevated pressure, high-performance alumina-silica insulation was custom fabricated to support the heaters and main reactor tube, while ensuring a reduced heat load on the pressure vessel walls. 


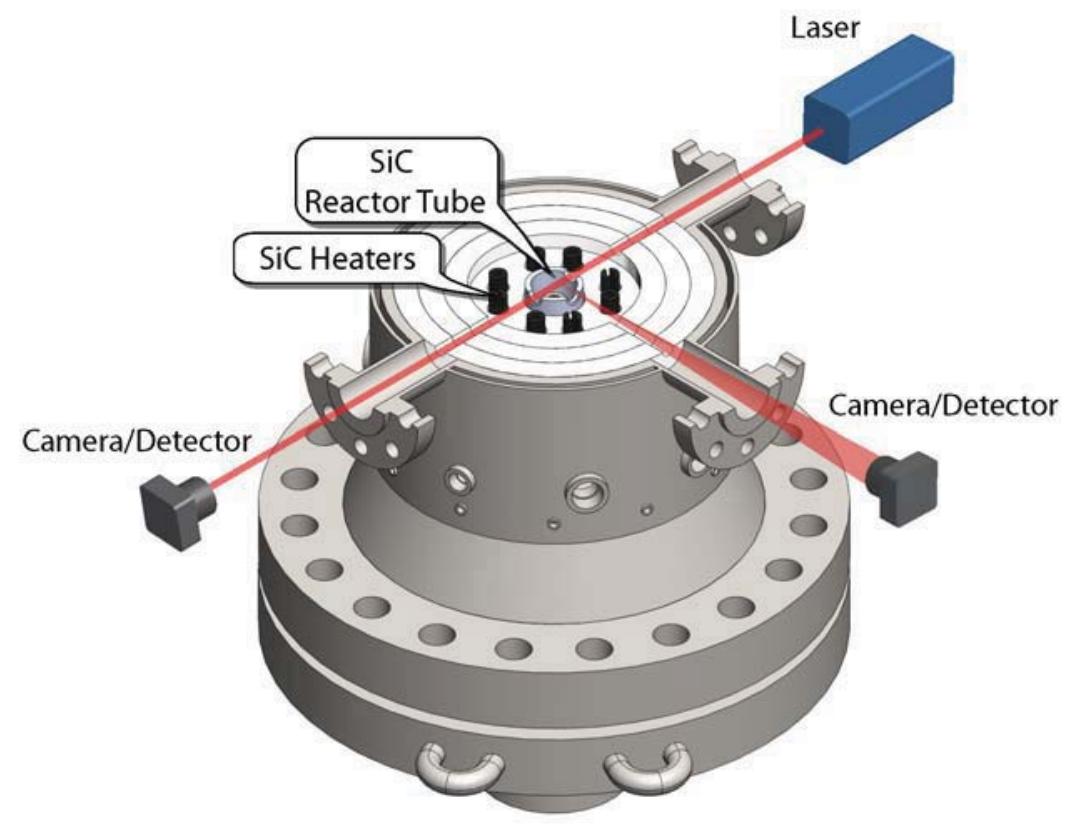

Figure 5. Schematic of core insulation with heater placement and reactor tube (optical access ports and potential optical diagnostics shown).

\subsection{Steam and oxygen injection}

Gasification requires steam addition. A steady stream of metered steam is accomplished using a Bronkhorst liquid mass flow controller, which meters up to 1.4 SLPH of distilled water. The water is then super heated by four cartridge heaters providing up to 4 kilowatts of electrical heating. Superheated steam at $600^{\circ} \mathrm{C}$ leaves the super heater and is delivered to the injector where it is mixed with coal and oxygen at the injector tip. Oxygen is mixed with the coal stream and maintained at a low temperature by a cooling water circuit until it exits the injector and is rapidly mixed with the steam. 


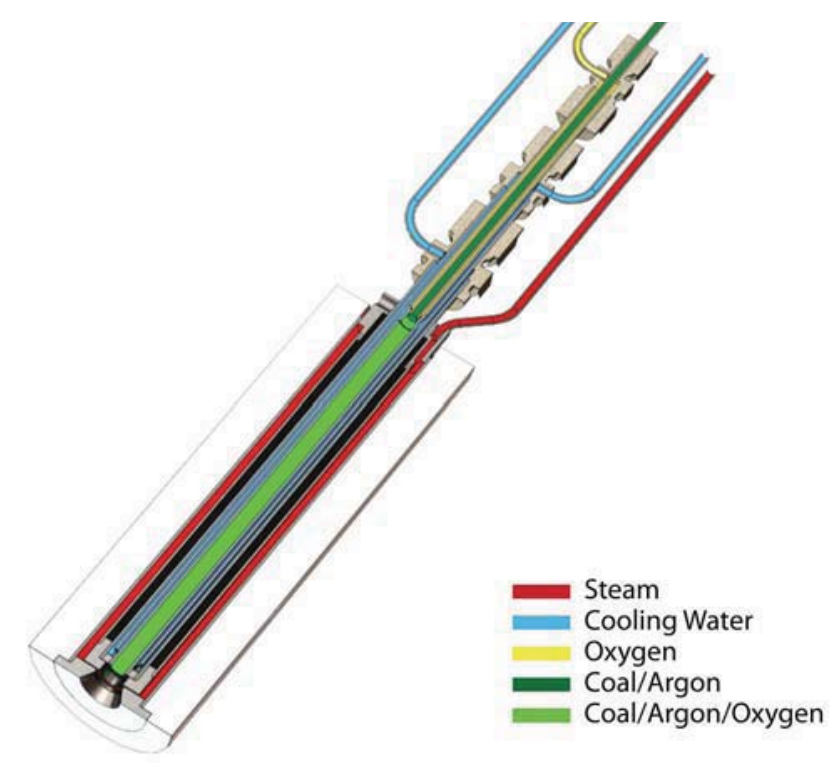

Figure 6. Schematic of gasifier injector showing color-coded injection pathways.

\subsection{Exhaust gas handling}

Product gases exiting the gasifier pass through an actively cooled exhaust probe. Active cooling is achieved by three means: an annular gas heat exchanger, an annular water heat exchanger, and direct gas quench by argon injection. Each flow rate is adjusted to achieve the desired gas outlet temperature and dilution (Figure 7). After exiting the gasifier, an optional secondary heat exchanger further reduces the temperature of the gases to $10^{\circ} \mathrm{C}$. The gases then flow through a large diameter condenser, which removes particulates if present (unreacted coal or ash).

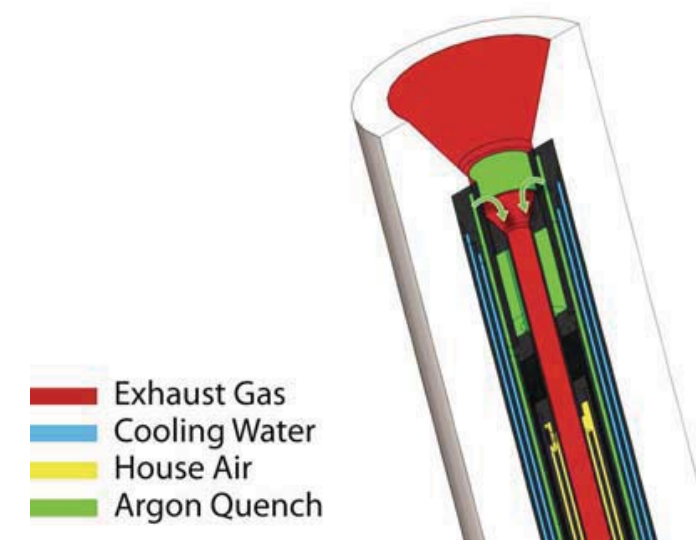

Figure 7. Schematic of extraction probe with flow channels highlighted.

Mass spectrometry and gas chromatography are used to analyze product gases. The mass spectrometer is an Stanford Research RGA200 and the gas chromatograph is an Agilent 3000A Micro GC. Currently, we are able to sample major species $\left(\mathrm{CO}, \mathrm{H}_{2}, \mathrm{CO}_{2}\right)$, but will develop minor species capabilities in the near future.

\subsection{Optical access}

As mentioned previously, the pressure vessel was designed with nine flanges for optical access (Figure 5). Optical access allows for in-situ probing of temperature and species concentrations. This is important for determining gas temperatures and for measuring intermediate species not 
accessible by extractive sampling and analysis with gas chromatography or mass spectrometry (e.g. radical species). This capability is currently not being used, but will be developed in the future.

\subsection{Diagnostics}

Real time measurements of temperature, pressure, feeding rates, flow rates, and heater powers are critical to the operation of the gasifier. There are 20 thermocouples monitoring temperatures in the system. Thermocouples measure the steam temperature, the exhaust temperature (before and after quench), the injector temperature, and the reactor core temperature in each zone. Pressure measurements are collected in the feeding pressure vessel, the gasifier pressure vessel, and supply lines. There are six flow controllers for water (steam), oxygen, argon sweep, argon purge, and argon quench. Voltage and current levels from the heater power controllers are also collected. The particulate feed rate is controlled by the auger drive motors, which have been calibrated to deliver a known feed rate of particulate (Figure 3).

\subsection{Control system}

Real-time control is used to process and record data collected from the diagnostics. Thermocouple data is collected, filtered, and amplified by a National Instruments SCXI chassis. A National Instruments Real-Time controller PXI data acquisition system provides real time control of the system using a custom Labview program designed specifically for the gasifier.

\section{Capabilities}

The CSM gasifier provides for controlled heating of gasification reactants with a unique range of temperature and pressure for realistic laboratory experiments relevant to industrial gasification. A summary of operating ranges for several parameters are shown in Table 1.

Table 1 Capabilities of the Colorado School of Mines gasifier.

\begin{tabular}{|c|c|c|c|c|}
\hline parameter & $\min$ & $\max$ & nominal & units \\
\hline Reactor tube length $^{1}$ & 0.05 & 1 & - & $(\mathrm{m})$ \\
\hline Temperature & 25 & 1650 & 1550 & $\left({ }^{\circ} \mathrm{C}\right)$ \\
\hline Pressure $^{2}$ & 1 & 41 & - & (atm) \\
\hline Feeder volume & - & 6 & 4 & (I) \\
\hline Water (liq) & 0.014 & 1.40 & 0.15 & (SLPH) \\
\hline Oxygen & 0.2 & 35 & 0.9 & (SLPM) \\
\hline Coal & 0.5 & 100 & 4.6 & $(\mathrm{~g} / \mathrm{min})$ \\
\hline Argon (Entrainment) & 1 & 50 & 6 & (SLPM) \\
\hline Argon (Quench) & 0.5 & 100 & 10 & (SLPM) \\
\hline Argon (Purge) & 0.1 & 10 & 3 & (SLPM) \\
\hline
\end{tabular}




\section{Testing and Results}

\subsection{Temperature and pressure shakedown testing}

Initial shakedown testing of the gasifier included testing to demonstrate that the gasifier could maintain the desired upper temperature limit. Core temperatures of $1550^{\circ} \mathrm{C}$ have been demonstrated. A significant hurdle at elevated temperatures was the electromagnetic interference of the heaters with the thermocouples. This was overcome by adjusting pull-up resistors on the SCXI chassis and by adequate digital filtering within the Labview data acquisition program. A blackbody furnace was used to verify calibrations for type $\mathrm{K}$ and type $\mathrm{C}$ thermocouples to $1000^{\circ} \mathrm{C}$.

In addition to hydrostatic pressure testing of the ASME certified pressure vessel, the vessel has been pressurized with argon to over $30 \mathrm{~atm}$. To date, the gasifier has operated at a pressure of $12 \mathrm{~atm}$ while maintaining a core temperature of $1500^{\circ} \mathrm{C}$.

\subsection{Coal gasification testing}

The first successful operation of the gasifier was achieved in February of this year, with another round of testing completed in June. A coal sample was donated by Hazen Research Inc. and ground to powder by Zybec Technologies. The coal powder was screened with a 230 mesh achieving a maximum coal particle size of $60 \mu \mathrm{m}$. The ultimate analysis of the coal sample is shown in Table 2.

Table 2. Ultimate Analysis of coal used for gasifier performance testing

\begin{tabular}{lcrr} 
Ultimate Analysis & unit & as-received & \multicolumn{1}{c}{ air-dried } \\
\hline Moisture & (wt. \%) & 7.61 & 0.00 \\
Carbon (C) & (wt. \%) & 67.23 & 72.76 \\
Hydrogen (H) & (wt. \%) & 4.52 & 4.89 \\
Nitrogen (N) & (wt. \%) & 1.40 & 1.52 \\
Sulfur (S) & (wt. \%) & 1.08 & 1.17 \\
Ash & (wt. \%) & 13.38 & 14.49 \\
Oxygen (O) & (wt. \%) & 4.78 & 5.17 \\
\hline Total & & 100.00 & 100.00
\end{tabular}

Gasifier testing was performed under the conditions listed in Table 3 and Table 4. The reported product mole fractions were recorded with an Agilent 3000A Micro GC gas chromatograph. 
Table 3. Gasifier operating conditions and syngas analysis $\left(\mathrm{T}=1450^{\circ} \mathrm{C}, \mathrm{P}=2.5 \mathrm{~atm}\right)$

\begin{tabular}{|c|c|c|c|c|c|}
\hline Reactants & Feeding rate & units & Products & $\begin{array}{c}\text { mole \% } \\
\text { (pre-quench) }\end{array}$ & $\begin{array}{c}\text { mole } \% \\
\text { (post-quench) }\end{array}$ \\
\hline Water (liq) & 0.15 & (SLPH) & Hydrogen & 28.2 & 15.5 \\
\hline Oxygen & 1.48 & (SLPM) & Carbon Monoxid & 18.2 & 10 \\
\hline Coal & 4.60 & (g/min) & Carbon Dioxide & 2.9 & 1.6 \\
\hline Argon (Entrainment) & 8.00 & (SLPM) & Nitrogen & 0.5 & 0.3 \\
\hline Argon (Quench) & 10.00 & (SLPM) & Argon & 50.2 & 72.6 \\
\hline Argon (Purge) & 3.00 & (SLPM) & $\overline{\text { Total }}$ & 100 & 100 \\
\hline
\end{tabular}

Table 4. Gasifier operating conditions and syngas analysis $\left(\mathrm{T}=1450^{\circ} \mathrm{C}, \mathrm{P}=8.5 \mathrm{~atm}\right)$

\begin{tabular}{|c|c|c|c|c|c|}
\hline Reactants & Feeding rate & units & Products & $\begin{array}{c}\text { mole \% } \\
\text { (pre-quench) }\end{array}$ & $\begin{array}{c}\text { mole \% } \\
\text { (post-quench) }\end{array}$ \\
\hline Water (liq) & 0.15 & (SLPH) & Hydrogen & 16.5 & 11.3 \\
\hline Oxygen & 1.48 & (SLPM) & Carbon Monoxidt & 11.5 & 7.9 \\
\hline Coal & 4.60 & (g/min) & Carbon Dioxide & 0.9 & 0.6 \\
\hline Argon (Entrainment) & 20.00 & (SLPM) & Nitrogen & 0.3 & 0.2 \\
\hline Argon (Quench) & 10.00 & (SLPM) & Argon & 70.8 & 80 \\
\hline Argon (Purge) & 3.00 & (SLPM) & Total & 100 & 100 \\
\hline
\end{tabular}

The gas analysis shows an appropriate ratio of hydrogen to carbon monoxide. This is a promising result, showing that the gasifier feeding was working as designed. Gas compositions are reported in two ways: pre-quench, which refers to the composition in the absence of argon purge and quench gases; and post-quech, which is the measured composition including argon quench and purge gases. The highest syngas concentrations to date are 50\%, however, the coal to argon entrainment ratio can be increased significantly. It is anticipated that syngas concentrations reaching as high as $80 \%$ are possible with this system, making it much more suitable to applications requiring high syngas concentrations (e.g. hydrogen-separation membrane testing).

\section{Summary and Conclusions}

The CSM gasifier has been designed, fabricated, and has undergone initial shakedown testing culminating over two and a half years of intensive effort on the part of several CSM researchers. The resulting gasifier is unique in the world and provides a fuel flexible, compact, and economical research gasifier for experimental gasification and synthesis gas studies. Several significant research challenges have been overcome in the CSM gasifier, most notably, reliable feeding of solids and high-temperature and high-pressure operation. 


\section{Future Work}

The CSM gasifier has demonstrated successful operation at design temperatures and elevated pressure, as well as successful gasification of coal. Current work is dedicated to generating synthesis gas for the Praxair/DOE hydrogen separation project. Samples of low-sulfur Wyoming coal have been acquired to reduce the sulfur composition in the resulting syngas. Future work will focus on the generation of archival quality coal gasification data. Generating this data will initially require the completion of a translatable sampling probe and improvements in gas analysis capabilities to capture the composition of minor species $\left(\mathrm{H}_{2} \mathrm{O}, \mathrm{CH}_{4}, \mathrm{H}_{2} \mathrm{~S}, \mathrm{COS}, \mathrm{NO}_{\mathrm{X}}\right.$, ...). Early testing will focus on characterization of the reactor tube temperature profile (via instrumentation of the translatable probe), and the influence of temperature, pressure, argon dilution, and coal particle size on syngas composition. While the CSM gasifier creates possibilities for studying a host of research topics, some specific directions for future work include: the influence of coal type on syngas composition, using $\mathrm{CO}_{2}$ as a carrier gas, biomass comingling, solid waste gasification, and in situ optical detection of trace and intermediate species.

\section{References}

[1] J. Fjellerup, E. Gjernes, and L. K. Hansen, "Pyrolysis and Combustion of Pulverized Wheat Straw in a Pressurized Entrained Flow Reactor†," Energy \& Fuels, vol. 10, no. 3, pp. 649651, Jan. 1996.

[2] S. Ouyang, H. Yeasmin, and J. Mathews, "A pressurized drop-tube furnace for coal reactivity studies," Review of Scientific Instruments, vol. 69, no. 8, p. 3036, 1998.

[3] T. Reichelt, T. Joutsenoja, H. Spliethoff, K. R. G. Hein, and R. Hernberg, "Characterization of burning char particles under pressurized conditions by simultaneous in situ measurement of surface temperature and size," Symposium (International) on Combustion, vol. 27, no. 2, pp. 2925-2932, 1998.

[4] M. J. Aho, K. M. Paakkinen, P. M. Pirkonen, P. Kilpinen, and M. Hupa, "The effects of pressure, oxygen partial pressure, and temperature on the formation of $\mathrm{N} 2 \mathrm{O}, \mathrm{NO}$, and $\mathrm{NO} 2$ from pulverized coal," Combustion and Flame, vol. 102, no. 3, pp. 387-400, Aug. 1995.

[5] C. Higman and M. van der Burgt, Gasification, Second Edition, 2nd ed. Gulf Professional Publishing, 2008. 


\title{
Investigation of Tar Reduction Methods
}

\author{
Sub-task I-B
}

Final Report

S. M. Villano, H-H. Carstensen, A. M. Dean

Chemical Engineering Department

Colorado School of Mines

Golden, CO 80401

Prepared for:

The U.S. Department of Energy

National Energy Technology Laboratory

626 Cochrans Mill Road

Pittsburgh, PA

Under contract no.: DE-NT0005202

1 October 2011

\section{COLORADOSCHOOLOFMINES}




\section{Table of Contents}

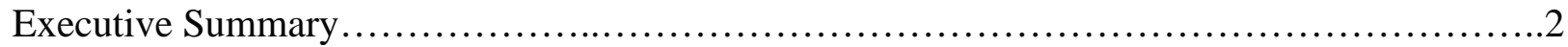

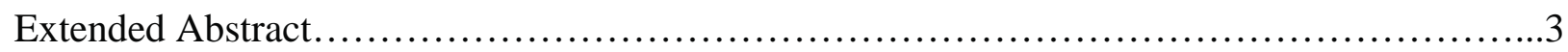

Paper: Journal of Physical Chemistry A ........................................... 


\section{Executive Summary}

A fundamental issue in coal and/or biomass gasification is that, in addition to the desired synthesis gas product (a mixture of $\mathrm{CO}, \mathrm{CO}_{2}, \mathrm{H}_{2}$, and $\mathrm{H}_{2} \mathrm{O}$ ), the gasifier effluent often contains undesirable species, which need to removed before further processing of the synthesis gas can occur. The conventional approach to reduce the concentration of unwanted hydrocarbons in a synthesis gas stream is use a downstream tar reformer, which adds substantially to capital and operational costs. One alternative mitigation strategy is to reduce the concentration of hydrocarbons in the gasifier stream via gas-phase selective partial oxidation. This study focused on the removal of organic compounds from a synthesis gas stream that could lead to deposit formation in downstream units (e.g., solid-oxide fuel cells or gas-to-liquids catalysts). The objectives of this work were to explore the potential for gas-phase partial oxidation reactions to remove deposit precursors, develop a suitable partial oxidation kinetic model to identify optimum conditions for this process, and assess the potential to increase the concentration of good fuels such as methane, hydrogen, and carbon monoxide in the gasifier stream. A detailed kinetic model was developed that indicated such selective oxidation could be achieved under certain conditions. These conditions were then verified in a series of experiments. We are able to leverage our efforts in this area with other on-going DOE funded programs. The good agreement between the model predictions and our experimental data also allowed us to interrogate the model to understand the reasons for the surprisingly selective oxidation. This research on selective oxidation of ethylene was been documented in a paper published in the Journal of Physical Chemistry A (presented below). Another manuscript is in preparation describing our research on selective oxidation of propylene. An extended abstract describing this effort is also presented below. We presented aspects of this research at the International Conference on Chemical Kinetics held in July 2011 at MIT.

This research has contributed to the following list of publications:

"Selective Removal of Ethylene, a Known Deposit Precursor, from a 'Dirty' Synthesis Gas Stream via Gas-Phase Partial Oxidation", Stephanie M. Villano, Jessica Hoffmann, HansHeinrich Carstensen, and Anthony M. Dean, J. Phys. Chem. A, 114, 6502-6514 (2010).

"Selective oxidation of ethylene in a model "dirty" synthesis gas stream: an experimental and kinetic modeling study" Stephanie M. Villano, Jessica Hoffmann, Hans-Heinrich Carstensen, and Anthony M. Dean, ACS National Meeting, San Francisco, CA, March 21-25, 2010.

"Selective removal of hydrocarbons from a 'dirty' synthesis gas stream via gas-phase partial oxidation", S. M. Villano, H.-H. Carstensen, and A. M. Dean, Symposium on Thermal and Catalytic Sciences for Biofuels and Biobased Products, Ames, IA, September 21-23, 2010.

"A Kinetic Analysis Of The Selective Removal Of Ethylene And Propylene From Syngas Via Partial Oxidation" Stephanie Villano, Hans-Heinrich Carstensen and Anthony M. Dean, International Conference on Chemical Kinetics, Cambridge, MA, July 11-14, 2011. 


\title{
Extended Abstract
}

Presented at the International Conference on Chemical Kinetics, Cambridge, MA, July 11-14, 2011

\section{A KINETIC ANALYSIS OF THE SELECTIVE REMOVAL OF ETHYLENE AND PROPYLENE FROM SYNGAS VIA PARTIAL OXIDATION}

\author{
Stephanie M. Villano, Hans-Heinrich Carstensen, and Anthony M. Dean \\ Chemical Engineering Department \\ Colorado School of Mines - Golden \\ Golden, CO 80401
}

\begin{abstract}
The partial oxidation of a synthesis gas stream doped with methane and ethylene or propylene has been investigated at ambient pressures, from $760-910^{\circ} \mathrm{C}$, and at residence times of $0.4-2.4 \mathrm{~s}$ using a tubular flow reactor. The addition of oxygen preferentially reduces the concentration of olefins while the concentrations of methane and hydrogen remain relatively unaffected. These results are compared to predictions with a plug flow model using a reaction mechanism that is designed to describe the pyrolysis and partial oxidation of small hydrocarbon species. The model is able to capture the observed experimental trends and provides insight into the underlying kinetics that leads to the selective oxidation of olefins. Analysis of the model reveals that ethylene and propylene are removed by very different pathways. For the selective removal of ethylene the reaction of vinyl plus $\mathrm{O}_{2}$ plays a key role. In contrast, for the selective removal of propylene the corresponding reaction of allyl radical plus $\mathrm{O}_{2}$ is slow. Instead propylene primarily reacts via $\mathrm{H}$-atom addition. In both cases, hydrogen and methane appear to be unreactive. However, the results show that at short reaction times they are initially consumed while at longer reaction times they are regenerated, leading to essentially no net change in their concentrations.
\end{abstract}

\section{Keywords}

Partial Oxidation, Kinetic Modeling, and Synthesis Gas

\section{Introduction}

Gasification of biomass produces a synthesis gas ("syngas", a mixture of $\mathrm{CO}, \mathrm{H}_{2}, \mathrm{H}_{2} \mathrm{O}$, and $\mathrm{CO}_{2}$ ) that contains a variety of unwanted byproducts such as methane, ethylene, polyaromatic hydrocarbons (PAHs) and other species (Carpenter 2010). The presence of unsaturated species (olefins and PAHs) is of particular concern since they may form deposits downstream on the equipment and deactivate catalysts. Use of a tar reformer to remove these species add substantially to both capital and operational costs, and so far the long-term stability of these catalytic tar reformers has been a problem (Bain 2005). A proposed inexpensive alternative method is to reduce the concentrations of olefins and PAHs via selective partial oxidation. This strategy seems particular interesting if the "cleaned" syngas is used for power generation in solid oxide fuel cells (SOFC), since the presence of methane is beneficial for SOFC operation.

Experimental data obtained for a surrogate syngas and doped with either ethylene (Villano 2010) or propylene demonstrate that indeed a substantial selective reduction of either ethylene or propylene via addition of small amounts of oxygen to the syngas mixture at typical gasification temperatures $\left(\sim 800^{\circ} \mathrm{C}\right)$ is possible. If the partial oxidation is done with syngas that contains methane in addition to either ethylene or propylene, the data show that not only the carbon monoxide, hydrogen, but also the methane concentration remain relatively unaffected as long as only a few percent $\mathrm{O}_{2}$ is added. In this study we use the CSM kinetic mechanism to model the experimental data. We find that our model is able to reproduce these observations. This allows us to use the mechanism to perform a kinetic 
analysis to explain how this apparently selective oxidation chemistry is possible.

\section{Review of the Experimental Data}

Experiments (Villano 2010) were conducted by passing a known flow of a model synthesis gas mixture through a tubular quartz reactor over a temperature range of $760-910^{\circ} \mathrm{C}$, at residence times of $0.4-2.4 \mathrm{~s}$, and at ambient (high-altitude) pressure of $\sim 0.8 \mathrm{~atm}$. The model synthesis gas is composed of $12 \%$ carbon monoxide, $9 \%$ carbon dioxide, and 12\% hydrogen, 5\% methane, and $1.7 \%$ ethylene or propylene with the balance as nitrogen or helium buffer gas. Partial oxidation studies were performed by substituting $1-5 \%$ of oxygen for the buffer gas. The reactor effluent is analyzed by gas chromatography (ThermoFisher Trace GCMS Ultra and/or a Hewlett Packard 5890 Series II+ GC). Permanent gases and light hydrocarbons are separated using a tandem Supelco $6 \mathrm{ft}$ x 1/8" stainless steel packed Porpack R and $15 \mathrm{ft} \times 1 / 8$ " stainless steel packed Carboxen 1000 columns with argon carrier gas. Light and heavy hydrocarbons are separated with a J\&W Fisher SPB-1 $60 \mathrm{~m}$ x $0.53 \mathrm{~mm}-\mathrm{ID}$ $5 \mu \mathrm{m}$ fused silica film capillary column with helium as the carrier gas. The gas composition is quantified using flame ionization and/or thermal conductivity detectors. Each data point is an average of at least three measurements and carbon mass closures within $3 \%$ is obtained in most cases. Since water cannot be quantified with this analytical setup, we estimate its concentration from the hydrogen and oxygen mass balances.

The solid symbols in Figure 1 show the selective reduction of ethylene in a synthesis gas mixture that contains both methane and ethylene at $810^{\circ} \mathrm{C}$ (Villano 2010). At the $3 \%$ oxygen level, approximately $62 \%$ of the ethylene is consumed while the concentrations of methane and hydrogen remain essentially unaffected. An increase of the oxygen concentration to $5 \%$ results in a $77 \%$ reduction in the ethylene concentration. Some of the methane and hydrogen is also consumed. However, a significant amount of carbon monoxide is formed preserving much of the total fuel concentration.

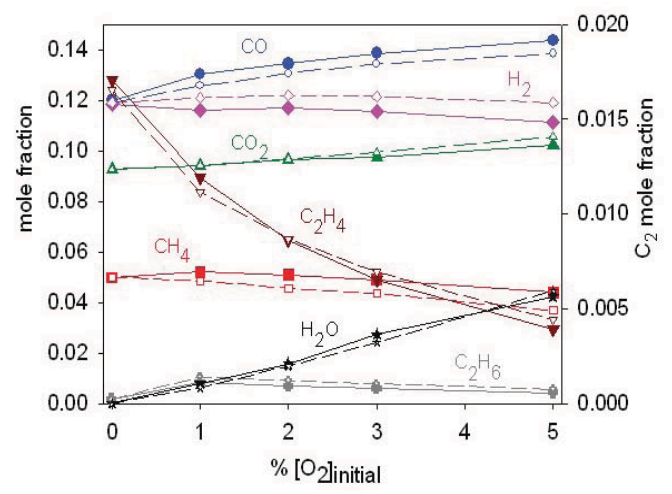

Figure 1: The effect of oxygen addition on a $\mathrm{CH}_{4} / \mathrm{C}_{2} \mathrm{H}_{4^{-}}$ doped synthesis gas stream $\left(T=810^{\circ} \mathrm{C} ; \mathrm{P}=0.8 \mathrm{~atm} ; \tau \sim\right.$ 1 s). Experiment: Solid Symbols; Model: Open Symbols.
The effect of adding oxygen to a synthesis gas stream that contains both methane and propylene at $810^{\circ} \mathrm{C}$ is shown by the solid symbols in Figure 2. Under pyrolysis conditions a small fraction of propylene is converted to methane and ethylene. As oxygen is added to the gas mixture, significantly more propylene is consumed while the methane and ethylene concentrations increase. A slight reduction in the hydrogen concentration is observed as well as an increase in both the concentrations of carbon monoxide and carbon dioxide. At the 3\% oxygen level approximately $95 \%$ of the propylene is removed. At this point the concentrations of both methane and ethylene decrease as well.

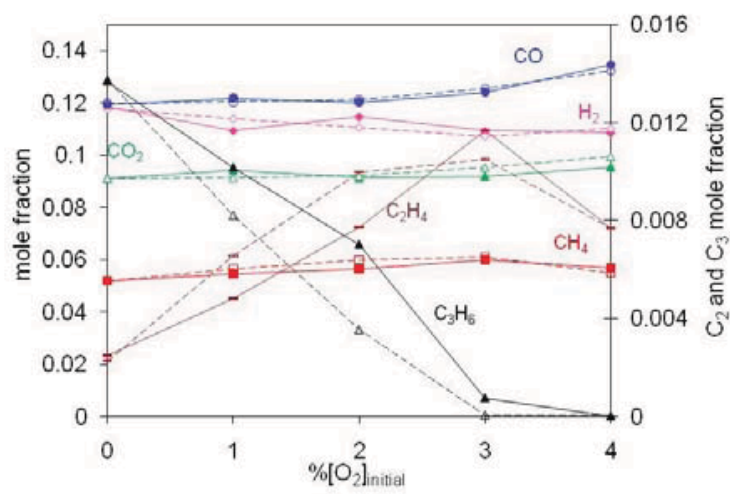

Figure 2: The effect of oxygen addition on a $\mathrm{CH}_{4} / \mathrm{C}_{3} \mathrm{H}_{6^{-}}$ doped synthesis gas stream $\left(T=810^{\circ} \mathrm{C} ; \mathrm{P}=0.8 \mathrm{~atm} ; \tau \sim\right.$ 1 s). Experiment: Solid Symbols; Model: Open Symbols

\section{Modeling Details}

The experimental results were simulated with an unadjusted combined $\mathrm{C}_{6}$ pyrolysis (Randolph 2007) and $\mathrm{C}_{3}$ oxidation (Naik 2006) mechanism that contains about 350 species and 4300 reactions. It has previously been validated extensively against experimental n-hexane pyrolysis (Randolph 2007) and ethane oxidation (Naik 2006) data. Simulations are performed with the plug flow module in the ChemKin-Pro software package (ChemKinPro 2008) using measured temperature-distance profiles and inlet gas flow rates.

The quality of the model predictions are shown by the open symbols in Figure 1 and 2. For the methane/ethylene doped synthesis gas mixture the model is able to predict the observed decay of ethylene as a function of added oxygen well. The model overpredicts the formation of hydrogen and underpredicts the formation of carbon monoxide and methane. For the methane/propylene doped synthesis gas mixture the model overpredicts the consumption of propylene and the formation of ethylene, but the overall profiles are predicted correctly. In this case, the deviation between the model predictions and the experimental data may in part be attributed to the slower kinetics when compared to the methane/ethylene doped gas mixture. For the methane/ethylene case the chemistry is essentially complete with in the first half of the reactor. In contrast, in the methane/propylene case the chemistry is quenched once the gas flow leaves the heated zone of the reactor. As a result, agreement between measurements and predictions is substantially more sensitive to errors in 
measured temperature profiles and flow rates in addition to the assignment of individual rate parameters. Current efforts are focused on improving the model predictions. Despite these discrepancies, in both cases, the model clearly captures the observed experimental trends.

\section{Results of the Kinetic Analysis}

The agreement between the model prediction and experimental trends suggest that the model contains all of the essential chemistry required to describe this system. Thus, we can use it to analyze how the selective removal of these olefins proceeds. In order to simplify the kinetic analysis, the calculations presented in this section are performed under isothermal conditions at $810^{\circ} \mathrm{C}$.

Analysis of the reaction pathways (provided in Figure $3 \mathrm{a}-\mathrm{c})$ for the methane/ethylene doped synthesis gas mixture reveals that the initially formed radicals such as $\mathrm{H}$ and $\mathrm{OH}$ react, as expected, with all available fuel molecules $\left(\mathrm{H}_{2}\right.$, $\mathrm{CH}_{4}$ and $\mathrm{C}_{2} \mathrm{H}_{4}$ ). In the case of $\mathrm{H}_{2}$ and $\mathrm{CH}_{4}$, these reactions are abstractions that yield the respective radicals. Subsequent $\mathrm{H}$ abstraction reactions of either $\mathrm{H}$ atoms or $\mathrm{CH}_{3}$ radicals, predominantly with formaldehyde $\left(\mathrm{CH}_{2} \mathrm{O}\right)$, regenerate the parent molecules. As shown in Figure 3, on the time scale of the experiment there is essentially no net loss of hydrogen and only a minor loss of methane. In contrast, only a small fraction of the vinyl radicals formed regenerate ethylene via $\mathrm{H}$ abstraction. A larger part reacts quickly with $\mathrm{O}_{2}$ to form $\mathrm{HCO}$ and $\mathrm{CH}_{2} \mathrm{O}$. This $\mathrm{CH}_{2} \mathrm{O}$ provides the $\mathrm{H}$ atom sources for the regeneration of $\mathrm{H}_{2}$ and $\mathrm{CH}_{4}$. Thus, the much higher reactivity of vinyl radicals towards $\mathrm{O}_{2}$ compared to $\mathrm{H}$ atoms and $\mathrm{CH}_{3}$ radicals leads to the apparent selective oxidation of ethylene at low oxygen concentrations.

The mechanistic explanation provided above is a highly simplified description of the underlying chemistry. This becomes clear from Figure 3c, which shows that ethylene conversion to vinyl presents only a fraction of the ethylene consumption. Most of the ethylene is consumed by $\mathrm{H}$ addition to its double bond. Typically radical addition reactions have lower activation energies than radical abstraction reactions. However, this reaction is only a partially successful reduction process, because about $50 \%$ of the ethyl radicals formed this way will react with oxygen to regenerate ethylene. This reaction sequence is interesting in the sense that it effectively converts $\mathrm{H}$ atoms to $\mathrm{HO}_{2}$ radicals and, therefore, lowers the probability for $\mathrm{H}_{2}$ regeneration.

In contrast to the selective removal of ethylene, $\mathrm{H}$ abstraction from propylene leads to a resonantly stabilized allyl radical that does not react rapidly with $\mathrm{O}_{2}$. Since the initial allylperoxy radical does not have low-energy product channels it re-dissociates back to the reactants. As a result the selective removal of propylene must proceed via a different mechanism. Figure $4 a-c$ shows the rates of production for the key reactions involving hydrogen, methane, and propylene in the methane/propylene doped synthesis gas mixture with $3 \%$ oxygen added. One notable difference from the above methane/ethylene doped gas mixture is that the chemistry occurs on a much longer time scale and, as shown in Figure 5, there appear to be two distinct reactivity regimes. At early reaction times, propylene primarily reacts via a dominant $\mathrm{H}$-atom addition channel to form methyl radicals plus ethylene (see Figure 2 for evidence of this ethylene formation). The methyl radicals regenerate the $\mathrm{H}$ atom concentration through $\mathrm{H}-$ atom abstraction from molecular hydrogen, ultimately promoting the loss of propylene. Propylene is also lost via $\mathrm{H}$-atom abstraction to form allyl radicals plus molecular hydrogen. However, as mentioned above, the addition reaction of allyl radical with $\mathrm{O}_{2}$ is slow. Due to its stability, the concentration of allyl radical is high. Propene essentially acts as a $\mathrm{H}$ atom trap inhibiting the formation of other oxidizing radicals such as $\mathrm{OH}$. Once the bulk of the propylene has reacted, the consumption of oxygen increases and molecular hydrogen is reformed through $\mathrm{H}$ atom abstraction reactions with methane as well as with ethylene and formaldehyde (see Figure 5). At this point the chemistry proceeds in a very similar manner as in the methane/ethylene doped case discussed above.
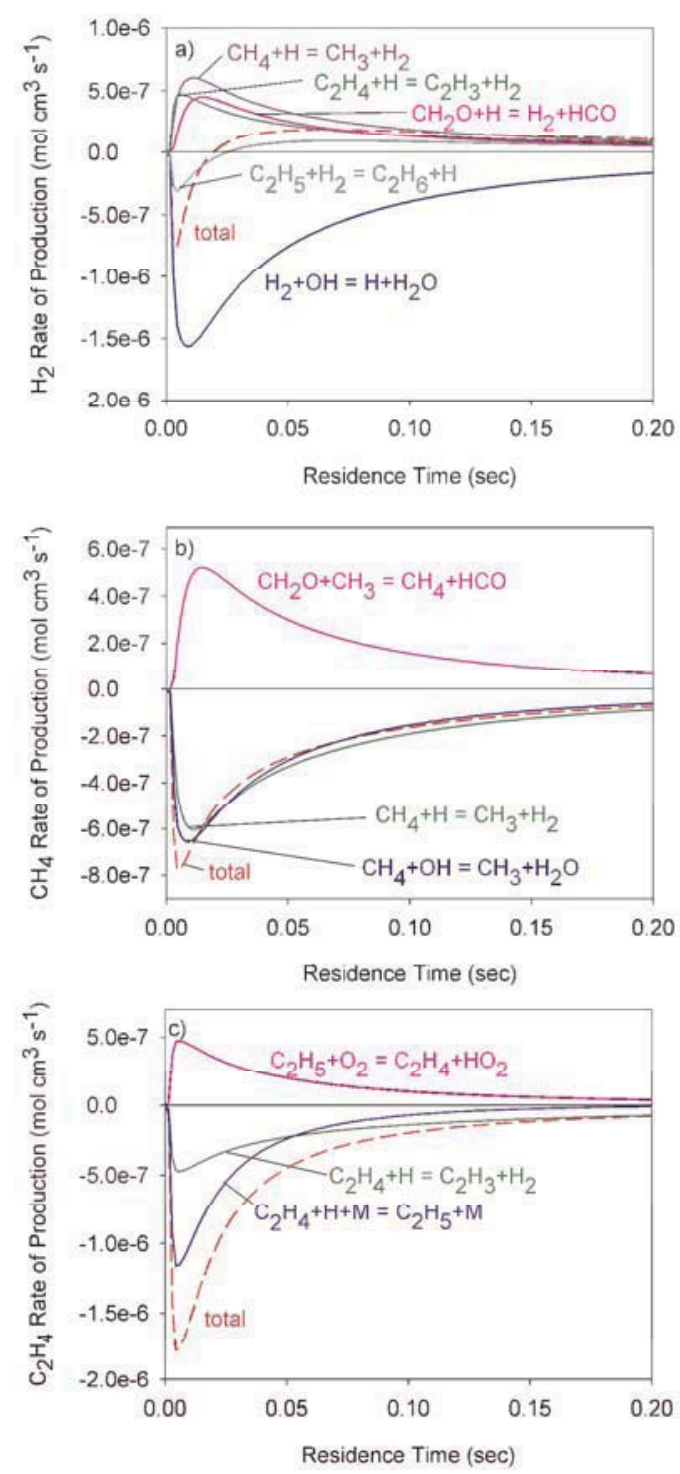

Figure 3:Rate of production analysis for a) $\mathrm{H}_{2}$, b) $\mathrm{CH}_{4}$, and c) $\mathrm{C}_{2} \mathrm{H}_{4}$ for the $\mathrm{CH}_{4} / \mathrm{C}_{2} \mathrm{H}_{4}$-doped synthesis gas mixture with $3 \%$ oxygen $\left(T=810^{\circ} \mathrm{C}, P=0.8 \mathrm{~atm}\right)$. 

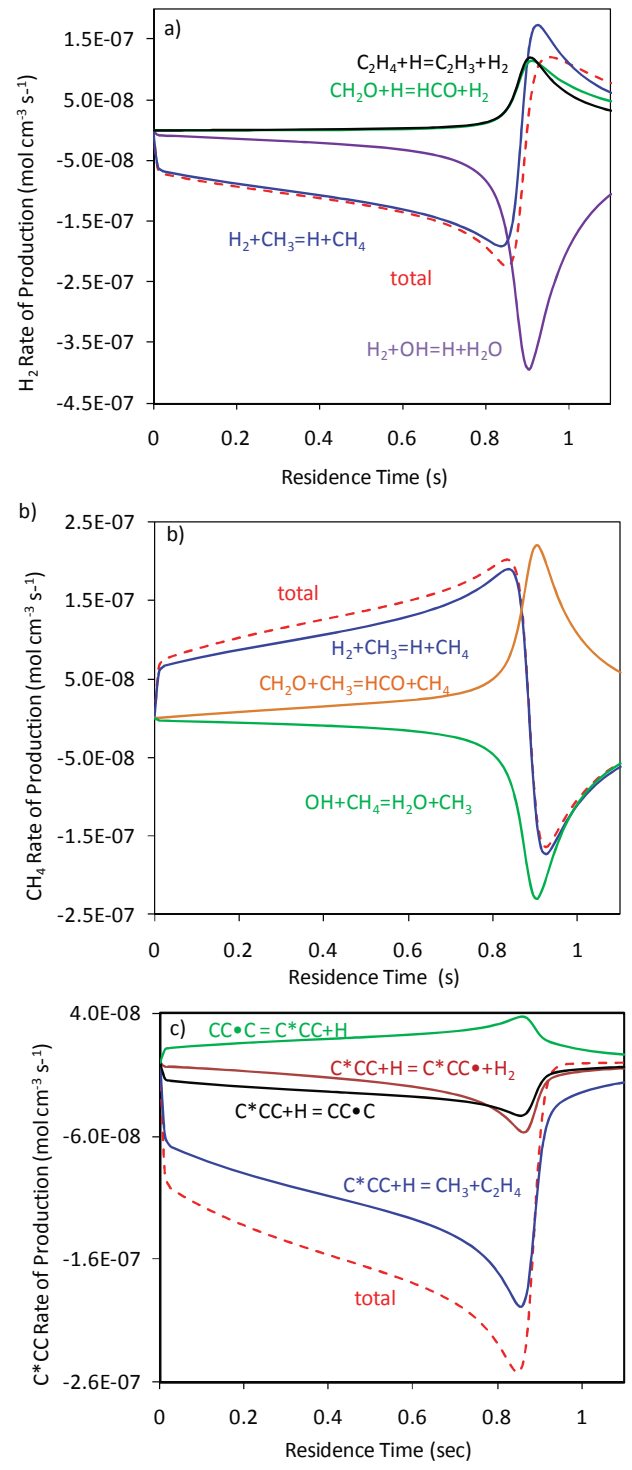

Figure 4: Rate of production analysis for a) $\mathrm{H}_{2}$, b) $\mathrm{CH}_{4}$, and c) $\mathrm{C}_{3} \mathrm{H}_{6}$ for the $\mathrm{CH}_{4} / \mathrm{C}_{3} \mathrm{H}_{6}$-doped synthesis gas mixture with $3 \%$ oxygen $\left(T=810^{\circ} \mathrm{C}, P=0.8 \mathrm{~atm}\right)$.

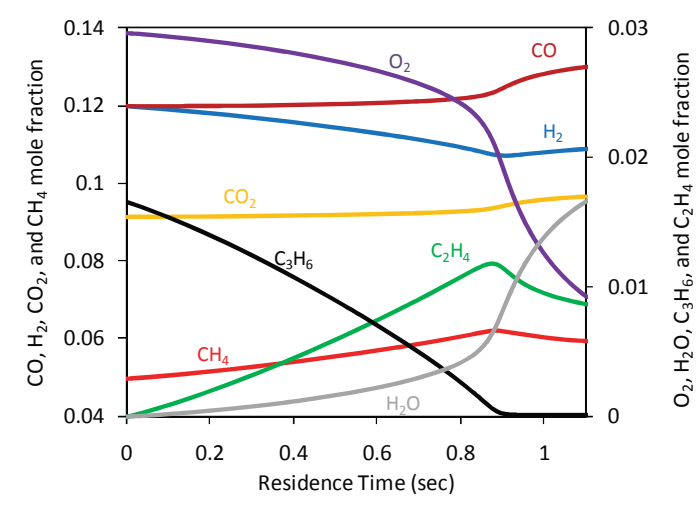

Figure 5: Calculated mole fraction for the $3 \% \mathrm{O}_{2}$ partial oxidation of a $\mathrm{CH}_{4} / \mathrm{C}_{3} \mathrm{H}_{6}$-doped synthesis gas $\left(\mathrm{T}=810^{\circ} \mathrm{C}\right.$, $P=0.8 \mathrm{~atm})$.

\section{Summary and Conclusions}

Both the experimental results and CSM model predictions show that ethylene and propylene can be selectively removed from a synthesis gas stream by adding a few percent of oxygen. Analysis of the predicted reaction pathways for the methane/ethylene doped synthesis gas mixture reveals that the reaction of vinyl radical with $\mathrm{O}_{2}$ plays a key role in the apparent selective oxidation of ethylene. This reaction not only prevents the regeneration of ethylene, but it also forms formaldehyde, which is a major $\mathrm{H}$ source for the regeneration of hydrogen and methane. For the methane/propylene doped synthesis gas mixture the reaction of allyl radical plus $\mathrm{O}_{2}$ is slow. Instead propylene primarily reacts via $\mathrm{H}$-atom addition to form $\mathrm{CH}_{3}$ radicals and ethylene. Subsequent reaction of $\mathrm{CH}_{3}$ radicals with hydrogen forms methane and $\mathrm{H}$ atoms, which promote the loss of propylene. Hence, in a simplified sense, propylene is consumed via pyrolysis reactions (abstraction, addition, $\beta$-scission) while ethylene is oxidized via conversion to vinyl radicals. $\mathrm{H}_{2}$ and $\mathrm{CH}_{4}$ appear to be unreactive because their initial consumptions are compensated by formation reactions.

\section{Acknowledgments}

This work is supported by the Department of Energy (DE-NT-0005202 and DE-FG36-08G088100) and the Colorado Center for Biorefining and Biofuels (66226).

\section{References}

Bain, R.L., Dayton, D.C., Carpenter, D.L., Czernik, S.R., Feik, C.J., French, R.J., Magrini-Bair, K.A., and Phillips, S.D., Evaluation of catalyst deactivation during catalytic steam reforming of biomass-derived syngas. Ind. Eng. Chem. Res., 2005, 44, 7945.

Carpenter, D.L, Bain, R.L., Davis, R.E., Dutta, A., Feik, C.J., Gaston, K.R., Jablonski, W.S., Phillips, S.D., and Nimlos, M.R., Pilot-scale gasification of corn stover, switchgrass, wheat straw, and wood: 1 parametric study and comparison with literature. Ind. Eng. Chem. Res., 2010, 49, 1859.

ChemKin-Pro (2008), Reaction Design: San Diego.

Naik, C. V. and A. M. Dean (2006). Detailed kinetic modeling of ethane oxidation. Combust. Flame 145, 16.

Randolph, K. L. and A. M. Dean (2007). Hydrocarbon fuel effects in solid-oxide fuel cell operation: an experimental and modeling study of n-hexane pyrolysis. Phys. Chem. Chem. Phys. 9, 4245.

Villano, S. M., Hoffmann J., Carstensen, H.-H., and Dean A. M. (2010). Selective removal of ethylene, a deposit precursor, from a "dirty" synthesis gas stream via gas-phase partial oxidation. J. Phys. Chem. A 114, 6502 . 


\title{
Selective Removal of Ethylene, a Deposit Precursor, from a "Dirty" Synthesis Gas Stream via Gas-Phase Partial Oxidation
}

\author{
Stephanie M. Villano, Jessica Hoffmann, Hans-Heinrich Carstensen, and Anthony M. Dean* \\ Chemical Engineering Department, Colorado School of Mines, Golden, Colorado 80401
}

Received: March 6, 2010; Revised Manuscript Received: April 15, 2010

\begin{abstract}
A fundamental issue in the gasification of biomass is that in addition to the desired synthesis gas product (a mixture of $\mathrm{H}_{2}$ and $\mathrm{CO}$ ), the gasifier effluent contains other undesirable products that need to be removed before any further downstream processing can occur. This work assesses the potential to selectively remove hydrocarbons from a synthesis gas stream via gas-phase partial oxidation. Specifically, the partial oxidation of methane-doped, ethylene-doped, and methane/ethylene-doped model synthesis gas mixtures has been investigated at ambient pressures over a temperature range of $760-910{ }^{\circ} \mathrm{C}$ and at residence times ranging from 0.4 to $2.4 \mathrm{~s}$ using a tubular flow reactor. For the synthesis gas mixtures that contain either methane or ethylene, the addition of oxygen substantially reduces the hydrocarbon concentration while only a small reduction in the hydrogen concentration is observed. For the synthesis gas mixtures doped with both methane and ethylene, the addition of oxygen preferentially removes ethylene while the concentrations of methane and hydrogen remain relatively unaffected. These results are compared to the predictions of a plug flow model using a reaction mechanism that is designed to describe the pyrolysis and partial oxidation of small hydrocarbon species. The agreement between the experimental observations and the model predictions is quite good, allowing us to explore the underlying chemistry that leads to the hydrocarbon selective oxidation. The implications of these results are briefly discussed in terms of using synthesis gas to produce liquid fuels and electrical power via a solid oxide fuel cell.
\end{abstract}

\section{Introduction}

To satisfy future energy needs in a sustainable manner, fossil fuels will have to be supplemented by renewable sources. One promising approach is to gasify biomass to produce a synthesis gas (a mixture of $\mathrm{H}_{2}$ and $\mathrm{CO}$ ) that can be used for power generation or can be catalytically converted to synthetic transportation fuels. However, one major problematic feature of synthesis gas generated from biomass is that it contains undesirable byproducts which first must be removed prior to further processing. Other major components in the biomass gasifier product stream include $\mathrm{CO}_{2}, \mathrm{H}_{2} \mathrm{O}, \mathrm{CH}_{4}$, and $\mathrm{N}_{2}$. Additionally, this gas stream typically contains impurities such as $\mathrm{C}_{2} \mathrm{H}_{4}$ and other light hydrocarbons, tars, $\mathrm{NH}_{3}, \mathrm{H}_{2} \mathrm{~S}, \mathrm{HCN}$, alkali metals, and particulates. ${ }^{1,2}$ The presence of these impurities is problematic for the downstream synthesis gas conversion equipment and catalysts, and therefore, it is critical to reduce their concentration to an acceptable level. The degree of cleanup required depends on the gasification medium, ${ }^{2-4}$ the process conditions, ${ }^{3-8}$ and the contaminant tolerance of the end-use application. ${ }^{1}$

One challenging aspect of this cleanup process is the removal of unwanted hydrocarbons and tars. Heavier hydrocarbons (i.e., molecular weight growth precursors) and tars are especially problematic as they can deposit on equipment and deactivate catalysts. For certain downstream applications light hydrocarbons are undesirable, even if they are inert, as they dilute the synthesis gas, reducing the efficiency of the downstream conversion. This is a primary obstacle in the production of mixed alcohols and Fischer-Tropsch fuels, where the presence of inert species increases the costs associated with compressing the

\footnotetext{
* Corresponding author, amdean@mines.edu.
}

synthesis gas to the pressure required for fuel synthesis. ${ }^{9}$ In this respect, methane is particularly problematic as it comprises a substantial portion of the product gas $(\sim 15 \%$ dry-basis of a biomass-based gasifier stream). ${ }^{2}$ For other downstream applications, the presence of methane may be desirable. For example, solid oxide fuel cells (SOFC) with internal reforming capabilities can convert methane to carbon monoxide and hydrogen within the anode channel. This process is endothermic and can be used to effectively use the waste heat generated during the electrochemical process. While having some methane present is beneficial, heavy and unsaturated hydrocarbons can lead to carbon deposition on the anode surface, ${ }^{10-16}$ reducing the fuel cell performance and ultimately leading to irreversible damage of the fuel cell anode.

The conventional approach to remove these unwanted hydrocarbons is to employ a downstream tar-reformer, which catalytically converts these species to $\mathrm{H}_{2}, \mathrm{CO}$, and $\mathrm{CO}_{2}$. This approach is attractive because it increases the synthesis gas yield, eliminates the need for the collection and disposal of tars, and operates at temperatures similar to those at the gasifier exit. However, this method adds substantially to both the capital and operational costs of the fuel production. The primary technical barrier is that long-term stability of the available catalysts has not yet been demonstrated. Additionally, in many instances, removal of certain hydrocarbons down to their target concentrations has proven to be difficult. ${ }^{9}$ Recently Bain et al. showed that while the reforming capabilities of a Ni-based/ $\mathrm{Al}_{2} \mathrm{O}_{3}$ catalyst is initially high toward both methane and tars, deactivation occurs rapidly within $2 \mathrm{~h}$ of operation. ${ }^{17}$ Similar behavior has been observed for commercial steam reforming catalysts, commercial methanation catalysts, and naturally occurring minerals. ${ }^{18}$ Deactivation of the reforming catalyst can occur 
through poisoning by sulfur, chlorine, and alkali contaminants that are also present in the gasifier effluent, carbon deposition, or attrition. ${ }^{19,20}$ Carbon deposition deactivates the catalyst by blocking the active sites on the catalysis surface. This process competes with hydrocarbon steam and dry reforming pathways. ${ }^{19}$

One alternative strategy to remove hydrocarbons from synthesis gas is via gas-phase partial oxidation. The challenging aspect of this method is to selectively remove unwanted hydrocarbons, while preserving the concentrations of $\mathrm{H}_{2}$ and $\mathrm{CO}$. Generally, gas-phase oxidation processes are nonselective. Thus, given that the hydrogen concentration in the gasifier effluent is higher than that of the hydrocarbon, one may anticipate that the addition of oxygen to a "dirty" synthesis gas stream would result in a substantial loss in $\mathrm{H}_{2}$. However, preliminary detailed kinetic modeling efforts ${ }^{21}$ suggest otherwise, indicating that it is possible to selectively reduce the hydrocarbon concentration without significantly affecting the hydrogen concentration.

In this work, we test this hypothesis experimentally by studying the impact of the addition of small amounts of oxygen to a surrogate synthesis gas stream, which contains methane and/or ethylene as representative small hydrocarbons. These two model hydrocarbons were chosen since they are the most prominent hydrocarbons produced in the gasification process ${ }^{1,2}$ and since ethylene is a known deposit precursor. ${ }^{22,23}$ Experiments were conducted under conditions that closely resemble the gasification process, spanning a temperature range of 760-910 ${ }^{\circ} \mathrm{C}$ and residence times of $0.4-2.4 \mathrm{~s}$. The results are most encouraging, confirming that hydrocarbons can indeed be selectively oxidized in the presence of excess hydrogen. The experimental data are compared to predictions of a plug flow model using a detailed reaction mechanism that is designed to describe the pyrolysis and partial oxidation of small hydrocarbon species. The agreement between the two is quite good, suggesting that the kinetic model contains all important reaction steps for this application. Thus, we can use this mechanism to analyze the underlying reactions and develop a fundamental understanding of how the selective oxidation of these hydrocarbons proceeds.

\section{Methods}

Experimental Description. The partial oxidation of a methane and/or ethylene-doped model synthesis gas stream was investigated using a continuous flow tubular reactor. ${ }^{12}$ Experiments are conducted over the temperature range of 760-910 ${ }^{\circ} \mathrm{C}$ at ambient (high altitude) pressures of $\sim 0.8 \mathrm{~atm}$. The synthesis gas used in this study is composed of $11.9 \%$ carbon monoxide (Matheson Trigas, 99\%), 9.2\% carbon dioxide (General Air, 99.99\%), and $11.9 \%$ hydrogen (General Air, 99.99\%), doped with either 5.00\% methane (Matheson Trigas, 99.999\%), 2.50\% ethylene (Matheson Trigas, 99.95\%), or a $5.00 \%$ methane $1.70 \%$ ethylene mixture. The balance is nitrogen (General Air, 99.998\%). This gas mixture was chosen to represent a real gasifier product stream obtained at the National Renewable Energy Laboratory from gasification of a Vermont wood feedstock. ${ }^{2}$ However, for experimental convenience, nitrogen was substituted for water since water does not react in the gas phase at the temperatures used in this study. An added advantage of using nitrogen was that it allowed for the determination of the change in moles in the system and for the indirect quantification of water as a product. Partial oxidation studies were performed by substituting 1.0, 2.0, 3.0, and in one case $5.0 \%$ of oxygen (General Air, 99.98\%) for the nitrogen buffer gas.

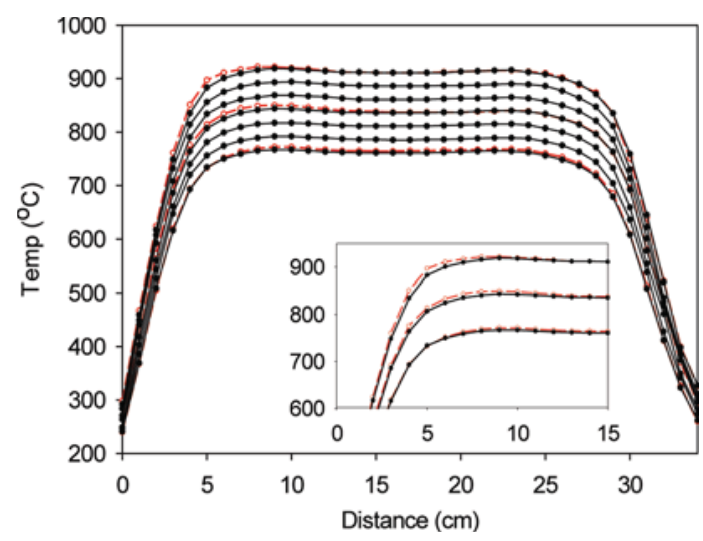

Figure 1. Reactor temperature-distance profiles collected using $\mathrm{CH}_{4} /$ $\mathrm{C}_{2} \mathrm{H}_{4}$-doped synthesis gas under pyrolytic conditions (solid black lines) and 3\% partial oxidation conditions (dashed red lines) at residence times of 1.0-1.2 s. The first $15 \mathrm{~cm}$ of the profile is blown up in the inset to shown the effect of oxygen.

The flow of each feed gas was controlled using calibrated Alicat Scientific Series 16 gas flow controllers. The synthesis gas components including oxygen were mixed together before entering the reactor. Prior to its mixing with the other synthesis gas components, the carbon monoxide feed gas was purified by passage through a heated quartz tube $\left(\sim 400^{\circ} \mathrm{C}\right)$ to thermally dissociate any trace metal carbonyl impurities, which are formed in the high-pressure carbon monoxide cylinder. ${ }^{24-27}$ These metal carbonyls are problematic since they dissociate under modest temperatures leaving metal deposits on the quartz reactor surface, which act as a catalyst. Before employing this $\mathrm{CO}$ purification method, erratic effects that could be attributed to catalysis were observed in our initial studies on the pyrolysis and partial oxidation of a methane-doped synthesis gas stream. All other gases were used without further purification. Unless otherwise specified, the total flow rate was held constant at 124.4 SCCM, which corresponds to residence times of approximately $1.0-1.2 \mathrm{~s}$. The actual residence time in the reactor (defined for the entire reactor length) is dependent upon the temperature profile, total flow, and extent of reaction (i.e., total number of moles in the reactor at a given distance) and is determined more precisely by model calculations that account for each one of these variables.

Experiments are performed by passing a known flow of the model synthesis gas through a $34 \mathrm{~cm}$ by $6 \mathrm{~mm}$ i.d. tubular quartz reactor housed in an electric furnace equipped with three Eurotherm model 2116 digital temperature controllers. The temperature profile of the reactor was measured using a thermocouple that has been coated with high temperature alumina adhesive. As shown in Figure 1, the temperature is approximately constant at the center of the reactor and the reproducibility of the measurement is $\pm 2{ }^{\circ} \mathrm{C}$. At the entrance and exit of the reactor the temperature gradient is steep, and the measurement is very sensitive to the exact axial position of the thermocouple. An estimated maximum error of $\pm 15{ }^{\circ} \mathrm{C}$ occurs at the first and last position of the profile; however, toward the center of the reactor the magnitude of this error decreases rapidly. Moreover, the temperatures at the edges of the reactor are sufficiently low such that chemistry is not expected to occur. The profiles were measured using a methane/ ethylene-doped synthesis gas stream under pyrolytic conditions for each temperature studied here (solid symbols). The profiles at 760,835 , and $910{ }^{\circ} \mathrm{C}$ were compared to those where $3 \%$ oxygen has been added (open symbols). The addition of oxygen results in a slight increase in temperature but only at the 
beginning of the reactor. In the most extreme case, at $910^{\circ} \mathrm{C}$, the temperature difference is less than $15^{\circ} \mathrm{C}$.

Following the reactor, the gas stream is qualitatively analyzed by a MKS Cirrus (LM99) mass spectrometer, which provides verification that the reactor effluent has reached steady state, and quantified using a Hewlett-Packard 5890 Series II Plus gas chromatograph (GC). Separation of the gas mixture is achieved via two analysis schemes. In both cases the initial oven temperature is held at $40{ }^{\circ} \mathrm{C}$ for $5 \mathrm{~min}$ and then ramped at 20 ${ }^{\circ} \mathrm{C} / \mathrm{min}$ to $220^{\circ} \mathrm{C}$. Permanent gases and light hydrocarbons are separated using tandem Supelco $6 \mathrm{ft} \times 1 / 8$ in. stainless steel packed Porpack $\mathrm{R}$ and $15 \mathrm{ft} \times 1 / 8$ in. stainless steel packed Carboxen 1000 columns with argon carrier gas and a thermal conductivity detector. In the second scheme, light and heavy hydrocarbons are separated using a J\&W Fisher SPB-1 $60 \mathrm{~m}$ $\times 0.53 \mathrm{~mm}$ i.d. $5 \mu \mathrm{m}$ fused silica film capillary column with helium as the carrier gas and a flame ionization detector. These two separation schemes provide dual detection of methane and ethylene, and the average relative agreement between the two is $2 \%$ and $5 \%$, respectively. Since flame ionization detection is more sensitive, the reported mole fractions for these two species are taken from the second separation scheme. The products were quantified by projecting their measured signal area onto a standard sample calibration curve. Since the number of moles of nitrogen buffer gas does not change during the reaction, the change in the mole fraction of nitrogen allows for the conversion of the product mole fractions to their molar concentrations. One limitation to the analytical method used in this study is that it does not provide for the direct quantification of water or oxygen. Instead, the concentration of water is estimated using the deviation in the hydrogen balance while the concentration of oxygen is estimated using the deviation in the oxygen balance once the contribution from water has been removed.

Kinetic Modeling. The reaction mechanism used to model these data was developed at the Colorado School of Mines (CSM) and is based on updated versions of the Randolph and Dean ${ }^{12} \mathrm{C}_{6}$ pyrolysis and the Naik and Dean ${ }^{28} \mathrm{C}_{3}$ oxidation mechanisms, which have been validated against both $n$ hexane pyrolysis ${ }^{12}$ and ethane oxidation ${ }^{28}$ data as well as other unpublished data. The mechanism contains 3508 reactions and 328 species. While it is not feasible to discuss each reaction contained within the mechanism, they can be broken down into three main classes: hydrogen atom abstraction reactions, addition/ $\beta$-scission reactions, and dissociation/ recombination reactions. When reliable experimental kinetic data are available, these values are implemented in the mechanism. In other cases, rate constants are determined using transition state theory based on the results of electronic structure calculations. Thermodynamic reversibility is used to determine reverse rate constants, where the thermodynamic parameters are either estimated from group additivity using THERM $^{29}$ or obtained from electronic structure calculations. Many of the reactions in the mechanism are pressure dependent. The rate coefficients for these reactions are evaluated as a function of both temperature and pressure using a three frequency Quantum Rice-Ramsperger-Kassel analysis coupled with the modified strong collision approximation (QRRK/MSC). ${ }^{30}$ For this study, rate coefficients of pressuredependent reactions are expressed as a function of temperature in modified Arrhenius form (eq 1) evaluated for a pressure of $0.8 \mathrm{~atm}$.

$$
k=A T^{n} \exp (-E / R T)
$$

Here $k$ is the reaction rate constant, $A$ is the preexponential factor, $n$ is a constant, $R$ is the ideal gas constant, $E$ is related to the activation energy, and $T$ is the temperature. The described mechanism was used for this study without any attempts to improve the predictions by adjusting rate expressions.

The simulations are performed using the ChemKin Pro suite of programs. ${ }^{31}$ The input parameters consist of the previously described kinetic mechanism and corresponding thermodynamic properties as well as the measured temperature profiles, flow rates, pressure, and reactor dimensions. The quartz reactor used in this study is treated as a plug flow reactor assuming that there are no wall effects. This assumption has previously been verified by comparison of results calculated using the plug flow model to those obtained using a parabolic flow model. ${ }^{12}$ We have also investigated how sensitive the model predictions are with respect to the temperature profile used. The product distributions obtained using temperature profiles collected under both pyrolysis and partial oxidation conditions are similar (the average relative deviation in the predicted mole fractions of the major products is $1 \%$ ).

\section{Results}

The experimental results for the partial oxidation of a methane-doped, an ethylene-doped, and a methane/ethylenedoped synthesis gas stream are summarized in Tables 1, 2, and 3 , respectively. The change in the product mole fractions is due both to reaction and to dilution effects as the number of moles in the system changes. However, in general, the latter effect is small as is evident by the observed minor change in the nitrogen mole fraction. Each reported data point is an average of at least three measurements, and the reported error reflects the standard deviation as well as the uncertainty in the concentration calibration curve. The carbon (C) mass balance is within $2 \%$. Under pyrolytic conditions the mass balances of hydrogen $(\mathrm{H})$ and oxygen $(\mathrm{O})$ also agree to within $2 \%$. As oxygen is added to the synthesis gas mixture, the amount of $\mathrm{H}$ and $\mathrm{O}$ measured at the outlet is less than that at the inlet. This is consistent with the formation of water, which is not detected gas chromatographically. However, since the deviation in the $\mathrm{O}$ balance is greater than half that of the deviation in the $\mathrm{H}$ balance, it is likely that a small amount of residual oxygen remains in the reactor effluent. Although neither water nor oxygen are directly quantified using gas chromatography, both species could be detected using mass spectrometry. The concentration of water is estimated using the deviations in the $\mathrm{H}$ balances, and the results are provided in Tables $1-3$. The oxygen concentration is estimated using the deviation in the $\mathrm{O}$ balances once water is accounted for. Due to the large uncertainty in the oxygen concentration estimation, oxygen mole fractions are only reported in Table 5 for one condition.

Figure 2 shows the effect of oxygen on a $\mathrm{CH}_{4}$-doped synthesis gas mixture at $810^{\circ} \mathrm{C}$, where the filled symbols correspond to the experimental results. Under pyrolytic conditions no reaction occurs. The addition of small amounts of oxygen decreases the methane concentration more than the hydrogen concentration, demonstrating some preference for selective oxidation. At the highest $\mathrm{O}_{2}$ concentration, roughly $29 \%$ of the $\mathrm{CH}_{4}$ has been consumed while only $7 \%$ of the $\mathrm{H}_{2}$ is lost. This is accompanied by an increase in carbon monoxide and carbon dioxide as well as the formation of minor amounts of ethylene and ethane. While the observed mole fractions of the $\mathrm{C}_{2}$ species are small, their formation accounts for a considerable fraction of methane conversion, especially at the lowest oxygen concentration where this decomposition route 
TABLE 1: Experimental Product Mole Fractions for the Partial Oxidation of a $\mathrm{CH}_{4}$-Doped Synthesis Gas Mixture ${ }^{a}$

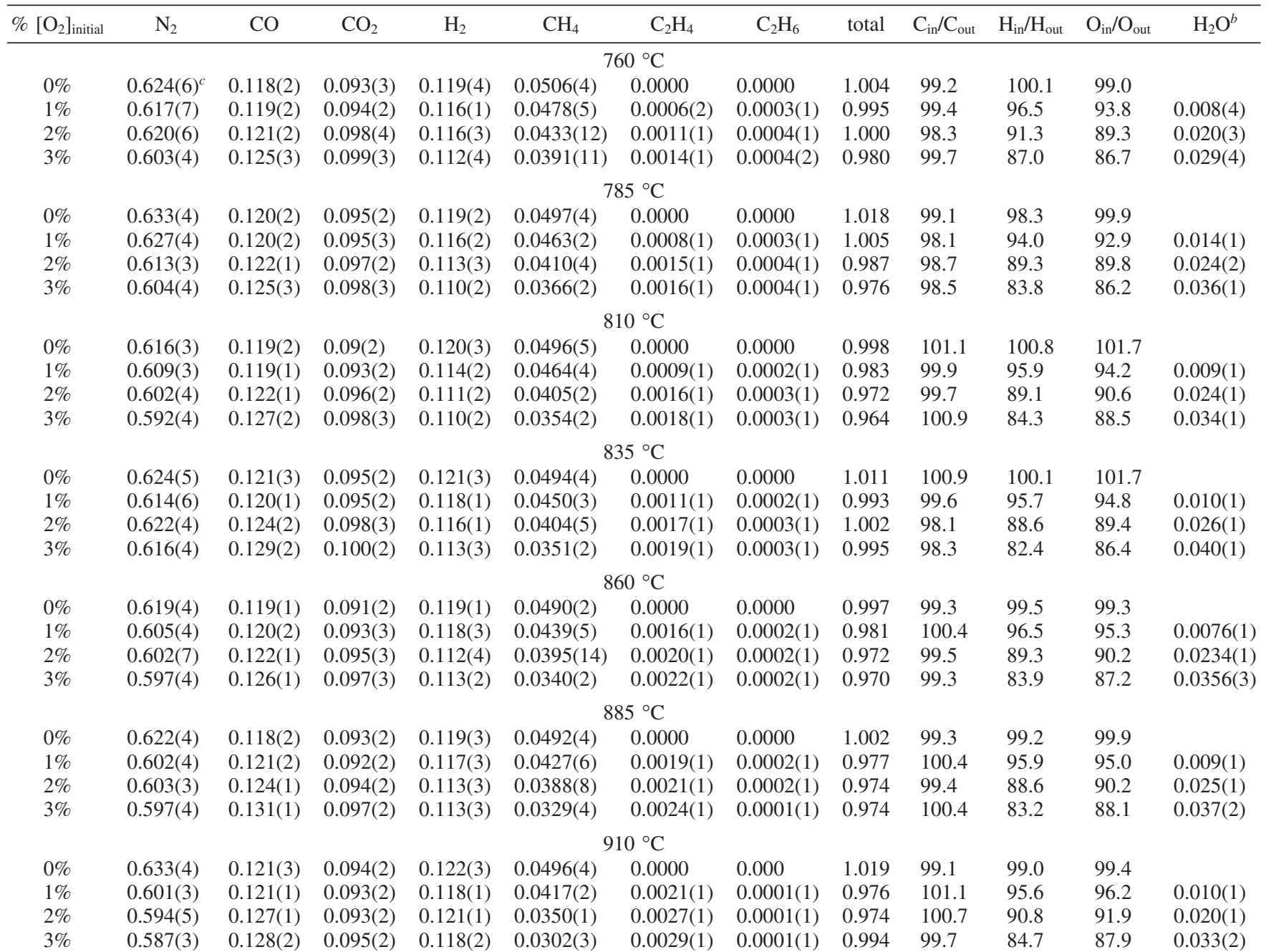

${ }^{a}$ Initial mole fractions: $\mathrm{CO} 0.119 ; \mathrm{CO}_{2} 0.092 ; \mathrm{H}_{2} \quad 0.119 ; \mathrm{CH}_{4} 0.0500 ; \mathrm{N}_{2} \quad 0.620 / \mathrm{O}_{2} \quad 0.00, \mathrm{~N}_{2} \quad 0.610 / \mathrm{O}_{2} \quad 0.010, \mathrm{~N}_{2} \quad 0.600 / \mathrm{O}_{2} \quad 0.020$, and $\mathrm{N}_{2}$ $0.590 / \mathrm{O}_{2}$ 0.030. ${ }^{b}$ Estimated from $\mathrm{H}_{\mathrm{in}} / \mathrm{H}_{\text {out }}$ for $1-3 \%$ oxygen addition. ${ }^{c}$ The number in parentheses reflects the uncertainty in the last digit of the measurement.

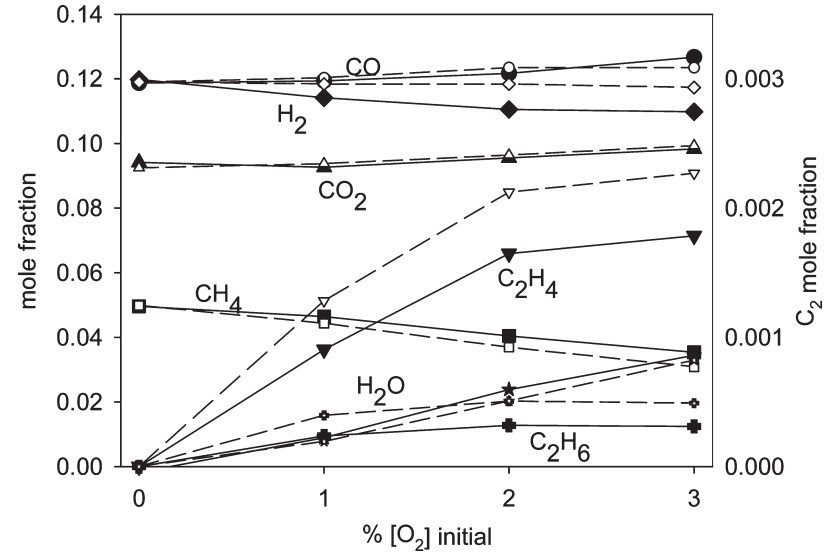

Figure 2. The product distribution that results from the partial oxidation of a $\mathrm{CH}_{4}$-doped synthesis gas mixture $\left(T=810^{\circ} \mathrm{C} ; P=0.8 \mathrm{~atm} ; \tau \sim\right.$ $1 \mathrm{~s})$. The solid symbols correspond to the experimental data, while the open symbols correspond to the model predictions. The mole fractions of ethylene and ethane are shown on the right-hand side $y$ axis.

dominates as shown in Figure 3. At higher oxygen concentrations the formation of $\mathrm{CO}$ and $\mathrm{CO}_{2}$ becomes more pronounced.

The effect of added oxygen on an $\mathrm{C}_{2} \mathrm{H}_{4}$-doped synthesis gas stream at $810^{\circ} \mathrm{C}$ is shown in Figure 4 . For comparison purposes,

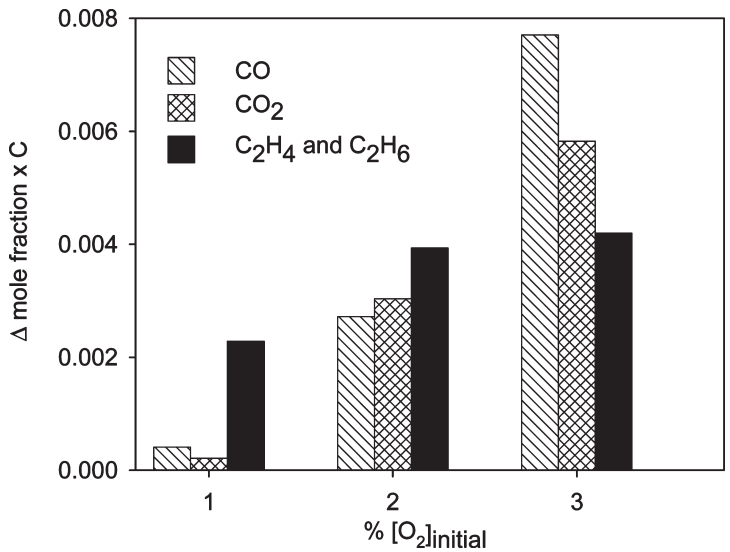

Figure 3. The changes in mole fraction for $\mathrm{CO}$ (striped), $\mathrm{CO}_{2}$ (cross hatched), and ethylene plus ethane species (black), normalized for the number of carbons $(x \mathrm{C})$, that result from the partial oxidation of a methanedoped synthesis gas mixture $\left(T=810{ }^{\circ} \mathrm{C} ; P=0.8 \mathrm{~atm} ; \tau \sim 1 \mathrm{~s}\right)$.

the amount of ethylene that is added to the gas mixture is half that of the amount of methane used in the above methane/ synthesis gas mixture, keeping the total amount of carbon between the two studies the same. Addition of oxygen significantly reduces the concentration of ethylene. At 3\% oxygen 
TABLE 2: Experimental Product Mole Fractions for the Partial Oxidation of a $\mathrm{C}_{2} \mathrm{H}_{4}$-Doped Synthesis Gas Mixture ${ }^{a}$

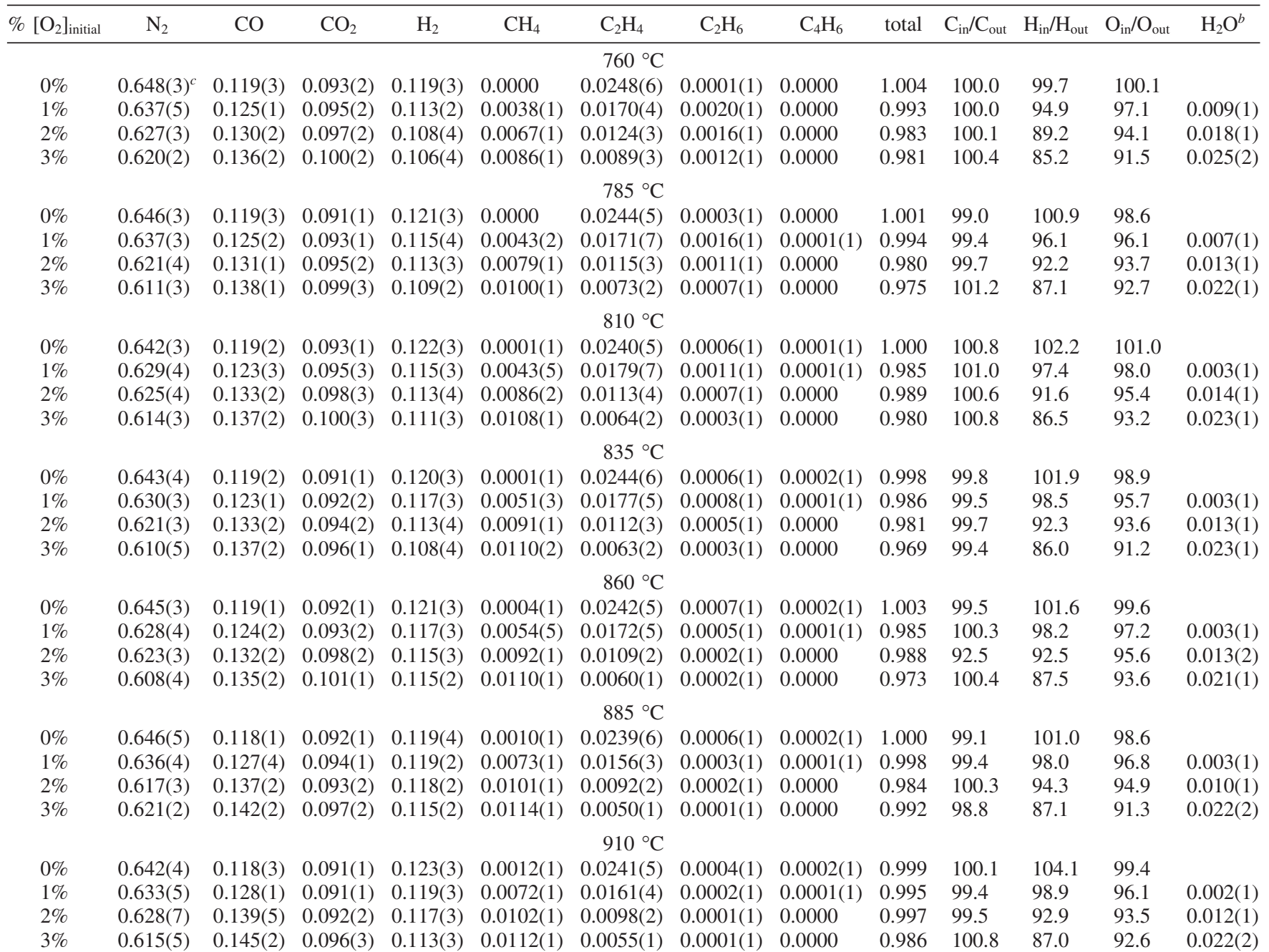

${ }^{a}$ Initial mole fractions: $\mathrm{CO} 0.119 ; \mathrm{CO}_{2} 0.092 ; \mathrm{H}_{2} 0.119 ; \mathrm{C}_{2} \mathrm{H}_{4} 0.0250$; and $\mathrm{N}_{2} \quad 0.645 / \mathrm{O}_{2} 0.00, \mathrm{~N}_{2} 0.635 / \mathrm{O}_{2} 0.010, \mathrm{~N}_{2} 0.625 / \mathrm{O}_{2} 0.020$, and $\mathrm{N}_{2} 0.615 /$ $\mathrm{O}_{2}$ 0.030. ${ }^{b}$ Estimated from $\mathrm{H}_{\mathrm{in}} / \mathrm{H}_{\text {out }}$ for $1-3 \%$ oxygen addition. ${ }^{c}$ The number in parentheses reflects the uncertainty in the last digit of the measurement.

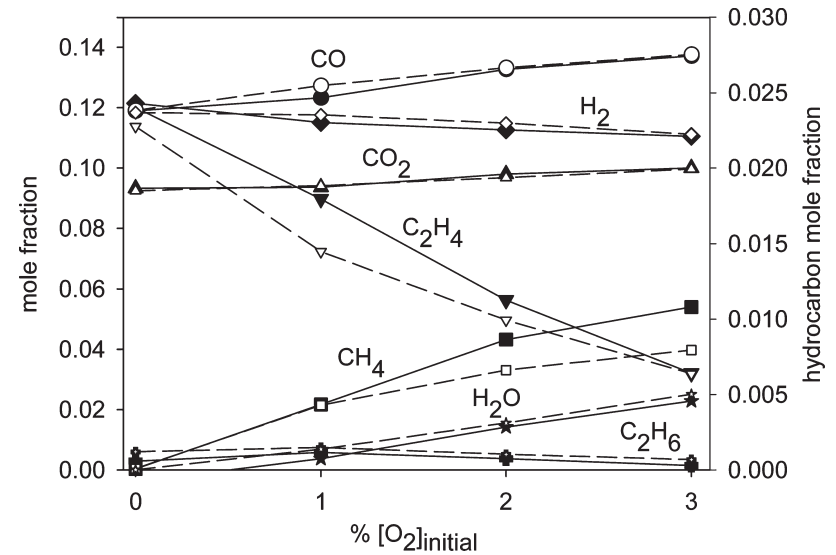

Figure 4. The product distribution that results from the partial oxidation of an ethylene-doped synthesis gas mixture $\left(T=810{ }^{\circ} \mathrm{C} ; P=0.8 \mathrm{~atm} ; \tau\right.$ $\sim 1 \mathrm{~s})$. The solid symbols correspond to the experimental data and the open symbols to the CSM model predictions. The mole fractions of methane, ethylene, and ethane are shown on the right-hand side $y$ axis.

addition the ethylene concentration is reduced by $\sim 74 \%$, while the hydrogen concentration is reduced by only $\sim 7 \%$. Although some hydrogen is lost, the sum of $\mathrm{H}_{2}$ and $\mathrm{CO}$ is approximately constant. Only a small increase in the concentration of carbon dioxide is observed as well as the formation of methane and

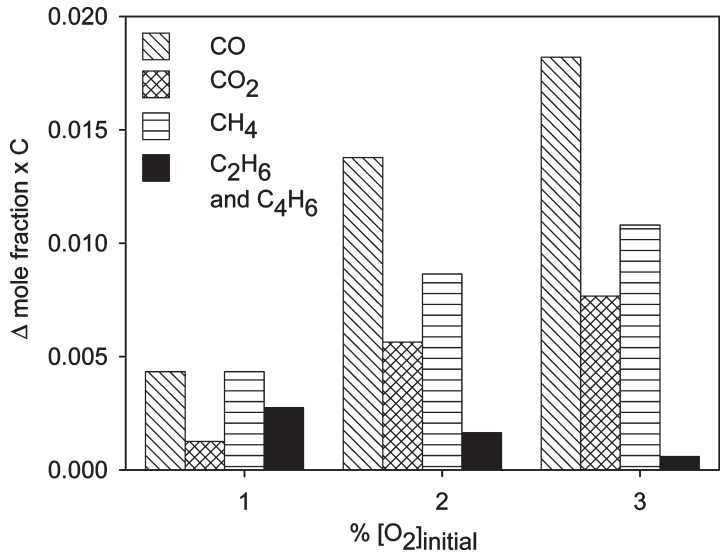

Figure 5. The changes in mole fraction for $\mathrm{CO}$ (diagonal stripes), $\mathrm{CO}_{2}$ (cross hatched), $\mathrm{CH}_{4}$ (horizontal stripes), and ethane plus 1,3butadiene (black), normalized for the number of carbons $(x \mathrm{C})$, that result from the partial oxidation of $\mathrm{C}_{2} \mathrm{H}_{4}$-doped synthesis gas mixture $(T=$ $\left.810{ }^{\circ} \mathrm{C} ; P=0.8 \mathrm{~atm} ; \tau \sim 1 \mathrm{~s}\right)$.

small amounts of ethane and 1,3-butadiene $\left(\mathrm{X}\left(\mathrm{C}_{4} \mathrm{H}_{6}\right) \leq 0.0002\right.$; not shown in Figure 4). Comparison of the change in normalized mole fractions of $\mathrm{CO}, \mathrm{CO}_{2}, \mathrm{CH}_{4}$, and the sum of $\mathrm{C}_{2} \mathrm{H}_{6}$ plus $\mathrm{C}_{3} \mathrm{H}_{6}$ at each oxygen concentration (Figure 5) shows that at the lowest oxygen concentration ethylene is almost equally con- 
TABLE 3: Experimental Product Mole Fractions for the Partial Oxidation of a $\mathrm{CH}_{4} / \mathrm{C}_{2} \mathrm{H}_{4}$-Doped Synthesis Gas Mixture ${ }^{a}$

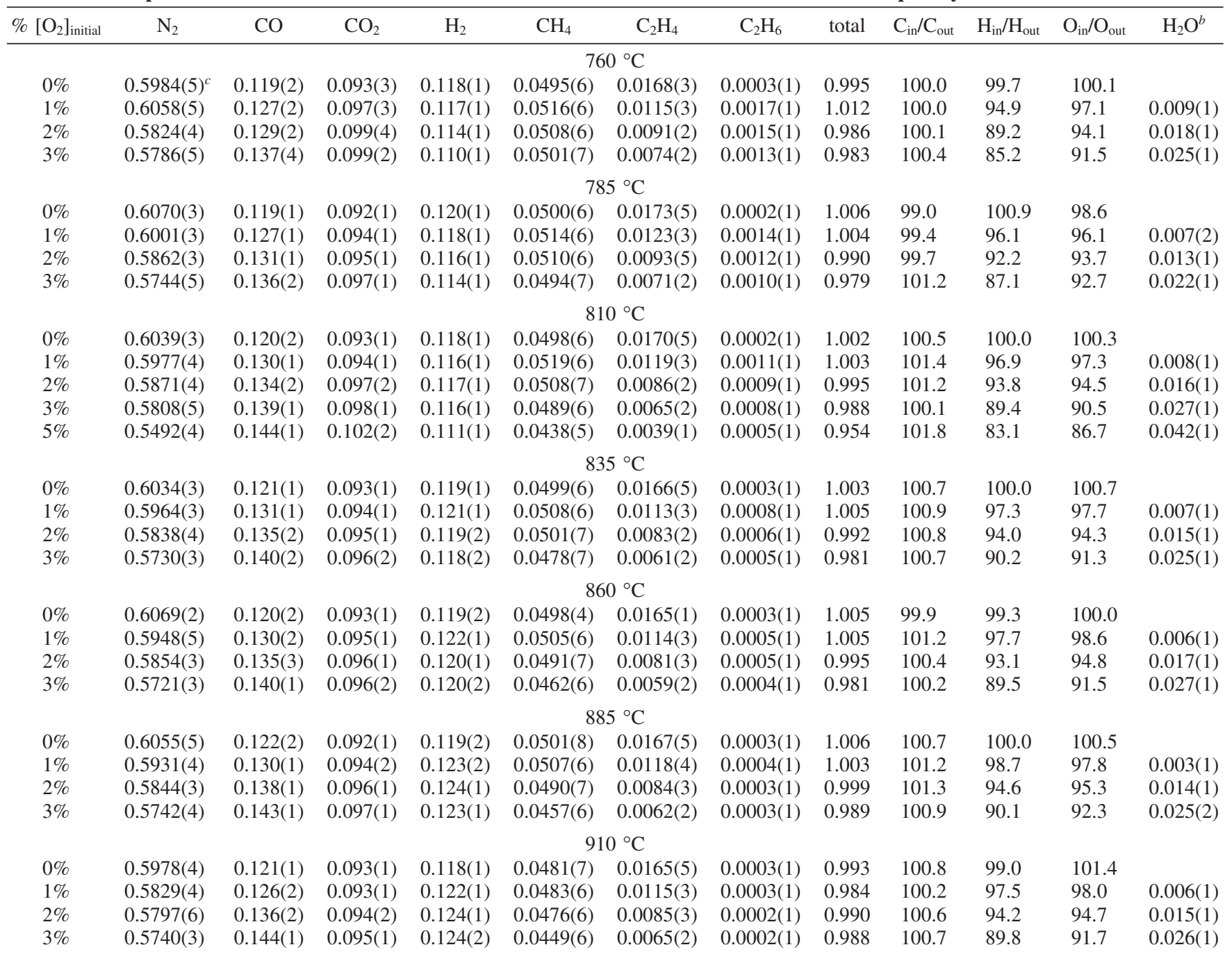

${ }^{a}$ Initial mole fractions: $\mathrm{CO} 0.119 ; \mathrm{CO}_{2} \quad 0.092 ; \mathrm{H}_{2} \quad 0.119 ; \mathrm{CH}_{4} 0.0500 ; \mathrm{C}_{2} \mathrm{H}_{4} \quad 0.0170 ; \mathrm{N}_{2} \quad 0.603 / \mathrm{O}_{2} \quad 0.000, \mathrm{~N}_{2} \quad 0.602 / \mathrm{O}_{2} \quad 0.010, \mathrm{~N}_{2} \quad 0.601 / \mathrm{O}_{2}$ $0.020, \mathrm{~N}_{2} 0.600 / \mathrm{O}_{2} 0.030$, and $\mathrm{N}_{2} 0.598 / \mathrm{O}_{2} 0.050 .{ }^{b}$ Estimated from $\mathrm{H}_{\text {in }} / \mathrm{H}_{\text {out }}$ for $1-3 \%$ oxygen addition. ${ }^{c}$ The number in parentheses reflects the uncertainty in the last digit of the measurement.

verted to $\mathrm{CO}$ and $\mathrm{CH}_{4}$, while at higher oxygen concentration it is preferentially converted to $\mathrm{CO}$. The formation of molecular weight growth species, ethane and 1,3-butadiene, decreases with increasing oxygen concentration.

Lastly, we have examined the selective oxidation of a $\mathrm{CH}_{4} /$ $\mathrm{C}_{2} \mathrm{H}_{4}$-doped synthesis gas mixture, where the concentrations of both hydrocarbons are based upon those found in a real synthesis gas stream. ${ }^{2}$ The experimental results at $810{ }^{\circ} \mathrm{C}$ are shown in Figure 6. For this mixture 5\% oxygen addition was also examined. Here the data show a very strong preference of ethylene oxidation relative to both hydrogen and methane. At $3 \%$ oxygen addition, approximately $62 \%$ of the ethylene is consumed while the concentrations of methane and hydrogen remain essentially unaffected. Increasing the oxygen concentration to $5 \%$ results in a $\sim 77 \%$ reduction in the ethylene concentration; however, at these high oxygen concentrations some methane and hydrogen is also consumed. While the addition of oxygen also results in some carbon dioxide formation, ethylene is preferentially converted to carbon monoxide as shown in Figure 7.

We have examined the partial oxidation of these model hydrocarbons over a temperature range of $760-910{ }^{\circ} \mathrm{C}$ and, in each case, varying the temperature has only a very minor

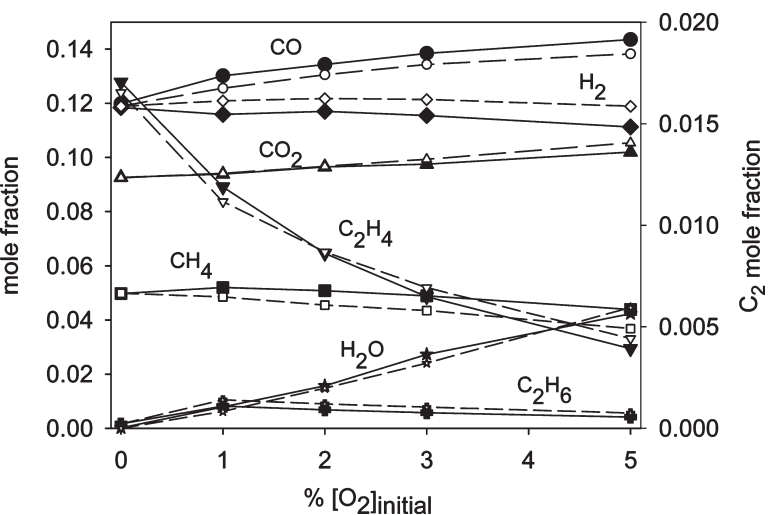

Figure 6. The product distribution that results from the partial oxidation of a $\mathrm{CH}_{4} / \mathrm{C}_{2} \mathrm{H}_{4}$-doped synthesis gas mixture $\left(T=810^{\circ} \mathrm{C}\right.$; $P=0.8 \mathrm{~atm} ; \tau \sim 1 \mathrm{~s})$. The solid symbols correspond to the experimental data and the open symbols correspond to the model predictions. The mole fractions of ethylene and ethane are shown on the right-hand side $y$ axis.

effect on the observed product distribution (see Tables 1-3). This is illustrated in Figure 8 for a $\mathrm{CH}_{4} / \mathrm{C}_{2} \mathrm{H}_{4}$-doped synthesis gas stream at $3 \%$ oxygen addition. Increasing the temperature 


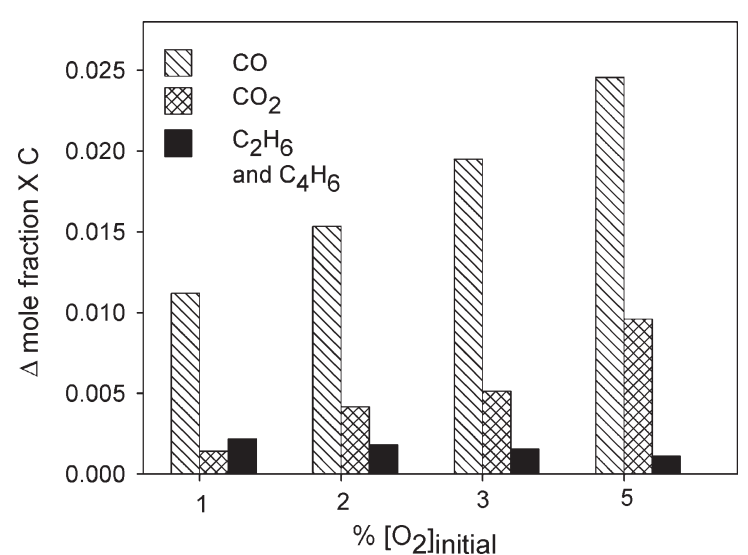

Figure 7. The changes in mole fraction for $\mathrm{CO}$ (stripes), $\mathrm{CO}_{2}$ (cross hatched), and ethane pus 1,3-butadiene (black), normalized for the number of carbons $(x \mathrm{C})$, that result from the partial oxidation of a $\mathrm{CH}_{4} / \mathrm{C}_{2} \mathrm{H}_{4}$-doped synthesis gas mixture $\left(T=810{ }^{\circ} \mathrm{C} ; P=0.8 \mathrm{~atm}\right.$; $\tau \sim 1 \mathrm{~s})$.

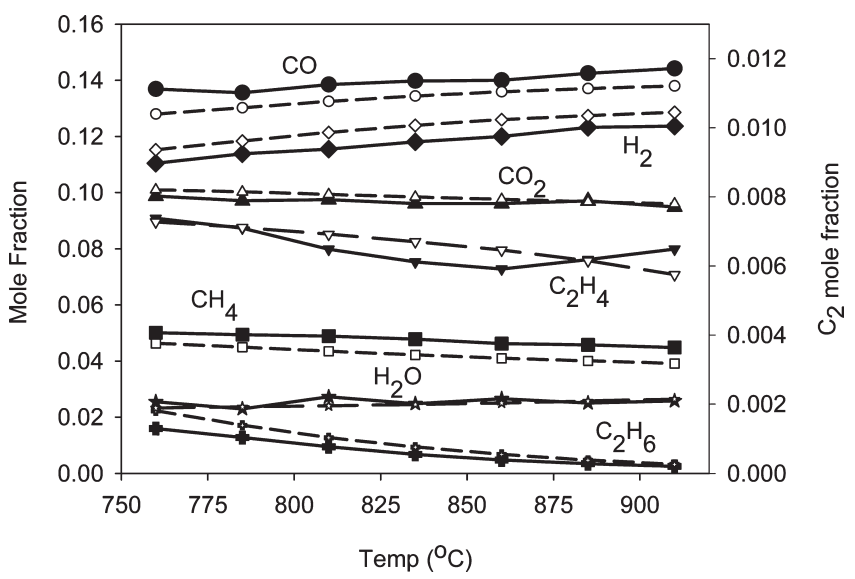

Figure 8. The product distribution that results from the partial oxidation of a $\mathrm{CH}_{4} / \mathrm{C}_{2} \mathrm{H}_{4}$-doped synthesis gas mixture as a function of temperature $\left(\left[\mathrm{O}_{2}\right]_{\text {initial }}=3 \% ; P=0.8 \mathrm{~atm} ; \tau \sim 1 \mathrm{~s}\right)$. The solid symbols correspond to the experimental data and the open symbols to the CSM model predictions. The mole fractions of ethylene and ethane are shown on the right-hand side $y$ axis.

leads to a minor increase in the carbon monoxide and hydrogen mole fractions, and a slight reduction in the carbon dioxide, methane, and ethane mole fractions. The ethylene mole fraction is observed to first decrease as the temperature is increased but then to slightly increase at higher temperatures.

The effect of residence time was examined at $760{ }^{\circ} \mathrm{C}$ for the $\mathrm{CH}_{4} / \mathrm{C}_{2} \mathrm{H}_{4}$-doped synthesis gas mixture by varying the total gas flow rate while keeping the initial gas composition the same. As summarized in Table 4, aside from ethylene, the concentrations of the synthesis gas components remain approximately constant over a time window of $0.4-2.4 \mathrm{~s}$. The ethylene mole fractions as a function of residence time at $1 \%, 2 \%$, and $3 \%$ oxygen addition are shown in Figure 9; the initial mole fraction of ethylene is 0.0170 . The consumption of ethylene occurs rapidly. At the shortest residence time $41 \%$ of the ethylene is already consumed at $3 \%$ oxygen addition, while $32 \%$ is consumed at $2 \%$ oxygen addition and $23 \%$ is consumed at $1 \%$ oxygen addition. The conversion is to a large part is complete within $1.2 \mathrm{~s}$ and relatively little change is observed between 1.2 and $2.4 \mathrm{~s}$.
All experimental results described in the previous paragraphs have been modeled using the CSM mechanism, which is designed to describe the pyrolysis of $\mathrm{C}_{6}$ and smaller species and the partial oxidation of $\mathrm{C}_{3}$ and smaller species. Comparisons of the model to the experimental observations as a function of oxygen addition (open symbols in Figures 2, 4, and 6), temperature, (open symbols in Figure 8), and residence time (open symbols in Figure 9) show that, in general, the agreement between the two is quite good. The model predictions clearly capture the observed partial oxidation trends. One minor discrepancy is that the model tends to systematically overpredict the consumption of methane and at the same time underpredict the consumption of hydrogen and the formation of carbon monoxide. This is most evident in the selective oxidation of the $\mathrm{CH}_{4}$-doped synthesis gas stream (Figure 2), where the conversion of methane to $\mathrm{C}_{2}$ species is also overestimated. For the partial oxidation of the $\mathrm{C}_{2} \mathrm{H}_{4}$-doped and $\mathrm{CH}_{4} / \mathrm{C}_{2} \mathrm{H}_{4}$-doped synthesis gas mixtures, the model does an excellent job of predicting the decay of ethylene (Figures 4 and 6, respectively). Again we see that the methane consumption is overestimated while the hydrogen consumption is underestimated. The model predictions for ethylene as a function of residence time are in reasonable agreement with the experimental observations (Figure 9). Additionally, the model successfully predicts a very subtle temperature dependence, consistent with the experimentally observations (Figure 8). The one inconsistency is that the model predicts a uniform decrease in the ethylene mole fraction as the temperature increases rather than the curved dependence that is experimentally observed.

As previously mentioned, the experimental method does not provide for the direct quantification of water. Instead the water mole fractions are calculated from the deviation in the $\mathrm{H}$ balances. Experimentally, this estimation can be justified by the good carbon mass closure. The model predictions provide additional support for this procedure as shown in Figures 2, 4, 6, and 8. More specifically, the model predicts there to be some remaining oxygen at concentrations comparable to the amounts obtained when using the deviation in both the $\mathrm{O}$ and $\mathrm{H}$ balances (see Table 5 for results at 810 ${ }^{\circ} \mathrm{C}$ ). Moreover, the model does not predict there to be any appreciable formation of species such as hydrogen peroxide, which also could account for the missing $\mathrm{H}$ and $\mathrm{O}$ mass balances. The overall agreement between the experimental observations and the model predictions indicates that we are indeed properly accounting for all major reaction products.

\section{Discussion}

Reaction Analysis. The main objective of the present study is to investigate the possibility of using gas-phase partial oxidation to remove or substantially reduce the concentration of undesired hydrocarbon species in "dirty" synthesis gas. The experimental results obtained with surrogate synthesis gas mixtures, supported by the predictions of our kinetic model, confirm that such a reduction is indeed possible without significantly affecting $\mathrm{CO}$ and $\mathrm{H}_{2}$ yields. Furthermore, we demonstrate that this chemistry is fast (e.g., the hydrocarbon reactions are essentially completed well within one second as shown in Figure 9) and that the final product distribution shows little temperature dependence in the range $760-910{ }^{\circ} \mathrm{C}$. One obvious issue to be addressed is the explanation for the observed selectivity of this oxidation process. The rate constants for $\mathrm{H}$ atom abstraction by $\mathrm{OH}$ 
TABLE 4: Experimental and Predicted Equilibrium Product Mole Fractions for the Partial Oxidation of a $\mathrm{CH}_{4} / \mathrm{C}_{2} \mathrm{H}_{4}-\mathrm{Doped}$ Synthesis Gas Mixture at $760{ }^{\circ} \mathrm{C}^{a}$

\begin{tabular}{|c|c|c|c|c|c|c|c|c|c|c|c|c|}
\hline$\tau(\mathrm{s})$ & $\mathrm{N}_{2}$ & $\mathrm{CO}$ & $\mathrm{CO}_{2}$ & $\mathrm{H}_{2}$ & $\mathrm{CH}_{4}$ & $\mathrm{C}_{2} \mathrm{H}_{4}$ & $\mathrm{C}_{2} \mathrm{H}_{6}$ & total & $\mathrm{C}_{\text {in }} / \mathrm{C}_{\text {out }}$ & $\mathrm{H}_{\text {in }} / \mathrm{H}_{\text {out }}$ & $\mathrm{O}_{\text {in }} / \mathrm{O}_{\text {out }}$ & $\mathrm{H}_{2} \mathrm{O}^{b}$ \\
\hline $1 \% \mathrm{O}_{2}, 0.5$ & $0.594(5)^{c}$ & $0.123(2)$ & $0.095(2)$ & $0.119(2)$ & $0.0503(7)$ & $0.0130(5)$ & $0.0013(1)$ & 0.991 & 100.2 & 98.6 & 96.1 & $0.004(1)$ \\
\hline 0.6 & $0.588(3)$ & $0.124(2)$ & $0.094(3)$ & $0.117(1)$ & $0.0501(6)$ & $0.0123(3)$ & $0.0014(1)$ & 0.983 & 101.0 & 98.6 & 97.1 & $0.004(1)$ \\
\hline 0.8 & $0.591(3)$ & $0.122(2)$ & $0.096(2)$ & $0.116(1)$ & $0.0502(6)$ & $0.0117(3)$ & $0.0015(1)$ & 0.982 & 100.8 & 97.5 & 97.5 & $0.006(1)$ \\
\hline 2.4 & $0.595(6)$ & $0.125(1)$ & $0.098(2)$ & $0.113(1)$ & $0.0515(6)$ & $0.0113(1)$ & $0.0020(1)$ & 0.986 & 101.1 & 96.2 & 98.1 & $0.010(2)$ \\
\hline equilibrium ${ }^{d}$ & 0.5225 & 0.2405 & 0.0170 & 0.2063 & 0.0027 & 0.0000 & 0.0000 & & & & & 0.0110 \\
\hline $2 \% \mathrm{O}_{2}, 0.5$ & $0.592(4)$ & $0.123(1)$ & $0.095(1)$ & $0.115(1)$ & $0.0503(7)$ & $0.0114(3)$ & $0.0013(1)$ & 0.974 & 98.0 & 94.6 & 89.5 & $0.014(1)$ \\
\hline 0.6 & $0.587(5)$ & $0.126(2)$ & $0.095(1)$ & $0.113(1)$ & $0.0509(6)$ & $0.0108(3)$ & $0.0014(1)$ & 0.971 & 99.9 & 94.9 & 91.2 & $0.013(1)$ \\
\hline 2.4 & $0.587(3)$ & $0.129(3)$ & $0.098(1)$ & $0.110(1)$ & $0.0517(7)$ & $0.0089(3)$ & $0.0017(1)$ & 0.969 & 100.5 & 92.9 & 93.3 & $0.018(1)$ \\
\hline equilibrium & 0.5183 & 0.2326 & 0.02759 & 0.2020 & 0.00147 & 0.0000 & 0.0000 & & & & & 0.01806 \\
\hline $3 \% \mathrm{O}_{2}, 0.5$ & $0.590(7)$ & $0.130(1)$ & $0.096(1)$ & $0.114(1)$ & $0.0498(6)$ & $0.0100(2)$ & $0.0013(1)$ & 0.968 & 98.3 & 91.4 & 86.0 & $0.022(1)$ \\
\hline 0.6 & $0.587(5)$ & $0.129(2)$ & $0.099(1)$ & $0.113(2)$ & $0.0499(7)$ & $0.0091(3)$ & $0.0013(1)$ & 0.964 & 99.0 & 90.9 & 87.8 & $0.023(2)$ \\
\hline 0.8 & $0.582(8)$ & $0.128(3)$ & $0.098(2)$ & $0.109(1)$ & $0.0502(7)$ & $0.0083(3)$ & $0.0013(1)$ & 0.952 & 99.2 & 90.2 & 87.9 & $0.025(2)$ \\
\hline 1.2 & $0.579(5)$ & $0.137(4)$ & $0.099(2)$ & $0.110(1)$ & $0.0501(7)$ & $0.0074(2)$ & $0.0013(1)$ & 0.958 & 101.8 & 89.9 & 91.1 & $0.026(2)$ \\
\hline
\end{tabular}

${ }^{a}$ Initial mole fractions: $\mathrm{CO} 0.119 ; \mathrm{CO}_{2} 0.092 ; \mathrm{H}_{2} 0.119 ; \mathrm{CH}_{4} 0.0500 ; \mathrm{C}_{2} \mathrm{H}_{4} 0.0170 ; \mathrm{N}_{2} 0.603 / \mathrm{O}_{2} 0.00, \mathrm{~N}_{2} 0.602 / \mathrm{O}_{2} 0.010, \mathrm{~N}_{2} 0.601 / \mathrm{O}_{2} 0.020$, and $\mathrm{N}_{2} 0.600 / \mathrm{O}_{2} 0.030 .{ }^{b}$ Estimated from $\mathrm{H}_{\text {in }} / \mathrm{H}_{\text {out }}$ for $1-3 \%$ oxygen addition. ${ }^{c}$ The number in parentheses reflects the uncertainty in the last digit of the measurement. ${ }^{d}$ Calculated using the CSM model.

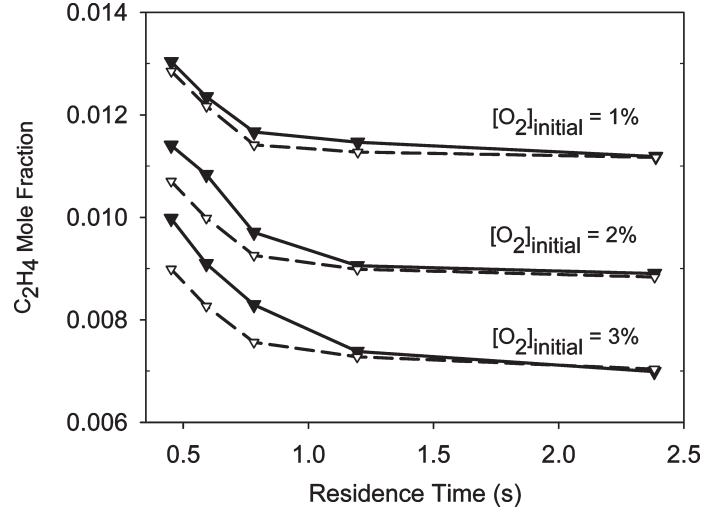

Figure 9. Experimental (solid symbols) and CSM model predicted (open symbols) mole fractions of ethylene for the partial oxidation of a $\mathrm{CH}_{4} / \mathrm{C}_{2} \mathrm{H}_{4}$-doped synthesis gas mixture $760{ }^{\circ} \mathrm{C}$ as a function of residence time.

radicals, a key oxidizing agent, indicate essentially no selectivity with respect to the three major fuel components $\mathrm{H}_{2}, \mathrm{CH}_{4}$, and $\mathrm{C}_{2} \mathrm{H}_{4}$.

$$
\begin{gathered}
\mathrm{H}_{2}+\mathrm{OH}=\mathrm{H}+\mathrm{H}_{2} \mathrm{O} \\
k\left(810^{\circ} \mathrm{C}\right)=1.6 \times 10^{12} \mathrm{~cm}^{3} \mathrm{~mol}^{-1} \mathrm{~s}^{-1} \\
\mathrm{CH}_{4}+\mathrm{OH}=\mathrm{CH}_{3}+\mathrm{H}_{2} \mathrm{O} \\
k\left(810^{\circ} \mathrm{C}\right)=1.6 \times 10^{12} \mathrm{~cm}^{3} \mathrm{~mol}^{-1} \mathrm{~s}^{-1} \\
\mathrm{C}_{2} \mathrm{H}_{4}+\mathrm{OH}=\mathrm{C}_{2} \mathrm{H}_{3}+\mathrm{H}_{2} \mathrm{O} \\
k\left(810^{\circ} \mathrm{C}\right)=1.3 \times 10^{12} \mathrm{~cm}^{3} \mathrm{~mol}^{-1} \mathrm{~s}^{-1}
\end{gathered}
$$

Keeping in mind the relative concentrations of hydrogen, methane, and ethylene used in this study, one would expect that hydrogen should react roughly 2.5 times faster than methane and 7 times faster than ethylene. Even though this

\begin{tabular}{|c|c|c|c|}
\hline$\%\left[\mathrm{O}_{2}\right]_{\text {initial }}$ & $\mathrm{H}_{2} \mathrm{O}^{a}$ & $\mathrm{O}_{2}{ }^{b}$ & $\Sigma$ oxygenates \\
\hline \multicolumn{4}{|c|}{$\mathrm{CH}_{4}$ Doped } \\
\hline $1 \%(\exp )$ & $0.009(1)^{c}$ & $0.005(1)$ & \\
\hline (model) & 0.009 & 0.004 & 0.00005 \\
\hline $2 \%(\exp )$ & $0.024(1)$ & $0.004(1)$ & \\
\hline (model) & 0.021 & 0.004 & 0.00008 \\
\hline $3 \%(\exp )$ & $0.034(1)$ & $0.004(1)$ & \\
\hline (model) & 0.034 & 0.003 & 0.00007 \\
\hline \multicolumn{4}{|c|}{$\mathrm{C}_{2} \mathrm{H}_{4}$ Doped } \\
\hline $1 \%(\exp )$ & $0.004(1)$ & 0.000 & \\
\hline (model) & 0.007 & 0.000 & 0.00005 \\
\hline $2 \%(\exp )$ & $0.014(1)$ & $0.001(1)$ & \\
\hline (model) & 0.015 & 0.001 & 0.00004 \\
\hline $3 \%(\exp )$ & $0.023(1)$ & $0.001(1)$ & \\
\hline (model) & 0.025 & 0.001 & 0.00003 \\
\hline \multicolumn{4}{|c|}{$\mathrm{C}_{2} \mathrm{H}_{4} / \mathrm{CH}_{4}$ Doped } \\
\hline $1 \%(\exp )$ & $0.008(1)$ & $0.001(1)$ & \\
\hline (model) & 0.006 & 0.002 & 0.00010 \\
\hline $2 \%(\exp )$ & $0.016(1)$ & $0.001(1)$ & \\
\hline (model) & 0.015 & 0.002 & 0.00011 \\
\hline $3 \%(\exp )$ & $0.027(1)$ & $0.004(1)$ & \\
\hline (model) & 0.024 & 0.003 & 0.00011 \\
\hline $5 \%(\exp )$ & $0.042(1)$ & $0.005(1)$ & \\
\hline (model) & 0.044 & 0.003 & 0.00010 \\
\hline
\end{tabular}
analysis ignores reaction pathways involving the double bond
TABLE 5: Comparison of the Estimated Amounts of Water and Oxygen with the Model Predictions for a $\mathrm{CH}_{4}$-Doped, $\mathrm{C}_{2} \mathrm{H}_{4}$-Doped, and $\mathrm{CH}_{4} / \mathrm{C}_{2} \mathrm{H}_{4}$-Doped Synthesis Gas Mixture at $810{ }^{\circ} \mathrm{C}$

${ }^{a}$ Estimated from the deviation in $\mathrm{H}_{\text {in }} / \mathrm{H}_{\text {out }} \cdot{ }^{b}$ Estimated from the deviation in $\mathrm{O}_{\text {in }} / \mathrm{O}_{\text {out }}$ after the contribution from $\mathrm{H}_{2} \mathrm{O}$ was removed. ${ }^{c}$ The number in parentheses reflects the uncertainty in the last digit of the measurement.

in ethylene, an obvious question is why hydrogen is not preferentially removed, followed by methane and then ethylene-opposite to the trend observed experimentally.

A closer look at the data reveals additional surprising results. Despite the highly reducing environment, the model predicts that some oxygen remains unreacted, even after $1.2 \mathrm{~s}$ residence time at $810^{\circ} \mathrm{C}$ (see Table 5). Mass spectrometric detection of $\mathrm{O}_{2}$ in the effluent of the reactor supports this conclusion, as does the gap in the oxygen mass balance after accounting for water. Another notable observation is that partial oxidation of the $\mathrm{CH}_{4} /$ synthesis gas mixture converts methane to roughly equal amounts of $\mathrm{CO}$ and $\mathrm{CO}_{2}$ (the ratio varies somewhat with the 

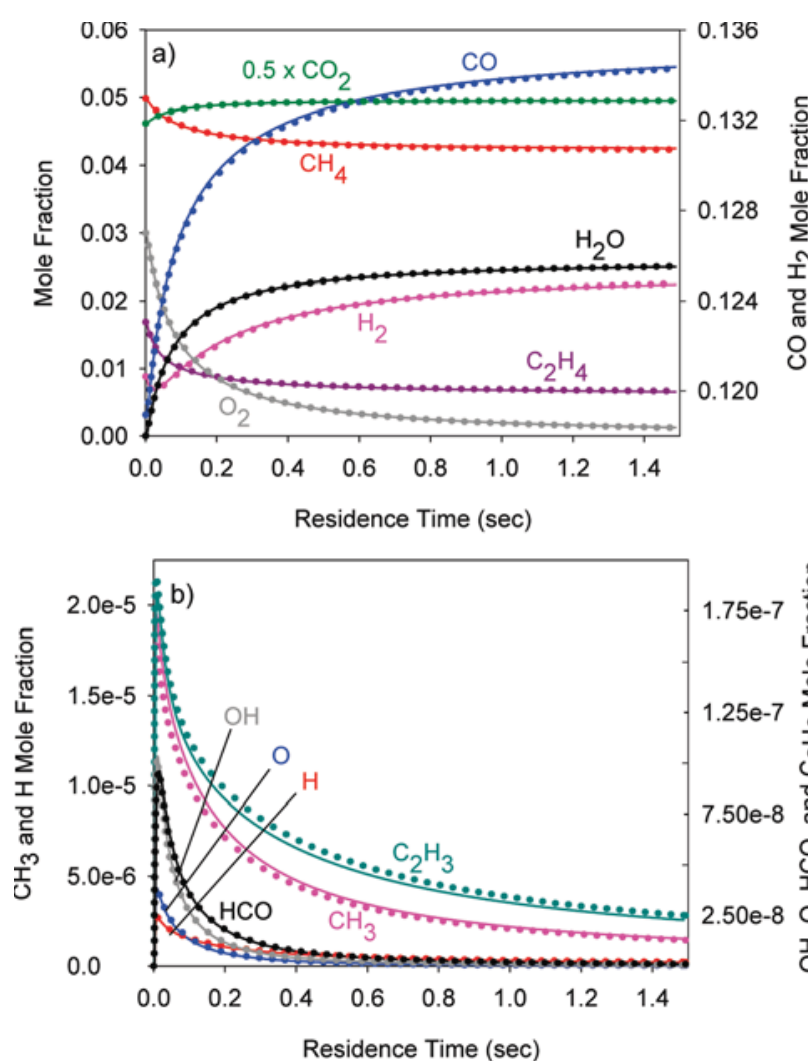

Figure 10. Calculated mole fraction profiles for (a) major species and (b) minor species for the $3 \% \mathrm{O}_{2}$ partial oxidation of a $\mathrm{CH}_{4} / \mathrm{C}_{2} \mathrm{H}_{4}$-doped synthesis gas mixture at $810^{\circ} \mathrm{C}$ and $0.8 \mathrm{~atm}$. The solid lines are determined using the full CSM mechanism and the dotted lines are determined using the reduced CSM mechanism. Note the different $y$ axes.

amount of $\mathrm{O}_{2}$ added) while partial oxidation of the ethylenedoped synthesis gas yields substantially more $\mathrm{CO}$ than $\mathrm{CO}_{2}$. Interestingly, the highest $\mathrm{CO} / \mathrm{CO}_{2}$ ratio is found for the $\mathrm{CH}_{4} /$ $\mathrm{C}_{2} \mathrm{H}_{4} /$ synthesis gas mixture. Related to this we also note that, despite the high hydrogen concentration in synthesis gas, the $\mathrm{CO}_{2}$ mole fraction, in all cases, increases during partial oxidation. This means that partial oxidation of the hydrocarbondoped synthesis gas mixtures moves the gas composition away from equilibrium, even at an extended residence time of $2.4 \mathrm{~s}$ (see Table 4 for calculated equilibrium mole fractions at $760{ }^{\circ} \mathrm{C}$ ).

Given the good agreement between measurements and model predictions, it seems safe to assume that our kinetic model accurately captures the essential underlying chemistry. Therefore, we are now in a position to use this reaction mechanism to address above-mentioned issues. To keep the analysis simple, we will focus the following analysis on model predictions for isothermal conditions at $810{ }^{\circ} \mathrm{C}$ and $0.8 \mathrm{~atm}$, and with few exceptions the discussion will mainly address the $\mathrm{CH}_{4} / \mathrm{C}_{2} \mathrm{H}_{4}$ doped synthesis gas case.

Figure 10a presents calculated time profiles for the major species for the partial oxidation of this mixture (the initial compositions are the same as those used in the experiments) with $3 \% \mathrm{O}_{2}$. Oxidation proceeds rapidly as is evident by the decays of $\mathrm{O}_{2}, \mathrm{CH}_{4}$, and $\mathrm{C}_{2} \mathrm{H}_{4}$ as well as the rise of $\mathrm{CO}, \mathrm{CO}_{2}$, and $\mathrm{H}_{2} \mathrm{O}$. The $\mathrm{H}_{2}$ concentration declines at early reaction times but increases later on - a first indication that molecular hydrogen actively participates in the partial oxidation chemistry. Figure 10b contains some selected radical profiles, which support the conclusion that a major part of the reaction occurs at very short reaction times. All radicals reach their peak concentration within a few tenths of a second and decline rapidly afterward.
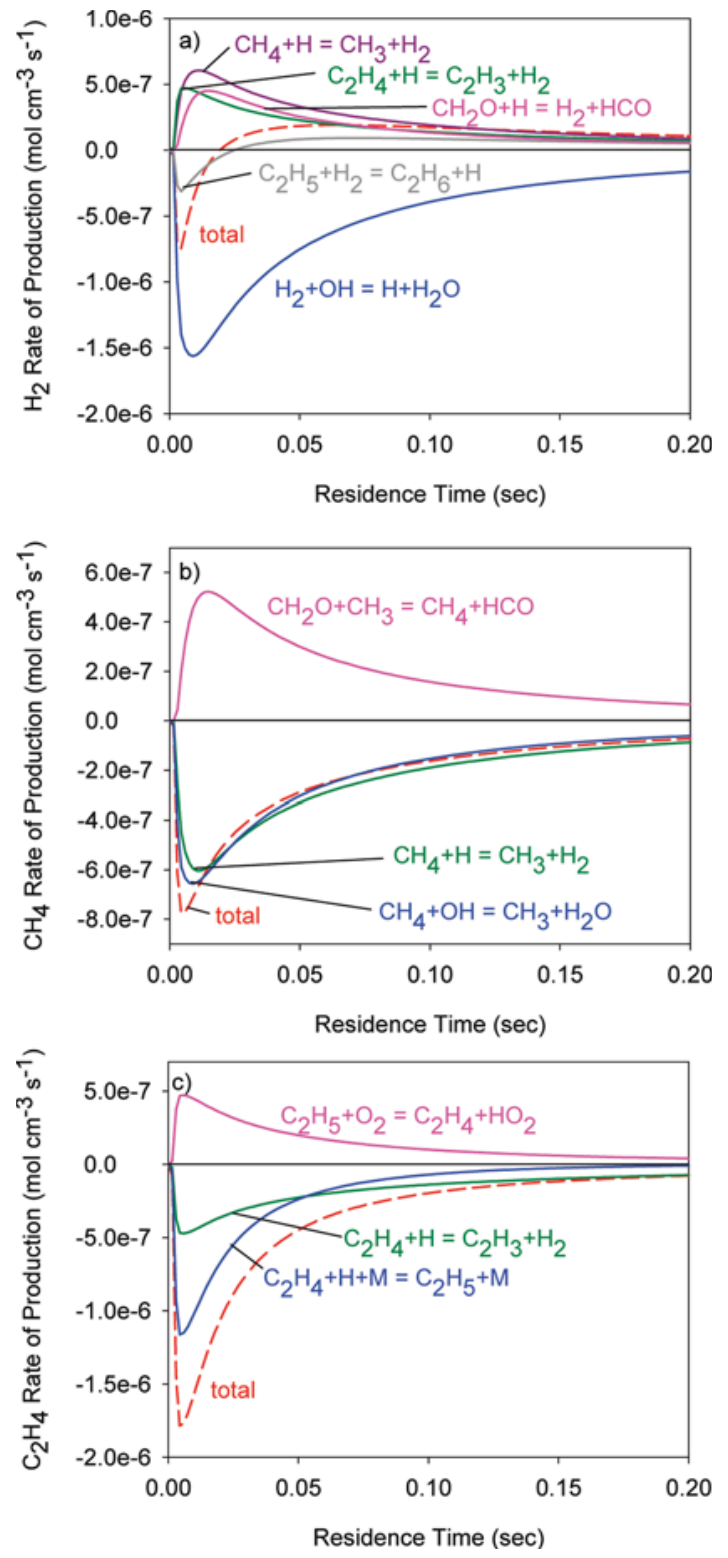

Figure 11. Rate of production analysis for (a) hydrogen, (b) methane, and (c) ethylene for the $\mathrm{CH}_{4} / \mathrm{C}_{2} \mathrm{H}_{4}$-doped synthesis gas mixture with $3 \%$ oxygen $\left(T=810^{\circ} \mathrm{C}, P=0.8 \mathrm{~atm}\right)$.

While the concentration of O-containing radicals decays quickly to low levels, we notice that $\mathrm{CH}_{3}$ and $\mathrm{C}_{2} \mathrm{H}_{3}$ radical concentrations maintain relatively high levels at longer times.

Under pyrolysis conditions the synthesis gas mixtures are stable on the time scale of seconds, consistent with the experimental observations (Tables 1-3). Thus, it is reasonable that the initial reactions identified by a rate of production analysis involve molecular $\mathrm{O}_{2}$ :

$$
\begin{gathered}
\mathrm{H}_{2}+\mathrm{O}_{2}=\mathrm{H}+\mathrm{HO}_{2} \\
\mathrm{CH}_{4}+\mathrm{O}_{2}=\mathrm{CH}_{3}+\mathrm{HO}_{2} \\
\mathrm{CO}+\mathrm{O}_{2}=\mathrm{CO}_{2}+\mathrm{O}
\end{gathered}
$$

Once the reaction starts, the radical pool grows quickly and reacts with the fuel molecules via abstraction reactions. In Figure 11 we present rate of production analysis results for $\mathrm{H}_{2}, \mathrm{CH}_{4}$, 
and $\mathrm{C}_{2} \mathrm{H}_{4}$ for the $\mathrm{CH}_{4} / \mathrm{C}_{2} \mathrm{H}_{4} /$ synthesis gas mixture. The corresponding data for the methane- and ethylene-doped synthesis gas mixtures are provided in the Supporting Information. The main hydrogen-consuming reaction in all three hydrocarbondoped cases is $\mathrm{H}$ abstraction by $\mathrm{OH}$ radicals

$$
\mathrm{H}_{2}+\mathrm{OH}=\mathrm{H}+\mathrm{H}_{2} \mathrm{O}
$$

If ethylene is available, $\mathrm{H}$ abstraction by $\mathrm{C}_{2} \mathrm{H}_{5}$ radicals is also important. At the same time, molecular hydrogen is regenerated through $\mathrm{H}$ abstraction by $\mathrm{H}$ atoms from methane and/or ethylene and ethane, as well as reaction intermediates such as formaldehyde. At short reaction times, the hydrogen consumption reactions dominate and the hydrogen concentration decreases (Figure 10a). However, at longer times more hydrogen is produced than consumed and the initially lost fraction of $\mathrm{H}_{2}$ is reformed. This occurs because other hydrogenated fuel molecules are present at sufficiently high concentrations such that they can supply the required $\mathrm{H}$ atoms to reform hydrogen. In the $\mathrm{CH}_{4} / \mathrm{C}_{2} \mathrm{H}_{4}$-doped synthesis gas case, the net effect at the end of the reactor is that the hydrogen concentration is essentially unchanged, leading to the appearance that hydrogen is inert toward partial oxidation. In contrast to hydrogen the consumption reactions for methane and ethylene dominate over the entire reaction time. Although some methane and ethylene is also reformed, a permanent decline in both concentrations occurs. The reason for the net loss is that the corresponding radicals are primarily consumed in oxidation (see below) and other consumption steps. Another important point is that ethylene is consumed at a much higher rate than methane is. This is because the major consumption reaction for ethylene is $\mathrm{H}$ addition to the double bond rather than $\mathrm{H}$ abstraction. Typically radical addition reactions have lower activation energies than radical abstraction reactions.

This part of the rate of production analysis also points to two key intermediates in the partial oxidation: formaldehyde and the formyl radical. According to the model, these species are formed via the following reactions (see Figure 12 for the rate of production of carbon monoxide, carbon dioxide, and formaldehyde)

$$
\mathrm{CH}_{3}+\mathrm{O}_{2}=\mathrm{CH}_{3} \mathrm{O}+\mathrm{O}
$$

followed by

$$
\begin{gathered}
\mathrm{CH}_{3} \mathrm{O}+\mathrm{M}=\mathrm{CH}_{2} \mathrm{O}+\mathrm{H}+\mathrm{M} \\
\mathrm{CH}_{3}+\mathrm{O}_{2}=\mathrm{CH}_{2} \mathrm{O}+\mathrm{OH} \\
\mathrm{C}_{2} \mathrm{H}_{3}+\mathrm{O}_{2}=\mathrm{CH}_{2} \mathrm{O}+\mathrm{HCO} \\
\mathrm{C}_{2} \mathrm{H}_{4}+\mathrm{O}=\mathrm{CH}_{2} \mathrm{O}+\mathrm{CH}_{2}
\end{gathered}
$$

Subsequent $\mathrm{H}$ abstraction from $\mathrm{CH}_{2} \mathrm{O}$ yields $\mathrm{HCO}$ radicals; $\mathrm{H}$ atom loss or abstraction from formyl radical yields the final product $\mathrm{CO}$

$$
\mathrm{HCO}+\mathrm{M}=\mathrm{H}+\mathrm{CO}+\mathrm{M}
$$

and
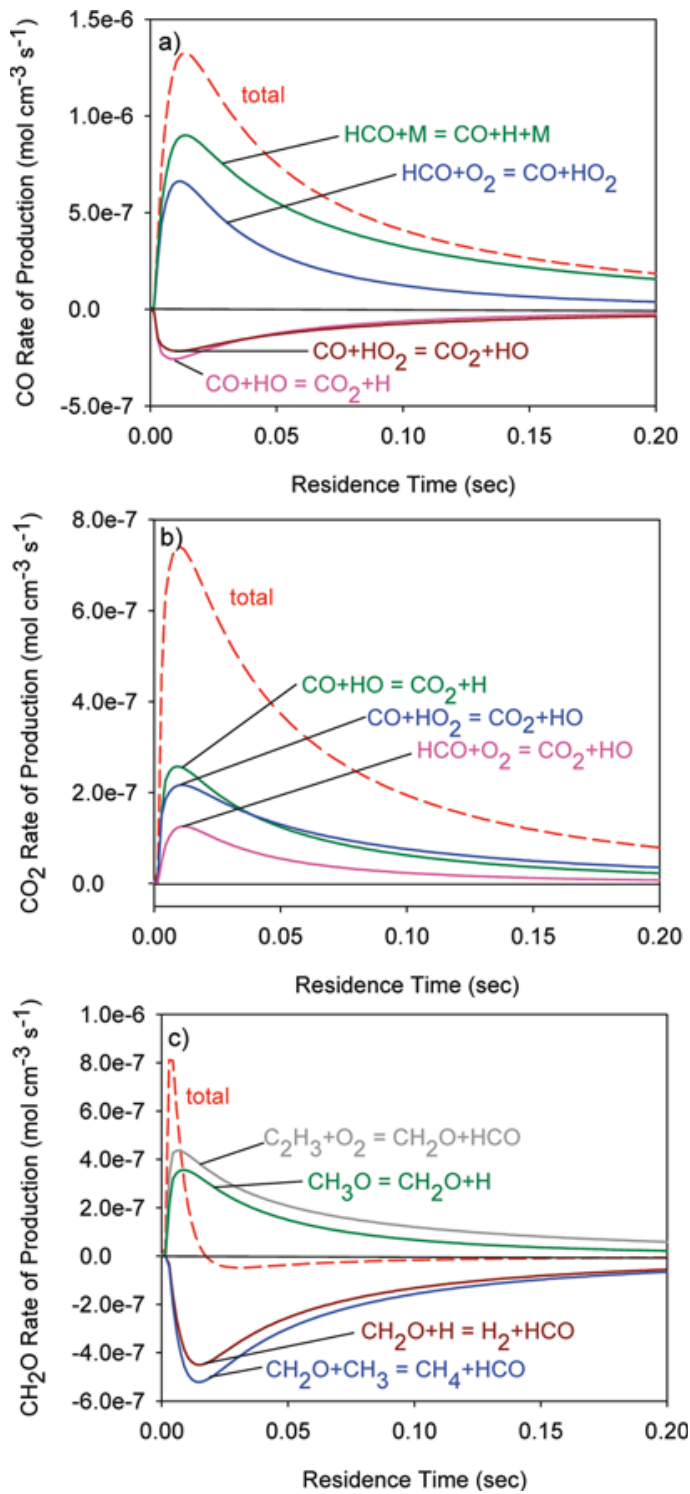

Figure 12. Rate of production analysis for (a) carbon monoxide, (b) carbon dioxide, and (c) formaldehyde for the $\mathrm{CH}_{4} / \mathrm{C}_{2} \mathrm{H}_{4}$-doped synthesis gas mixture with $3 \%$ oxygen $\left(T=810{ }^{\circ} \mathrm{C}, P=0.8\right.$ atm $)$.

Unimolecular dissociation of $\mathrm{HCO}$ is the dominant pathway at 810 ${ }^{\circ} \mathrm{C}$ and produces, beside $\mathrm{CO}$, some $\mathrm{H}$ atoms needed to restore the initially depleted $\mathrm{H}_{2}$ concentration. A second channel $(<20 \%$ at $810^{\circ} \mathrm{C}$ ) of the reaction of $\mathrm{HCO}$ with $\mathrm{O}_{2}$ yields $\mathrm{CO}_{2}$

$$
\mathrm{HCO}+\mathrm{O}_{2}=\mathrm{CO}_{2}+\mathrm{OH}
$$

This reaction pathway produces only a small fraction of the $\mathrm{CO}_{2}$. Instead, $\mathrm{CO}_{2}$ is mainly formed via oxidation of $\mathrm{CO}$ by $\mathrm{OH}$ and $\mathrm{HO}_{2}$ (Figure 12b)

$$
\mathrm{CO}+\mathrm{OH}=\mathrm{H}+\mathrm{CO}_{2}
$$

and

$$
\mathrm{CO}+\mathrm{HO}_{2}=\mathrm{OH}+\mathrm{CO}_{2}
$$

This means that the total amount of $\mathrm{CO}_{2}$ generated depends mainly upon the $\mathrm{OH}$ and $\mathrm{HO}_{2}$ radical concentrations (since the $\mathrm{CO}$ 
concentration of the synthesis gas mixture remains relatively constant). It turns out that the concentrations of these radicals are comparable in all three hydrocarbon-doped synthesis gas mixtures, and therefore, similar amounts of $\mathrm{CO}_{2}$ are formed in these three cases (at $810^{\circ} \mathrm{C}$ ), as shown in Figures 3, 4, and 7 .

Coming back to the formation pathways of $\mathrm{CH}_{2} \mathrm{O}$ and $\mathrm{HCO}$, one can see that these species are predominantly formed in reactions of the fuel radicals $\left(\mathrm{CH}_{3}\right.$ and $\left.\mathrm{C}_{2} \mathrm{H}_{3}\right)$. The rate of production analysis for the $\mathrm{CH}_{4} / \mathrm{C}_{2} \mathrm{H}_{4}$-doped synthesis gas mixture reveals that the $\mathrm{C}_{2} \mathrm{H}_{3}+\mathrm{O}_{2}$ reaction contributes more to the $\mathrm{CH}_{2} \mathrm{O}$ formation than the second most important channel, the dissociation of $\mathrm{CH}_{3} \mathrm{O}$ (see Figure 12c). According to Figure 10 , the $\mathrm{CH}_{3}$ concentration is 2 orders of magnitude higher than the $\mathrm{C}_{2} \mathrm{H}_{3}$ concentration. This shows that $\mathrm{C}_{2} \mathrm{H}_{3}$ radicals react much faster with $\mathrm{O}_{2}$ than $\mathrm{CH}_{3}$ radicals do. As a consequence, $\mathrm{CO}$ is produced slowly in the partial oxidation of the $\mathrm{CH}_{4}$-doped synthesis gas mixture. The measured low CO yield (Figure 3) confirms this. On the other hand, those mixtures that contain ethylene produce significantly higher yields of $\mathrm{CO}$. This explains why the $\mathrm{CO} / \mathrm{CO}_{2}$ ratio is much lower in the $\mathrm{CH}_{4}$-doped synthesis gas experiments than in the two other cases.

The calculations also provide at least a qualitative explanation why the partial oxidation reaction does not bring the system closer to equilibrium and why not all of the oxygen is consumed. At short reaction times, the reaction of $\mathrm{O}_{2}$ with $\mathrm{HCO}$ radicals forming $\mathrm{CO}$ and $\mathrm{HO}_{2}$ has the largest contribution to $\mathrm{O}_{2}$ removal. The most important $\mathrm{HO}_{2}$ consumption reaction in the $\mathrm{CH}_{4} / \mathrm{C}_{2} \mathrm{H}_{4} /$ synthesis gas mixture

$$
\mathrm{HO}_{2}+\mathrm{CH}_{3}=\mathrm{OH}+\mathrm{CH}_{3} \mathrm{O}
$$

leads not only to chain branching but also to the consumption of another $\mathrm{O}_{2}$ molecule via

$$
\mathrm{CH}_{3} \mathrm{O}+\mathrm{O}_{2}=\mathrm{CH}_{2} \mathrm{O}+\mathrm{HO}_{2}
$$

Therefore, the $\mathrm{O}_{2}$ concentration declines very rapidly. A decrease of the $\mathrm{O}_{2}$ concentration, however, makes the unimolecular decomposition of $\mathrm{HCO}$ (to $\mathrm{H}+\mathrm{CO}$ ) more competitive and the $\mathrm{H}$ atoms now also undergo abstraction or addition reactions in favor of reacting with the remaining $\mathrm{O}_{2}$. Chain branching is stopped and $\mathrm{O}_{2}$ consumption slows down to a point that residual levels are detectable experimentally even after more than $1 \mathrm{~s}$ residence time. At long residence times, the rates of production calculations indicate that the main $\mathrm{O}_{2}$ removal reactions are

$$
\begin{gathered}
\mathrm{H}+\mathrm{O}_{2}=\mathrm{O}+\mathrm{OH} \\
\mathrm{C}_{2} \mathrm{H}_{3}+\mathrm{O}_{2}=\mathrm{CH}_{2} \mathrm{O}+\mathrm{HCO}
\end{gathered}
$$

Since all radical concentrations are low, $\mathrm{O}_{2}$ consumption is slow, but according to the model calculations the final $\mathrm{O}_{2}$ concentration is clearly lower in the partial oxidation of the $\mathrm{C}_{2} \mathrm{H}_{4}$-doped synthesis gas than in the corresponding $\mathrm{CH}_{4}$-doped synthesis gas mixture, because of the $\mathrm{C}_{2} \mathrm{H}_{3}+\mathrm{O}_{2}$ reaction.

Even if the $\mathrm{O}_{2}$ concentration has decreased, it seems as if $\mathrm{H}$ atom addition to $\mathrm{O}_{2}$ molecules can still keep the $\mathrm{HO}_{2}$ concentration high enough to allow for a continued production of $\mathrm{CO}_{2}$ $(+\mathrm{OH})$ rather than having it consumed via

$$
\mathrm{H}+\mathrm{CO}_{2}=\mathrm{OH}+\mathrm{CO}
$$

Thus even at long residence times, the $\mathrm{CO}_{2}$ concentration grows or remains constant, despite the fact that it is thermodynamically unstable and should be reduced quantitatively to CO (see Table 4).

The above analysis shows that the major observations can be explained with only a small number of reactions in the CSM model. While we have previously shown that the model can predict the observed mole fractions, it is important to consider how sensitive the predictions are to particular rate constant assignments. A tool to do so is a sensitivity analysis. In this method the Arrhenius preexponential factors are systematically varied to evaluate how dependent the mole fraction of a particular species is on a given reaction. This type of analysis is insightful since, in many cases, the concentration of a particular species may be very dependent on a reaction that it is not directly linked to. However, this should not imply that only reactions identified by sensitivity analysis are important, as other key reactions may be sufficiently fast such that they are partially equilibrated and, therefore, changes in these rate coefficients do not significantly affect the product distribution. A sensitivity analysis with respect to the major species was performed for a $\mathrm{CH}_{4} / \mathrm{C}_{2} \mathrm{H}_{4} /$ synthesis gas mixture at $810{ }^{\circ} \mathrm{C}$ with $3 \%$ oxygen addition. This analysis reveals only a small set of important reactions and out of these only four reactions have sensitivity coefficients greater than 0.1. (A sensitivity coefficient of 0.1 means that an increase of the rate constant by a factor of 2 results in a change in the relative concentration by 0.1 .) This reconfirms that the chemistry can be described by only a small subset of the CSM mechanism. We will take advantage of this later when we discuss a reduced mechanism. It should be noted that the rate constant assignments for these four reactions are based on well-established sources and have not been adjusted to achieve the good agreement.

Implications. The results presented in this study suggest that addition of a few percent oxygen to the high-temperature gasifier effluent upstream of the tar reformer can selectively reduce the concentration of ethylene, a deposit precursor, in synthesis gas. This approach seems particularly promising in terms of using a synthesis gas stream as fuel for a SOFC, where $\mathrm{CO}$ and $\mathrm{CH}_{4}$, in addition to $\mathrm{H}_{2}$, are valuable fuels. It might also be considered as an initial cleanup step, when the effluent is directed to a catalytic reforming/water gas shift process for $\mathrm{H}_{2}$ production. In either application, such an approach could substantially relax the requirements for catalytic reforming and extend the time on stream of the catalyst by lowering the deposit-forming propensity of the gasifier effluent. This being the case, the usefulness of the partial oxidation process will depend on several issues such as (1) whether a reduction below the threshold for catalytic applications is possible with no or only minor $\mathrm{H}_{2}$ penalty, (2) if partial oxidation is capable to reduce other hydrocarbon impurities, and (3) how easily such a process can be integrated into the overall process.

To explore how much ethylene can practically be removed via gas-phase partial oxidation, we have performed a series of model calculations at higher oxygen concentrations. As shown in Table 6 , according to our model up to $7 \%$ oxygen can be added without significantly depleting the total fuel content $\left(\mathrm{H}_{2}\right.$ $+\mathrm{CO}+\mathrm{CH}_{4}$ ), resulting in a $82 \%$ reduction in the ethylene concentration. Addition of larger amounts of oxygen further reduces the ethylene mole fraction, but at the price of now beginning to oxidize valuable fuel components in the synthesis gas stream. For example, at $15 \%$ oxygen addition ethylene is reduced by $96 \%$; however, $92 \%$ of the methane and $19 \%$ of the hydrogen concentrations are also consumed.

A similar analysis has been performed for a synthesis gas stream that contains only methane. This gas composition may resemble that of a synthesis gas stream where the bulk of larger 
TABLE 6: Gas Composition for the Partial Oxidation of a $\mathrm{CH}_{4} / \mathrm{C}_{2} \mathrm{H}_{4}$-Doped and a Methane-Doped Synthesis Gas Mixture at $810^{\circ} \mathrm{C}$ and a Residence Time of $\sim 1.2 \mathrm{~s}$ Evaluated Using the CSM Mechanism ${ }^{a}$

\begin{tabular}{|c|c|c|c|c|c|}
\hline \multirow[b]{2}{*}{$\%\left[\mathrm{O}_{2}\right]_{\text {initial }}$} & \multicolumn{2}{|c|}{$\mathrm{CH}_{4} / \mathrm{C}_{2} \mathrm{H}_{4}$ doped } & \multicolumn{3}{|c|}{$\mathrm{CH}_{4}$ doped } \\
\hline & $\% \mathrm{C}_{2} \mathrm{H}_{4}$ & $\% \mathrm{H}_{2}+\mathrm{CO}+\mathrm{CH}_{4}$ & $\% \mathrm{CH}_{4}$ & $\% \mathrm{C}_{2}$ & $\% \mathrm{H}_{2}+\mathrm{CO}$ \\
\hline 0 & 4.16 & 72.5 & 9.27 & 0.00 & 65.3 \\
\hline 1 & 2.79 & 73.4 & 7.63 & 0.457 & 65.9 \\
\hline 2 & 2.16 & 73.5 & 6.02 & 0.561 & 66.4 \\
\hline 3 & 1.71 & 73.5 & 4.83 & 0.525 & 66.5 \\
\hline 5 & 1.09 & 72.7 & 3.07 & 0.383 & 65.4 \\
\hline 7 & 0.744 & 71.3 & 1.79 & 0.240 & 62.7 \\
\hline 9 & 0.543 & 69.3 & 0.909 & 0.125 & 57.9 \\
\hline 11 & 0.395 & 66.9 & 0.400 & 0.0522 & 50.3 \\
\hline 13 & 0.263 & 63.7 & 0.171 & 0.0199 & 39.7 \\
\hline 15 & 0.146 & 59.4 & 0.043 & 0.0019 & 26.7 \\
\hline
\end{tabular}

${ }^{a}$ Mole percentages are reported on a $\mathrm{N}_{2}$ - and $\mathrm{H}_{2} \mathrm{O}$-free basis.

hydrocarbons have been removed via catalytic steam reforming. Typically, a considerable amount of methane still remains after this process, ${ }^{9}$ which is problematic for a mixed alcohol synthesis. Results from this analysis are also presented in Table 6, where the initial concentration of methane is twice that of ethylene used above. In this case, up to $5 \%$ oxygen can be added without significantly depleting the total fuel content $\left(\mathrm{H}_{2}+\mathrm{CO}\right)$. At this concentration $33 \%$ of the methane remains. At low oxygen concentrations the conversion of methane leads to the formation of $\mathrm{C}_{2}$ species (see Figure 3), a very unfavorable result. The amount of $\mathrm{C}_{2}$ species formed, however, decreases with increasing oxygen addition, indicating that these molecular weight growth product concentrations can be minimized. At $5 \%$ oxygen addition the amount of $\mathrm{C}_{2}$ species formed is roughly one-tenth that of the remaining methane. For the initial concentration of methane utilized here, $\sim 9 \%$ oxygen addition is required to achieve the $1 \%$ mole fraction threshold recommended for mixed alcohol synthesis, ${ }^{9}$ resulting in a significant decrease in the hydrogen concentration.

These modeling results demonstrate that further reduction of undesired hydrocarbon components (ethylene or methane), beyond what was observed experimentally, can be achieved through increasing the levels of added oxygen but that this hydrocarbon reduction occurs at some point at the expense of depleting the concentration of valuable fuel components. From a practical point of view, the introduction of oxygen to a hot synthesis gas-stream may present a safety hazard. To avoid high local oxygen levels, the oxygen addition could be staged. Using the model, we have explored this idea for both a methane-doped and methane/ethylene-doped synthesis gas stream by adding $3 \%$ oxygen in three equal increments at $810{ }^{\circ} \mathrm{C}$. No substantial differences in the product distributions were observed between the staged versus bulk addition of oxygen. This suggests that staging might be a viable option.

A second important question to address is whether partial oxidation is suitable to reduce the concentration of other hydrocarbon impurities besides methane (the simplest alkane) and ethylene (the simplest alkene). Hence we used the model to explore the potential to remove propylene, which is the simplest model compound that forms a resonantly stabilized radical. More specifically, we predicted the product distribution for the partial oxidation of synthesis gas mixtures that contain both methane and propylene. For comparison purposes, these calculations were performed exactly as in the $\mathrm{CH}_{4} / \mathrm{C}_{2} \mathrm{H}_{4} /$ synthesis gas case with $3 \%$ oxygen, except that ethylene was replaced with propylene and that the concentration of propylene is reduced to two-thirds that of ethylene in order to preserve the total amount of carbon. As shown in Figure 13, the model

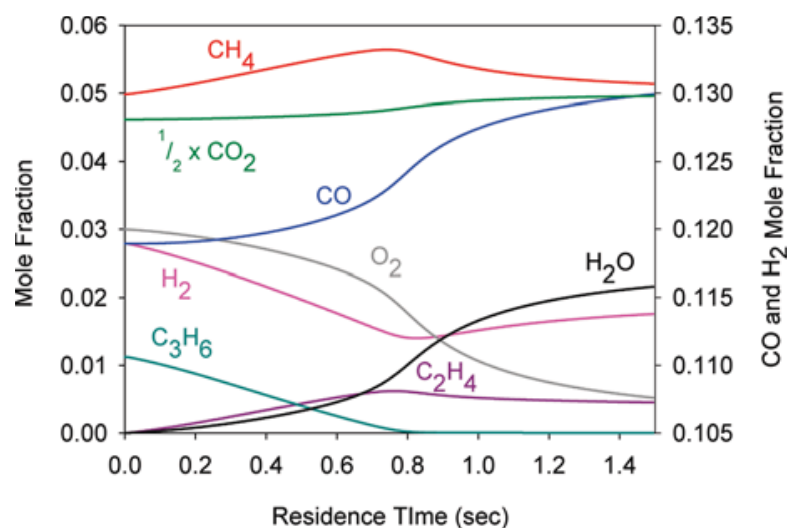

Figure 13. Calculated species profiles for the $3 \% \mathrm{O}_{2}$ partial oxidation of a $\mathrm{CH}_{4} / \mathrm{C}_{3} \mathrm{H}_{6}$-doped synthesis gas mixture at $810^{\circ} \mathrm{C}$ and $0.8 \mathrm{~atm}$. The mole fractions of $\mathrm{CO}$ and $\mathrm{H}_{2}$ are provided on the right-hand side $y$ axis.

predicts that propylene is consumed, but on a much slower time scale than expected, and this consumption coincides with the production of ethylene and methane. Interestingly, the oxygen concentration changes very little during the initial phase of the reaction, in contrast to the previous observations for the $\mathrm{CH}_{4}$ / $\mathrm{C}_{2} \mathrm{H}_{4}$ /synthesis gas mixture. Similarly formation of $\mathrm{CO}$ and $\mathrm{CO}_{2}$ is delayed as well. Examination of the rates of production for propylene (Figure 14) shows that the consumption of propylene occurs via typical pyrolysis reactions such as $\mathrm{H}$-atom addition to form methyl radical and ethylene or isopropyl radical, and $\mathrm{H}$-atom abstraction to form allyl radical and hydrogen

$$
\begin{gathered}
\mathrm{C}_{3} \mathrm{H}_{6}+\mathrm{H}=\left[n-\mathrm{C}_{3} \mathrm{H}_{7}\right]^{*}=\mathrm{CH}_{3}+\mathrm{C}_{2} \mathrm{H}_{4} \\
\mathrm{C}_{3} \mathrm{H}_{6}+\mathrm{H}=i-\mathrm{C}_{3} \mathrm{H}_{7} \\
\mathrm{C}_{3} \mathrm{H}_{6}+\mathrm{H}=\mathrm{C}_{3} \mathrm{H}_{5}+\mathrm{H}_{2}
\end{gathered}
$$

During this pyrolysis phase, only a small fraction of oxygen is consumed. This notable difference to the ethylene case can be attributed to the much lower rate coefficient for the reaction of the allyl radical with oxygen as compared to the reaction of vinyl with oxygen. The much lower rate coefficient for the resonantly stabilized allyl radical reacting with oxygen is due to formation of an adduct that is much less stable than the analogous vinyl-oxygen adduct. As soon as the bulk of the propylene is consumed, the oxidation processes are accelerated. At this point the consumption

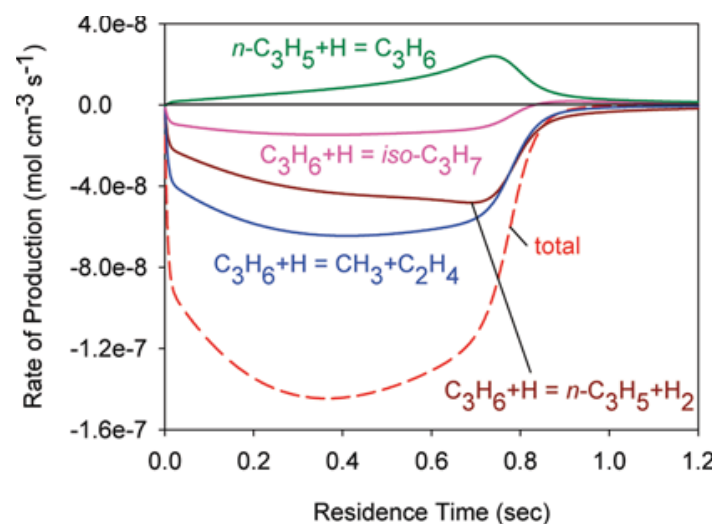

Figure 14. Rate of production analysis for propylene for the $\mathrm{CH}_{4} /$ $\mathrm{C}_{3} \mathrm{H}_{6}$-doped synthesis gas mixture with $3 \%$ oxygen $\left(T=810^{\circ} \mathrm{C}, P=\right.$ $0.8 \mathrm{~atm})$. 
of oxygen occurs analogous to the above $\mathrm{CH}_{4} / \mathrm{C}_{2} \mathrm{H}_{4} /$ synthesis gas case. Another similarity is that hydrogen is initially consumed but then regenerated via $\mathrm{H}$ abstraction. For this particular case, the net effect is a slight loss in hydrogen. Again both the $\mathrm{CO}$ and $\mathrm{CO}_{2}$ concentrations increase. These results suggest that selective oxidation is not unique to ethylene and that the concentration of other olefins can be removed via this gas-phase chemistry. Future work should experimentally verify these predictions and extend the investigations to aromatic model compounds that serve as surrogates for tar.

All investigations reported in this study are based on homogeneous gas mixtures. One important issue that needs to be addressed in the context of practical applications is the impact of imperfect mixing due to variations in the temperature or oxygen concentrations. A coupled kinetic and computational fluid dynamic (CFD) analysis could provide insight into mixing times as well as guidance for potential oxygen inlet designs. In this context, it is important to use validated kinetic models, such as that presented in this work. However, the full CSM mechanism is much too large to be coupled to CFD calculations. In order to provide a condensed mechanism for CFD calculations, we have used the Chemkin MFC3.5 $5^{32}$ mechanism reduction tools to systematically remove unnecessary species and reactions from the full CSM mechanism, with the constraint that predictions using the reduced mechanism do not deviate more than $5 \%$ from those of the complete mechanism. The reduction procedure was performed using a $\mathrm{CH}_{4} / \mathrm{C}_{2} \mathrm{H}_{4}$-doped synthesis gas stream with $3 \%$ oxygen addition at $810{ }^{\circ} \mathrm{C}$. The reduced mechanism (308 reactions and 44 species) contains all the key reactions discussed above and is able to reproduce observed trends with similar quality than the larger CSM mechanism. An example of the quality of the predictions is shown by the dotted lines in Figure 10. The reduced mechanism is provided in the Supporting Information with the hope that it will provide a valuable tool to optimize reaction conditions and to provide help with process design questions.

\section{Conclusions}

The experimental and modeling results presented in this work demonstrate the very real potential to selectively reduce the concentration of hydrocarbons in a "dirty" synthesis gas stream via gas-phase oxidation. Addition of small amounts of oxygen to a methane/ethylene-doped synthesis gas mixture significantly decreases the ethylene concentration while the concentrations of hydrogen and methane remain relatively unaffected. This chemistry was found to be fast (on the time scale of seconds) and rather insensitive to temperature in the range of 760-910 ${ }^{\circ} \mathrm{C}$, which is comparable to temperatures employed in gasification processes. The predictions with the CSM model are in good agreement with the experimental findings, providing important insight into the chemical processes that lead to the apparent selective hydrocarbon oxidation. While selective gas-phase partial oxidation might not completely reduce all hydrocarbon impurities down to desired specifications, it can substantially relax the cleanup requirements for a subsequent catalytic step. We provide a validated mechanism that can be used for efficient exploration of a wide range of potential operating conditions. Thus for a given set of initial concentrations, one can identify optimum oxygen concentrations that maximize the selective removal of undesired species, thereby substantially reducing the number of scoping experiments required.

Acknowledgment. We are grateful to Ms. Whitney Jablonski at NREL for helpful discussions and suggestions and to Ms.
Kelly Fleming for assisting in the experimental measurements. Additionally, we acknowledge Dr. Ahmed Al Shoaibi for his early modeling efforts that prompted this investigation. This work is supported by the Department of Energy (DE-NT0005202 and DE-FG36-08G088100) and the Colorado Center for Biorefining and Biofuels (66226).

Supporting Information Available: The concentration profiles and rates of production for the $\mathrm{CH}_{4}$-doped and $\mathrm{C}_{2} \mathrm{H}_{4}$ doped synthesis gas mixtures at $810^{\circ} \mathrm{C}$ at $3 \%$ oxygen addition and the reduced CSM mechanism. This information is available free of charge via the Internet at http://pubs.acs.org.

\section{References and Notes}

(1) Stevens D. J. Hot Gas Conditioning: Recent Progress with Larger Scale Biomass Gasification Systems. NREL/SR-510-29952, National Renewable Energy Laboratory: Golden, CO, 2001; http://www.osti.gov/ bridge.

(2) Carpenter, D. L.; Bain, R. L.; Davis, R. E.; Dutta, A.; Feik, C. J.; Gaston, K. R.; Jablonski, W. S.; Phillips, S. D.; Nimlos, M. R. Ind. Eng. Chem. Res. 2010, 49, 1859.

(3) Herguido, J.; Corella, J.; Gonzalezsaiz, J. Ind. Eng. Chem. Res. 1992, 31, 1274.

(4) de Jong, W.; Unal, O.; Andries, J.; Hein, K. R. G.; Spliethoff, H. Appl. Energy 2003, 74, 425.

(5) Franco, C.; Pinto, F.; Gulyurtlu, I.; Cabrita, I. Fuel 2003, 82, 835.

(6) Lv, P. M.; Xiong, Z. H.; Chang, J.; Wu, C. Z.; Chen, Y.; Zhu, J. X. Bioresour. Technol. 2004, 95, 95.

(7) Weerachanchai, P.; Horio, M.; Tangsathitkulchai, C. Bioresour. Technol. 2009, 100, 1419.

(8) Narvaez, I.; Orio, A.; Aznar, M. P.; Corella, J. Ind. Eng. Chem. Res. 1996, 35, 2110

(9) Phillips, S. D. Ind. Eng. Chem. Res. 2007, 46, 8887.

(10) Kee, R. J.; Zhu, H. Y.; Sukeshini, A. M.; Jackson, G. S. Combust. Sci. Technol. 2008, 180, 1207.

(11) Hofmann, P.; Panopoulos, K. D.; Fryda, L. E.; Schweiger, A.; Ouweltjes, J. P.; Karl, J. Int. J. Hydrogen Energy 2008, 33, 2834.

(12) Randolph, K. L.; Dean, A. M. Phys. Chem. Chem. Phys. 2007, 9, 4245.

(13) McIntosh, S.; Gorte, R. J. Chem. Rev. 2004, 104, 4845.

(14) Kim, T.; Liu, G.; Boaro, M.; Lee, S. I.; Vohs, J. M.; Gorte, R. J.; Al-Madhi, O. H.; Dabbousi, B. O. J. Power Sources 2006, 155, 231.

(15) Pomfret, M. B.; Marda, J. M.; Jackson, G. S.; Eichhorn, B. W.; Dean, A. M.; Walker, R. W. J. Phys. Chem. C 2008, 112, 5232.

(16) McIntosh, S.; He, H. P.; Lee, S. I.; Costa-Nunes, O.; Krishnan, V. V.; Vohs, J. M.; Gorte, R. J. J. Electrochem. Soc. 2004, 151, A604.

(17) Bain, R. L.; Dayton, D. C.; Carpenter, D. L.; Czernik, S. R.; Feik, C. J.; French, R. J.; Magrini-Bair, K. A.; Phillips, S. D. Ind. Eng. Chem. Res. 2005, 44, 7945 .

(18) Corella, J.; Aznar, M. P.; Delgado, J.; Martinez, M. P.; Aragues, J. L. Stud. Surf. Sci. Catal. 1991, 68, 249.

(19) Yung, M. M.; Jablonski, W. S.; Magrini-Bair, K. A. Energy Fuels 2009, 23, 1874.

(20) Sutton, D.; Kelleher, B.; Ross, J. R. H. Fuel Process. Technol. 2001, 73,155 .

(21) Al Shoaibi, A. Experimental and Modeling Analysis of Hydrocarbon Pyrolysis. PhD Thesis, Chemical Engineering Department, Colorado School of Mines, Golden, CO, 2008.

(22) Yoon, S.; Kang, I.; Bae, J. Int. J. Hydrogen Energy 2008, 33, 4780.

(23) Kang, I.; Kang, Y.; Yoon, S.; Bae, G.; Bae, J. Int. J. Hydrogen Energy 2008, 33, 6298.

(24) Andersen, P. C.; Cooper, G.; Houlding, V. H. Semicond. Int. 1998, $21,127$.

(25) Tepe, R. K.; Vassallo, D.; Jacksier, T.; Barnes, R. M. Spectrochim. Acta, Part B 1999, 54, 1861. 1641

(27) Williams, T. C.; Shaddix, C. R. Combust. Sci. Technol. 2007, 179, 1225 .

(28) Naik, C. V.; Dean, A. M. Combust. Flame 2006, 145, 16.

(29) Ritter, E. R.; Bozzelli, J. W. Int. J. Chem. Kinet. 1991, 23, 767.

(30) Chang, A. Y.; Bozzelli, J. W.; Dean, A. M. Z. Phys. Chem. 2000,

214, 1533 .

(31) ChemKin-Pro, Reaction Design: San Diego, 2008.

(32) ChemKin-MFC 3.5, Reaction Design: San Diego, 2009.

\section{JP102049C}




\title{
Modeling, Analysis, and Optimization of Integrated Gasification Fuel Cell Systems
}

\author{
Sub-task I-C
}

Final Report

R. J. Braun, L. Hanzon, and R. Huberg

1610 Illinois Street

Engineering Division

Colorado School of Mines

Golden, CO 80401

Prepared for:

The U.S. Department of Energy

National Energy Technology Laboratory

626 Cochrans Mill Road

Pittsburgh, PA

Under contract no.: DE-NT0005202

1 October 2011

\section{COLORADOSCHOOLOFMINES}




\section{Table of Contents}

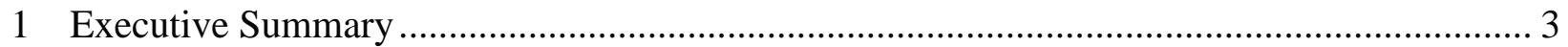

1.1 Focus Area (1): Employing Existing Technology to Achieve Highly-Efficient IGFC Systems with Optional Carbon Capture ${ }^{2}$.................................................................... 4

1.2 Focus Area (2) Evaluating Carbon Capture Strategies for IGFC Hybrid Power Systems. 8

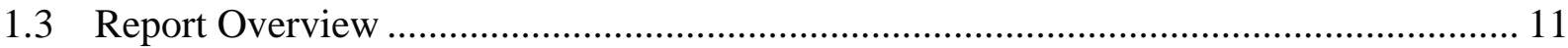

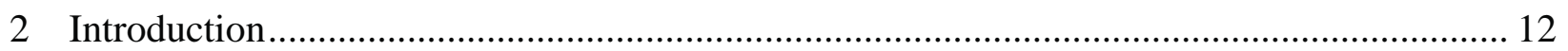

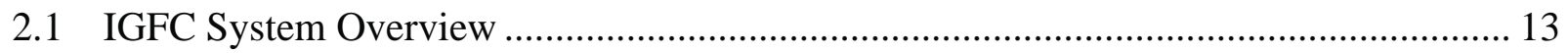

2.2 Project Scope of Analysis and Objectives.................................................................. 13

2.2.1 Focus Area (1): Employing Existing Technology to Achieve Highly-Efficient IGFC Systems with Optional Carbon Capture ............................................................... 14

2.2.2 Focus Area (2): Evaluating Carbon Capture Strategies for IGFC Hybrid Power Systems .................................................................................................. 15

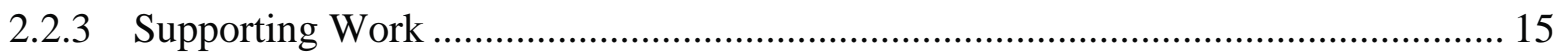

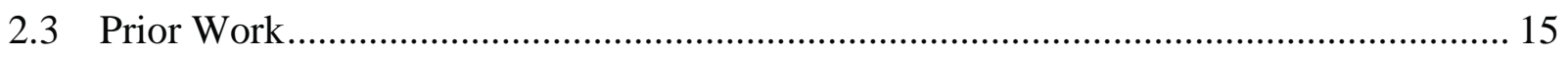

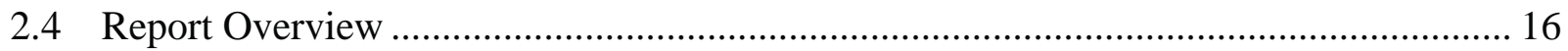

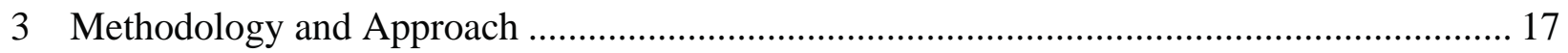

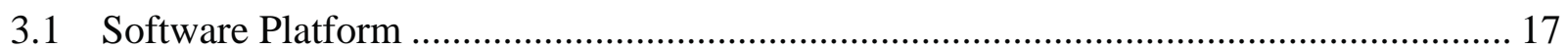

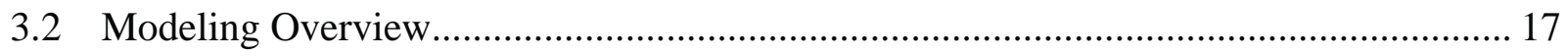

3.3 System Study Matrix ………………………………............................................. 18

3.4 Technology Readiness Level ................................................................................... 19

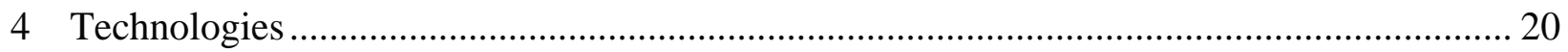

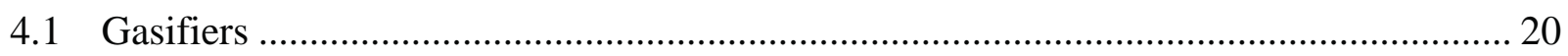

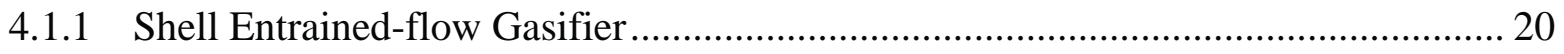

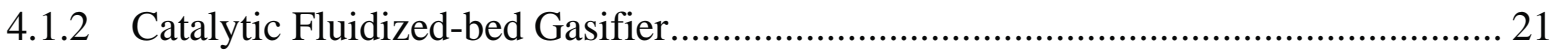

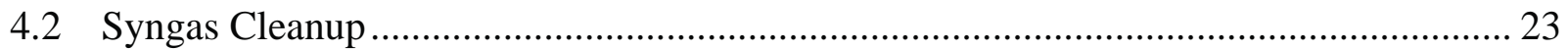

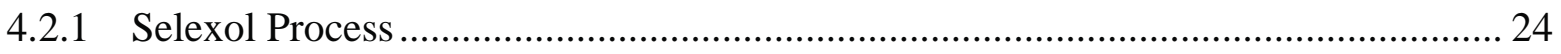

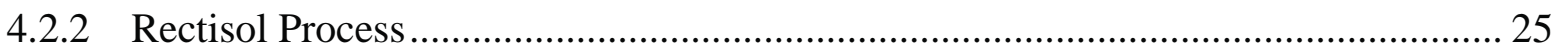

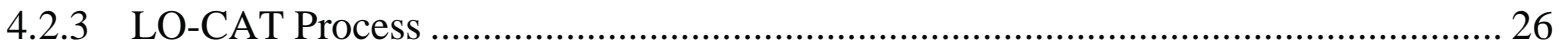

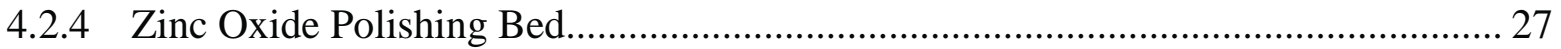

4.2.5 Regenerable $\mathrm{ZnO}$ - Warm Gas Desulfurization ..................................................... 27

4.3 SOFC Model Development and Benchmarking......................................................... 29

DE-NT0005202 I-C, p. 1 


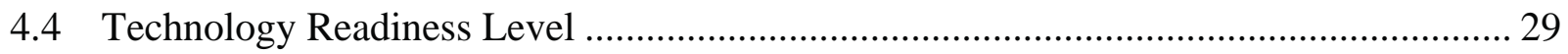

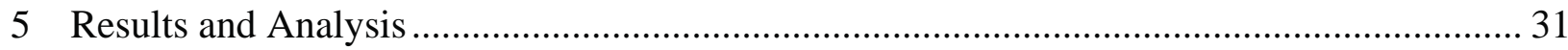

5.1 Focus Area (1): Employing Existing Technology to Achieve Highly-Efficient IGFC Systems with Optional Carbon Capture ${ }^{2}$................................................................... 31

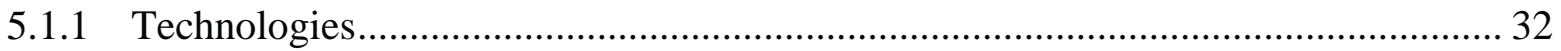

5.1.2 Modeling Approach............................................................................................ 35

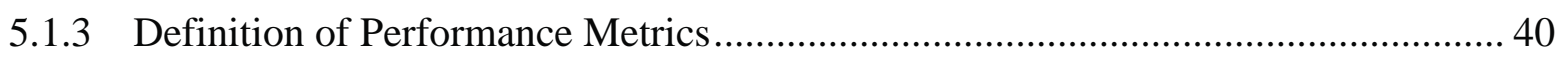

5.1.4 IGFC System Concept Design and Analysis ........................................................... 41

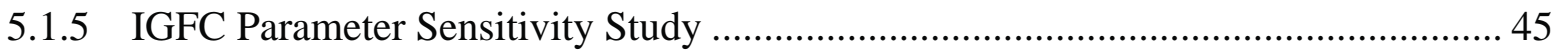

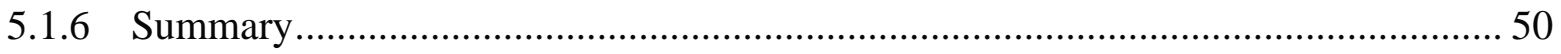

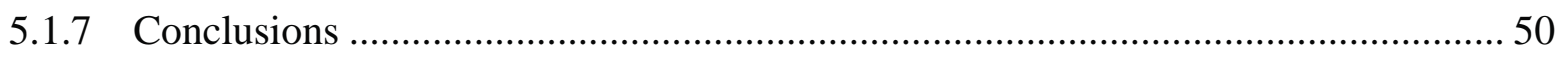

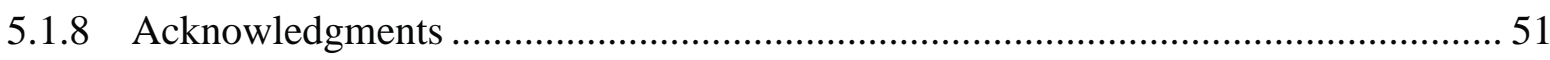

5.2 Focus Area (2) Evaluating Carbon Capture Strategies for IGFC Hybrid Power Systems52

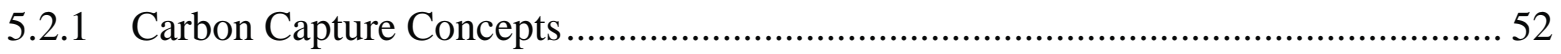

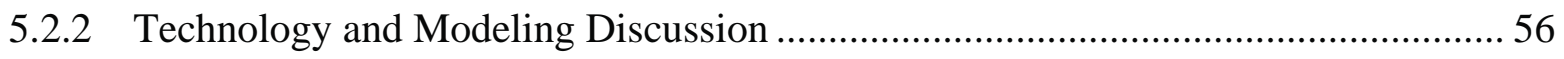

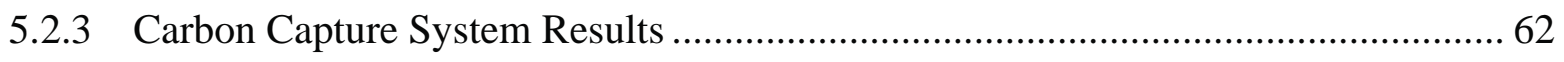

5.2.4 Preliminary Techno-economic Performance Comparisons ........................................ 72

5.2.5 Focus Area (2) Summary and Conclusions ................................................................ 76

5.2.6 Acknowledgements ............................................................................................... 76

6 Task I-C Summary and Future Work............................................................................. 77

6.1 Focus Area (1): IGFC Integration with Existing Technologies ........................................ 77

6.2 Focus Area (2): Post- and Pre-SOFC CCS concept evalution using membranes ............. 78

6.3 Future Work Recommendations............................................................................. 79

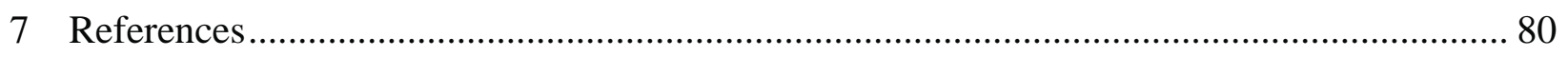

DE-NT0005202 I-C, p. 2 


\section{Executive Summary}

Future integrated gasification fuel cell (IGFC) and combined cycle (IGCC) power plants will require $\mathrm{CO}_{2}$ capture. Carbon capture is typically accomplished with either pre-combustion purification using Rectisol or Selexol absorption processes or via post-combustion separation using oxy-combustion or mono-ethanol-amine based chemical absorption technologies. In IGFC systems, pre-combustion (or pre-SOFC) carbon capture can lower system efficiency through thermal integration challenges associated with the syngas cleanup and fuel delivery to the prime mover.

The project foci explored in Task I-C Modeling, Analysis, and Optimization of IGFC systems were motivated along two primary lines of investigation: (1) understanding IGFC performance when SOFCs are integrated with existing or capacity-scaled commercial power generation and gas cleanup technologies; and (2) developing carbon capture concepts and quantifying the merit of the various emerging capture strategies in IGFC systems. In particular, Focus Area (1) set out to evaluate the performance of IGFC systems that leverage existing or scaled, pre-commercial technologies where possible, with a focus on hardware integration strategies and system performance sensitivity to variations in SOFC operating parameter selection. The objective of Focus Area (2) was to explore IGFC systems that employ advanced membrane separation technologies to evaluate the myriad of carbon capture strategies on both technical and economic bases.

The general objectives of this task are several fold: (1) generate modeling tools to perform system analysis of integrated gasification fuel cell power plants (IGFC) that employ advanced technologies, such as high temperature hydrogen or oxygen transfer membranes; (2) perform a quantitative assessment of the potential system benefits and performance issues when such hardware is integrated within gasification plants where the analysis is inclusive of carbon capture concepts; and (3) evaluate the importance of system operating parameters (such as gasifier and SOFC-GT operating conditions) and quantify the sensitivity of system performance to a variation in these parameters.

System models were built in ASPEN Plus to study performance sensitivities due to variations in system configurations and operating parameters. Plant size and SOFC stack performance were targeted for consistency with DOE SECA program goals $\left(>100 \mathrm{MW}\right.$ and $>0.3 \mathrm{~W} / \mathrm{cm}^{2}$ power density). One journal paper derived from Focus Area (1) has been published in the ASME Journal of Gas Turbines and Power. Another journal paper derived from Focus Area (2) is in draft. The results for both focus areas have been presented in three different talks given at the ASME International Colloquium on Environmentally Preferred Advanced Generation (ICEPAG) in 2010 and 2011. Details regarding Focus Area (1) and (2) results are given in the following subsections. 


\subsection{Focus Area (1): Employing Existing Technology to Achieve Highly-Efficient IGFC Systems with Optional Carbon Capture ${ }^{2}$}

Integrated coal-gasification fuel cell power plant concepts have been investigated using modeling and simulation. Portions of this work were carried out in conjunction with United Technologies Corporation as a part of DOE contract DE-FC26-02NT41246. The plant concepts evaluated feature entrained-flow, oxygen-blown slagging gasifiers integrated with planar SOFC technology, Pratt \& Whitney gas turbines, carbon capture via oxy-combustion of the anode tailgas, and waste heat recovery through either steam or organic Rankine cycle systems. The current system-level models have been generated employing zero-dimensional thermodynamic component models.

A viable system configuration was first established and sizing of the SOFC power block was derived from matching of reactant flows to the P\&W FT8 gas turbine requirements. In this analysis, the high-pressure turbine stage and combustor were removed from the P\&W FT8-3 product line and gas turbine performance was estimated with the low-pressure $(P R=5.2)$ turbine spool alone. Design parameters were then varied to gauge performance sensitivity. Key parameters and the ranges explored are summarized in Table 3 of Section 5.1. Bounds for the range were constrained by hardware performance characteristics, such as maximum SOFC outlet temperature, or flow and compressor pressure ratios for the gas turbine spool.

Initial studies of IGFC plant concepts established the DC power rating of the SOFC power block near $115 \mathrm{MW}$ and focused on integrating the SOFC power section with the low-pressure spool of the P\&W FT8 gas turbine and a scaled-up version of the PureCycle organic rankine cycle waste heat power generator. Additional studies evaluated the integration of a higher temperature $\mathrm{P} \& \mathrm{~W} / \mathrm{TurboDen} \mathrm{ORC}$ product line into the plant. A process flow diagram of the system concept is presented in Figure ES-1. A pure oxygen stream is supplied from the gasifier air-separation plant to the oxy-combustor which oxidizes the anode tail-gas, thereby producing only $\mathrm{CO}_{2}, \mathrm{H}_{2} \mathrm{O}$, and a small amount of $\mathrm{N}_{2}$. The anode tail-gas is not mixed with the cathode exhaust gas stream and thereby, makes the process for $\mathrm{CO}_{2}$ separation and capture a simple one through the use of a condenser to knock-out the water vapor present in the stream. The system also employs both hot anode and cathode gas recycle. The anode gas recycle is accomplished with an ejector and the cathode recycle is developed with a high temperature blower. The power plant concept is projected to have a capacity of $149 \mathrm{MW}$ at $51.4 \%-\mathrm{LHV}(48.1 \%-\mathrm{HHV})$ efficiency without $\mathrm{CO}_{2}$ capture and compression costs and $139 \mathrm{MW}$ at $\sim 48 \%-\mathrm{LHV}$ efficiency with $\mathrm{CO}_{2}$ capture to sequestration-ready pipeline conditions. 


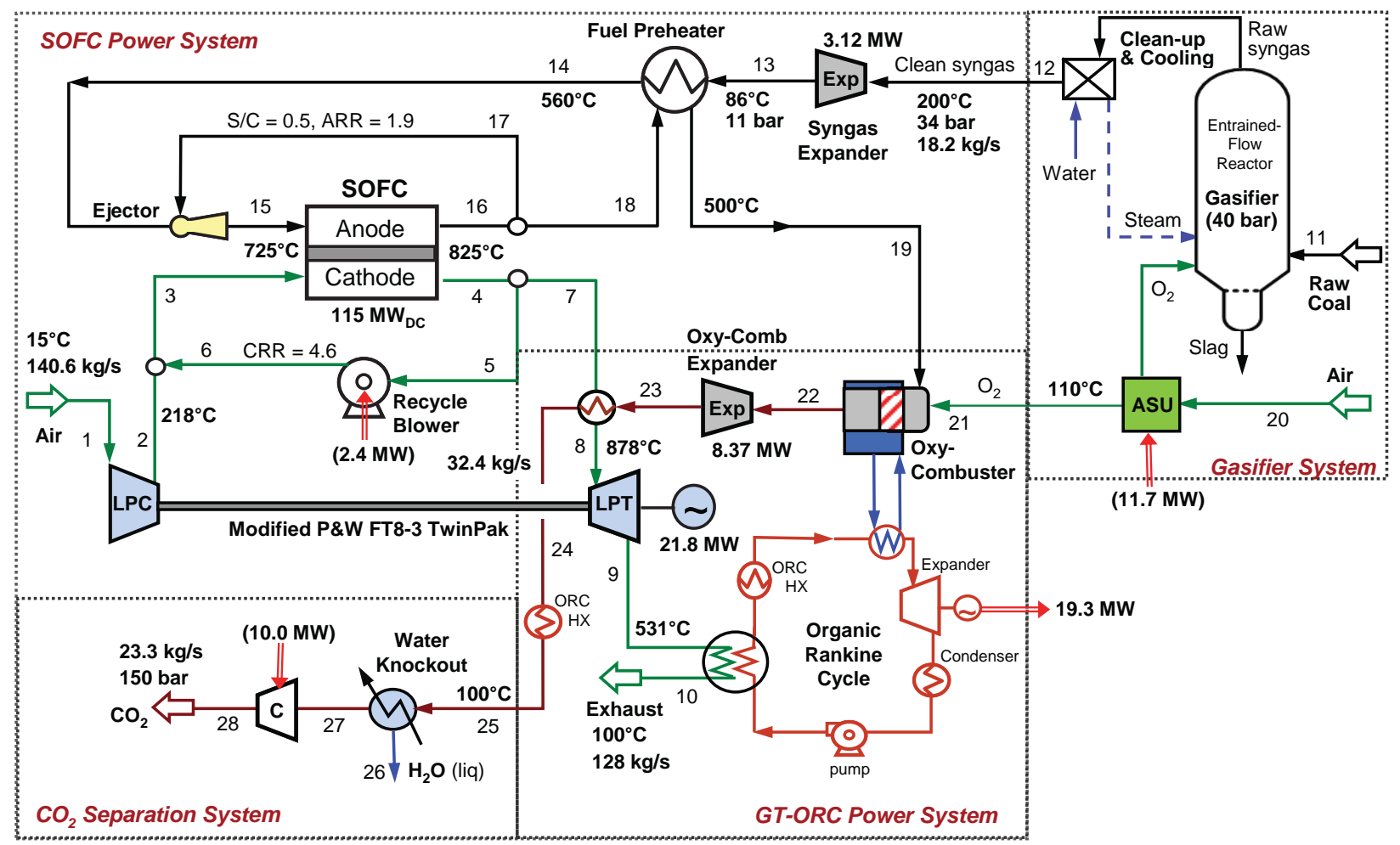

Figure ES-1. Process Flow Diagram of Focus Area (1) Hybrid IGFC Plant Concept

Table ES-1 summarizes the hybrid IGFC system performance including the overall impact to the system when accounting for the energy requirements of carbon capture and storage. Results for three different bottoming Rankine cycle power plants are given in the table. The PureCycle ORC integrated power plant generates $156 \mathrm{MW}$ of net ac power, where the re-designed FT8 and the scaled-up UTC Power PureCycle sub-systems contributing nearly $20 \mathrm{MW}$ each. The SOFC operates nominally at $775{ }^{\circ} \mathrm{C}$ with an average cell voltage of $0.75 \mathrm{~V}$, a fuel utilization of $80 \%$, a power density of $0.45 \mathrm{~W} / \mathrm{cm}^{2}$, a $100^{\circ} \mathrm{C}$ temperature rise across both the anode and the cathode, and a $2.5 \mathrm{kPa}$ pressure drop across the cathode. The SOFC power block provides about $68 \%$ of the total gross power from the plant, the gas turbine and scaled-up ORC systems supply approximately $13 \%$ and $12 \%$, respectively, and the gas expanders about $7 \%$. The compression of $\mathrm{CO}_{2}$ using intercooled compression stages each at $82 \%$ isentropic efficiency to sequestrationready pressure levels requires about $10 \mathrm{MW}$ of power.

The net system efficiency of the power plant employing the modified PureCycle ORC bottoming cycle is $65.7 \%$ (LHV) when operating from clean syngas supplied at the fuel preheater inlet, and $51.5 \%$ on raw coal (i.e., accounting for the inefficiency in the gasifier). Syngas-based system performance includes the power generated from the oxy-combustor expander, but not the syngas expander, and includes the power required to supply $\mathrm{O}_{2}$ to the oxy-combustor $(1.7 \mathrm{MW})$. The total system performance after including the energy requirements for CC\&S reduces the net system efficiency to $61.3 \%$ and $47.8 \%$ when based on clean syngas and raw coal feedstocks, respectively. Futher details can be found in Section 5.1 of this report. 
Table ES-1. Performance summary for hybrid IGFC system

\begin{tabular}{|c|c|c|c|}
\hline \multirow{4}{*}{$\begin{array}{l}\text { Fuel In } \\
\text { Raw Coal, MW (LHV) } \\
\text { Syngas*, MW (LHV) }\end{array}$} & \multicolumn{3}{|c|}{ Bottoming Cycle Type } \\
\hline & PureCycle ORC & TurboDen ORC & SRC \\
\hline & 290 & 290 & 290 \\
\hline & 238 & 238 & 238 \\
\hline \multicolumn{4}{|l|}{ Power (MW) } \\
\hline SOFC, $\mathrm{MW}_{\mathrm{AC}}$ & 111 & \multirow{5}{*}{22.7} & \multirow{5}{*}{29.9} \\
\hline GT & 21.8 & & \\
\hline Rankine Bottoming Cycle (ORC or SRC) & 19.3 & & \\
\hline Oxy-combustor Expander & 8.37 & & \\
\hline SynGas Expander & 3.08 & & \\
\hline ASU $\mathrm{O}_{2}$ and $\mathrm{N}_{2}$ supply & -11.9 & & \\
\hline $\mathrm{CO}_{2}$ compression & -10.0 & & \\
\hline Absorbent regen. and misc. CC\&S power & -0.5 & & \\
\hline Recycle Blower & -2.4 & & \\
\hline Net Power on syngas & 156.3 & 159.7 & 167.0 \\
\hline Net Power on syngas with CC\&S & 145.8 & 149.2 & 156.5 \\
\hline Net Power on coal & 149.3 & 152.6 & 159.9 \\
\hline Net Power on coal with CC\&S & 138.8 & 142.1 & 149.4 \\
\hline \multicolumn{4}{|l|}{ Efficiencies (\%) } \\
\hline Gasifier & 82.0 & \multirow{9}{*}{23.5} & \multirow{9}{*}{31.0} \\
\hline Recycle blower & 50.0 & & \\
\hline Dc/Ac Inverter & 96.5 & & \\
\hline Expanders & 88.0 & & \\
\hline FT-8 LPC & 84.0 & & \\
\hline FT-8 LPT & 91.8 & & \\
\hline FT-8 PT & 85.8 & & \\
\hline ORC or SRC (net) & 20.0 & & \\
\hline $\mathrm{CO}_{2}$ Compression & 82.0 & & \\
\hline \multicolumn{4}{|l|}{ System Performance (\%-LHV) } \\
\hline Net Efficiency on syngas & 65.7 & 67.1 & 70.2 \\
\hline Net Efficiency on syngas with CC\&S & 61.3 & 62.7 & 65.7 \\
\hline Net Efficiency on coal & 51.5 & 52.6 & 55.1 \\
\hline Net Efficiency on coal with CC\&S & 47.8 & 49.0 & 51.5 \\
\hline
\end{tabular}

Table ES-1 shows that the use of the higher temperature P\&W ORC TurboDen product line offers a bottoming cycle efficiency improvement of $3.5 \%$ and increases the net efficiency of the system on syngas to $67.1 \%$ and to $49.0 \%$ on coal with CC\&S. (Note that the TurboDen ORC and steam Rankine cycle (SRC) columns of Table ES-1 only report values when they are different than the PureCycle ORC case.) These IGFC plants using ORC bottoming cycles with CC\&S amount to 14.0 and 15.2 percentage point improvements in efficiency, respectively, over conventional IGCC/CCS power plant performance.

The high-grade thermal energy that is available for input into the ORC subsystem suggests that a steam-based Rankine power subsystem is also viable. Indeed, while the purpose of this study was to investigate the performance with primarily ORC systems, a steam turbine plant potentially offers even higher efficiency depending on the boiler pressure and superheat 
temperatures achievable. Assuming a simple rankine cycle net efficiency of $31 \%$, the IGFC system efficiency on coal could produce about 10.6 MW of additional power and increase net system efficiency by 3.7 percentage points to $55.1 \%$ (51.5\% with CC\&S) as summarized in Table ES-1.

The following summary and conclusions statements are made from results established from Focus Area (1) efforts:

- Hybrid SOFC systems with ORC bottoming cycles could achieve electric efficiencies of 49 to $52 \%$ including CC\&S and as high as $67 \%$ when operating off a clean syngas and venting the $\mathrm{CO}_{2}$ to the atmosphere.

- The impact of integrating an ORC bottoming cycle was found to add as much as 8 percentage points of efficiency to the system. Use of a steam power cycle, in lieu of the ORC, could increase net plant efficiency by another $3.7 \%$.

- Additionally, the strategic use of gas expanders is particularly advantageous to offset carbon capture compression requirements or air separation unit auxiliary power requirements.

A study of system performance sensitivity to a variation in SOFC design parameters revealed the strongest influences are design cell voltage, SOFC fuel utilization, and system pressure. In particular:

- The net system efficiency can vary by as much as 3 percentage points over the range studied for changes to any of these parameters and thus, SOFC-GT-ORC system efficiency could top 52\%-LHV when optimal SOFC operating parameters are selected.

- Anode tail gas recycle ratio and cathode side design parameters, such as pressure drop and temperature rise, only mildly affect system efficiency; however, increasing the recycle ratio of anode tail-gas has the negative effect of decreasing SOFC power density and hence, increasing the number of cell-stacks required.

- Depending on power density, two to three thousand 300-kW SOFC stacks are required to generate $115 \mathrm{MW}$ of dc power.

- It was also noted that additional analyses related to changes in the system design, such as ASU integration with the gas turbine or catalytic gasification could substantially improve the system performance beyond what is reported herein. 


\subsection{Focus Area (2) Evaluating Carbon Capture Strategies for IGFC Hybrid Power Systems}

Focus Area (2) carried out techno-economic analyses to evaluate concepts that employed either hydrogen or oxygen transfer membrane technologies strategically located upstream or downstream of the SOFC power block. In particular, the analysis focused on examination of pre-SOFC and post-SOFC CCS concepts. Preliminary capital cost estimates were made to enable a more complete assessment of the attractiveness of one concept over another. Details can be found in Section 5.2 of this report.

In performing the configuration performance analyses, the method of syngas generation was constant for all system concepts explored and the basic set of processes employed is as follows:

Gasifier: Shell Entrained-flow Slagging (EFS)

ASU: $\quad$ Cryogenic Distillation (at an electric consumption of $0.285 \mathrm{kWh} / \mathrm{kg} \mathrm{O}_{2}$ )

Cleanup: High-temperature halide and mercury cleanup with either warm-gas desulfurization or Selexol

SOFC: $\quad 10 \mathrm{bar}, 0.78 \mathrm{~V} / \mathrm{cell}, 80 \%$ utilization

GT: $\quad$ Rubber turbine with PR $=10$

ST: $\quad 120 \mathrm{bar} / 540^{\circ} \mathrm{C} / 540^{\circ} \mathrm{C}$ reheat steam cycle

The six different plant concept cases explored are broken down into four post-SOFC and two pre-SOFC CCS configurations and they differ as follows:

Baseline: Post-SOFC CCS with oxycombustion

Case 1: Post-SOFC CCS with water-gas shift membrane reactor (WGSMR) with no sweep gas Case 2: Post-SOFC CCS with WGSMR and nitrogen sweep gas

Case 3: Post-SOFC CCS with oxygen conducting membrane reactor (OCMR)

Case 4: Pre-SOFC CCS with 2-stage Selexol unit

Case 5: Pre-SOFC CCS with WGSMR

IGFC plant efficiency and economic performance comparisons were made to gauge the overall effectiveness of the various carbon capture concepts. Details regarding the different cases can be found in Section 5.2 of this report. An energy balance and efficiency summary which details the performance of each plant concept is given in Table ES-2 below. System efficiency ranges from 45.9\%-LHV (Case 1) to 49.8\% (Case 5). 
Table ES-2. Focus Area (2) IGFC Energy Balance Performance Summary

\begin{tabular}{|c|c|c|c|c|c|c|}
\hline \multirow[b]{2}{*}{ [all units = MW] } & \multicolumn{4}{|c|}{ Post-SOFC CCS } & \multicolumn{2}{|c|}{ Pre-SOFC CCS } \\
\hline & Baseline & $\begin{array}{c}\text { Case } 1 \\
\text { WGSMR } \\
\text { no sweep }\end{array}$ & $\begin{array}{c}\text { Case } 2 \\
\text { WGSMR } \\
\text { N2 Sweep }\end{array}$ & $\begin{array}{c}\text { Case } 3 \\
\text { OCM }\end{array}$ & $\begin{array}{l}\text { Case } 4 \\
\text { Selexol }\end{array}$ & $\begin{array}{c}\text { Case } 5 \\
\text { WGSMR }\end{array}$ \\
\hline Gasifier Input & 290 & 290 & 290 & 290 & 290 & 290 \\
\hline \multicolumn{7}{|l|}{ Plant Production } \\
\hline SOFC & 100.1 & 100.1 & 100.1 & 100.1 & 101.8 & 90.0 \\
\hline Syngas Expander & 2.4 & 2.4 & 2.4 & 2.4 & 2.5 & 1.8 \\
\hline Anode Expander & 14.5 & 5.7 & 5.8 & 11.5 & 19.3 & 40.8 \\
\hline Steam Cycle/ORC & 32.5 & 33.8 & 32.1 & 31.9 & 28.2 & 31.0 \\
\hline N2 Expander & 4.5 & 4.3 & 4.3 & 4.3 & 3.8 & 3.8 \\
\hline Cathode Expander & 61.8 & 64.3 & 68.5 & 66.5 & 45.3 & 27.8 \\
\hline Total & 215.7 & 210.6 & 213.1 & 216.6 & 200.9 & 195.2 \\
\hline \multicolumn{7}{|l|}{ Parasitics } \\
\hline Pumps/Misc & 0.3 & 0.4 & 0.4 & 0.4 & 0.6 & 0.4 \\
\hline CO2 Compressor & 14.5 & 14.2 & 14.3 & 14.1 & 5.7 & 2.4 \\
\hline Cathode Blower & 0.9 & 0.9 & 0.9 & 0.9 & 0.8 & 0.8 \\
\hline O2 Compressor & 2.0 & 2.0 & 2.0 & 2.0 & 2.0 & 2.0 \\
\hline $\begin{array}{l}\text { O2/Air } \\
\text { Compressor }\end{array}$ & 0.09 & 2.22 & 2.9 & - & 0.00 & 0.00 \\
\hline Air Compressor & 43.2 & 43.2 & 43.2 & 43.2 & 34.3 & 32.9 \\
\hline $\begin{array}{l}\text { Recycle } \\
\text { Compressor* }\end{array}$ & 0.02 & 0.02 & 0.02 & 0.02 & 0.02 & 0.02 \\
\hline ASU Duty & 10.5 & 8.8 & 8.8 & 8.8 & 8.8 & 8.8 \\
\hline $\begin{array}{l}\text { Cooling Tower + } \\
\text { Chiller }\end{array}$ & 3.7 & 3.7 & 3.6 & 3.6 & 3.5 & 1.4 \\
\hline Selexol Duty & - & - & - & - & 3.2 & - \\
\hline Misc & 2.0 & 2.0 & 2.0 & 2.0 & 2.0 & 2.0 \\
\hline Total & 77.3 & 77.5 & 78.2 & 75.0 & 60.9 & 50.8 \\
\hline Net Total & 138.4 & 133.2 & 134.9 & 141.6 & 139.9 & 144.4 \\
\hline $\begin{array}{l}\text { System Efficiency } \\
\text { (\%-LHV) }\end{array}$ & 47.7 & 45.9 & 46.5 & 48.8 & 48.3 & 49.8 \\
\hline $\begin{array}{l}\mathrm{CO}_{2} \text { capture } \\
\text { penalty }\end{array}$ & 5.01 & 4.89 & 4.94 & 4.84 & 3.07 & 0.84 \\
\hline
\end{tabular}

An economic analysis was also carried out and is preliminary in that hardware cost estimates were made for key sub-systems but a complete bottoms-up analysis was not performed. Instead, the gasifier and bottoming steam Rankine power generation cycle capital costs were assumed to be unaffected by changes in system configurations. The entrained-flow gasifier in each system operates with the same feedstock flows and at the same operating conditions. The Rankine power cycle operates within a $10 \%$ power level deviation across all configurations. The focus of economic performance comparisons was made to understand the impact of membrane-based CCS on gas cleanup, SOFC and gas turbine power blocks, and air separation sub-systems. 
The comparative results are displayed in the form of a bar graph in Figure ES-2. The installed capital cost estimate (not including gasifier and bottoming Rankine cycle) for the Baseline oxycombustion system that produces nearly $140 \mathrm{MW}$ of power is about $\$ 116$ million. When comparing the Baseline IGFC system to the post-SOFC CCS plants, capital cost increases nearly $20 \%$ in Case 1 and decreases by over 5\% in Case 3. Use of a 2-stage Selexol plant in the preSOFC CCS configuration of Case 4 increases plant capital cost by over $46 \%$ with little efficiency performance increase. As Figure ES-2 shows, Case 5 achieves a $2.1 \%$ efficiency gain and a capital cost reduction of about $\$ 3$ million dollars $(\sim 3 \%)$. Thus, these results indicate that PostSOFC CCS Case 3 with OCMR and Pre-SOFC CCS Case 5 with WGSMR are the most technoeconomically attractive system concepts.

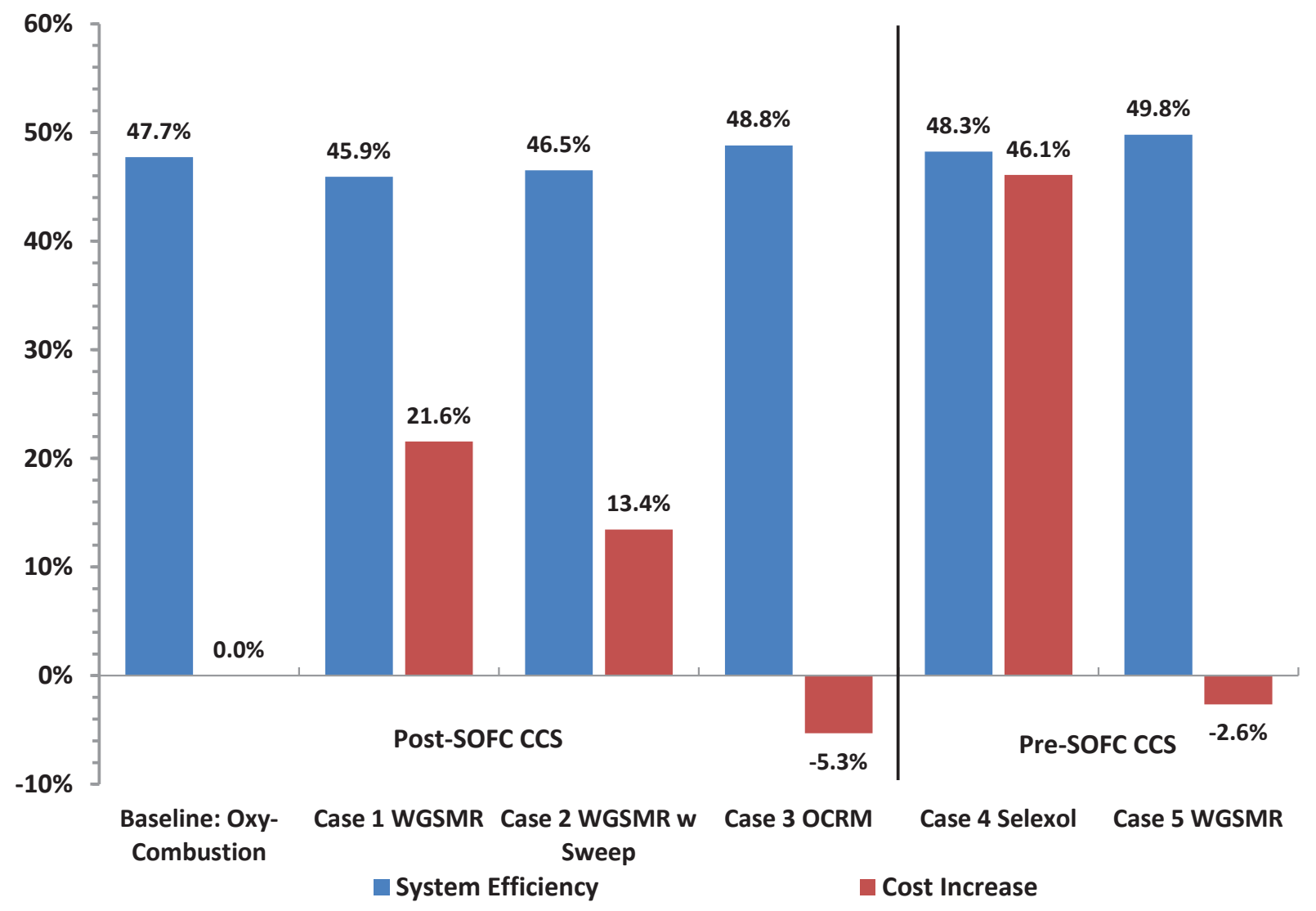

Figure ES-2: Comparison of IGFC system efficiency and percent cost change for CCS concepts 
The conclusions of the analysis for pre-SOFC and post-SOFC carbon capture concepts employing emerging membrane gas separation technology are as follows:

\section{Post-SOFC CCS Summary}

- High efficiency IGFC system concepts employing membrane reactors in the SOFC tailgas achieve system efficiencies are comparable to those with oxy-combustion.

- Tail-gas WGS membrane reactors are unattractive due to large area requirements (and therefore, cost) from dilute $\mathrm{H}_{2}$ concentration in SOFC tail-gas.

- The usage of oxygen conducting membrane reactor indicates both a cost $(-\$ 5.3 \mathrm{M})$ and efficiency $(+1.1 \%)$ advantage in these preliminary studies.

\section{Pre-SOFC CCS Summary:}

- Efficiency gains in Pre-SOFC systems are largely associated with reduced auxiliary power in $\mathrm{CO}_{2}$ compression and air separation.

- Further, there is significant potential for SOFC stack cost reduction due to the higher $\mathrm{H}_{2}$ concentration in the feedgas which increases power density at the same design voltage (i.e., same stack efficiency).

- Cost reductions of $\sim 3 \%$ and efficiency increases of $2.1 \%$ may be possible with mature WGSMR technology.

- If pre-SOFC carbon capture is to be performed, these results suggest to do so with WGSMRs versus Selexol (for mature hydrogen transfer membrane technology) which allows for both capital cost reduction and efficiency performance increases $(2.1 \%)$.

- Mixing of tail-gases is not necessarily a preferred configuration from cost and efficiency performance standpoints, but deserves further exploration.

\subsection{Report Overview}

In addition to the system studies, in Section 3 of this report, we discuss the overall modeling approach and methodology employed to carry out the analyses. This section is inclusive of software platform analysis, and a systems study roadmap. Section 4 provides overviews and preliminary analyses of key technologies that are employed within IGFC systems, particularly gasifiers, SOFCs, gas cleanup and carbon capture. A high-level assessment of the technology readiness of gas cleanup processes is also given. Detailed modeling and analysis results of Focus Areas are then presented in Section 5. The report concludes with a summary of results and acknowledgements in Section 6. 


\section{Introduction}

Solid oxide fuel cells (SOFCs) are considered to be a key technology for high-efficiency, low/zero-emission fossil power plants of the future. In particular, the accelerating development activity of SOFCs under the auspices of the U.S. DOE Solid State Energy Conversion Alliance (SECA) program is focused on utilizing SOFCs as building blocks for large-scale integrated coal-gasification power plants. When SOFCs are fueled from coal syngas and combined with gas turbines, an ultra-high efficiency hybrid system can be obtained. A steam Rankine bottoming cycle (SRC) can also be integrated to further enhance efficiency and power production and carbon dioxide capture and sequestration (CCS) is necessary to achieve near-zero emission levels. It has been estimated that an integrated gasification fuel cell (IGFC) power plant with CCS can achieve an efficiency advantage of nearly 24 percentage points over a comparable integrated gasification combined cycle plant with CCS [1].

There are numerous challenges in integrating the many subsystems that comprise an IGFC power plant. Achieving robust operability and control and a flexible operating envelope in a costeffective manner are significant concerns for hybrid power systems, especially those involving numerous unproven technologies. Technical challenges include gasifier-fuel cell integration, fuel cell-gas turbine integration, power block integration with carbon capture hardware, and system control. Gasifier-fuel cell integration is subject to the very narrow operating envelope of SOFC technology established by both tolerance to anode fuel gas impurities, and cell-stack temperature and pressure control. Excursions of reactant gas temperatures, pressures, and compositions from design conditions can lead to cell cracking, carbon deposition, anode oxidation, and accelerated cell degradation (reduced lifetime). Fuel cell-gas turbine integration is subject to the same SOFC operating constraints as gasifier integration and is further hampered by several control challenges that involve compressor surge, shaft overspeed, and cell overheating [2]. Detailed examination of the integration challenges is beyond the scope of this work, but the interested reader is referred to several literature studies on the topic $[2,3,4,5,6,7$, $8,9]$.

Despite the numerous technical challenges that need to be overcome, both the efficiency performance and the economics of 'mature' IGFC systems are promising. Recent economic assessments of large-scale (>100 MW) integrated gasification combined cycle (IGCC) plants employing entrained-flow gasifiers and F-class syngas turbines have estimated total plant capital costs at about $\$ 1800 / \mathrm{kW}^{1}$ (in 2007\$) using commercially available technologies without carbon capture $[1,10]$. It is estimated that capturing carbon dioxide in these plants adds another $30 \%$ to the total plant capital cost [1]. In contrast, the cost of an IGFC plant that employs catalytic gasifier technology and carbon capture has been estimated to reduce the plant capital cost by $30 \%$ (i.e., $\sim \$ 1670 / \mathrm{kW}$ ) while offering an efficiency advantage of nearly 24 percentage points over its IGCC/CCS counterpart [1]. Such cost and performance advantages make IGFC/CCS systems very attractive, however, considering the substantial technical challenges of realizing

\footnotetext{
${ }^{1}$ This cost reflects an overnight installed capital cost that can be $50 \%$ lower than actual turn-key plant cost.
} 
these performance expectations, continued exploration of system integration concepts is warranted.

\subsection{IGFC System Overview}

One of the aims of the systems modeling work is to evaluate pre- and post-combustion carbon capture strategies. But before delving deeper into technical objectives, it is helpful to review the main process steps involved in an advanced coal gasification plant for power production. A schematic diagram is given in Figure 1 that provides an overview of a coal-based IGFC hybrid system with bottoming Rankine cycle and post-combustion $\mathrm{CO}_{2}$ capture. The first step of the IGFC system is production of a syngas through gasification of the coal feedstock. The coal is fed into the high-pressure gasifier using nitrogen as an inert pressurizing agent that is supplied from the air separation unit. Syngas cleanup and cooling occur next before admittance into the SOFC power block. In one sense, the IGFC system is very similar to its more conventional integrated gasification combined cycle (IGCC) counterpart in that the SOFC serves as a combustor that also produces electric power. Thus, the compressor of the gas turbine supplies air to the SOFC unit and the heat gain of the cathode air from the SOFC processes is returned to the turbine. The depleted anode tail-gas is kept separate from the cathode gases and is sent to the oxy-combustor where the remaining fuel gas is combusted. Thermal energy is recovered from both gas turbine and oxy-combustor exhaust gases via the bottoming Rankine cycle. Carbon dioxide is separated in the final stage of the plant process as shown in Figure 1. Either steam or organic Rankine bottoming cycles could in theory be applied in an IGFC system. Typically, an organic Rankine cycle (ORC) offers lower efficiency than a conventional steam cycle given the availability of the relatively high temperature heat sources in the IGFC system, but there are potential cost benefits associated with integration of an ORC system that merit further exploration of its potential use as will be discussed further in Section 5 of this report.

\subsection{Project Scope of Analysis and Objectives}

The project foci explored in this Task were motivated along two primary lines of investigation: (1) understanding IGFC performance when SOFCs are integrated with existing or capacityscaled commercial technology; and (2) developing carbon capture concepts and quantifying the merit of the various capture strategies in IGFC systems. In particular, Focus Area (1) set out to evaluate the performance of IGFC systems that leverage existing or scaled, pre-commercial technologies where possible, with a focus on hardware integration strategies and system performance sensitivity to variations in SOFC operating parameter selection. The objective of Focus Area (2) was to explore IGFC systems that employ advanced membrane technologies to evaluate the myriad of carbon capture strategies on both technical and economic bases. Further discussion on the project focus areas is given below. 


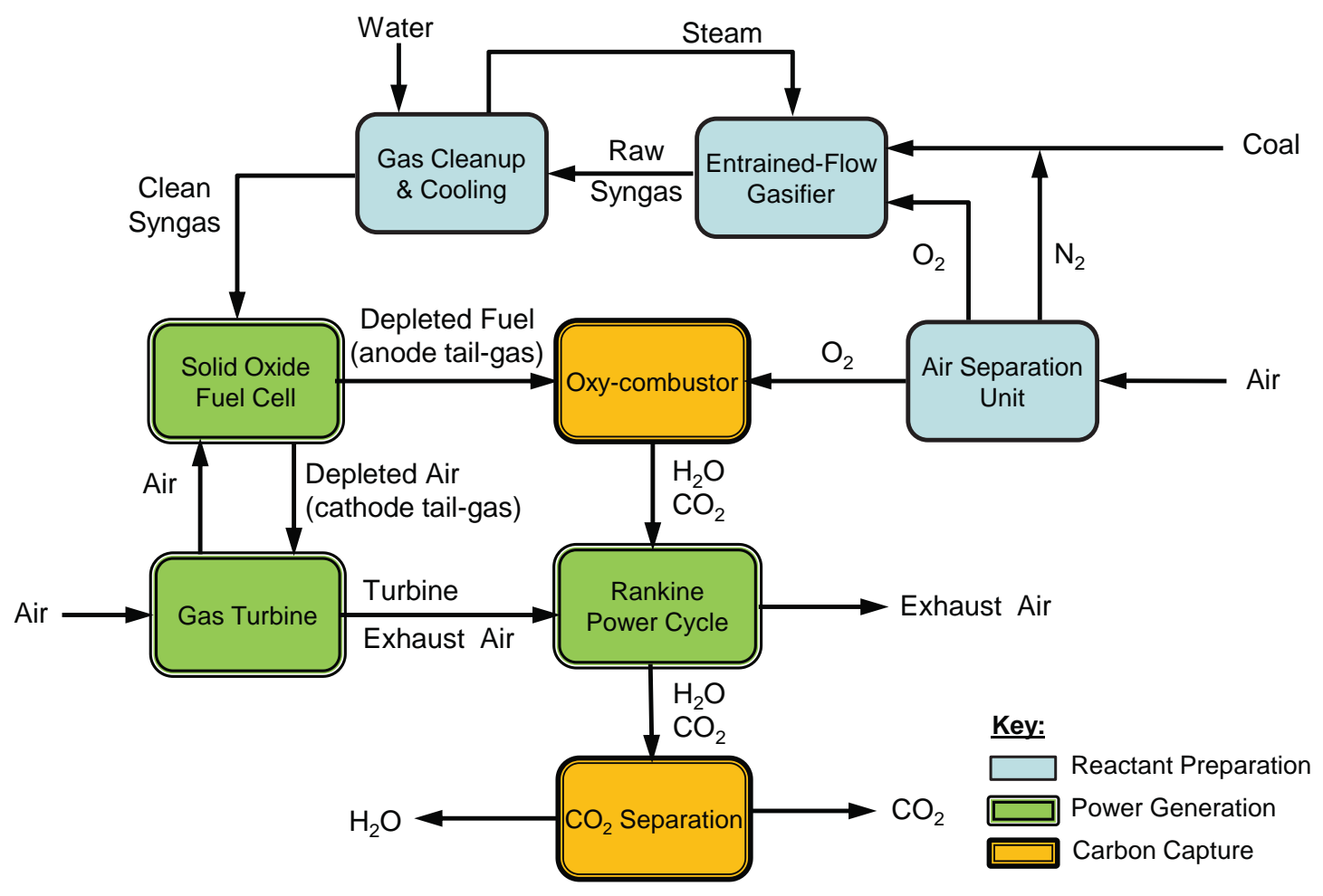

Figure 1. Schematic overview of IGFC hybrid system with post-combustion $\mathrm{CO}_{2}$ capture

\subsubsection{Focus Area (1): Employing Existing Technology to Achieve Highly-Efficient IGFC Systems with Optional Carbon Capture}

The objectives of this Focus Area were to:

(1) quantify IGFC system performance using commercial coal gasifier, gas turbine, and Rankine cycle (both steam and organic Rankine) technologies,

(2) perform a sensitivity study of system performance due to variations in SOFC power block design parameters, and

(3) identify additional areas for system design and performance improvements.

This work was carried out in conjunction with United Technologies Corporation as a part of DOE contract DE-FC26-02NT41246. The plant concepts evaluated feature entrained-flow, oxygen-blown slagging gasifiers integrated with planar SOFC technology, Pratt \& Whitney gas turbines, carbon capture via oxy-combustion of the anode tail-gas, and waste heat recovery through Rankine cycle systems as described by Figure 1. 


\subsubsection{Focus Area (2): Evaluating Carbon Capture Strategies for IGFC Hybrid Power Systems}

Focus Area (2) is motivated by the need for a common basis in the quantitative evaluation of emerging membrane technologies versus conventional carbon capture methods. Membrane reactor technologies may offer cost, efficiency, and thermal integration advantages compared to other carbon separation technologies. The objectives of this focus area were to:

(1) Generate system concepts and quantify IGFC/CCS performance employing membrane reactors in both pre-SOFC and post-SOFC configurations,

(2) For pre-SOFC capture system configurations, examine Selexol versus water-gas shift membrane reactors and for post-SOFC configurations, compare hydrogen and oxygen transfer membranes with oxy-combustion.

(3) Evaluate the IGFC system performance on both efficiency and capital cost bases.

\subsubsection{Supporting Work}

Several other research activities are documented herein that supported the above focus areas. These activities include performing technology readiness level (TRL) assessments of gas cleanup hardware, gasifier operating condition studies for both entrained-flow and catalytic gasifier types, and benchmarking of the SOFC ASPEN Plus model created by DOE NETL against independently developed SOFC models by the Co-PI's at CSM, principally those of Braun [11, 12], and Kee and Zhu [13].

\subsection{Prior Work}

There are several prior theoretical research efforts in the open literature that have examined integrating SOFCs with coal gasification and power generation cycles. In particular, Lobachyov and Richter evaluated integrating an indirectly-heated fluidized-bed coal gasifier with gas turbine and SOFC [14]. Efficiencies exceeding 60\%-LHV were reported with generic gas turbine and obsolete monolithic SOFC technologies and no carbon capture. Kivisaari et al., [15] examined integration of an entrained-flow gasifier with either molten carbonate or solid oxide fuel cell technology for combined heat and power (CHP). In this study, integration with power cycles was not performed nor was $\mathrm{CO}_{2}$ capture of interest. Similarly, Ghosh and De carried out a study on employing entrained-flow gasification with SOFCs, however, gas and steam turbine integration for CHP were also incorporated [16]. Verma et al., [17] performed an analysis on IGFC systems inclusive of a steam cycle, ion transport membrane, and carbon capture technologies. SOFC parameter and system conceptual design variations were studied and efficiencies as high as 50\%-HHV were reported. More recently, Romano et al., examined an IGFC system operating with an oxygen-blown, entrained-flow Shell gasifier [18]. The study details the integration of gasifier and power block islands, but does not offer carbon capture and sequestration. A sensitivity analysis of SOFC pressure and fuel and oxidant utilizations is given. Results of a 7-11 percentage point efficiency gain over advanced IGCC systems are reported. Liese reported on an IGFC system performance with pre- and post-SOFC carbon capture for a hybrid system employing a Conoco-Philips gasifier and a bottoming steam Rankine cycle [19]. 
The focus of this study was on the impact of various carbon capture methods. IGFC studies that employ low-temperature catalytic gasification have also been made [20,21]. These studies show even more promising efficiency performance potential of IGFC hybrid systems in part due to the methane content of gasifier syngas and the associated benefit to the SOFC power block. In terms of SOFC-ORC hybrid systems, Verda performed an integration study with a natural gas fueled commercial-scale tubular SOFC system of about $100 \mathrm{~kW}$ and a $30 \mathrm{~kW}$ ORC system [22]. Results point to a $5.6 \%$ efficiency improvement from the addition of the bottoming ORC system.

\subsection{Report Overview}

This study examines the design and performance of solid oxide fuel cell (SOFC)-based integrated gasification power plant concepts at the utility scale (>100 MW). Both $\mathrm{CO}_{2}$ removal methods, as well as equipment integration for an SOFC with the gasifier and bottoming cycles are analyzed. The primary system concept evaluated was a pressurized $\sim 150 \mathrm{MW}$ SOFC hybrid power system integrated with an entrained-flow, dry-fed, oxygen-blown, slagging coal gasifier and a combined cycle in the form of a gas turbine and either steam or organic Rankine cycle (ORC) power generator. The analyzed concepts include pre- and post-combustion carbon capture followed by water knockout (where necessary) and gas compression to pipeline-ready $\mathrm{CO}_{2}$ sequestration conditions.

This report is organized such that aspects of the Task I-C effort that are common to both modeling and analysis focus areas are first discussed, before the specific results from Focus Areas (1) and (2) are presented. In Section 3 of this report, we discuss the overall modeling approach and methodology employed to carry out the analyses. This section is inclusive of software platform analysis, and a systems study roadmap. Section 4 provides overviews and preliminary analyses of key technologies that are employed within IGFC systems, particularly gasifiers, SOFCs, gas cleanup and carbon capture. A high-level assessment of the technology readiness of gas cleanup processes is also given. Detailed modeling and analysis results of Focus Areas are then presented in Section 5. The report concludes with a summary of results and acknowledgements. 


\section{Methodology and Approach}

\subsection{Software Platform}

gPROMS, HySyS and ASPEN Plus software platforms were evaluated qualitatively through discussions with industry and academic experts. The co-PI of this task has extensive experience with gPROMS which has the positive attributes of open model source code, powerful computational optimization routines, and relatively easy implementation of dynamic simulations. Issues include properties and the quality of model libraries available for the highly complex IGFC plant sub-systems. HySyS was considered to be the most intuitive and easiest to use 'outof-box', but has issues with solids handling and recycle streams. ASPEN Plus is considered to be the industry standard and nearly all national laboratories involved in coal and biomass gasification systems utilize this software. When systems are built in equation-oriented mode they are much more stable, the ASPEN Plus property database is extensive, and numerous relevant example gasification sub-systems are available through ASPEN Tech Support. All modeling platforms have stability issues with avoiding software crash and obtaining convergence.

A two-pronged approach was utilized. Given the effort already made using gPROMS in Focus Area (1), that software platform was continued as the solids handling capability was surmounted by only modeling the gasifier and gas cleanup portions of the plant at a black-box level. For Focus Area (2), ASPEN Plus was selected as the software platform of choice due to the desire to perform full systems integration of gasifier, cleanup, and power block. Additionally, its widespread use and ease of interface with national labs were advantageous.

\subsection{Modeling Overview}

A high-level process description of the IGFC system was given in Figure 1. Within each block of the diagram, there are several unit operations or different technology types to model. The list of components modeled in either gPROMS or ASPEN Plus environments are given below, with many of the models developed and benchmarked against OEM- or developer-supplied data. Modeling details are provided in Section 5 of this report.

\section{Gasifier}

- Entrained-flow slagging

- Bubbling fluidized bed (biomass emphasis)

- Catalytic gasifier

\section{Syngas Cleanup}

- Particulate (cyclone)

- Halide and mercury removal (simple separator with mass/energy balance)

- Desulfurization (RTI warm-gas transport desulfurizer, Selexol, LO-CAT, ZnO polishing)

\section{Air Separation}

- Simple (Empirical power parasitic) 


\section{Carbon Capture}

- 2-stage Selexol

- Oxy-combustor

- Membrane reactors (water-gas shift, oxygen conducting)

\section{SOFC}

- UTRC-based (Focus Area (1) effort)

- NETL-supplied (Focus Areas (2) effort -- Model benchmarked against CSM models)

\section{Combined Cycle}

- Gas Turbine (6FA/6B, 7F/H-class, Pratt \& Whitney FT-8, 'Rubber' turbines)

- Rankine bottoming cycles (steam and organic Rankine)

\subsection{System Study Matrix}

The array of system configurations explored in this task is summarized in Table 1

Table 1. IGFC System Study Matrix

\begin{tabular}{|c|c|c|}
\hline Configuration & Focus Area (1) & Focus Area (2) \\
\hline Gasifier & Shell Entrained-Flow & Shell Entrained-Flow \\
\hline Gas Cleanup & Not modeled & $\begin{array}{l}\text { (1.) Particular removal } \\
\text { (2.) Warm-gas desulfurization } \\
\text { (3.) Selexol } \\
\text { (4.) Halide and Mercury removal }\end{array}$ \\
\hline SOFC & $\begin{array}{c}750^{\circ} \mathrm{C}, 5.2 \mathrm{bar} \\
0.75 \mathrm{~V} / \mathrm{cell}, 80 \% \mathrm{FU}\end{array}$ & $\begin{array}{c}750^{\circ} \mathrm{C}, 10 \mathrm{bar} \\
0.78 \mathrm{~V} / \mathrm{cell}, 80 \% \mathrm{FU}\end{array}$ \\
\hline Gas Turbine & P\&W 25 MW modified FT8 & Rubber turbine, $\mathrm{PR}=10$ \\
\hline Rankine Cycle & $\begin{array}{l}\text { (1.) Steam Rankine (black box) } \\
\text { (2.) Organic Rankine - P\&W } \\
\text { PureCycle / TurboDen }\end{array}$ & $\begin{array}{c}\text { Steam cycle: } 120 \text { bar } / 540^{\circ} \mathrm{C} \\
/ 540^{\circ} \mathrm{C}\end{array}$ \\
\hline $\begin{array}{l}\text { Carbon Capture } \\
\text { Strategy }\end{array}$ & $\begin{array}{l}\text { Post-SOFC: } \\
\text { (1.) Oxycombustion }\end{array}$ & $\begin{array}{l}\text { Post-SOFC: } \\
\text { (1.) Oxy-combustion } \\
\text { (2.) } \mathrm{H}_{2} \text { Membrane Reactor } \\
\text { (3.) } \mathrm{O}_{2} \text { Membrane Reactor } \\
\text { Pre-SOFC: } \\
\text { (1.) Selexol } \\
\text { (2.) } \mathrm{H}_{2} \text { Membrane Reactor }\end{array}$ \\
\hline
\end{tabular}


Focus Area (1) effort is centered on systems integration employing commercial or modified commercial technologies where possible. Within this focus, the sensitivity of system performance to variations in SOFC operating parameters is also investigated. In contrast, Focus Area (2) examines conventional and emerging carbon capture technologies and the impact on system efficiency and cost. Importantly, given their differing objectives, Focus Area (1) and (2) are not meant to be directly compared with one another.

\subsection{Technology Readiness Level}

An attempt has been made to approximate the status of the technologies discussed in this report. To that end, gasifier and gas cleanup options have been assigned a Technology Readiness Level (TRL). The TRL designations used are based on the Department of Defense (DOD) TRL scale of 1 through 9, with 'one' being a concept based on fundamentals but with no experimental backing and 'nine' being a mature, deployed technology. Table 2 shows the designations with descriptions modified from the DOD definition for application to biorefinery technologies. TRL assessment of the syngas cleanup options can be found in Section 4 of this report.

Table 2. Technology Readiness Levels

\begin{tabular}{|c|c|}
\hline TRL & Description of Technology Readiness Level (TRL) \\
\hline 1 & $\begin{array}{l}\text { Basic principles/properties of technology observed and reported. Scientific results not yet translated into } \\
\text { application. }\end{array}$ \\
\hline 2 & Concept for application of technology developed. Analytical/paper studies completed. \\
\hline 3 & $\begin{array}{l}\text { Laboratory studies to physically validate analytical predictions of individual elements of the technology } \\
\text { completed. }\end{array}$ \\
\hline 4 & Component and/or breadboard validation of system in laboratory environment \\
\hline 5 & Component and/or breadboard validation of system in simulated operating environment \\
\hline 6 & Prototype system tested in a relevant environment. \\
\hline 7 & Pilot plant demonstration (sub-scale) under actual operational conditions. \\
\hline 8 & $\begin{array}{l}\text { Numerous demonstrations w/ commercial technology that is currently being used under similar operating } \\
\text { conditions. Minor testing needed to verify proper operation under design/off-design conditions. }\end{array}$ \\
\hline 9 & Commercial technology that is currently being used under identical operating conditions and warranty. \\
\hline
\end{tabular}




\section{Technologies}

This section details supporting research efforts aimed at characterizing critical technologies and process steps in the highly-complex and integrated sub-systems that make up an IGFC power plant. Selection of coal gasifier type and performance sensitivity is first given, followed by a detailed summary of syngas cleanup. Next, benchmarking of an ASPEN Plus SOFC model supplied by DOE NETL is presented and is followed by a summary of a high-level technology readiness level assessment that was made in an effort to judge the relative status of various gas cleanup and carbon capture technologies. Since different modeling approaches were employed for Focus Area (1) and (2) efforts, details on modeling of each sub-system or process are left to their respective sections found in Section 5 of this report.

\subsection{Gasifiers}

The gasifier employed in both of the IGFC system analyses contained within Focus Areas (1) and (2) are dry-fed oxygen-blown, entrained-flow slagging gasifiers representative of Shell gasifier technology. However, given that catalytic gasification technology is a focus of several DOE-sponsored IGFC studies [e.g., 21], a preliminary study on its potential performance and integration within an integrated gasification plant was made. Catalytic gasification is viewed favorably for IGFC systems as it can generate methane molar concentrations as high as $20 \%$ in the syngas which provides enhanced thermal management for the SOFC stack due to internal reforming. However, given the sparse performance and operating information for catalytic gasification, the more proven Shell gasifier technology was selected for the system integration studies performed in Section 5 of this report.

\subsubsection{Shell Entrained-flow Gasifier}

Entrained-flow (EF) gasifiers operate at relatively modest pressures (25-40 bar) and high temperature $\left(1300-1400^{\circ} \mathrm{C}\right)$. The high temperatures are well-above the ash agglomeration temperature and thus, these gasifiers are a slagging type in which the molten slag coats the inner vessel membrane wall and is gravity drained, quenched, and removed. The high temperature operation promotes a syngas very near chemical equilibrium. A thermodynamic study was performed to assess the performance sensitivity of the EF gasifier to changes in operating conditions. Figure 2 depicts the dependence of the syngas composition to variations in oxygento-carbon and steam-to-carbon ratios at constant reactor temperature. As $\mathrm{O}_{2} / \mathrm{C}$ increases, hydrogen and carbon monoxide concentrations decrease as the operating regime moves from partial oxidation to combustion. This is further evidenced by the proportional increase in $\mathrm{H}_{2} \mathrm{O}$ and $\mathrm{CO}_{2}$ molar concentrations which are products of combustion. While not shown, it is apparent that syngas calorific content also decreases with increasing $\mathrm{O}_{2} / \mathrm{C}$ thereby reducing the gasifier cold gas efficiency. Figure 2(b) illustrates the affect of steam to carbon ratio on syngas composition. While CO is largely influenced, hydrogen content of the syngas is less sensitive as it is likely that shift conversion and steam methane reforming are taking place driving the hydrogen content up and mitigating the dilution effect of the increasing amount of steam 
injection. As a result, gasifier cold gas efficiency is largely constant throughout the $\mathrm{H}_{2} \mathrm{O} / \mathrm{C}$ range explored here.

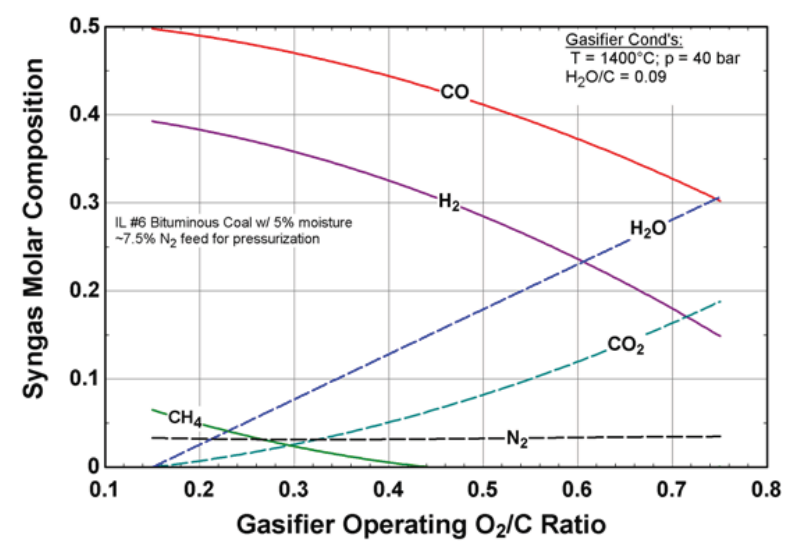

(a.)

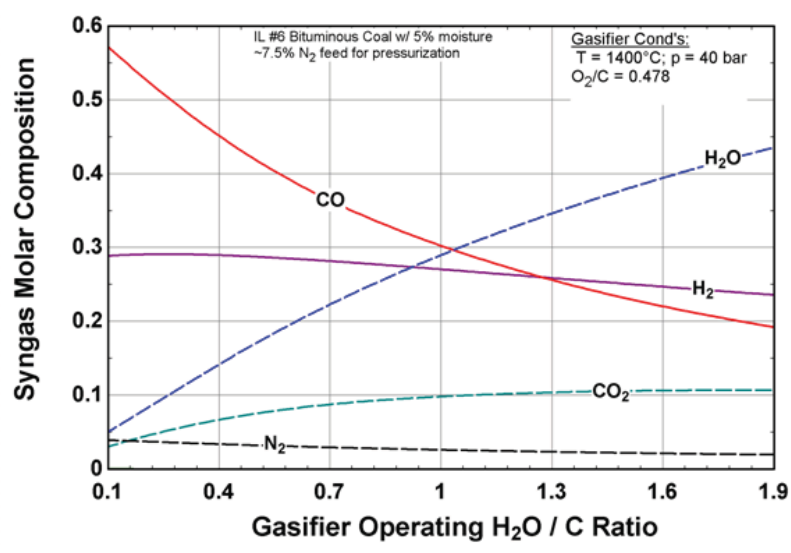

(b.)

Figure 2. Shell Entrained-Flow Gasifier Sensitivity

\subsubsection{Catalytic Fluidized-bed Gasifier}

Catalytic fluidized-bed gasification modeling and performance has been carried out due to its inherent advantages for integration with solid oxide fuel cells. Modeling was based in part on the work of Probstein and Hicks [23] and was performed using equilibrium calculations assuming a potassium carbonate $\left(\mathrm{K}_{2} \mathrm{CO}_{3}\right)$ catalyst that is admitted to the gasifier in an amount equal to $15 \%$ of the coal flowrate. Limited data is available for component benchmarking, but the simulation results are consistent with a recent NETL publication on IGFC cost and performance [21]. Results of the model study are shown in Figure 3 for constant reactor temperature and a constant molar $\mathrm{O}_{2} / \mathrm{C}$ ratio of 0.25 . Figure 3(a) depicts the sensitivity of the gasifier syngas composition to temperature, pressure, and steam-to-carbon ratio. One can see the strong effect of changes in these operating conditions on methane production. The methane production in catalytic gasification can theoretically reach molar fractions of $25 \%$, although this has not been demonstrated to date. Methane formation favors low temperature, high pressure, and low steam-to-carbon operating ratios. However, as seen in Figure 3(b), gasifier cold gas

efficiency performance favors the exact opposite trend (i.e., high temperature, low pressure, and high steam-to-carbon), due to the changes in syngas heating value produced. 

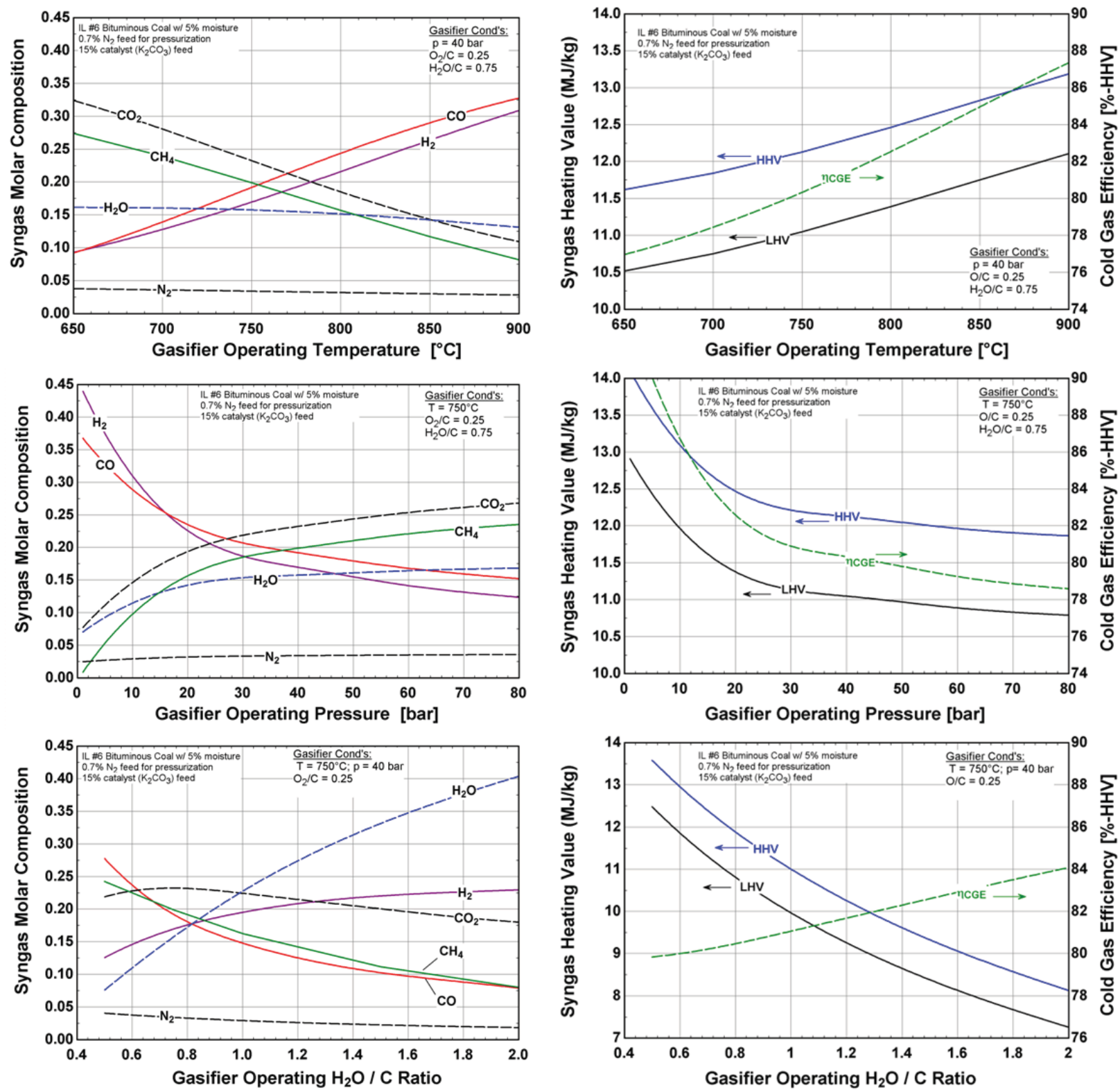

(a.)

(b.)

Figure 3. Catalytic Gasifier Performance Sensitivity to Operating Conditions

Additionally, an increase in gasifier operating temperature or pressure also changes the degree of exothermicity of the gasifier as seen in Figure 4. The heat duty is based on a coal feed rate of 30 $\mathrm{kg} / \mathrm{s}$ and an outlet syngas flowrate of about $64 \mathrm{~kg} / \mathrm{s}$. As temperature is increased, the tendency of the thermal energy requirements in the gasifier is to move toward an endothermic operating regime for temperatures exceeding about $790^{\circ} \mathrm{C}$. As one might expect, Figure 4 shows that the reverse is true for increases in gasifier operating pressure, where above 20 bar operation the heat balance on the gasifier becomes exothermic. The formation of methane via the reverse steam 
reforming reaction is a highly exothermic process and given the thermodynamic characteristics found in Figure 3, the trends in Figure 4 are adequately explained.
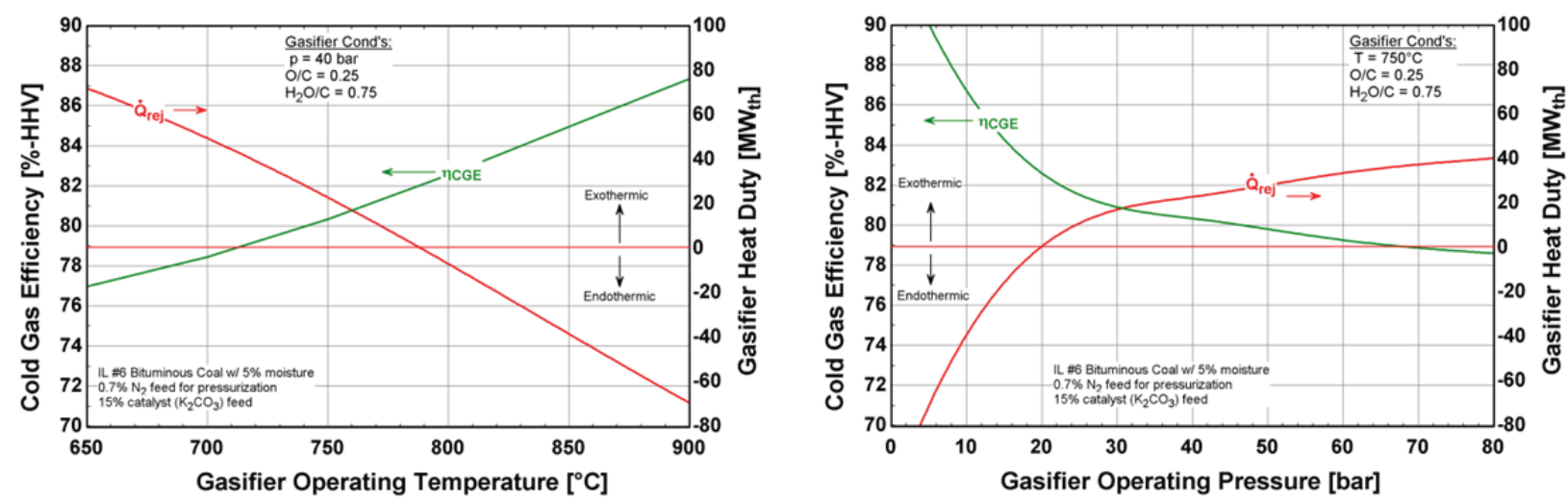

Figure 4. Effect of Temperature and Pressure on Gasifier Heat Requirements

\subsection{Syngas Cleanup}

Study of syngas cleanup technologies and operating conditions was carried out to facilitate process design and simulation upstream of the SOFC-GT power block. Syngas cleanup consists of several process steps including: particulate scrubbing, halide removal, mercury removal, tar mitigation (if the coal feedstock is commingled with biomass), and desulfurization. In this effort, particular focus was placed on exploration of four different technologies for sulfur removal: LO-CAT, transport desulfurization, Selexol, and Rectisol processes. Sulfur in syngas exists in a variety of forms i.e. $\mathrm{H}_{2} \mathrm{~S}, \mathrm{COS}, \mathrm{SO}_{\mathrm{x}}$, and long-chain sulfur compounds. While Selexol and Rectisol are well-established technologies, LO-CAT and transport desulfurization are less well-known. The LO-CAT process is a commercial technology for removal of hydrogen sulfide. It uses a non-toxic cheleated iron, liquid catalyst that is one of the most environmentally benign options available for sulfur removal. In addition to environmental benefits, the process requires no additional equipment to recover elemental sulfur. LO-CAT is typically operated at temperatures between $20-80^{\circ} \mathrm{C}$. Relative to other common sulfur removal technologies, such as Rectisol and Selexol, LO-CAT is one of the least expensive and least power intensive options. However, there are some drawbacks to the technology. The process can only produce product gas that contains 10 ppmv hydrogen sulfide [24], forcing an additional polishing step to reach the sub-1 ppmv level required for SOFC applications. Additionally, LO-CAT does not have the ability to remove carbon dioxide and carbonyl sulfide must be removed by hydrolysis prior to entering the LO-CAT reactor.

While LO-CAT, Selexol and Recitsol processes are commercially available, warm gas desulfurization (WGDS) is a promising technology. All of the commercial bulk sulfur removal options require significantly cooling the synthesis gas. If sulfur could be removed at elevated temperature, significant process cooling is not required and overall plant efficiencies could be 
improved for power production. Currently, WGDS research has been demonstrated at the precommercial scale [25]. Inlet temperatures of $350-650^{\circ} \mathrm{C}$ have been reported in literature which is a drastic improvement over the $60-80^{\circ} \mathrm{C}$ inlet required of Selexol and LO-CAT processes. While outlet concentrations of less than 1 ppmv have been reported [26], concentrations of 15-20 ppmv are more likely [27]. Unfortunately, this means that a polishing bed would be needed to meet fuel production standards. Fortunately, commercial zinc-oxide sulfur polishing beds operate at temperatures around $375^{\circ} \mathrm{C}$ so this is a feasible possibility. The major technical challenges being addressed are soot formation, carbon deposition and catalyst degradation. Initial designs may favor oxygen-blown gasification systems because high $\mathrm{CO}$ syngas seems to reduce soot formation and carbon deposition [26].

\subsubsection{Selexol Process}

The Selexol process is a physical absorption process originally developed by Allied Chemical Corporation and is now licensed by UOP. Physical solvent processes have many advantages over the chemical absorption process including: high selectivity for $\mathrm{H}_{2} \mathrm{~S}$ and $\mathrm{COS}$ over $\mathrm{CO}_{2}$, solvent stability, low heat requirements for regeneration, and high loading capability at high acid gas partial pressures [28]. The Selexol solvent is a proprietary mixture of polyethylene glycol diakyl ethers which are non-toxic, non-corrosive to metals, and biodegradable. Selexol plants are one of the most commercially deployed technologies for acid gas removal with more than 55 Selexol plants in operation worldwide [29]. The process can be configured in a number of ways, depending on the types and amount of acid gas removal required. The process is basically the same as for other absorber-stripper configurations: feed gas enters the bottom of the absorber tower and bubbles up through the solvent which selectively absorbs the $\mathrm{H}_{2} \mathrm{~S}$. Lean gas exhausts out the top of the absorber tower and the $\mathrm{H}_{2} \mathrm{~S}$-rich solvent solutions is removed from the bottom of the tower and circulated to the stripping unit. The rich solvent is regenerated via a multi-stage flashing process. The regenerated solvent is then re-circulated to the top of the absorbing tower to begin the cycle again, see Figure 5 .

The Selexol process is capable of producing highly concentrated acid gas streams $\left(\mathrm{H}_{2} \mathrm{~S}\right.$ or $\left.\mathrm{CO}_{2}\right)$ which may then be recovered as either sulfuric acid through a wet sulfuric acid (WSA) process or elemental sulfur through a Claus process. In the case of $\mathrm{CO}_{2}$ removal, secondary absorberstripper configuration is required in which the solvent absorbs the $\mathrm{CO}_{2}$ and is regenerated in another tower. The captured $\mathrm{CO}_{2}$ can then be compressed and transported to a sequestration location. The Selexol solvent is highly selective towards absorbing $\mathrm{H}_{2} \mathrm{~S}$ and is particularly suited to high pressure operation (> 300 psia) as it becomes more efficient as the pressure increases [30]. This makes it particularly good for pressurized gasification systems. The Selexol process is capable of producing a syngas with $<1 \mathrm{ppmv}$ [31]. The system operates at approximately $60^{\circ} \mathrm{C}$ making this a low point in the thermal integration of the gas cleanup system. 


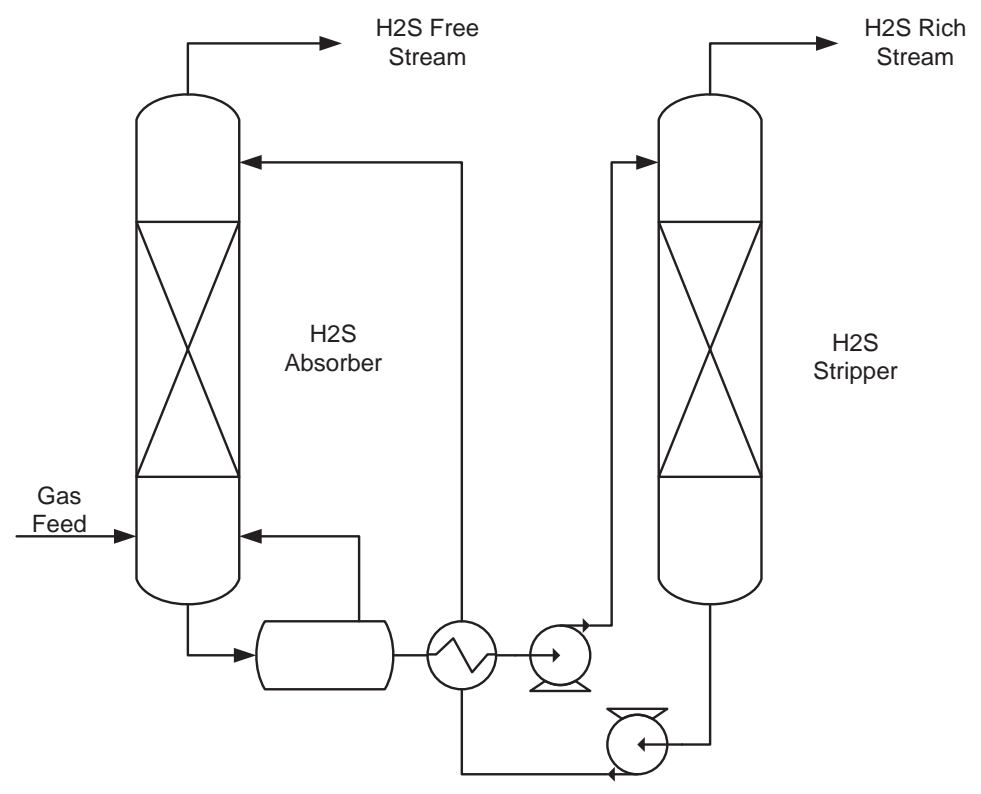

Figure 5. Selexol Process

\subsubsection{Rectisol Process}

The Rectisol process is another acid gas removal system very similar to the Selexol process. It is the one of the most widely used processes with more than 100 plants installed worldwide. Rather than employing a complex proprietary solvent, the Rectisol process uses refrigerated methanol. Methanol is very inexpensive and when chilled $\left(-40^{\circ} \mathrm{C}\right)$ has a very high selectivity for $\mathrm{H}_{2} \mathrm{~S}$ over $\mathrm{CO}_{2}$. This allows for very deep sulfur removal $\left(<0.1 \mathrm{ppmv} \mathrm{H}_{2} \mathrm{~S}\right.$.) The process is similar to Selexol, except that after being regenerated the methanol must be chilled again to ensure sufficient selectivity, Figure 6. This makes the process more energy-intensive than the Selexol process.

The Rectisol process can produce a highly concentrated $\mathrm{H}_{2} \mathrm{~S}$ stream which can then be processed to recover the sulfur via a Claus or WSA process. Also, with the addition of $\mathrm{CO}_{2}$ absorbingstripping towers a high purity $\mathrm{CO}_{2}$ stream can be produced. From a cost perspective the complex nature of the process hardware as well as the energy required to refrigerate the methanol to the $40^{\circ} \mathrm{C}$ to $-80^{\circ} \mathrm{C}$, make this one of the more effective but expensive gas cleanup options [32]. It is typically used in situation where the syngas will later be processed through catalytic reactors that require a high-purity syngas to prevent catalyst poisoning. 


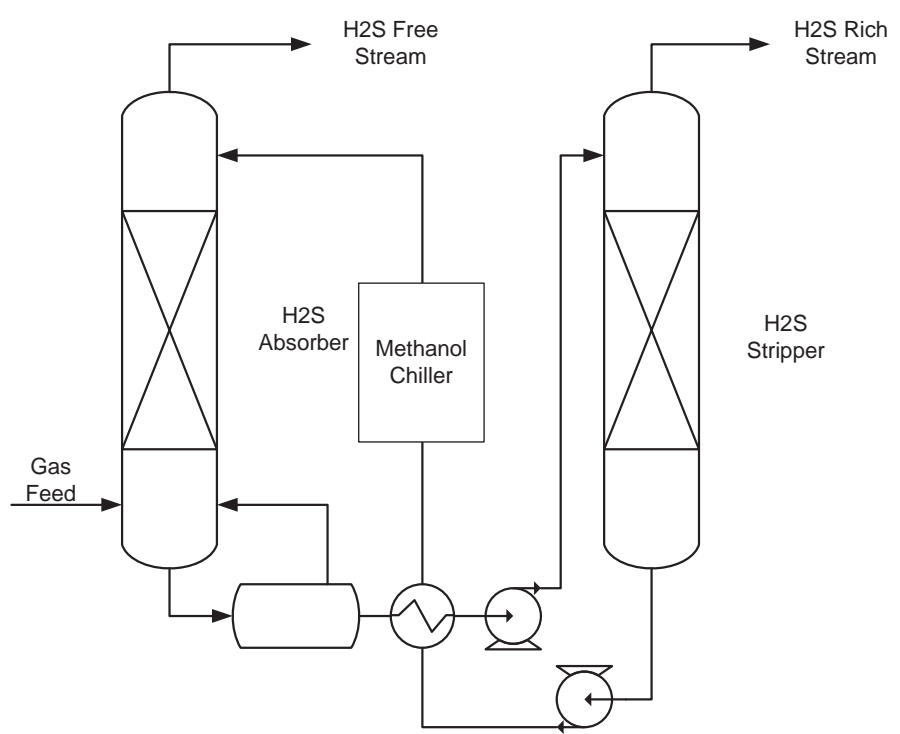

Figure 6. Rectisol Process Diagram

\subsubsection{LO-CAT Process}

The LO-CAT process is owned by Merichem Company. It uses a liquid chelated iron catalyst that is non-toxic and regenerable, which provides for a low operating cost and no environmental concerns. The liquid catalyst is circulated through an absorber tower where the $\mathrm{H}_{2} \mathrm{~S}$ from the syngas absorbs into the catalyst solution. The $\mathrm{H}_{2} \mathrm{~S}$ is oxidized to solid sulfur state by reducing the iron ion in the catalyst from a ferric to a ferrous state. In this solid state the sulfur precipitates and can be recovered for later processing. The catalyst solution is then circulated out of the absorber tower into an oxidizing tank where it is exposed to atmospheric oxygen. The iron ion is once again re-oxidized to the ferric ion and can be recycled to the absorbing tower [33] as shown in Figure 7.

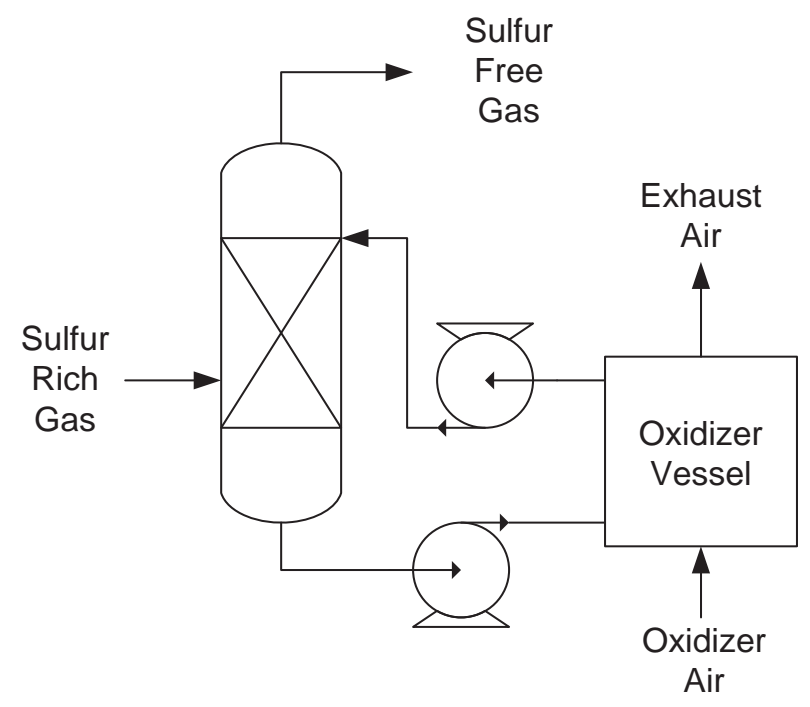

Figure 7. LO-CAT Process Diagram 
The LO-CAT process operates at approximately $60^{\circ} \mathrm{C}$ which typically requires significant cooling in gasification systems prior to being admitted into the absorber tower. Typically the LO-CAT process is capable of removing $\mathrm{H}_{2} \mathrm{~S}$ down to a concentration of about $10 \mathrm{ppmv}$ [34].

\subsubsection{Zinc Oxide Polishing Bed}

Zinc oxide-based sulfur removal systems are one of the simplest technologies. They consist of a packed bed reactor filled with the $\mathrm{ZnO}$ sorbent. $\mathrm{H}_{2} \mathrm{~S}$ in the feed gas stream reacts with the $\mathrm{ZnO}$ according to equation 1 .

$$
\mathrm{ZnO}+\mathrm{H}_{2} \mathrm{~S} \rightarrow \mathrm{ZnS}+\mathrm{H}_{2} \mathrm{O}
$$

In non-regenerable systems $\mathrm{ZnO}$ sorbents are only employed as a primary sulfur removal step when the sulfur levels in the inlet gas are relatively low $<20$ ppmv. In gases with concentrations $>20$ ppmv the sorbent saturates very quickly increasing the frequency at which the bed material must be replaced. In these conditions another primary method is typically used and the $\mathrm{ZnO}$ sorbent bed is employed as a polishing step. $\mathrm{ZnO}$ sorbent beds are very effective at sulfur removal; final gas concentrations in the ppb range have been reported [34]. ZnO sorbent beds must be operated at temperatures $>350^{\circ} \mathrm{C}$ which can be a energy intensive process when placed after other primary sulfur removal methods that operate at much lower temperatures.

\subsubsection{Regenerable ZnO - Warm Gas Desulfurization}

Another Zinc-based bulk $\mathrm{H}_{2} \mathrm{~S}$ removal process is warm gas desulfurization (WGDS) which operate at significantly higher temperature than Selexol or LO-CAT processes. These processes also reduce $\mathrm{HCl}$ and thus, serve as a chloride removal step. If sulfur can be removed without significant cooling, overall plant efficiencies are improved for both fuel synthesis and power production pathways.

Significant research is currently being done to produce a commercial WGDS process and the RTI transport desulfurization technology appears to be furthest along with demonstrations at pilot plant scale [35]. According to Cicero et al. [28], the majority of the sulfur sorbents are zinc oxide-based because of their favorable thermodynamics, kinetics, and good stability under reducing and oxidizing conditions. RTI WGDS technology is based on a fluidized bed absorber (reactor)/re-generator system. The absorber reactor catalyst is unknown, but is ZnO-based and may involve zinc-titanate as it is one of the most likely candidates for WGDS, although many other options are being explored [36]. Representative sulfur adsorption and desorption reactions are shown in Eqs. 4-2 and 4-3.

$$
\begin{aligned}
& \mathrm{ZnO}+\mathrm{H}_{2} \mathrm{~S} \rightarrow \mathrm{ZnS}+\mathrm{H}_{2} \mathrm{O} \\
& \mathrm{ZnS}+\frac{3}{2} \mathrm{O}_{2} \rightarrow \mathrm{ZnO}+\mathrm{SO}_{2}
\end{aligned}
$$


The reactor is basically a fluidized-bed reactor (FBR) paired with a regenerating column. Gas enters the FBR and is mixed with the catalyst in the fluidized bed. Sulfur is adsorbed by the catalyst via the reactions previously mentioned, and the clean syngas is exhausted out of the top of the column. During the circulation of the bed material, a portion is drawn off to the regenerating tower. Here, the catalyst is heated and combined with oxygen from air to reform the $\mathrm{ZnO}$ and release the sulfur as seen in Eq. (4-3). The regenerated catalyst is then recycled to the adsorbing reactor to begin the cycle again (Figure 8).

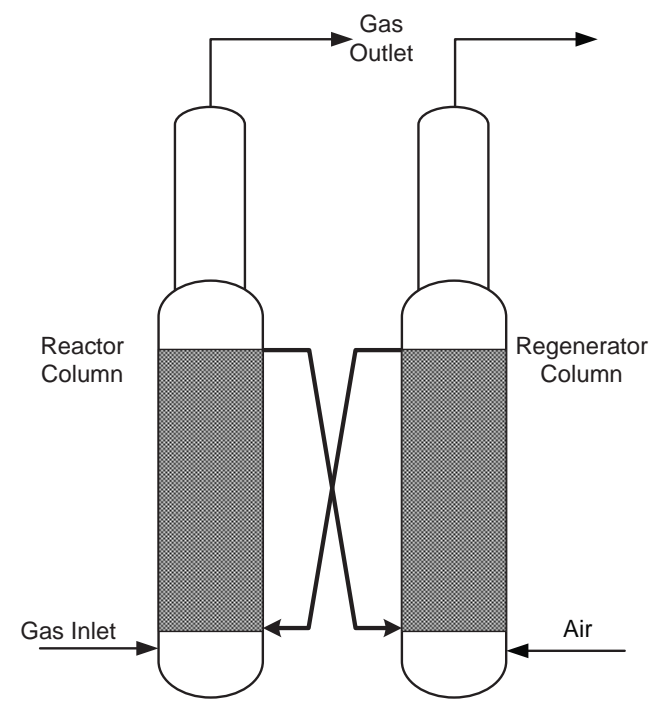

Figure 8. WGDS Process Diagram

Inlet temperatures of $350-650^{\circ} \mathrm{C}$ have been reported in literature, which is a drastic improvement over the $60^{\circ} \mathrm{C}$ possible with LO-CAT or Selexol [37] Since both reactions are exothermic, outlet temperatures from the reactor are higher than inlet temperatures and dependent on the amount of hydrogen sulfide in the syngas. Representative values would be syngas inlet temperatures of 425$500^{\circ} \mathrm{C}$ and a catalyst regenerator temperature of $600-650^{\circ} \mathrm{C}$ [38]. While outlet concentrations of less than 1 ppmv have been reported [26], concentrations of 10-20 ppmv are more likely [35, 39] and $\mathrm{HCl}$ concentrations down to 50 ppbw [35].

To recover elemental sulfur from the catalyst regenerator tail gas a direct sulfur removal process (DSRP) would be needed. In a DSRP the $\mathrm{SO}_{2}$ is converted to elemental sulfur by the reaction shown in Eq 4-4. A slipstream of clean syngas could be used to provide the required hydrogen, or product could be recycled [35].

$$
\mathrm{SO}_{2}+3 \mathrm{H}_{2} \rightarrow \mathrm{H}_{2} \mathrm{~S}+\mathrm{H}_{2} \mathrm{O}
$$

The ongoing developmental challenges for WGDS are soot formation, carbon deposition and catalyst degradation. Initial designs may favor oxygen blown gasification systems because syngas with high concentrations of $\mathrm{CO}$ seem to reduce soot formation and carbon deposition [39]. 


\subsection{SOFC Model Development and Benchmarking}

Benchmarking of a DOE NETL 'in-house' ASPEN Plus model was performed to ensure the integrity of the model for future IGFC simulations in the ASPEN Plus software environment. This effort is relevant for Focus Area (2). The benchmarking effort compares the NETL model with separate higher fidelity models by the project co-PIs, R.J. Braun and R.J. Kee. A brief comparative summary is given in Figure 9(a) and (b). The Braun model is representative of a 1dimensional model of a planar anode-supported SOFC with reactants in a co-flow arrangement. The Kee and Zhu model is of even higher fidelity using multi-dimensional fundamental physicsbased models for gaseous transport through porous media coupled with detailed heterogeneous chemistry and electrochemistry. The Kee and Zhu model results shown assume an isothermal cell in order to save on computational time. Models were compared with one another using the same inlet conditions and trying to match fuel utilization and overall cell power density. The results indicate that assuming an overall cell temperature based on averaging inlet and outlet cathode gas temperatures is not necessarily representative. It is observed that the NETL model slightly over-predicts the number of cells required to deliver a specific power output.

\begin{tabular}{|c|c|c|c|}
\hline & NETL & Braun & Zhu \\
\hline T_cell $\left({ }^{\circ} \mathrm{C}\right)$ & 725 & 800 & 725 \\
\hline Vcell $(V)$ & 0.772 & 0.769 & 0.75 \\
\hline Power density $(\mathrm{W} / \mathrm{cm} 2)$ & 0.193 & 0.192 & 0.194 \\
\hline ASR (ohm-cm2) & 0.322 & 0.334 & \\
\hline Ncells & 1212067 & 1161498 & 1169811 \\
\hline Fuel Utilization & 0.8 & 0.8 & 0.793 \\
\hline per cell anode inlet flow $(\mathrm{kg} / \mathrm{h})$ & 0.2758 & 0.2757 & 0.2757 \\
\hline per cell cathode inlet flow $(\mathrm{kg} / \mathrm{h})$ & 0.5787 & 0.5828 & 0.5828 \\
\hline \multicolumn{4}{|l|}{ Anode outlet composition } \\
\hline (2) & 0.0157 & 0.01558 & 0.019153 \\
\hline $\mathrm{co}$ & 0.024 & 0.02374 & 0.018361 \\
\hline $\mathrm{CO} 2$ & 0.5785 & 0.5788 & 0.584880 \\
\hline $\mathrm{H} 2 \mathrm{O}$ & 0.3486 & 0.3486 & 0.343531 \\
\hline $\mathrm{N} 2$ & 0.0332 & 0.03318 & 0.033165 \\
\hline
\end{tabular}

(a.)

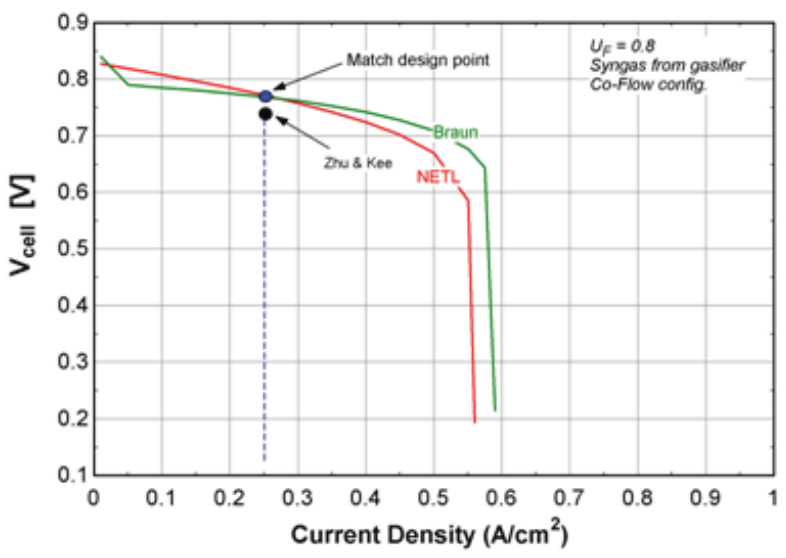

(b.)

Figure 9. SOFC Model Benchmark results

\subsection{Technology Readiness Level}

Coal gasification and fuel cell systems represent a mix of conventional and emerging technologies. In order to facilitate our understanding of technology status, a technology readiness level (TRL) assessment has been made by modifying the DoD/NASA TRL guidelines to be consistent with stationary energy applications. It is possible that catalytic gasifier technology or the commingling of biomass with coal in entrained flow gasifiers may produce tars in the raw syngas. Thus, tar cracking and water-gas shift (WGS) processes are also of interest in this modeling study. Figure 10 summarizes the TRL assessment for the above mentioned syngas cleanup technologies on a scale of 1 to 9, where for example, a TRL of 9 indicates a fully commercial technology with units in the field; TRLs of 4-6 indicate subsystem/component testing in laboratory environment; and TRLs of 1-3 range from concept studies to sub-scale 
proof-of-concept experiments. The RTI warm gas desulfurization technology appears to have advanced to a TRL of 6-7 with pilot scale demonstrations, where tar cracking can be as low as a TRL of 4. WGS is a fully commercial technology, and is inclusive of a sulfur-tolerant catalyst for sour shift applications.
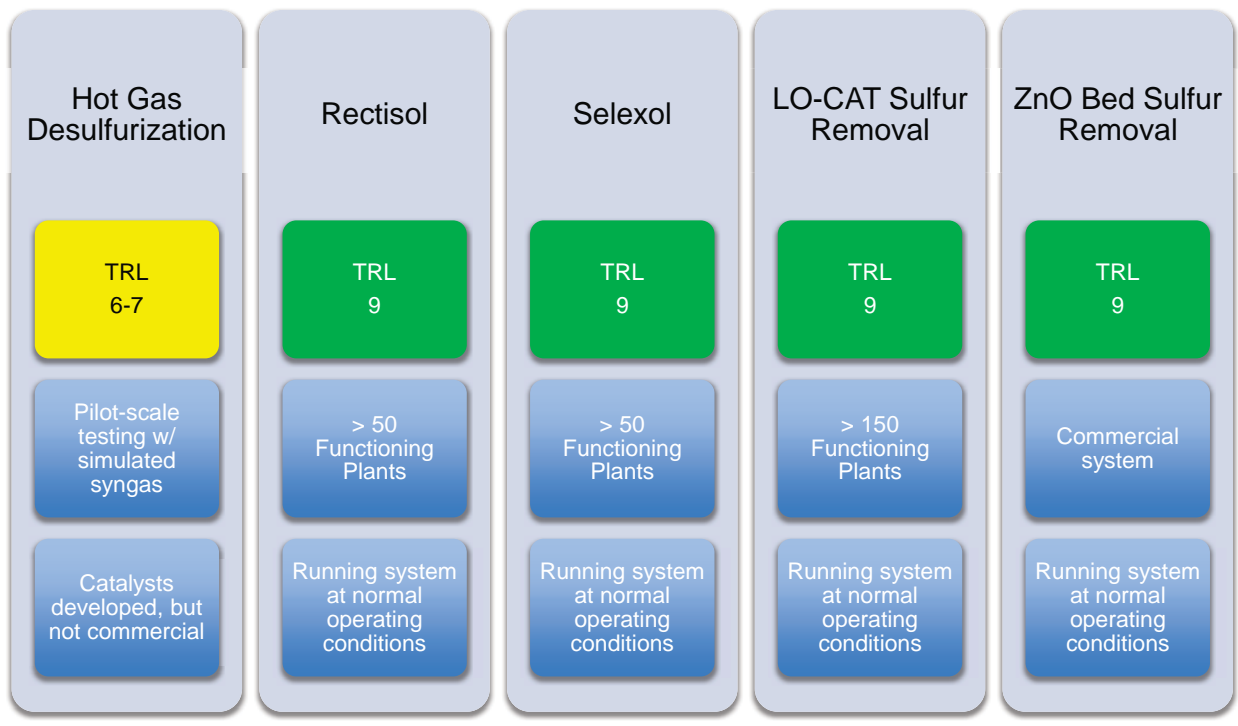

(a) Desulfurization technologies
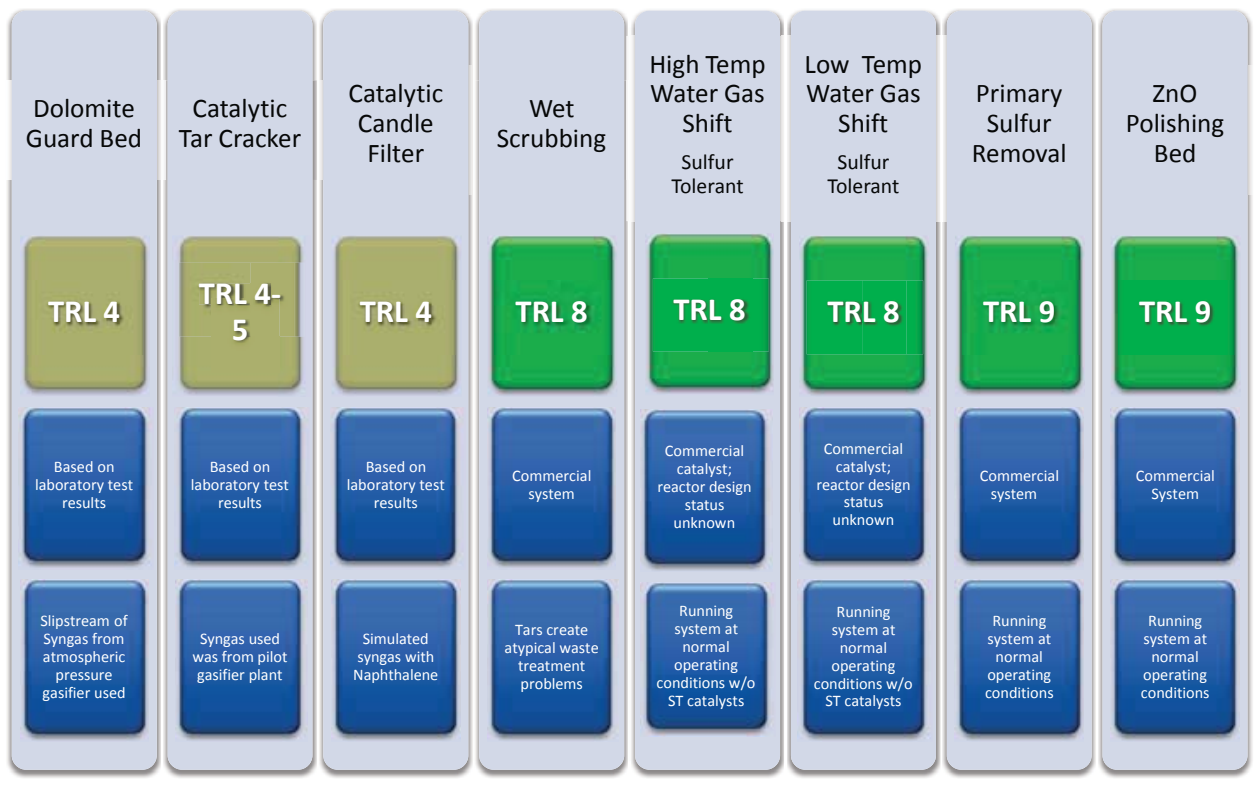

(b) Other gas cleanup technologies

Figure 10. Technology Readiness Level Assessment of Syngas Cleanup 


\section{Results and Analysis}

The following results are broken down into those associated with Focus Area (1) and (2). Focus Area (1) examines the expected performance of an IGFC power plant when the SOFC power section is integrated with modified and/or scaled-up commercial gas turbine and ORC power generation technology. The results presented here are directly taken from a technical publication by the co-PI in the ASME Journal of Gas Turbines and Power ${ }^{2}$. Focus Area (2) centers on evaluating differing carbon capture integration strategies with emerging membrane reactors on thermodynamic and economic performance bases. A draft journal paper has been produced from these results and shall be submitted.

\subsection{Focus Area (1): Employing Existing Technology to Achieve Highly-Efficient IGFC Systems with Optional Carbon Capture ${ }^{2}$}

Integrated coal-gasification fuel cell power plant concepts have been investigated using modeling and simulation. The plant concepts evaluated feature entrained-flow, oxygen-blown slagging gasifiers integrated with planar SOFC technology, Pratt \& Whitney gas turbines, carbon capture via oxy-combustion of the anode tail-gas, and waste heat recovery through organic Rankine cycle systems. Physics-based component models and diagnostic tools previously developed at UTC facilitate fast prototyping of innovative fuel cell, turbine, and combined heat and power system configurations. The current system-level models have been generated employing zero-dimensional thermodynamic component models.

Table 3. Parameters for system-level sensitivity study

\begin{tabular}{||l|c||}
\hline \multicolumn{1}{|c|}{ Parameter } & Range \\
\hline System operating pressure & $3-5$ bar \\
\hline $\begin{array}{l}\text { Nominal SOFC operating } \\
\text { temperature }\end{array}$ & $775^{\circ} \mathrm{C}$ (Fixed) \\
\hline $\begin{array}{l}\text { Allowable cathode air temperature } \\
\text { rise }\end{array}$ & $75-150^{\circ} \mathrm{C}$ \\
\hline SOFC cathode pressure drop & $2-10 \mathrm{kPa}$ \\
\hline SOFC fuel utilization & $66-86 \%$ \\
\hline SOFC average single cell voltage & $0.68-0.79$ \\
& $\mathrm{~V} / \mathrm{cell}$ \\
\hline
\end{tabular}

A viable system configuration was first established and sizing of the SOFC power block was derived from matching of reactant flows to the P\&W FT8 gas turbine requirements. Design parameters were then varied to gauge performance sensitivity. Key parameters and the ranges

\footnotetext{
${ }^{2}$ R.J. Braun, S. Kameswaran, J. Yamanis, and E. Sun, "Highly Efficient IGFC Hybrid Power Systems Employing Bottoming Organic Rankine Cycles With Optional Carbon Capture," ASME J. Gas Turbines and Power, accepted for publication, (2011).
} 
explored are summarized in Table 3. Bounds for the range were constrained by hardware performance characteristics, such as maximum SOFC outlet temperature, or flow and compressor pressure ratios for the gas turbine spool.

\subsubsection{Technologies}

System technologies employed in the integrated gasification fuel cell power plant concept designs are briefly described below.

\subsubsection{Coal Gasifier}

The gasifier employed in the IGFC system analysis is a dry-fed oxygen-blown, entrained-flow slagging gasifier representative of Shell gasifier technology. It was assumed that the cold-gas gasifier efficiency (defined as LHV syngas out over LHV coal feed in) was $82 \%$ [40]. In this study, the focus was on effective integration of the prime movers, and thus gasifier and syngas cleanup sub-systems were not integrated with the SOFC-combined cycle power block. All steam generation needs for the gasifier and gas cleanup unit operations are generated by syngas process cooling needs, which can exceed the thermal energy required for steam generation by as much as $250 \%$. Thus, while such integration considerations are not a focus of the current study, auxiliary power requirements in the gasifier and cleanup operations could easily be met with expanders or larger ORC capacity. The excess process heat that is available could be employed to drive an ORC or SRC system and produce additional power thereby, increasing system efficiency. The potential reduction in system efficiency is estimated ${ }^{3}$ at 1-2 percentage points from lack of tight thermal integration with power block and syngas production and cleanup unit operations, making the performance predictions given in the forthcoming sections more conservative.

\subsubsection{SOFC Technology}

The solid oxide fuel cell stack is based on planar cell technology that achieves performance levels consistent with DOE SECA performance targets, such as power density and cathode temperature rise. The 'high performance' cell technology is based on a porous nickel-zirconium oxide anode supported thin $(\sim 10 \mu \mathrm{m})$ zirconium oxide electrolyte and a porous strontium-doped lanthanum cobalt ferrite (LSCF) cathode electrode. The cell and the balance-of-stack components are optimized for 40,000 hour durability. The stack power section is assumed to operate at low $(3 \mathrm{kPa})$ pressure drops on both the anode and cathode gas streams in order to minimize parasitic power loss. The stack design and the stack arrangement for MW-scale power plants can be tailored to operate under near ambient ( 1.0 bar) or elevated pressures ( $\sim$ bar). The anode-supported SOFC technology employed in this study typically operates in the 750 $775^{\circ} \mathrm{C}$ range with a maximum cathode outlet temperature of $850^{\circ} \mathrm{C}$, and with a cell power density of $0.45 \mathrm{~W} / \mathrm{cm}^{2}$ on syngas.

\footnotetext{
${ }^{3}$ The estimation is made by taking the $250 \%$ excess process thermal energy and generating power through either ORC or SRC power cycles at the efficiencies employed in this analysis.
} 


\subsubsection{Gas Turbine}

The gas turbine technology utilized in this study is based on the Pratt \& Whitney FT8 Twin PAC $50 \mathrm{MW}$ power system. It is comprised of two-single $25 \mathrm{MW}, 37 \%$-LHV efficiency (on natural gas) systems coupled to a single generator. The FT8 POWERPAC single-engine $25 \mathrm{MW}$ gas turbine from Pratt \& Whitney Power Systems is a 3,600-rpm machine employed for $60 \mathrm{~Hz}$ electric power generation and has demonstrated operation in combined cycle (GT/steam Rankine cycle).

Figure 11 shows a simplified schematic of a $\mathrm{P} \& \mathrm{~W}$ aeroderivative gas turbine power generator. The engine is mainly comprised of a low-pressure compressor, high-pressure spool (compressor, turbine, and shaft), low-pressure turbine, power turbine, and synchronous $60 \mathrm{~Hz}$ generator. The low-pressure compressor typically develops a pressure ratio of 4.5, but can go as high as 5.2 bar. The high-pressure spool employs a concentric shaft and includes high-pressure compressor, diffuser, combustor, and high-pressure turbine components. The high-pressure spool operates at a speed greater than the low-pressure spool and the operating pressure of the combustor is typically on the order of 18-19 bar. As the SOFC design operating pressure is 5 bar, removal of the high-pressure spool of turbine when integrating with the SOFC is required. One of the challenges in matching a gas turbine power generator with an IG-SOFC topping plant is in the potential flow mismatch between compressor and expander due to the use of the low-calorific coal syngas in the system. When the SOFC capacity is selected to match the design flowrate and pressure ratio (PR) of the low-pressure compressor (LPC) section of the FT8 gas turbine product line, the mass flow delivered to the low-pressure turbine (LPT) section is too large for the unit. Another challenge is that since the high-pressure spool has been removed, the required inlet pressure to the low-pressure turbine is 2 bar higher than the outlet pressure available from the low-pressure compressor. Thus, removal of the high pressure spool presents an off-design aerodynamic inlet condition, even in cases where the compressor and turbine flowrates are properly matched. If the mismatch in either flow and pressure ratio are large enough, significant speed differences between turbine and compressor may exist which then necessitate the addition of a gearbox or other workaround solution. Matching the SOFC exhaust gas flow to the maximum LPT flow capacity was considered to be the best approach as it avoided the need to vent compressor air flow to the surroundings, while the off-design flow delivered to the LP compressor still enabled a high-efficiency operating point to be achieved. 


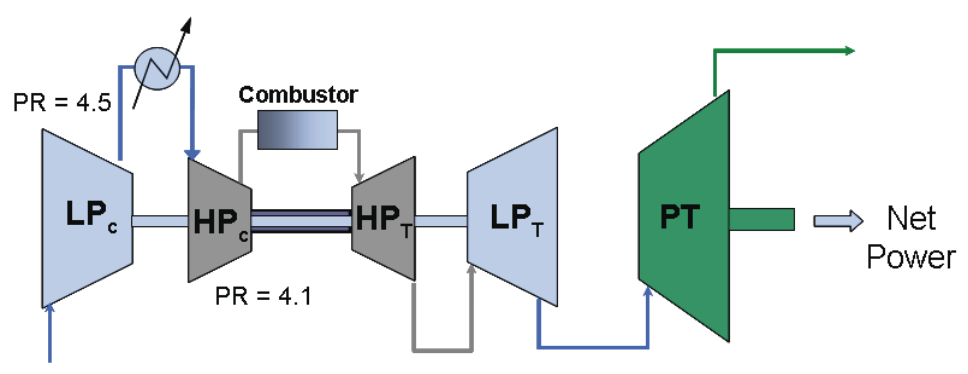

Figure 11. Simplified schematic diagram of PW FT8-series gas turbine power generator

A high-level engineering design change analysis was carried out by $\mathrm{P} \& \mathrm{~W}$ to assess both the number and magnitude of changes required to modify an FT8-3 generator for integration with a pressurized IG-SOFC power plant. Removal of the high-pressure spool necessitates consideration of lubrication systems, secondary air systems management (bleed streams), exhaust and inlet volute designs, engine rotor dynamics, and engine gearbox/startup modifications. Overall, changes to the existing FT8-3 engine design are considered to be significantly simpler and more cost-effective than either making design changes to a different product line or to beginning a new turbine development program. Additionally, FT8 design changes are estimated to result in a $40 \%$ reduction in capital cost on the engine itself and a 10$15 \%$ overall capital cost reduction of the gas generator when considering the supporting hardware, sub-system, and parts count reduction. Other synergies, such as a reduction in turbine maintenance and an increase in engine life, are also anticipated due to the design changes outlined above.

\subsubsection{Organic Rankine Cycle}

The ORC technology to be integrated at the utility-scale is based on modular designs that do not have a strong pressure-flow coupling with the topping systems (i.e., syngas production, SOFC, and GT) due to thermal integration via indirect transfer heat exchangers. ORCs are similar to steam Rankine cycle systems in that they consist of turbine, condenser (air-cooled or watercooled), pump, and evaporator components, yet they differ in the type of working fluid employed, which is usually an organic fluid such as a refrigerant whose specific type depends on the temperature of the heat source. The selection of an ORC system (versus a steam power cycle) is generally driven by the better match of power capacity and turbine design with lowtemperature heat sources. While ORC power systems demonstrate lower efficiency than steam cycles, they may offer economic benefits that offset their performance disadvantage. ORC systems are typically modular, closed systems with flanged connections. The economic merit of an ORC power system is primarily associated with its comparatively lower installation and operating costs than the more conventional steam Rankine cycle system. Lower operating costs for ORCs are in part due to the packaged nature of the system, their capability for remote unattended operation, and the lack of water treatment systems typically required for steam Rankine cycles. Ultimately, a detailed plant economic analysis is required to properly assess the 
net benefits of ORC technology at this scale, but such an effort is outside the scope of this work. Importantly, one aspect of this study is to simply quantify the performance potential of ORC integrated IGFC systems and compare them with a more conventional steam Rankine cycle configuration.

ORC technology can be scaled in capacity to match the waste heat exhaust from the SOFC and SOFC-GT subsystems. Two ORC technologies are examined in this study: (1) a scaled-up version of the $200 \mathrm{~kW}$ water-cooled, UTC PureCycle ${ }^{\mathrm{TM}}$ ORC product line and (2) the P\&W Turboden HRS (high-electric efficiency units) product. PureCycle power scale-up is based on both increasing the size $(>10 \mathrm{X})$ of an individual unit and combining units in parallel. The PureCycle system achieves a thermal efficiency of $14 \%$ from lower-temperature $\left(<150^{\circ} \mathrm{C}\right)$ heat sources and is based on an off-the-shelf Carrier compressor and the Carrier 19XR5 chiller. The turbine is combined with a high speed permanent magnet (PM) or traditional synchronous generator to convert the mechanical energy into electric energy. A high speed PM generator requires an ac/ac power electronic converter to connect to the $60 \mathrm{~Hz}$ electric grid. Heat rejection is accomplished with a cooling tower fed by the circulating water system. The efficiency of the water-cooled ORC system can be improved to $20 \%$-LHV with a system design currently being targeted for development at UTC. The extent of the development for such a system to be integrated within the current IG-SOFC power plant concept requires heat exchanger redesign, optimal refrigerant selection, and expander impeller changes. In comparison, the Turboden HRS system can operate from heat sources as high as $500^{\circ} \mathrm{C}$ and achieves net electric efficiencies exceeding $23 \%$ (LHV) for commercial systems in the $2.2 \mathrm{MW}$ power range [41]. Power modules from Turboden are available up to $7 \mathrm{MW}$, thus 3 modules are envisioned for the present study. Both P\&W PureCycle and Turboden systems are included the analysis, although the efficiency advantage of the Turboden is clear.

\subsubsection{Modeling Approach}

The component modeling effort draws upon the large library of fuel cell and combined heat and power (CHP) proprietary models developed by the United Technologies Research Center (UTRC) and its sister division, UTC Power. This library has been developed using the commercially available general PROcess Modelling System (gPROMS) software. gPROMS is an equation-oriented modeling system typically used within the process industry for building, validating, and executing first-principle models within a flowsheeting framework [42]. The software employs user-specified ODE and DAE simultaneous equation solvers to enable process modeling, simulation, parameter estimation, and optimization. gPROMS can be employed for either dynamic or steady-state modeling efforts. Steady-state modeling and simulation has been performed in this study.

\subsubsection{Gasifier and Syngas Cleanup}

Gasifier and syngas cleanup are not explicitly modeled but simply serve as boundary conditions to the system study. Gasifier and cleanup efficiency are assumed to be $82 \%$ from coal feed inlet to clean syngas outlet (see). Syngas composition entering the power block is approximated as 
$61 \% \mathrm{CO}, 33.7 \% \mathrm{H}_{2}, 2 \% \mathrm{CO}_{2}, 0.3 \% \mathrm{H}_{2} \mathrm{O}, 2.0 \% \mathrm{~N}_{2}$, and $1 \% \mathrm{Ar}$ on a molar basis with sub-ppmv levels of $\mathrm{H}_{2} \mathrm{~S}, \mathrm{COS}$, mercury, ammonia, and chlorides. This composition is consistent with Shell gasifier technology operating near $1375^{\circ} \mathrm{C}$ and 40 bar with molar feed ratios such that $\mathrm{O} / \mathrm{C}$ $+\mathrm{H}_{2} \mathrm{O} / \mathrm{C}=1.0[40,43]$. The oxy-combustor requires a pure $\mathrm{O}_{2}$ stream that is supplied by the ASU at a marginal electrical energy cost of $0.285 \mathrm{kWh} / \mathrm{kg} \mathrm{O}_{2}$ as estimated from the literature $[44,45,46,47]$.

Catalytic gasification technology is the focus of several DOE-sponsored IGFC studies [e.g., 21] as it can generate methane molar concentrations as high as $20 \%$ in the syngas which provides enhanced thermal management for the SOFC stack due to internal reforming. However, given the sparse performance and operating information for catalytic gasification, the more proven Shell gasifier technology was selected for these initial integration studies.

\subsubsection{SOFC System Modeling}

The SOFC stack model is based on a lumped, single-node thermodynamic representation that accounts for internal reforming and water-gas shift equilibrium, electrochemical polarizations and the associated heat generation, mass transfer via cell reactions, and overall energy balances within a single-cell repeat unit. Reactant gas supply is assumed to be uniformly distributed among the cells within the cell-stack and among the channels within each repeat unit. Thus, single-cell performance is extrapolated to produce SOFC stack performance. This representation can be readily constructed as quantities such as stack voltage and stack power are scaled versions of single-cell voltage and power. Thus, a single-cell model forms the heart of stack system model. A co-flow reactant gas configuration is envisioned for the SOFC stack as little to no methane is present in the coal syngas and thus, internal reforming is not active with the anode compartment.

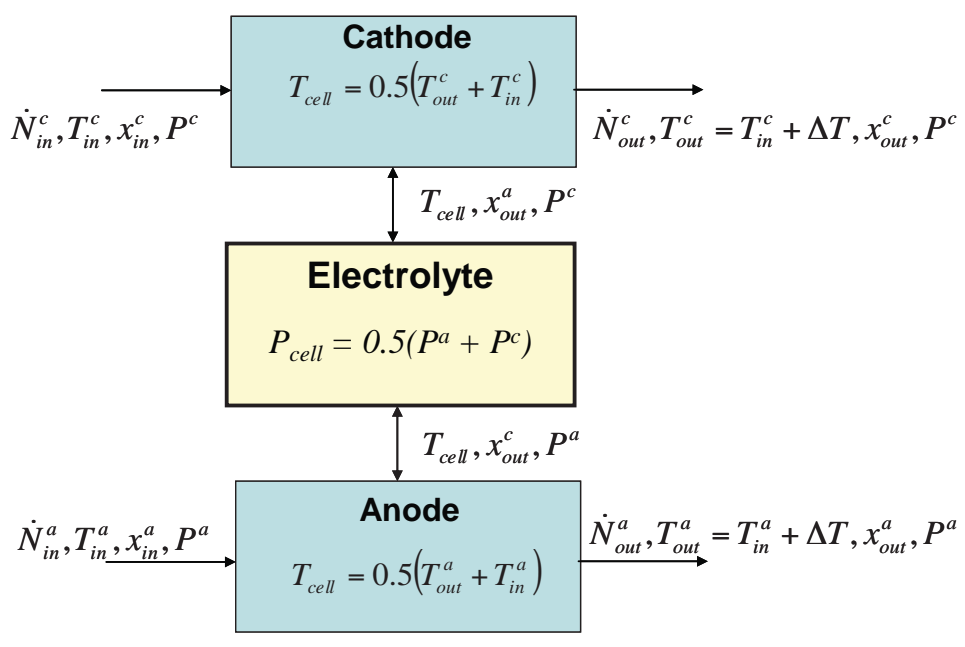

Figure 12. SOFC Stack Model Overview

Figure 12 depicts the architecture of a single-cell model where $\Delta \mathrm{T}$ is typically specified, and $T_{\text {cell }}$ and $P_{c e l l}$ are the temperature and pressure at which all of the electrochemistry functions are 
evaluated. The model is comprised of three compartments - the anode, the cathode, and the electrolyte. Mass balances are written individually for the anode and the cathode compartments taking into account that the consumption of $\mathrm{H}_{2}$ in the anode and $\mathrm{O}_{2}$ in the cathode is governed by Faraday's law and is proportional to the current density. As given in the figure, $\dot{N}_{i}$ is the molar flow of species $i, x_{i}$ is the molar fraction of species $i, T$ is temperature, $\Delta T$ is temperature rise, and superscripts ' $a$ ' and ' $c$ ' refer to anode and cathode compartments, respectively. It is assumed that hydrocarbons and carbon monoxide are not electrochemically active but are consumed rather through reforming and water-gas shift (WGS) reactions. For coal syngases, $\mathrm{H}_{2}$ and $\mathrm{CO}$ dominate the anode feed gas composition and thus, the $\mathrm{CO}$ is shifted via WGS reactions to $\mathrm{CO}_{2}$ and the produced $\mathrm{H}_{2}$ then is the only participant in electrochemical oxidation at the triplephase boundary. It is assumed that the WGS and reforming reactions are at equilibrium in the anode. Provision is made in the mass balance equations to account for compounds consumed/produced due to the WGS, reforming, and electrochemical reactions. Quantities such as fuel utilization and $\mathrm{O}_{2}$-stoichiometry are calculated from the mass-balance equation framework.

An overall system energy balance is implemented as a part of the model. The total enthalpy-flow into the system has two components: the anode inlet flow and the cathode inlet flow. Similarly, the enthalpy-flow out of the system has the anode outlet and cathode outlet flow components. The lumped system produces power and rejects thermal energy to both the surroundings and the cathode cooling air stream.

The electrochemistry equations that describe the electrolyte compartment in the model are shown below:

$$
\begin{aligned}
& V_{\text {ref }}=-\frac{\Delta G}{2 F}+\frac{R T_{\text {cell }}}{2 F} \ln \left(\frac{P_{H 2}}{P_{H 2 O}} \sqrt{P_{O 2}(\text { bars })}\right) \\
& R_{\text {ohm }}=\frac{L_{E} T_{\text {cell }}}{A_{\text {ohm }}} \exp \left(\frac{E_{\text {act-ohm }}}{R T_{\text {cell }}}\right) \\
& V_{\text {act }}=\frac{R T}{2 F} \sinh ^{-1}\left(\frac{J}{A_{\text {act }}} \exp \left(\frac{E_{\text {act }}}{R T_{\text {cell }}}\right)\right) \\
& V=V_{\text {ref }}-R_{\text {ohm }} J-V_{\text {act }}
\end{aligned}
$$

where, $V_{\text {ref }}$ is the open circuit voltage, $R_{o h m}$ is the ohmic resistance (primarily due to electrolyte), $L_{E}$ is the electrolyte thickness, $V_{a c t}$ represents the activation losses, $V$ is the cell voltage, $J$ is the current density, $T_{\text {cell }}$ is the temperature of the cell, and $P_{\mathrm{H} 2}, P_{\mathrm{H} 2 \mathrm{O}}$ and $P_{\mathrm{O} 2}$ are the partial pressures of hydrogen, water and oxygen, respectively, taken at the tail-gas outlet. All other quantities in Eqs. (5-1)-(5-4) are model parameters that were initially tuned to be representative of near-term 
anode-supported planar SOFC technology [48]. These other model parameters include $A_{a c t}$, a charge transfer coefficient parameter and activation energies $\left(E_{\text {act-ohm }}\right.$ and $\left.E_{\text {act }}\right)$. Cell power density was increased by V-I slope adjustment to obtain performance that was consistent with SECA targets of $0.45 \mathrm{~W} / \mathrm{cm}^{2}$ on syngas. Concentration polarization is neglected in this model as (i) the electrochemical model with the parameters given above provided sufficient fidelity to reproduce V-I curves from developers data, and (ii) the voltage-current response is dominated by the transfer of electrons through the cell trilayer and across the material interfaces at low- and mid-range current densities of anode-supported SOFCs [49]. The cell operating conditions in the following analyses are far away from the high current region that is dominated by diffusion limitations in the porous anode. The resulting model-generated single-cell $\mathrm{V}$-j (voltage-current density) curve is depicted in Figure 13.

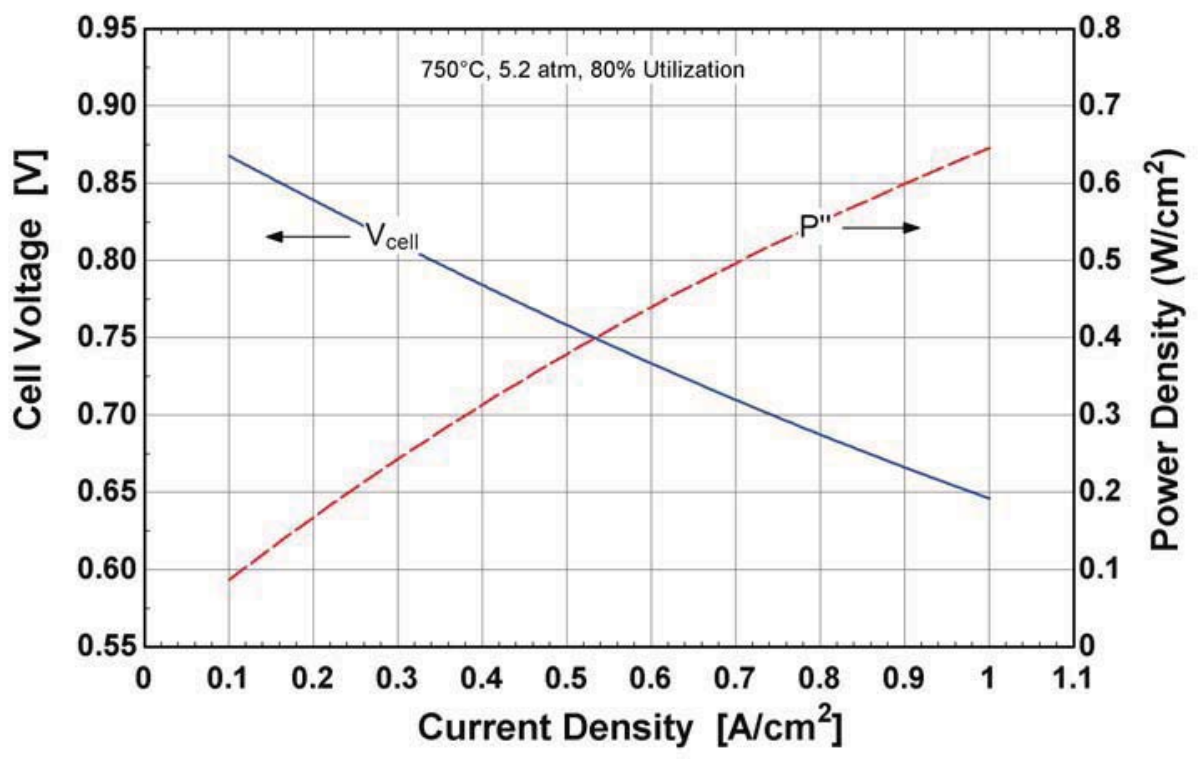

Figure 13. SOFC V-j Model Performance Characteristic

\subsubsection{Gas Turbine Modeling}

An integral part of the system component models are the performance maps for the P\&W FT8-3 gas turbine. Conventional turbine and compressor performance maps typically involve speed as one of the inputs, and the outputs include quantities such as pressure ratio and efficiency. As speed is more of a design variable and is not of interest as far as system studies are concerned, the functional input/output format of the performance map was reversed. The LPC inputs consist of the mass flow through a compressor, and the pressure ratio (PR) associated with the compressor. The conditions for the inlet air are fixed at $15^{\circ} \mathrm{C}$ and $1 \mathrm{~atm}$ pressure. Given these two inputs, the performance maps predict the compressor efficiency from which quantities, such as power required for compression and compressor outlet temperature can be obtained using simple thermodynamic calculations. Based on tests with residuals obtained using different polynomial functions, the following functional form was deemed most suitable: 


$$
\eta_{L P C}=\sum_{i=0}^{2} \sum_{j=0}^{2} a_{i+j}(P R)^{i}(\text { Mass Flow })^{j}
$$

The advantage of the above functional form is that the process of obtaining the polynomial coefficients can be cast as a linear-least-squares optimization problem, which is easily solved using MS-Excel's SOLVER tool.

In the case of the LPT, the operational speed can be adjusted so as to maintain a constant efficiency of $91.8 \%$, but at the cost of altering the expansion pressure ratio (PR) with different inlet conditions. Thus, the expansion pressure ratio of the LPT is defined as a function of the inlet temperature. If the inlet stream conditions (mass flow, temperature and pressure) are specified, then efficiency and pressure ratio can be calculated, which in turn can be used to calculate the outlet stream properties and the power obtained from the expansion process. In the case of the power turbine (PT), the outlet pressure is fixed at $1.016 \mathrm{~atm}$ and the inlet pressure is determined by the outlet pressure of the LPT. The PT efficiency is observed to be a function of inlet temperature (in K) and pressure (in atm). The functional form for the efficiency curve is given by:

$$
\eta_{P T}=\left(\sum_{i=0}^{4} a_{i} P_{i n}^{i}\right)\left(\sum_{i=0}^{3} b_{i}\left(\frac{T_{i n}}{1000}\right)^{i}\right)
$$

The above functional form was chosen after several trials with different functional forms. The optimization problem in this case is a nonlinear-least squares problem, which was also solved using MS-Excel's SOLVER tool. Given the inlet pressure and temperature the performance map predicts the PT efficiency from which quantities such as power obtained from the expansion process and PT outlet temperature can be obtained using simple thermodynamic calculations.

\subsubsection{Bottoming Rankine Cycle (ORC or SRC) Modeling}

The work in this paper does not explicitly model ORC and steam turbine systems, but assumes that the available thermal energy from various process streams in the plant can be used to produce power at a specified thermal efficiency. Performance modeling of the ORC system is derived from the UTC PureCycle water-cooled product line which at the $200 \mathrm{~kW}$-scale achieves a thermal efficiency of $14 \%$. When scaling up to $20 \mathrm{MW}$, and employing a higher source temperature for heat addition to the cycle, changes to the PureCycle ORC system design are necessary. After a preliminary engineering analysis of such changes, it is estimated that a $20 \%$ efficiency performance is achievable with a redesign of the PureCycle system that moves to higher system temperatures and pressures in conjunction with changes to the generator speed and approaches to the associated bearing and gear lubrication. A higher temperature ORC system was also examined via the Pratt \& Whitney TurboDen ORC product line. Net efficiency performance for heat recovery from turbine exhaust ranges from 23.3 to $23.6 \%$ [50]. Finally, to facilitate a comparison between ORC and SRC systems, a 30-MW class steam turbine cycle is 
evaluated using an estimated net thermal efficiency of $31 \%$ based on several literature references $[19,51,52]$. A simple model that sums all heat additions and employs an overall thermal efficiency is used to estimate power production according to the relation, $\dot{W}_{O R C}=\eta_{O R C} \sum_{j} \dot{Q}_{i n, j}$.

\subsubsection{Definition of Performance Metrics}

System performance metrics used throughout the subsequent sections of the systems analysis are defined in the following equations. Efficiency bases with and without $\mathrm{CO}_{2}$ capture and sequestration are also provided.

$$
\begin{aligned}
& \eta_{\text {coal }}=\frac{\dot{W}_{\text {sys,net }}}{\dot{m}_{\text {coal }} \cdot L H V_{\text {coal }}}=\eta_{\text {syngas }} \cdot \eta_{\text {gasifier }} \\
& \eta_{\text {gasifier }}=\frac{\dot{m}_{\text {syngas }} \cdot L H V_{\text {syngas }}}{\dot{m}_{\text {coal }} \cdot L H V_{\text {coal }}} \\
& \eta_{\text {syngas }}=\frac{\dot{W}_{\text {sys,net }}}{\dot{m}_{\text {syngas }} \cdot L H V_{\text {syngas }}} \\
& \eta_{\text {coal,CO2 }}=\frac{\dot{W}_{\text {sys,net }}}{\dot{m}_{\text {coal }} \cdot L H V_{\text {coal }}+\dot{E}_{\text {sep }}+\dot{W}_{\mathrm{CO} 2}} \\
& \eta_{\mathrm{ORC}}=\frac{\dot{W}_{\text {ORC }}}{\dot{Q}_{\mathrm{ORC}, \text { in }}} \\
& \dot{W}_{\text {sys,net }}=\dot{W}_{\text {SOFC }}+\dot{W}_{F T 8, \text { net }}+\dot{W}_{\text {ORC }}+\sum_{i} \dot{W}_{\text {exp }, i} \\
& -\dot{W}_{\text {blower }}-\dot{W}_{C O 2}-\dot{E}_{\text {sep }}-\dot{E}_{\text {ASU }}
\end{aligned}
$$

where $\dot{W}_{\text {sys,net }}$ is the net ac electric power derived from the IGFC power plant including SOFC ( $\left.\dot{W}_{\text {SOFC }}\right)$, gas turbine $\left(\dot{W}_{\text {FT8,net }}\right)$, syngas expanders $\left(\dot{W}_{\text {exp }}\right)$, and ORC power subsystems $\left(\dot{W}_{\text {ORC }}\right)$. $\dot{E}_{\text {sep }}$ is the energy spent in supplying cooling water for water knockout and regeneration of water sorbents, $\dot{W}_{\mathrm{CO} 2}$ is the compression work required to raise the captured $\mathrm{CO}_{2}$ to pipeline sequestration-ready conditions (150 bar). $\dot{W}_{\text {blower }}$ is the power required by the cathode recycle blower. $\quad \dot{E}_{\mathrm{ASU}}$ is the electric power required to operate the air separation unit. $\dot{Q}_{\mathrm{ORC}, \text { in }}$ is the net thermal energy addition to the ORC system. $L H V_{\text {syngas }}$ is the lower heating value of the gasifier syngas downstream of gas cleanup and cooling. 


\subsubsection{IGFC System Concept Design and Analysis}

Initial studies of IGFC plant concepts established the DC power rating of the SOFC power block near $115 \mathrm{MW}$ and focused on integrating the SOFC power section with the P\&W FT8 gas turbine and a scaled-up version of the PureCycle organic rankine cycle waste heat power generator. The resulting system concept is presented in Figure 14. A pure oxygen stream is supplied from the gasifier air-separation plant to the oxy-combustor which oxidizes the anode tail-gas, thereby producing only $\mathrm{CO}_{2}, \mathrm{H}_{2} \mathrm{O}$, and a small amount of $\mathrm{N}_{2}$. The anode tail-gas is not mixed with the cathode exhaust gas stream and thereby, makes the process for $\mathrm{CO}_{2}$ separation and capture a simple one through the use of a condenser to knock-out the water vapor present in the stream. The system also employs hot cathode gas recycle. The power plant concept is projected to have a capacity of $149 \mathrm{MW}$ at 51.4\%-LHV (48.1\%-HHV) efficiency without $\mathrm{CO}_{2}$ capture and compression costs and $139 \mathrm{MW}$ at $\sim 48 \%-\mathrm{LHV}$ efficiency with $\mathrm{CO}_{2}$ capture to sequestration-ready pipeline conditions [53].

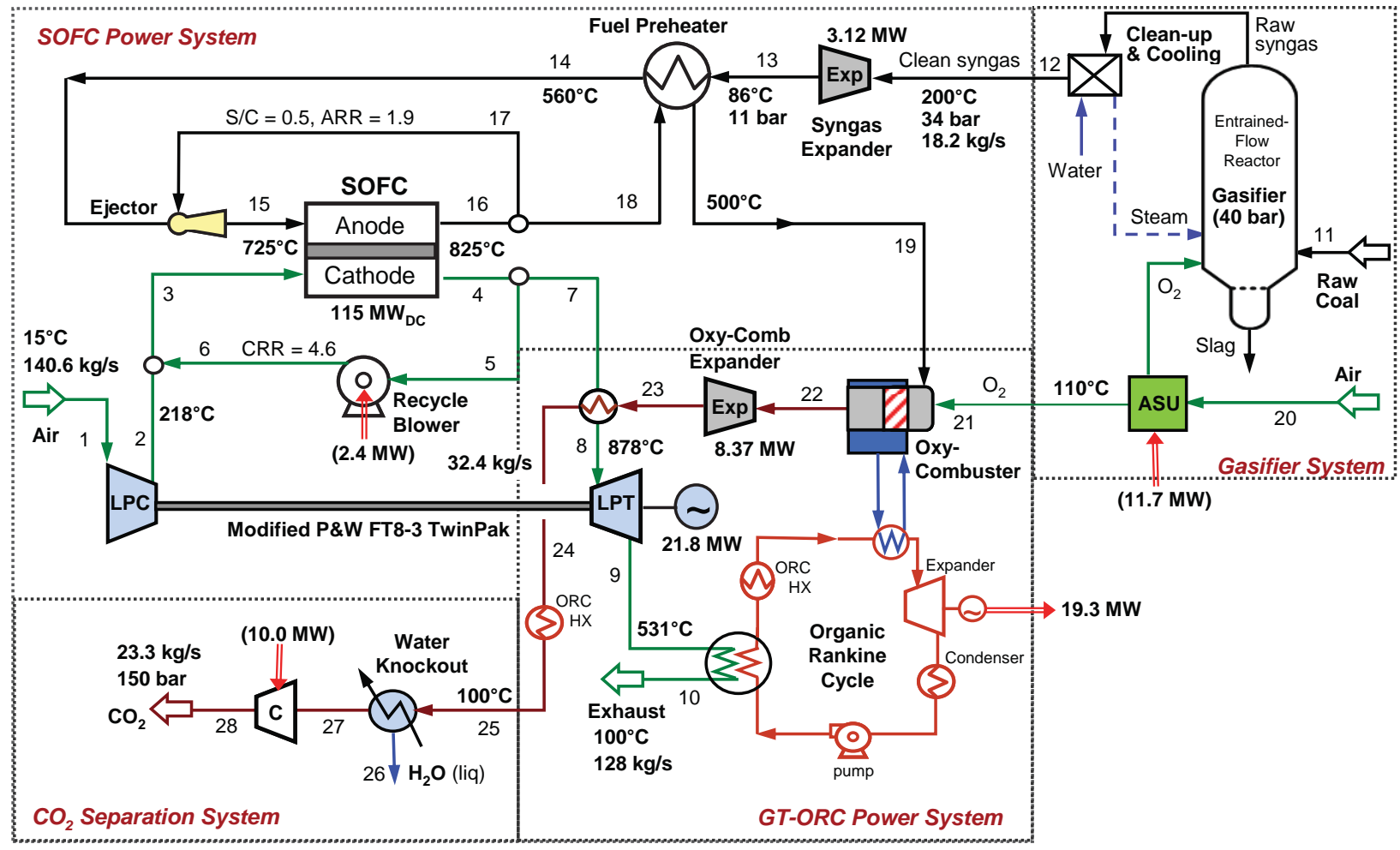

Figure 14. Hybrid IGFC Plant Concept Flowsheet Depicting Gasifier, SOFC, GT-ORC, and CC\&S Subsystems

The incoming system air at station (1) is compressed to the system pressure ratio of 5.2 using the LPC from the modified P\&W FT8 engine. The LPC has a well-defined performance map where the efficiency is a function of the mass flow rate of air through the system and the compressor PR. The conditions (flow, temperature and pressure) of stream (2) are such that when mixed with the cathode recirculation stream (6), the conditions of the resulting stream (3) meet the inlet requirements of the cathode compartment of the SOFC stack. Part of the stack cathode exhaust 
stream is re-circulated (5) with a high-temperature cathode recycle blower. The balance of the flow (7) receives thermal energy transferred from the oxygen burner outlet stream. Burner product gases transfer heat to the cathode exhaust in a high-temperature heat exchanger. The constraint on the heat-exchanger is that it should maintain a pinch temperature of at least $15{ }^{\circ} \mathrm{C}$ and at the same time ensure that the outlet temperature of stream (8) is as close to $950^{\circ} \mathrm{C}$, which is the maximum allowable LPT inlet temperature. The modified FT8 TwinPak requires a flow split for the two sets of parallel turbines (not shown). As described previously, each turbine set is comprised of a low-pressure turbine whose expansion pressure ratio is on the order of 2.5, a power turbine whose outlet pressure is close to atmospheric pressure ( 1.01 bar), and synchronous $60 \mathrm{~Hz}$ electric generator. The thermal energy accompanying the turbine exhaust gases (9) is transferred to the bottoming ORC heat engine via a heat recovery refrigerant economizer/evaporator before being vented out as exhaust gas at a temperature of $100^{\circ} \mathrm{C}(10)$.

Raw coal is fed to the entrained-flow gasifier plant where it is mixed with oxygen at a molar $\mathrm{O}_{2} / \mathrm{C}$ ratio of 0.48 and steam at an $\mathrm{H}_{2} \mathrm{O} / \mathrm{C}$ ratio of 0.10 . The composition of the $\mathrm{H}_{2} / \mathrm{CO}$-rich syngas exiting the gasifier is generated using equilibrium at the gasifier operating temperature of $1375^{\circ} \mathrm{C}$ and 40 bar. After quench cooling, scrubbing, and cleanup, the high-pressure syngas (34 bar) is expanded in a turbine generating over $3 \mathrm{MW}$ of power. The expander outlet gas (13) is supplied to the SOFC power block at elevated pressure $(\sim 11 \mathrm{bar})$ and temperature $\left(60^{\circ} \mathrm{C}\right)$. In the fuel preheater, the fuel-gas is preheated to a temperature (14) such that, when mixed with the recirculated anode exhaust stream (17), its temperature matches the temperature and pressure of the stack anode inlet (15) while maintaining a steam-to-carbon ratio of 0.5 to minimize the potential carbon deposition and soot formation within the stack manifolding and anode gas channels. With this level of recycle, the resulting oxygen-to-carbon and hydrogen-to-carbon ratios of the anode inlet gas are well-below the threshold for carbon formation at $725^{\circ} \mathrm{C}$ based on calculations for $\mathrm{C}-\mathrm{H}-\mathrm{O}$ equilibrium using ternery diagrams (cf. [19, 54]). It is further envisioned that piping for the anode feed gas will be made from zinc-free, copper-lined alloys or aluminacoated stainless steels to essentially eliminate catalytically activated (carbon forming) nucleation sites on piping inner surfaces. The syngas supply pressure is sufficiently high to drive the gas ejector to provide the anode exhaust gas recycle flow. The supply pressure to the gas ejector has been conservatively estimated by simulation of a gas ejector operating with an ejector efficiency ${ }^{4}$ of $20 \%$ as well as confirmation checks with Ref. [55]. The required gas ejector supply pressure then establishes the minimum outlet pressure of the syngas expander. While a portion of the anode tail-gas is re-circulated, the thermal energy accompanying the balance of the flow (18) is used to preheat the coal syngas in the fuel preheater. The residual fuel in the anode tail-gas stream is then burned in the oxygen combustor using $\mathrm{O}_{2}$ supplied by the 'over-sized' ASU.

In order to ensure complete combustion in the oxy-combustor, excess oxygen is supplied such that there is a molar concentration of $0.1 \% \mathrm{O}_{2}$ in the product gas. This relatively low value of

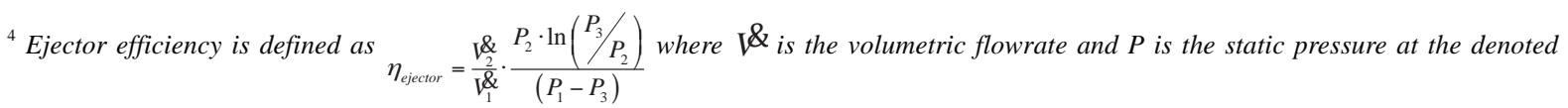
location in the ejector. The subscripts 1, 2, and 3 refer to the primary driving flow (fresh air), the secondary flow (recycle), and the mixed flow at the ejector outlet, respectively. 
excess oxyen has been selected in part to meet DOE guidelines for non-condensables in $\mathrm{CO}_{2}$ sequestration pipelines and to minimize ASU parasitic power. In contrast, some studies supply excess oxygen such that a concentration of $1 \% \mathrm{O}_{2}$ is obtained in the combustion products [21]. While the low value of excess oxygen required is optimistic, the impact of this value (in the range of 0.1 to $1 \%$ ) on overall plant efficiency is negligible (less than $0.1 \%$ ). The use of pure oxygen in the combustor can generate gas temperatures higher than $1500^{\circ} \mathrm{C}$ depending on the amount of fuel utilization and presents material and durability issues in combustor design. The present concept is to employ an actively-cooled burner tube which would limit combustor temperatures to $1100^{\circ} \mathrm{C}$. Heat rejection from the burner tube would then be transferred to the ORC unit in a separate heat exchanger. (Another alternative is to recycle cooler oxy-combustion product gases back to the burner inlet using a gas ejector driven by the anode tail-gas.) The oxycombustor combustion gases are then expanded down to 2 bar, producing nearly $8.4 \mathrm{MW}$ of additional power. The inlet gas temperature of the LPT can be as high as $950^{\circ} \mathrm{C}$. To take advantage of this capability, a regenerative heat exchanger is shown in Figure 14 to boost the cathode tail-gas temperature from $825^{\circ} \mathrm{C}$ to almost $880^{\circ} \mathrm{C}$ with the goal of making it as close to $950^{\circ} \mathrm{C}$ as possible. This heat exchanger has severe temperature requirements and is envisioned to be a rotating, ceramic core regenerative-type heat exchanger currently being developed for $300 \mathrm{~kW}$ microturbines in distributed generation applications [56]. Finally, the remaining thermal energy associated with the burner outlet stream at station (22) is transferred to the ORC in a lower-temperature heat exchanger $\left(750-800^{\circ} \mathrm{C}\right)$ made from high-grade stainless steel or a hightemperature alloy. This oxygen combustor product gas stream contains mostly $\mathrm{CO}_{2}$ and $\mathrm{H}_{2} \mathrm{O}$. After condensing out the water with a combination of cooling and a conventional water absorbent (e.g., triethylene glycol mixture or lithium-chloride solution), $90 \%$ of the $\mathrm{CO}_{2}$ is compressed to 150 bar (2200 psig) and piped to a sequestration location (28), with the remaining $10 \%$ vented to the atmosphere. Thus, the ORC has three primary heat addition sources: (i) thermal energy transfer from the water-cooled oxygen combustor tube, (ii) the hot exhaust gas from the power turbine, and (iii) the high-temperature heat exchanger located between stations (23) and (24). The arrangement of heat exchangers shown in the ORC of Figure 14 is not intended to be representative of an actual heat exchanger network integration scheme.

Table 4 summarizes the hybrid system performance including the overall impact to the system when accounting for the energy requirements of carbon capture and storage (CC\&S). CC\&S in this study includes $\mathrm{CO}_{2}$ separation via water knockout and a conventional water absorbent, and $\mathrm{CO}_{2}$ compression to pipeline sequestration conditions of 150 bar [53]. Energy requirements for regeneration of the water sorbent and pumping of the coolant flow for the water knockout heat exchanger are unknown, but assumed to be $5 \%$ of the $\mathrm{CO}_{2}$ compression power for the purposes of this study. The power plant generates $156 \mathrm{MW}$ of net ac power, where the re-designed FT8 and the scaled-up UTC Power PureCycle sub-systems contributing nearly $20 \mathrm{MW}$ each. The SOFC operates nominally at $775{ }^{\circ} \mathrm{C}$ with an average cell voltage of $0.75 \mathrm{~V}$, a fuel utilization of $80 \%$, a power density of $0.45 \mathrm{~W} / \mathrm{cm}^{2}$, a $100^{\circ} \mathrm{C}$ temperature rise across both the anode and the cathode, and a $2.5 \mathrm{kPa}$ pressure drop across the cathode. The SOFC power block provides about $68 \%$ of the total gross power from the plant, the gas turbine and scaled-up ORC systems supply 
approximately $13 \%$ and $12 \%$, respectively, and the gas expanders about $7 \%$. The compression of $\mathrm{CO}_{2}$ using intercooled compression stages each at $82 \%$ isentropic efficiency [45] to sequestration-ready pressure levels requires about $10 \mathrm{MW}$ of power. The LPC, LPT and PT operate at 84.0, 91.8 and $85.8 \%$ isentropic efficiencies, respectively. The recycle blower operates at $50 \%$ efficiency (52.6\% isentropic) and consumes about $2.4 \mathrm{MW}$ of power for a cathode recycle ratio of 4.6 and a cathode recycle loop pressure rise requirement of $3 \mathrm{kPa}$. Efficiencies reported in Table 4 are total efficiencies, that is, they include motor and mechanical inefficiencies. Thus, in the case of the FT8 turbines and $\mathrm{CO}_{2}$ compressor, the mechanical efficiency is approximated to nearly $100 \%$.

Table 4. Performance summary for hybrid IGFC system

\begin{tabular}{|c|c|c|c|}
\hline \multirow{4}{*}{$\begin{array}{l}\text { Fuel In } \\
\text { Raw Coal, MW (LHV) } \\
\text { Syngas*, MW (LHV) }\end{array}$} & \multicolumn{3}{|c|}{$\begin{array}{r}\text { Bottoming Cycle Type } \\
\end{array}$} \\
\hline & PureCycle ORC & TurboDen ORC & SRC \\
\hline & 290 & 290 & 290 \\
\hline & 238 & 238 & 238 \\
\hline \multicolumn{4}{|l|}{ Power (MW) } \\
\hline SOFC, $\mathrm{MW}_{\mathrm{AC}}$ & 111 & \multirow{5}{*}{22.7} & \multirow{5}{*}{29.9} \\
\hline GT & 21.8 & & \\
\hline Rankine Bottoming Cycle (ORC or SRC) & 19.3 & & \\
\hline Oxy-combustor Expander & 8.37 & & \\
\hline SynGas Expander & 3.08 & & \\
\hline ASU $\mathrm{O}_{2}$ and $\mathrm{N}_{2}$ supply & -11.9 & & \\
\hline $\mathrm{CO}_{2}$ compression & -10.0 & & \\
\hline Absorbent regen. and misc. CC\&S power & -0.5 & & \\
\hline Recycle Blower & -2.4 & & \\
\hline Net Power on syngas & 156.3 & 159.7 & 167.0 \\
\hline Net Power on syngas with CC\&S & 145.8 & 149.2 & 156.5 \\
\hline Net Power on coal & 149.3 & 152.6 & 159.9 \\
\hline Net Power on coal with CC\&S & 138.8 & 142.1 & 149.4 \\
\hline \multicolumn{4}{|l|}{ Efficiencies (\%) } \\
\hline Gasifier & 82.0 & \multirow{9}{*}{23.5} & \multirow{9}{*}{31.0} \\
\hline Recycle blower & 50.0 & & \\
\hline Dc/Ac Inverter & 96.5 & & \\
\hline Expanders & 88.0 & & \\
\hline FT-8 LPC & 84.0 & & \\
\hline FT-8 LPT & 91.8 & & \\
\hline FT-8 PT & 85.8 & & \\
\hline ORC or SRC (net) & 20.0 & & \\
\hline $\mathrm{CO}_{2}$ Compression & 82.0 & & \\
\hline \multicolumn{4}{|l|}{ System Performance (\%-LHV) } \\
\hline Net Efficiency on syngas & 65.7 & 67.1 & 70.2 \\
\hline Net Efficiency on syngas with CC\&S & 61.3 & 62.7 & 65.7 \\
\hline Net Efficiency on coal & 51.5 & 52.6 & 55.1 \\
\hline Net Efficiency on coal with CC\&S & 47.8 & 49.0 & 51.5 \\
\hline
\end{tabular}

*syngas refers to the coal gasifier outlet and is not a plant input 
The net system efficiency of the power plant employing the modified PureCycle ORC bottoming cycle is $65.7 \%$ (LHV) when operating from clean syngas supplied at the fuel preheater inlet, and $51.5 \%$ on raw coal (i.e., accounting for the inefficiency in the gasifier). Syngas-based system performance includes the power generated from the oxy-combustor expander, but not the syngas expander, and includes the power required to supply $\mathrm{O}_{2}$ to the oxy-combustor $(1.7 \mathrm{MW})$. The total system performance after including the energy requirements for $C C \& S$ reduces the net system efficiency to $61.3 \%$ and $47.8 \%$ when based on clean syngas and raw coal feedstocks, respectively. The use of the $\mathrm{P} \& \mathrm{~W}$ ORC TurboDen product line offers a bottoming cycle efficiency improvement of $3.5 \%$ and increases the net efficiency of the system on syngas to $67.1 \%$ and to $49.0 \%$ on coal with CC\&S. These IGFC plants using ORC bottoming cycles with CC\&S amount to 14.0 and 15.2 percentage point improvements in efficiency, respectively, over conventional IGCC/CCS power plant performance (estimated at $\sim 33.8 \%$-LHV in Ref. [1]).

The high-grade thermal energy that is available for input into the ORC subsystem suggests that a steam-based rankine power subsystem is also viable. Indeed, while the purpose of this study was to investigate the performance with primarily ORC systems, a steam turbine plant potentially offers even higher efficiency depending on the boiler pressure and superheat temperatures achievable. Assuming a simple rankine cycle net efficiency of $31 \%$, the IGFC system efficiency on coal could produce about $10.6 \mathrm{MW}$ of additional power and increase net system efficiency by 3.7 percentage points to $55.1 \%$ (51.5\% with CC\&S) as summarized in Table 4 .

\subsubsection{IGFC Parameter Sensitivity Study}

Having established the baseline performance, select system parameters were varied and the sensitivity of these parameters to the baseline IGFC system performance was evaluated. Cell voltage, fuel utilization, system pressure ratio, anode $\mathrm{S} / \mathrm{C}$ ratio, cathode-side pressure drop, and stack $\Delta \mathrm{T}$ were the system parameters varied. The $\mathrm{DC}$ power from the stack was fixed at 115 MW throughout this study. Given a cell planform and a fixed number of cells per stack, the number of stacks is then calculated based on design voltage, and overall power setting. This provides an estimate of fuel cell power density. Figure 15 through Figure 20 present trends in system performance metrics such as efficiency, number of stacks required, total power from the gas turbine system, power obtained from the PureCycle ORC unit, and recycle blower parasitic power as functions of the different parameters. Importantly, in order to separate out the gasifier efficiency considerations, the efficiency reported in the following analyses is the net system efficiency from syngas without CC\&S penalties.

Figure 15 illustrates the effect of cell voltage on system efficiency, power density (as reflected by the number of cell-stacks), and parasitic power in the system. An increase in voltage results in lower blower parasitic power, as well as, as a reduction in total power produced by the FT8 and PureCycle ORC systems. Reductions in power output from the bottoming cycles occur because increasing cell voltage translates into increasing cell-stack efficiency, and correspondingly lower quantities of waste heat in the product gas. It is interesting to observe that stack power density is nearly halved by an increase in cell voltage of only $100 \mathrm{mV}$. Such high sensitivity of power density to changes in cell voltage is explained by the cell $\mathrm{V}$-j performance 
characteristic previously given in Figure 13. For example, at $0.7 \mathrm{~V}$, the single-cell power density is approximately $0.53 \mathrm{~W} / \mathrm{cm}^{2}$. At $0.8 \mathrm{~V}$, the power density is about $0.27 \mathrm{~W} / \mathrm{cm}^{2}$. Thus, while high-performance, high power density cell-stacks can be cheaper and more efficient, the shallow slope of their $\mathrm{V}-\mathrm{j}$ characteristic is such that small changes in voltage result in large changes in operating current.

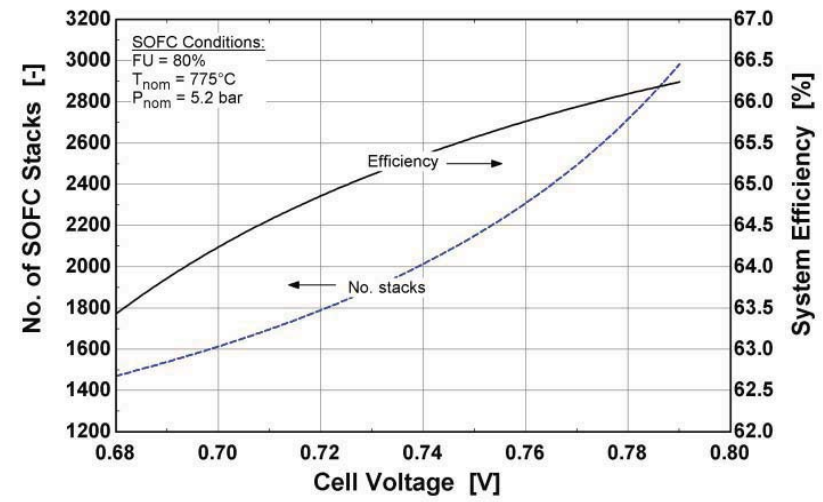

(a)

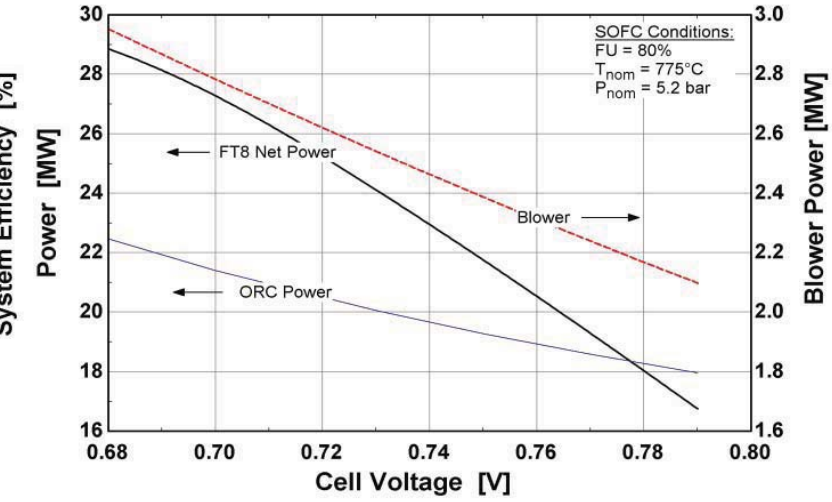

(b)

Figure 15. Effect of cell voltage on system parameters associated with the hybrid IGFC system

The effect of fuel utilization on performance is shown in Figure 16. At a prescribed cell voltage, system efficiency is correlated with fuel utilization as is ORC power production. The increase in net system efficiency is off-set by reductions in FT8 and ORC power production. The power density of the SOFC is also lowered with increasing fuel utilization as revealed in the figure by the increasing number of SOFC stacks required. Interestingly, net power from the FT8 gas turbine system reaches a maximum at a fuel utilization of $70 \%$. Further increases in gas turbine power production with decreasing fuel utilization are constrained by turbine inlet temperature limits. Increases in SOFC fuel utilization lower the energy available in the tail-gas and thereby, lower the power output of the FT8. The bottoming ORC power output is directly correlated with fuel utilization and as expected, decreases with increasing fuel utilization due to lower available thermal energy associated with the burner outlet stream. 


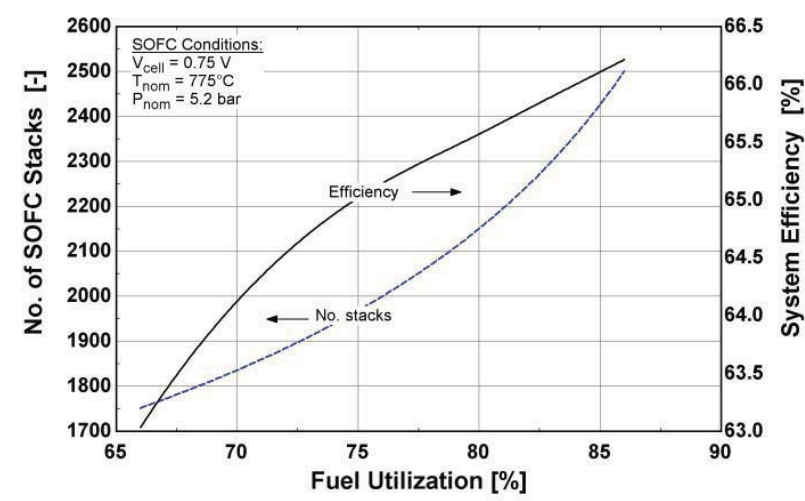

(a)

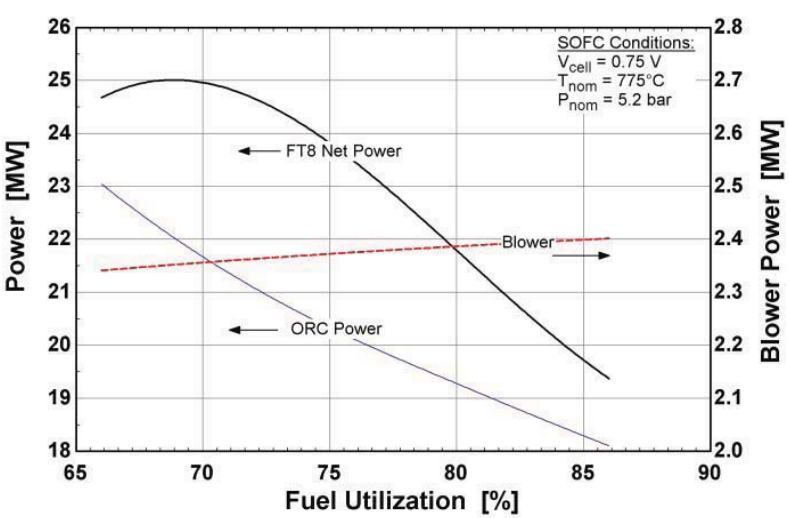

(b)

Figure 16. Effect of fuel utilization on system parameters associated with the hybrid IGFC system

Operating the power plant system at elevated pressure is very important to achieving SOFC power density goals of $0.45 \mathrm{~W} / \mathrm{cm}^{2}$, as Figure 17 shows. Net system efficiency also benefits substantially ( $\sim 3.5$ percentage points) when increasing the system pressure from 3 to 5.2 bar operation. The cathode recycle blower power parasitic decreases substantially ( 43\%) in response to increases in system operating pressure due to reductions in hot gas density and hence, volume flowrate. However, the primary factors that enable higher system efficiency from increasing the system pressure arise from higher efficiency SOFC and FT8 gas turbine operation. Higher efficiency SOFC operation in response to elevated pressure is well-documented [e.g., 57]. The FT8 produces some $57 \%$ more net power by design point allowing the LPT shaft power to increase incrementally more than the increase in the LPC power consumption.

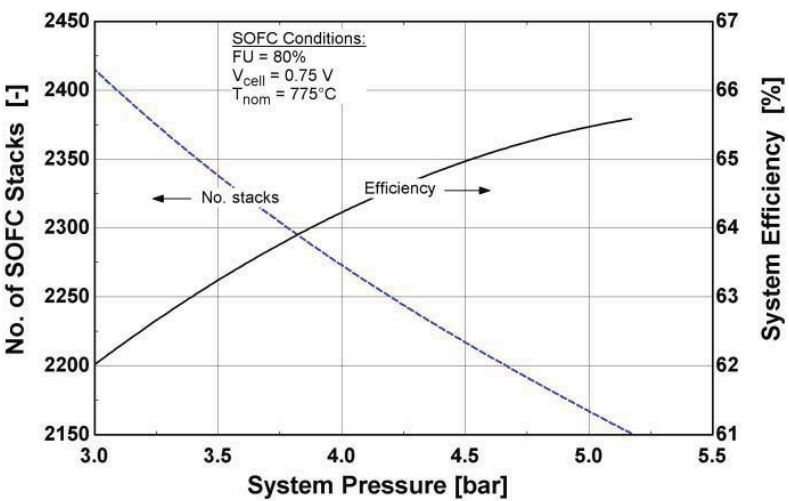

(a)

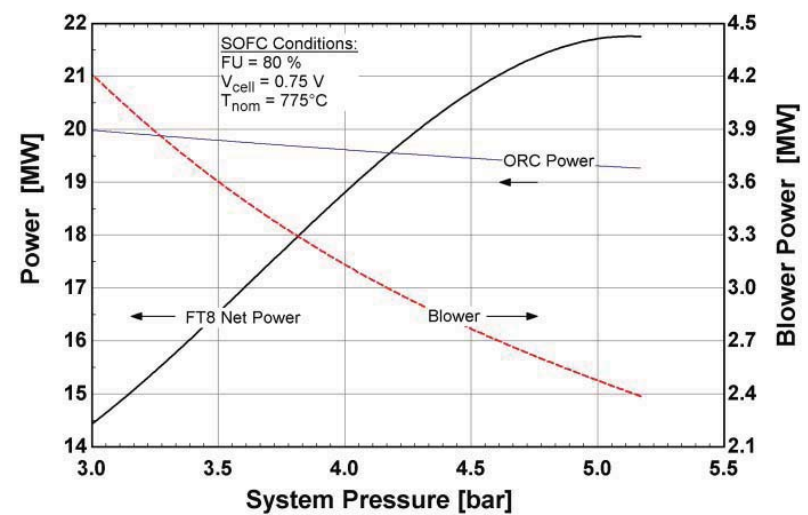

(b)

Figure 17. Effect of system pressure ratio on parameters associated with the hybrid IGFC system

The presence of carbon monoxide $(\mathrm{CO})$ in the dry coal-gas stream delivered to the power plant requires consideration of coking formation side reactions within piping runs and hardware. In particular, as noted by Probstein and Hicks [54], fuel gas mixtures with O/C ratios of 1.0 and $\mathrm{H} / \mathrm{C}$ ratios of 2 are likely to form carbon in the temperature range between $625^{\circ} \mathrm{C}$ to $925^{\circ} \mathrm{C}$. The 
Boudouard coking mechanism can be inhibited and/or controlled with steam injection. The approach taken in the system design efforts to limit the potential for undesirable coke formation is centered on a two-pronged strategy where (1) fuel gas piping is lined with copper or oxide layers that minimize nucleation sites for coke formation and (2) injecting steam (albeit at a lower steam-to-carbon ratio) into the fuel syngas stream via an ejector and anode gas recycle. Since the coal fuel gas provided by the gasifier is significantly pressurized, the ejector can be effectively driven to provide the desired recycle flows.

Figure 18 relates the effect of steam-to-carbon (SC) ratio on system performance. Note again that as with the previous analyses, the design cell voltage has been fixed in this parameter variation. One of the main effects of increasing SC ratios is the reduction in SOFC power density due to dilution of the anode gas feed and hence, a lowering of the Nernst potential. This dramatically increases the number of fuel cell stacks required to deliver $115 \mathrm{MW}$ of power. The overall system efficiency is also correlated with the amount of anode recycle (and hence, SC). Interestingly, the increase in SC ratio produces an increase in system efficiency even though the bottoming cycle power production is reduced. The root of this performance change is related to an increase in effective system fuel utilization. In this analysis, the per-pass (or in-cell) fuel utilization was held constant at $80 \%$. The increase in recycle actually increases the overall system fuel utilization. Thus, the system efficiency trends with increasing SC are not unlike those of increasing per pass fuel utilization within the SOFC (although the concavity of the plots is different).

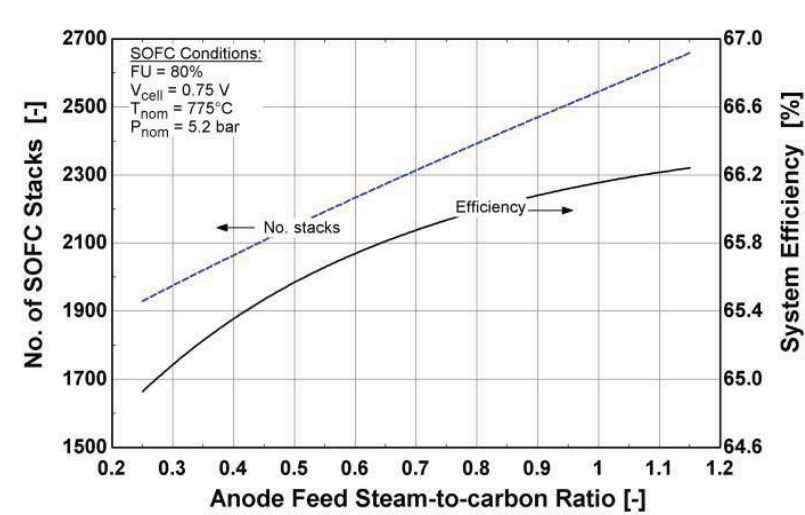

(a)

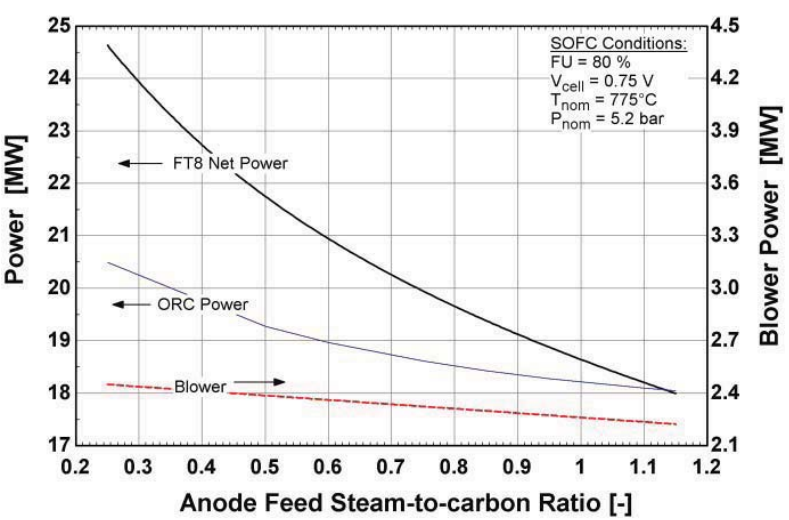

(b)

Figure 18. Effect of anode $\mathrm{S} / \mathrm{C}$ ratio on system parameters 


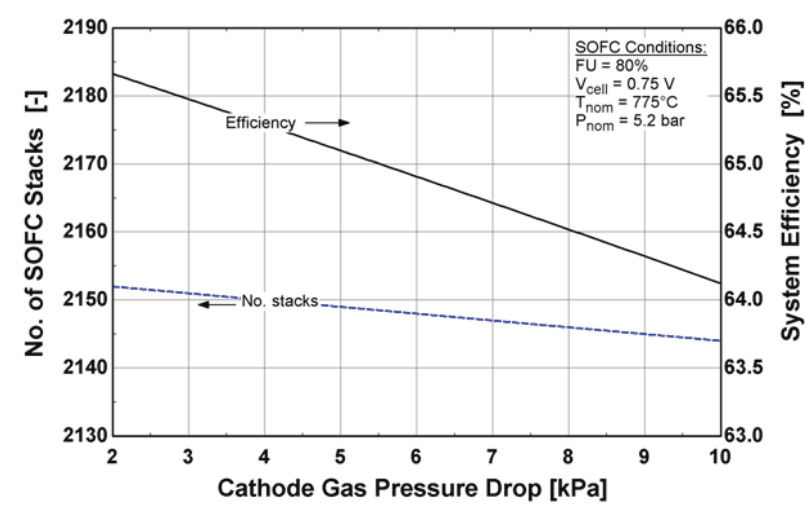

(a)

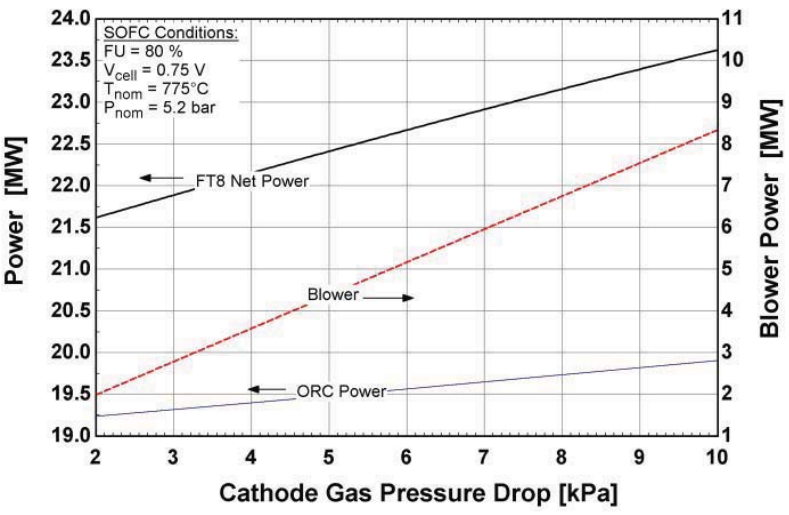

(b)

Figure 19. Effect of cathode-side pressure drop on system parameters

Figure 19 and Figure 20 depict the sensitivity of cathode side pressure drop and temperature rise on system performance, respectively. While the recycle blower parasitic power appears to be strongly influenced by cathode loop pressure drop, it is actually a relatively mild effect when considering pressurized gas flows and the percentage of net power production from the plant. There is a much stronger system-level efficiency effect associated with cathode pressure drop in near-ambient pressure SOFC systems (i.e., 1.0 to 1.1 bar), such as the demonstration power plant. Cathode temperature rise has a direct influence on SOFC power density due to increases in per pass oxidant utilization as Figure 20 shows, but the system efficiency and net power production from the ORC are only mildly affected. The net FT8 power production is slightly decreased due to the reduction in mass flow through the unit. While cathode temperature rise can provide substantial blower parasitic power reductions, greater system efficiency advantages can be obtained with increases in cell temperature [58].

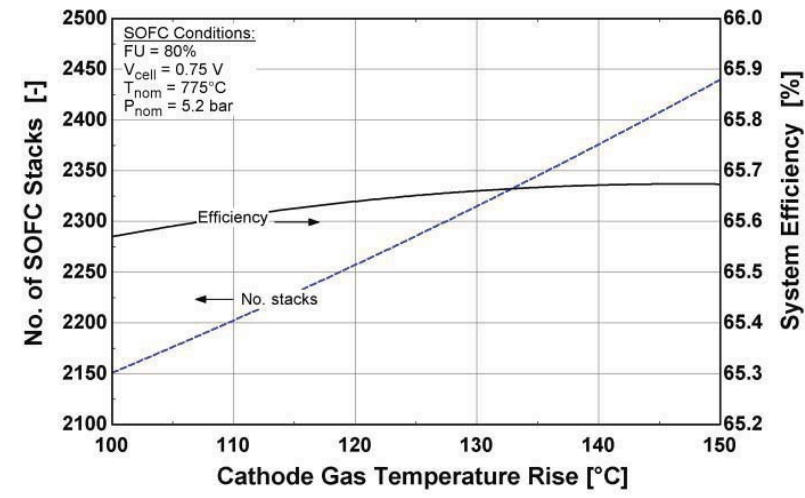

(a)

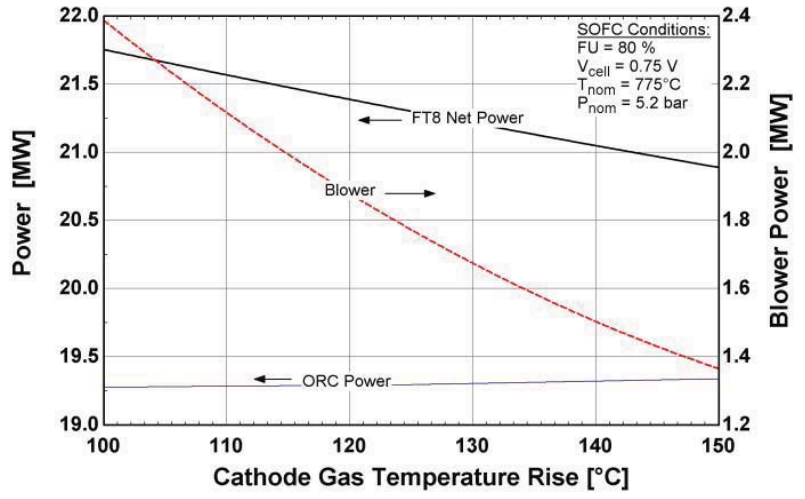

(b)

Figure 20. Effect of stack $\Delta \mathrm{T}$ on various system parameters in the hybrid IGFC system 


\subsubsection{Summary}

Overall, while efficiency is reasonably correlated to fuel utilization, system pressure and anode $\mathrm{S} / \mathrm{C}$ ratio, the number of stacks required to achieve $115 \mathrm{MW}$ from the SOFC system is sensitive to each of these parameters. An optimal selection of parameters is possible if cost data are available.

Given that the parametric analyses did not include the gasifier technology and performance, system integration advantages may be overlooked. In general, by fixing the SOFC stack power, the results and trends of the study are constrained by the interactions between SOFC stack, gas turbine, and ORC subsystems. For example, an increase in SOFC efficiency via design operating cell voltage increase, results in a decrease of reactant gas flows to the gas turbine and thereby lowering its output power. Alternatively, enabling the means for fixing gas turbine flow via either supplemental syngas firing or utilizing nitrogen available from the ASU could provide improved net system performance. Additional considerations include (1) integrating the FT8 low-pressure compressor with the ASU, (2) syngas firing to maintain FT8 gas turbine inlet temperature as close to $950^{\circ} \mathrm{C}$ as possible subject to $90 \%$ carbon capture constraints, (3) recuperation of syngas cleanup cooling loads to the ORC unit, and (4) examination of catalytic gasification technology which has as much as a 10 percentage point cold-gas efficiency advantage over entrained-flow gasification systems.

Nevetheless, the present study does reveal that entrained-flow gasifiers with oxy-combustion system configurations can indeed lead to high power plant efficiencies. It also quantifies the effect of SOFC pressurization in the $3-5$ bar range on system performance. It is worthwhile to note that these results have been obtained by using actual FT8 performance maps and SOFC performance based on near-term planar technology. In this study, a parametric sensitivity study was conducted on a given system configuration. It is not clear if the proposed system is the best possible design. However, the combined effect of selecting more 'optimal' SOFC stack operating parameters, such as increasing cell voltage to $0.8 \mathrm{~V}$, cathode temperature rise to $150^{\circ} \mathrm{C}$, and decreasing per pass cell utilization (while maintaining overall fuel utilization) is expected increase system performance by 3 percentage points or more giving an overall efficiency of $51 \%$.

\subsubsection{Conclusions}

This study detailed the performance of a $100 \mathrm{MW}$-scale IGFC hybrid power plant that integrated a pressurized SOFC power block with the low-pressure turbine spool of the Pratt \& Whitney FT8-3 gas turbine and either a scaled-up, water-cooled version of the P\&W PureCycle ORC or the larger $\mathrm{P} \& \mathrm{~W}$ TurboDen product lines. The basic system concept included carbon capture via oxy-combustion followed by water knockout and $\mathrm{CO}_{2}$ compression to pipeline ready $\mathrm{CO}_{2}$ sequestration conditions. Performance results were reported that indicate hybrid SOFC systems could achieve electric efficiencies of $49 \%$ including CC\&S and as high as $67 \%$ when operating off a clean syngas and venting the $\mathrm{CO}_{2}$ to the atmosphere. The impact of integrating an ORC bottoming cycle was found to add as much as 8 percentage points of efficiency to the system. Use of a steam power cycle, in lieu of the ORC, could increase net plant efficiency by another 
3.7\%. Additionally, the strategic use of gas expanders is particularly advantageous to offset carbon capture compression requirements or air separation unit parasitic power requirements.

A study of system performance sensitivity to a variation in SOFC design parameters revealed the strongest influences are design cell voltage, SOFC fuel utilization, and system pressure. The net system efficiency can vary by as much as 3 percentage points over the range studied for changes to any of these parameters. Anode tail gas recycle ratio and cathode side design parameters, such as pressure drop and temperature rise, only mildly affect system efficiency; however, increasing the recycle ratio of anode tail-gas has the negative effect of decreasing SOFC power density and hence, increasing the number of cell-stacks required. Depending on power density, two to three thousand SOFC stacks are required to generate $115 \mathrm{MW}$ of dc power. Techno-economic analysis could identify optimal stack design parameters.

It was also noted that additional analyses related to changes in the system design, such as ASU integration with the gas turbine or catalytic gasification could substantially improve the system performance beyond what is reported herein.

\subsubsection{Acknowledgments}

Portions of this work were completed with the collaboration of United Technologies Research Center (UTRC) personnel. The co-PI would like to acknowledge the contributions of Shiva Kameswaran, John Yamanis, and Ellen Sun for their assistance with the work of Focus Area (1) on integration of SOFCs with commercial gas turbine and organic Rankine cycle technologies. The work documented in Section 5.1 extended some of the prior efforts under DOE contract DEFC26-02NT41246. Dr. Sean Emerson at UTRC also provided hydrogen membrane reactor performance maps. The Co-PI would also like to thank Pamela McNary, Bruce Wendus, and Joe Hilmon at Pratt \& Whitney for their assistance in generating performance maps for and engineering modifications to the FT8-3 gas turbine power system, and Lili Zhang at United Technologies Research Center for her helpful information on P\&W PureCycle performance characteristics. 


\subsection{Focus Area (2) Evaluating Carbon Capture Strategies for IGFC Hybrid Power Systems}

This study provides a quantitative evaluation of emerging membrane technologies employed in either pre- or post-combustion IGFC configurations for the purposes of carbon capture and compares their performance with more conventional methods. A journal paper derived from this work is in draft. The objectives of this focus area were to:

(1) Generate system concepts and quantify IGFC/CCS performance employing membrane reactors in both pre-SOFC and post-SOFC configurations,

(2) For pre-SOFC capture system configurations, examine Selexol versus water-gas shift membrane reactors and for post-SOFC configurations, compare hydrogen and oxygen transfer membranes with oxy-combustion.

(3) Evaluate the IGFC system performance on both efficiency and capital cost bases.

In the following sections, system configurations for various carbon capture concepts are presented, followed by technology and modeling discussions. Six different IGFC system configurations are investigated and performance estimated: four post-combustion and two precombusion carbon capture systems. In each configuration, the coal energy input is the same (290 MW) and variations in cost, net power, and efficiency performance are observed. System performance and economic results are given that illustrate the most attractive configurations and technologies for IGFC hybrid systems. The section concludes with a summary of findings.

\subsubsection{Carbon Capture Concepts}

An IGFC system that employs post-SOFC carbon capture using oxy-combustion is established as a baseline for comparative analyses. Figure 1 of Section 2.1 introduced the high-level IGFC system concept with oxy-combustion of the SOFC tail-gas. Figure 21 depicts a simplified diagram of the oxy-combustion concept in the SOFC periphery that serves as the baseline system for the ensuing study. Air enters the compressor and is preheated and fed to the cathode side of the SOFC. Clean syngas is preheated and delivered to the anode-side of the SOFC. Anode gas recycle is not shown, but could be envisioned in this simple configuration as well. Importantly, the anode tail-gas is not mixed with the cathode exhaust, but is instead oxidized using a nearly pure oxygen stream from an ASU in the oxy-combustor. Combustion products, consisting of mostly $\mathrm{CO}_{2}$ and $\mathrm{H}_{2} \mathrm{O}$ vapor, are then cooled such that the water is condensed, leaving a lowdewpoint carbon dioxide gas stream for compression and pipeline transport to a sequestration location. Cathode tail-gas has slightly reduced mass flow, but has elevated temperature (by 100$150^{\circ} \mathrm{C}$ ) which is then fed to a gas turbine. The enthalpy in the turbine exhaust is sufficient to raise steam and provide a substantial portion of the thermal energy addition needed for the steam Rankine cycle via a heat recovery steam generator. 


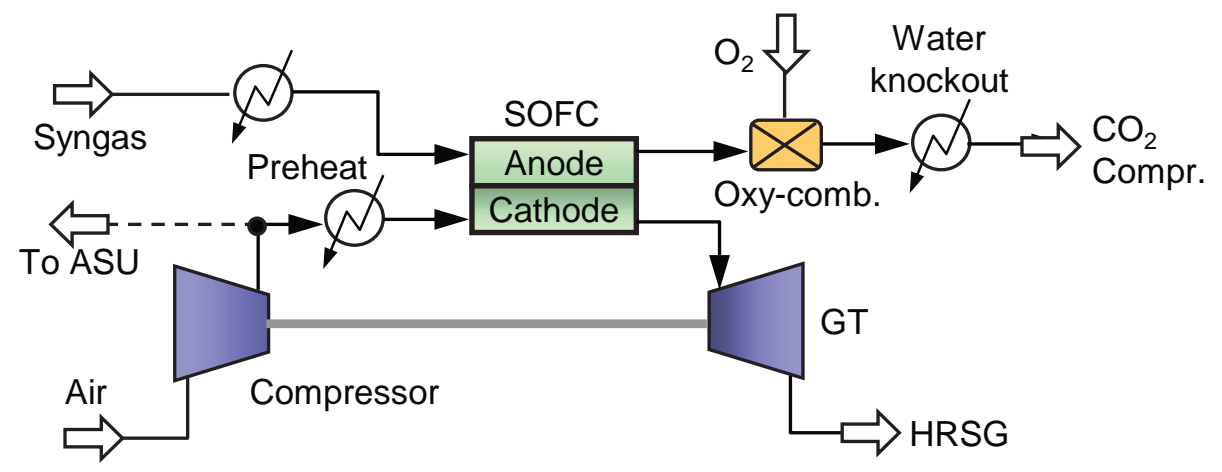

Figure 21. Simplified Schematic of Post-SOFC CCS using Oxy-combustion (Baseline)

The method of syngas generation is the same for all system configurations explored and the basic set of processes employed is as follows:

Gasifier: Shell Entrained-flow Slagging

ASU: $\quad$ Cryogenic Distillation (at an electric consumption of $0.285 \mathrm{kWh} / \mathrm{kg} \mathrm{O}_{2}$ )

Cleanup: High-temperature halide and mercury cleanup with either warm-gas desulfurization or Selexol

SOFC: $\quad 10$ bar, $0.78 \mathrm{~V} / \mathrm{cell}, 80 \%$ utilization

GT: $\quad$ Rubber turbine with $\mathrm{PR}=10$

ST: $\quad 120 \mathrm{bar} / 540^{\circ} \mathrm{C} / 540^{\circ} \mathrm{C}$ reheat steam cycle

\subsubsection{Post-SOFC CCS Concepts}

Three post-SOFC carbon capture concepts using membrane reactors are explored in addition to the baseline oxy-combustion configuration given in Figure 21. Cases 1 and 2 utilize a water-gas shift membrane reactor (WGSMR) that is configured in the anode tail-gas as shown in Figure 22(a). In this system concept, clean and pressurized syngas is delivered to the anode compartment of the SOFC. After electrochemical oxidation, the depleted tail-gas is admitted into the WGSMR where both hydrogen transport through a palladium-based tubular membrane wall and the water-gas shift reaction occur simultaneously. The hydrogen transport away from the retentate side of the membrane enhances the forward shift reaction yielding $100 \%$ conversion of $\mathrm{CO}$ to $\mathrm{CO}_{2}$. The permeate is then mixed with the cathode tail-gas and combusted prior to delivery to the gas turbine. In Case 2, the basic system configuration is the same as given by Figure 22(a), but an inert nitrogen sweep gas is employed to enhance hydrogen transport and reduce the required membrane area. As will be seen, one of the challenges of this configuration is maintaining high partial pressure driving forces for sufficient hydrogen transport and minimizing the associated parasitic power and ancillary hardware such that a net gain in efficiency and cost can be realized. 


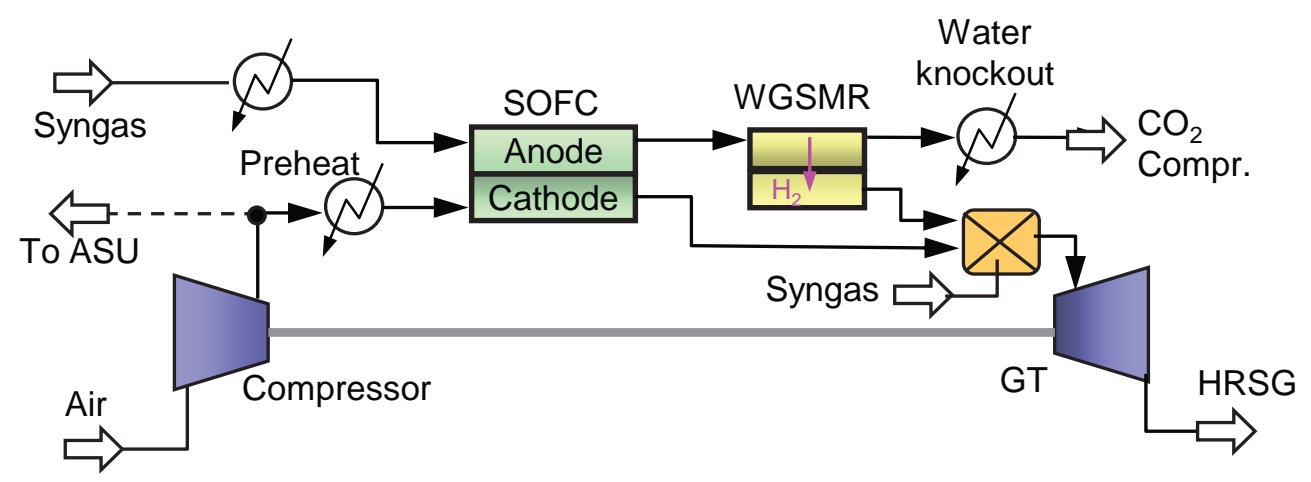

(a.) Case 1 and 2: Post-SOFC CCS using water-gas shift membrane reactor

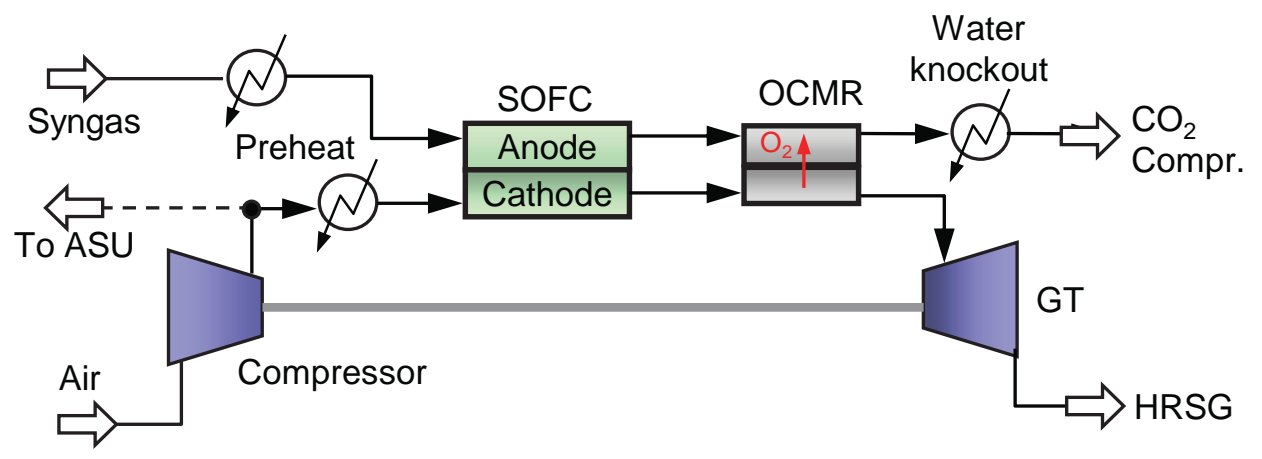

(b.) Case 3: Post-SOFC CCS using oxygen-conducting membrane reactor

Figure 22. Simplified Schematic of Post-SOFC CCS using Membrane Reactors

The Case 3 post-SOFC CCS concept employs an oxygen conducting membrane reactor (OCMR) whereby oxygen from the cathode tail-gas is transported to the anode exhaust thereby oxidizing the residual hydrogen and carbon monoxide without the introduction of an inert, noncondensable gas which would prohibit water knockout and a pure carbon dioxide stream.

\subsubsection{Pre-SOFC CCS Concepts}

Two IGFC system concepts where CCS occurs upstream of the SOFC power block were examined. Case 4 employs a conventional 2-stage Selexol process to capture carbon as shown in the simplified schematic diagram of Figure 23(a). As the figure shows, syngas from the gasifier is first shifted in a sour water-gas shift reactor train and then delivered to the Selexol plant which removes both $\mathrm{H}_{2} \mathrm{~S}$ and $\mathrm{CO}_{2}$. With the $\mathrm{CO}_{2}$ removed upstream of the SOFC power block, the anode tail-gas can be oxidized with an air stream in a combustor and then expanded in gas turbine or the cathode and anode exhaust gases can be mixed and burned as shown in Figure 23(b). The results for both mixing and not mixing tail-gas streams are given in Section 5.2.3. 


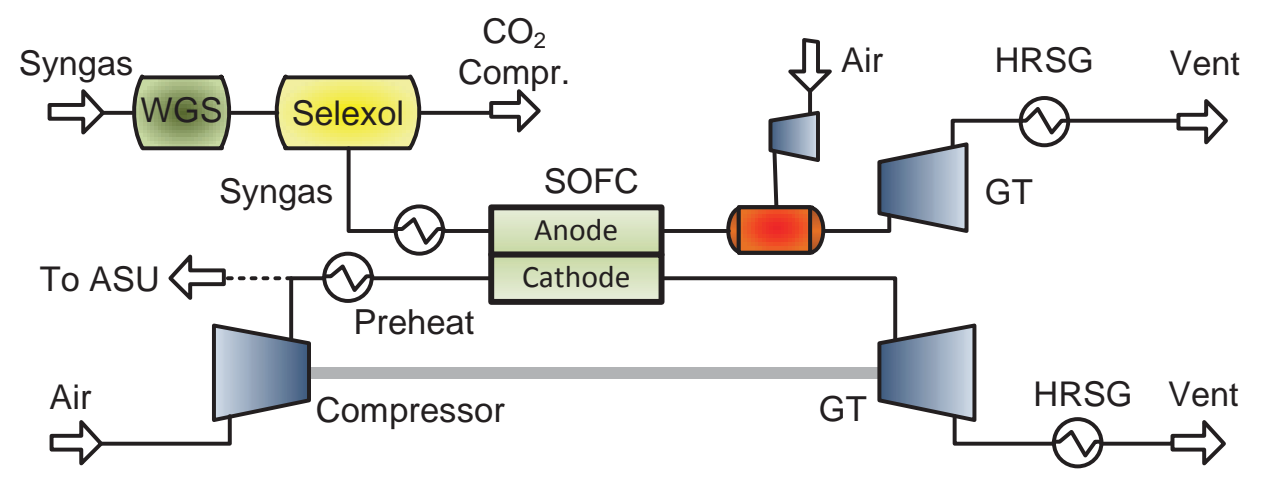

(a.) Case 4: Pre-SOFC CCS using Selexol process

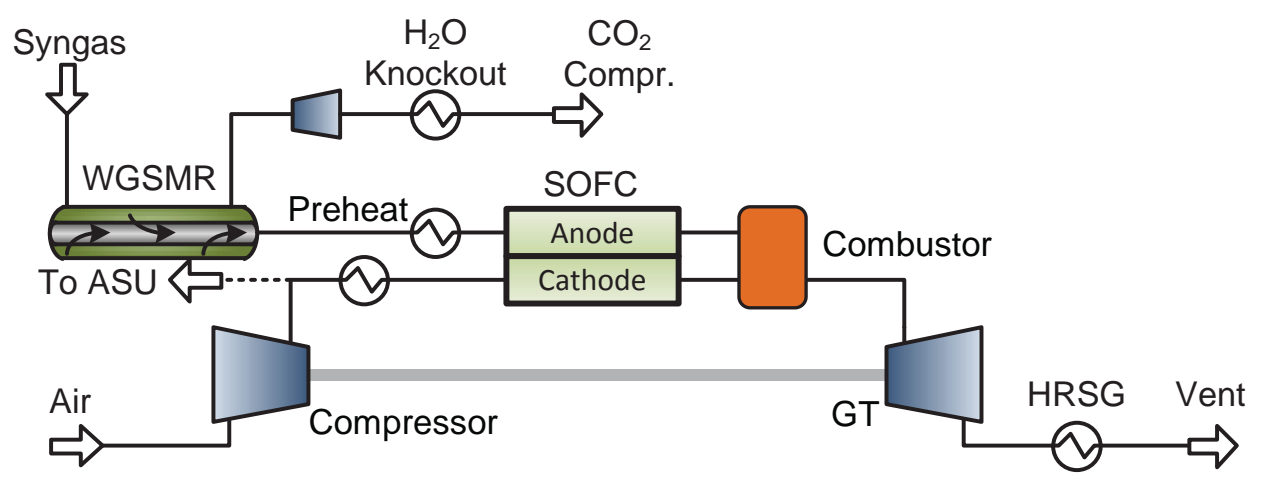

(b.) Case 5: Pre-SOFC CCS using water-gas shift membrane reactor

Figure 23. Simplified schematic of Pre-SOFC CCS concepts

In contrast with Case 4, Case 5 employs a WGSMR as an emerging technology for enabling preSOFC carbon capture. In this configuration, the syngas enters a water-gas shift membrane reactor upstream of the SOFC power block; and the permeate is sent to the anode compartment of the SOFC and water is removed from the retentate stream to produce a high-purity $\mathrm{CO}_{2}$ gas ready for sequestration. Advantages in reduced $\mathrm{CO}_{2}$ compression auxiliary power and increases in SOFC power density are observed in pre-SOFC concepts as discussed in Section 5.2.3 of this report.

The configurations for the Baseline and Cases 1 thru 5 are summarized in Table 5. The six different plant concept cases explored are broken down into four post-SOFC and two pre-SOFC CCS configurations and they differ as follows:

Baseline: Post-SOFC CCS with oxycombustion

Case 1: Post-SOFC CCS with water-gas shift membrane reactor (WGSMR) with no sweep gas

Case 2: Post-SOFC CCS with WGSMR and nitrogen sweep gas

Case 3: Post-SOFC CCS with oxygen conducting membrane reactor (OCMR)

Case 4: Pre-SOFC CCS with 2-stage Selexol unit

Case 5: Pre-SOFC CCS with WGSMR 
Table 5. Summary of post- and pre-SOFC carbon capture configurations

\begin{tabular}{|c|c|c|c|c|c|c|}
\hline & \multicolumn{4}{|c|}{ Post-SOFC } & \multicolumn{2}{|c|}{ Pre-SOFC } \\
\hline & Baseline & Case 1 & Case 2 & Case 3 & Case 4 & Case 5 \\
\hline $\begin{array}{l}\text { CC\&S } \\
\text { Method }\end{array}$ & $\begin{array}{c}\text { Oxy- } \\
\text { combustion }\end{array}$ & WGSMR & $\begin{array}{l}\text { WGSMR w } \\
\text { sweep gas }\end{array}$ & OCMR & Selexol & WGSMR \\
\hline Gasifier & Shell EFS & & & & & \\
\hline $\begin{array}{l}\text { Gas } \\
\text { Cleanup }\end{array}$ & $\begin{array}{c}\text { Warm-gas } \\
\text { Desulfurization } \\
\text { (WGD) }\end{array}$ & & & & Selexol & $\begin{array}{l}\text { WGD + } \\
\text { WGSMR }\end{array}$ \\
\hline SOFC & $\begin{array}{l}10 \mathrm{bar} \\
0.78 \mathrm{~V} / \text { cell } \\
80 \% \text { Utiliz. }\end{array}$ & & & & & \\
\hline Gas Turb & $P R=10$ & & & & & \\
\hline $\begin{array}{l}\text { Steam } \\
\text { Cycle }\end{array}$ & $\begin{array}{l}120 \text { bar / } \\
540^{\circ} / 540^{\circ} \mathrm{C}\end{array}$ & & & & & \\
\hline
\end{tabular}

\subsubsection{Technology and Modeling Discussion}

The following sub-section briefly discusses the technologies and modeling approaches employed in ASPEN Plus software to carryout the performance comparison of Cases 1 thru 5.

\subsubsection{Gasifier and cleanup}

With over 11 commercial plants operating worldwide at scales of $250 \mathrm{MW}$, a Shell dry fed, oxygen-blown, entrained-flow slagging gasifier was employed as the basis for the present study. The operating conditions selected were 40 bar and $1375^{\circ} \mathrm{C}$ with a $30 \%$ quench gas recycle to lower the syngas down to about $1000^{\circ} \mathrm{C}$. The gasifier was modeled in the same manner as Focus Area (1), i.e., assuming the syngas to be of equilibrium composition at that gasifier temperature and pressure.

Other unit operations modeled include high temperature halide and mercury cleanup where the operating conditions were established from the literature. However, these processes are only modeled at low-fidelity using mass separators in ASPEN Plus given the purpose of the study and the fact that the overall mass and energy balances of such devices are small compared to the other process steps.

The Selexol process has over 50 plants worldwide and was fully-modeled in ASPEN Plus as a separate program where the overall mass and energy requirements of the process were establised and then employed in the IGFC system model as a simplified separator model. A high-level diagram of the Selexol process is shown in Figure 24. A Selexol process overview has been given in Section 4.2.1; here, we merely highlight that the Selexol process has been modeled with 
an approximation to the proprietary Selexol solvent working fluid and achieves a product gas that contains less than 10 ppmv of $\mathrm{H}_{2} \mathrm{~S}$ while capturing $95 \%$ of the carbon dioxide and ammonia. The operating temperature was $60^{\circ} \mathrm{C}$ and 40 bar.

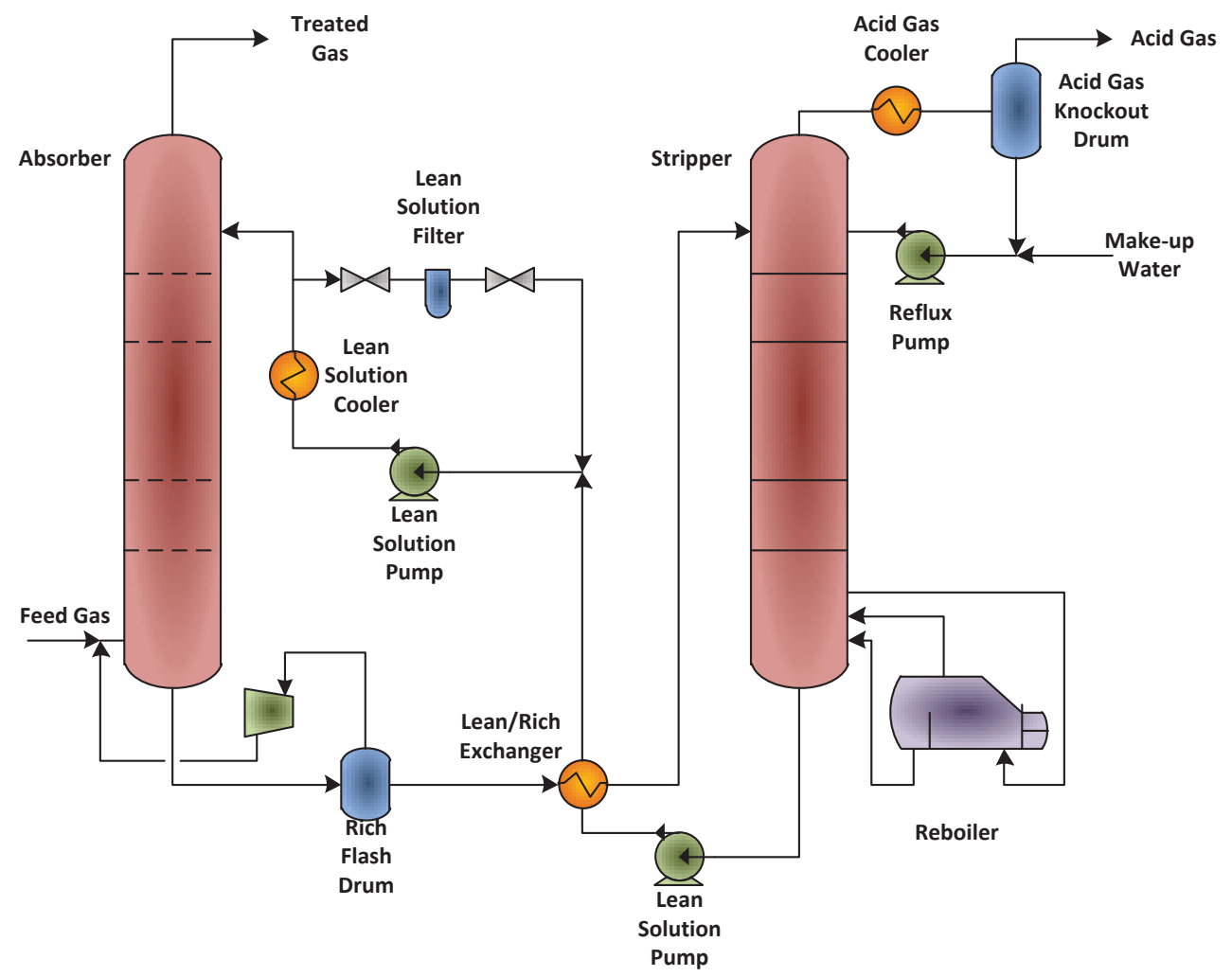

Figure 24. Selexol process as modeled in ASPEN Plus

\subsubsection{Power generation}

\section{Gas turbine / Expanders / Compressors}

Simple gas turbine models were employed using isentropic efficiencies that ranged from $90 \%$ for large turbines, to $80 \%$ for smaller expanders. Similarly, large-scale compressors were modeled with isentropic efficiencies of $88 \%$ and small compressors with efficiencies of $80 \%$.

\section{Solid oxide fuel cell}

The SOFC ASPEN model employed was based on the DOE NETL model developed by John VanOsdol and Randy Gemmen and has been benchmarked against other models as previously discussed in Section 4.3. A generic voltage-current performance curve was generated based on this model that is derived from DOE SECA performance targets. The model is zero-dimensional using average electrode gas properties and achieves a cell power density of $0.31 \mathrm{~W} / \mathrm{cm}^{2}$ operating on syngas at $80 \%$ fuel utilization and 0.78 V/cell as shown in Figure 25. 


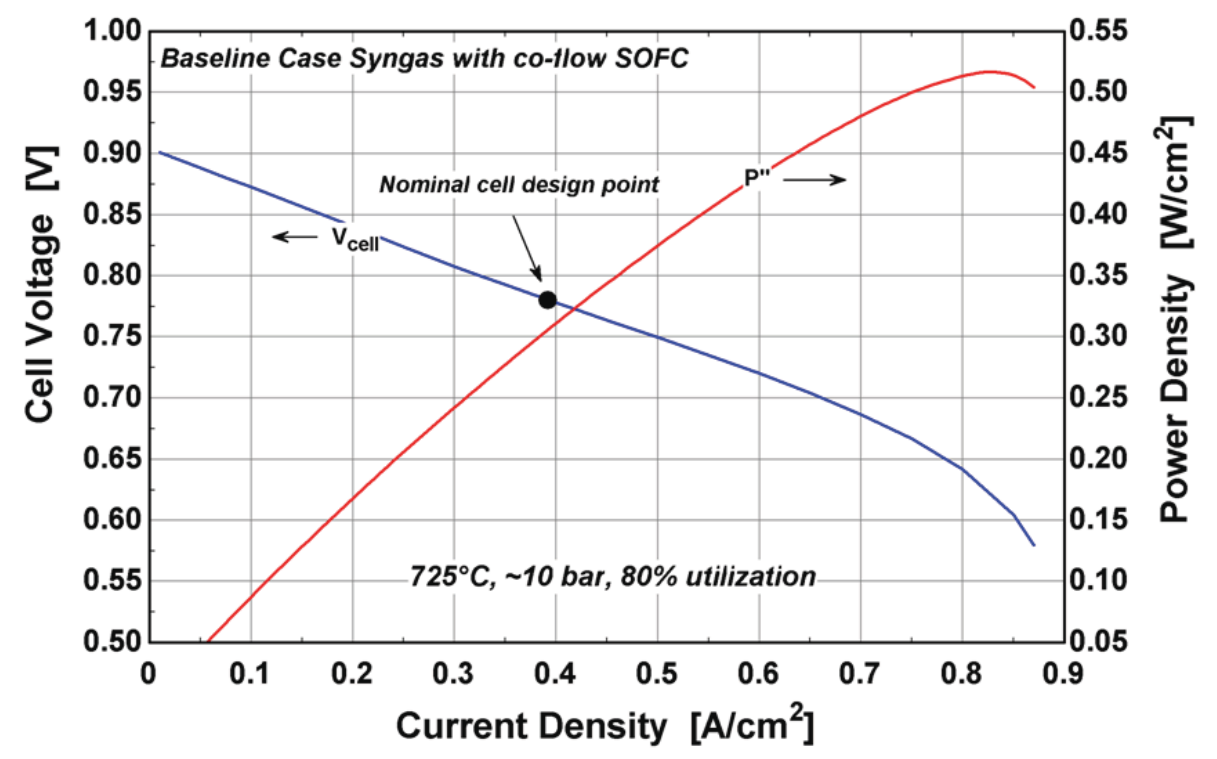

Figure 25. SOFC performance characteristic for Focus Area (2)

The operating conditions for the SOFC are summarized in Table 6. An SOFC operating pressure of 10 bars was chosen as the baseline. While some preliminary studies were done exploring the effect of SOFC operating pressure on these results, project schedule constraints limited any pursuit of them to the point of being able to discuss useful results in detail.

Table 6. SOFC Operating Parameters

\begin{tabular}{|l|c|}
\hline Parameter & Value \\
\hline System operating pressure & $10 \mathrm{bar}$ \\
\hline Nominal SOFC operating temperature & $725^{\circ} \mathrm{C}$ \\
\hline Allowable cathode air temperature rise & $150^{\circ} \mathrm{C}$ \\
\hline SOFC cathode pressure drop & $5 \mathrm{kPa}$ \\
\hline SOFC fuel utilization & $80 \%$ \\
\hline SOFC average single cell voltage & $0.78 \mathrm{~V} / \mathrm{cell}$ \\
\hline
\end{tabular}

\subsubsection{WGSMR}

Hydrogen transfer membranes (HTMs) are an attractive process intensification technology that offer high hydrogen selectivity, are capable of high temperature operation $\left(\sim 400-450^{\circ} \mathrm{C}\right)$, and when used in conjunction with a water-gas shift catalyst, offer greater than equilibrium $\mathrm{CO}$ conversion. Due to the use of palladium and other precious metal alloys, costs can be high for these membranes and poisoning (via $\mathrm{H}_{2} \mathrm{~S}, \mathrm{HCl}$, etc.) and durability performance are still being 
established. The status of WGSMR technology in terms of performance metrics is given in Table 7. The targets shown in the table below are for a relatively pure hydrogen gas feed stream but any hydrogen recovery specification at the table conditions is notably absent from the DOE targets. Hydrogen flux from a coal-derived syngas is expected to be substantially lower given the reduced driving force.

Table 7. Hydrogen transfer membrane technology status [59]

\begin{tabular}{|l|c|c|c|c|}
\hline Performance Criteria & Units & $\begin{array}{c}\text { 2010 Status } \\
\text { (Pd-based) }\end{array}$ & 2010 Target & 2015 Target \\
\hline Flux & $\mathrm{ft}^{3} / \mathrm{hour}^{\prime} \mathrm{ft}^{2}$ & $\sim 200-300$ & 200 & 300 \\
\hline Temperature & ${ }^{\circ} \mathrm{C}$ & $300-500$ & $300-600$ & $250-500$ \\
\hline S Tolerance & $\mathrm{Ppmv}$ & $\sim 5$ & 20 & $>100$ \\
\hline Cost & $\$ / \mathrm{ft}^{2}$ & $140-600$ & 100 & $<100$ \\
\hline WGS Activity & - & $\mathrm{n} / \mathrm{a}$ & Yes & Yes \\
\hline$\Delta$ P Capability & Psi & TBD & Up to 400 & Up to $800-1000$ \\
\hline CO Tolerance & - & Some & Yes & Yes \\
\hline $\mathrm{H}_{2}$ Purity & $\%$ & $>99.5$ & 99.5 & 99.99 \\
\hline Stability/Durability & Years & 0.9 & 7 & 10 \\
\hline
\end{tabular}

\section{Modeling}

The flux of hydrogen can generally be characterized by a Sievert's Law relationship where the flux is proportional to the square root of the partial pressure driving force between retentate and permeate streams as shown in,

$$
J=\frac{k D}{\delta} \cdot\left(P_{H_{2}, \text { Ret }}^{0.5}-P_{H_{2}, p e r m}^{0.5}\right)
$$

The WGSMR modeling effort investigated performance characteristics of United Technologies' palladium-copper alloy membrane development activity [60]. This technology faces development challenges to meet the DOE flux targets of $200 \mathrm{ft}^{3} / \mathrm{h}-\mathrm{ft}^{2}$ at $475^{\circ} \mathrm{C}$ operation with a pure hydrogen feed gas, but it is likely to achieve high performance hydrogen flux in the real operation scenario of a gasification-based syngas mixture that contains low-level amounts of $\mathrm{H}_{2} \mathrm{~S}$. Hydrogen permeability and flux performance was coupled to water-gas shift kinetics based on the rate equation from Moe [61]. The CSM membrane model was benchmarked against UTRC data (see Figure 26) and then used to explore membrane performance sensitivity due to variations in membrane temperature and feed gas composition. As Figure 26 shows, good agreement between an isothermal membrane model and test data was obtained. 
The temperature dependence of membrane permeability and required area for $90 \%$ hydrogen recovery is shown in Figure 27. In this plot, temperature and compositional variation is depicted. As the temperature increases, permeability increases and the required area for $90 \%$ hydrogen recovery decreases. Area requirements show a non-linear dependence.

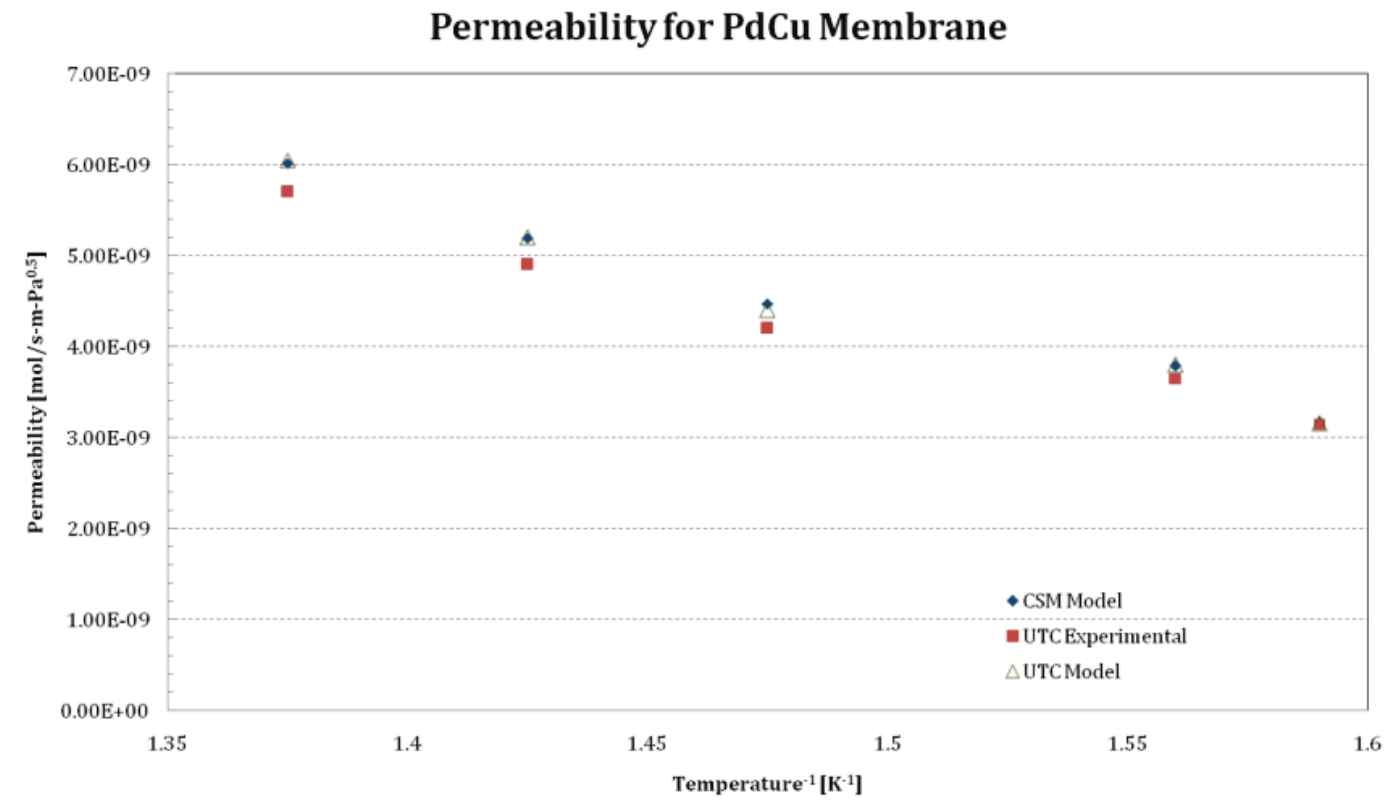

Figure 26. Benchmarking of CSM membrane model to UTRC performance data

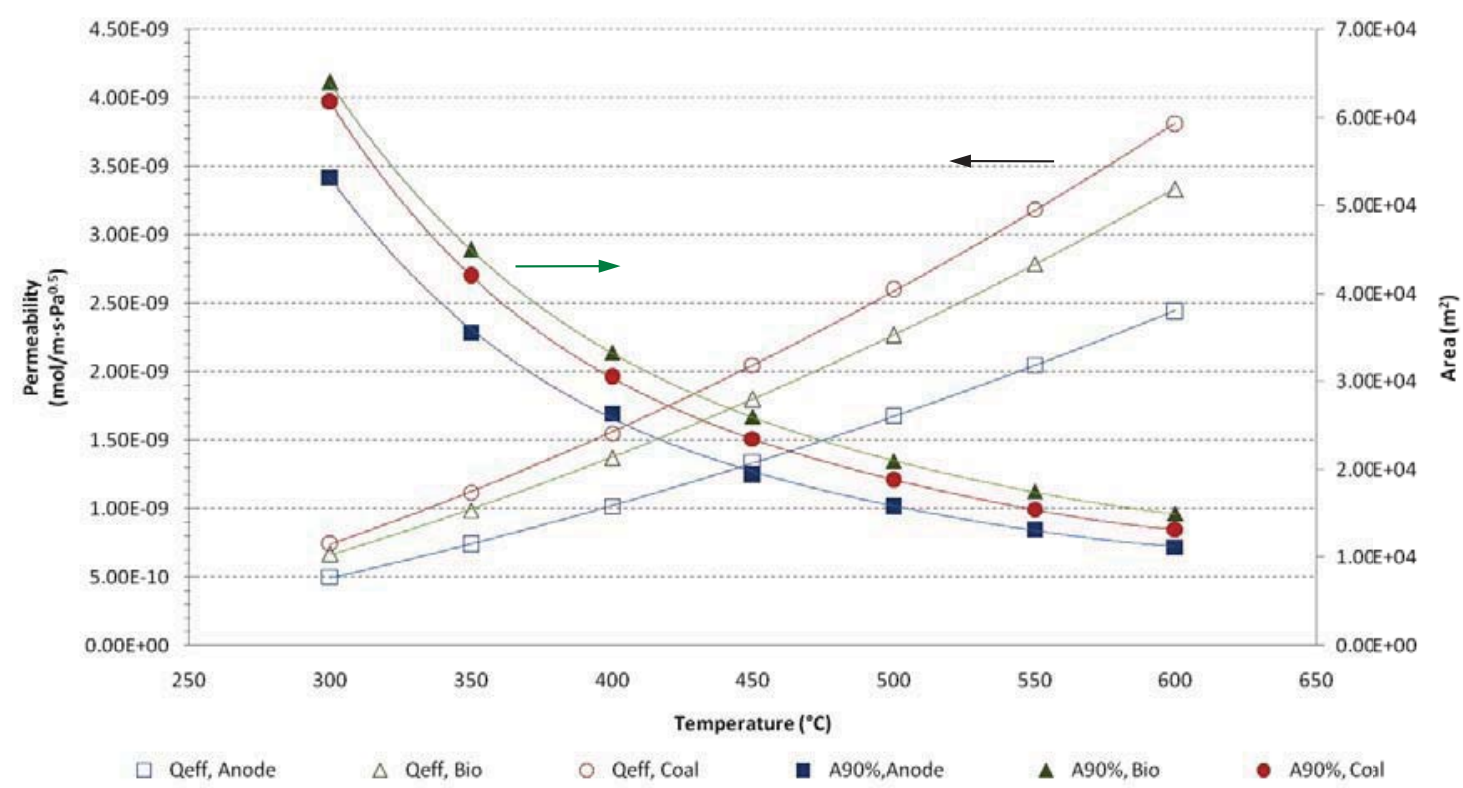

Figure 27. Temperature dependence of membrane permeability and required area

The permeability sensitivity to syngas $\mathrm{H}_{2}+\mathrm{CO}$ concentration was assessed by testing the model against syngas from an oxygen-blown, dry-fed slagging gasifier (e.g., Shell), a directly-heated, 
oxygen-blown fluidized-bed biomass gasifier, and from the anode tail-gas of a solid oxide fuel cell. The $\mathrm{H}_{2}+\mathrm{CO}$ composition varies from $64 \%$ for the coal syngas to $45 \%$ for the biomass gasifier to $4 \%$ for the anode tail-gas. The highest permeability is observed for the the coal syngas. Interestingly, the biomass syngas registers a lower area requirement for $90 \%$ recovery, largely because while the permeability is lower than a coal syngas, the pressure driving force across the membrane is effectively larger, registering a net gain.

Focus Area (2) membrane modeling employed a supported 5 micron Pd-alloy HTM whose performance was similar to the UTRC technology, but not identical. The performance was based on laboratory scale permeability data and the model was Excel-based with a 1-D plug flow assumption. Actual model predicted performance on syngas is summarized in Table 8.

Table 8. WGSMR model-predicted performance on syngas

\begin{tabular}{|l|c|}
\hline Average Flux & $68 \mathrm{ft}^{3} / \mathrm{hour} / \mathrm{ft}^{2}$ \\
\hline Temperature & $350^{\circ} \mathrm{C}$ \\
\hline Retentate Pressure & $34 \mathrm{bar}$ \\
\hline Permeate Pressure & $17 \mathrm{bar}$ \\
\hline
\end{tabular}

\subsubsection{OCMR}

Oxygen-conducting membranes examined in this study are based on perovskite materials and operate at high temperatures that are compatible with SOFCs. A performance and cost target summary has been compiled and is given in Table 9 below.

Table 9. Oxygen conducting membrane performance summary

\begin{tabular}{|c|c|c|}
\hline Performance Criteria & Units & $\begin{array}{c}\text { Current-Status } \\
\text { (Perovskite Membranes) }\end{array}$ \\
\hline Flux & $\mathrm{ml} / \mathrm{cm}^{2}-\mathrm{min}$ & $15\left(\sim 30 \mathrm{ft}^{3} / \text { hour }-\mathrm{ft}^{2}\right)^{[62]}$ \\
\hline Temperature & ${ }^{\circ} \mathrm{C}$ & $800-900$ \\
\hline S Tolerance & ppmv & TBD \\
\hline Cost & $\$ / \mathrm{ft}^{2}$ & 110 (expected) $^{[66]}$ \\
\hline CO Tolerance & - & TBD \\
\hline $\mathrm{O}_{2}$ Selectivity & $\%$ & $\sim 100^{[63]}$ \\
\hline Stability/Durability & Hours & $12000^{[66]}$ \\
\hline $\begin{array}{l}\text { Challenges in syngas } \\
\text { environment }\end{array}$ & & $\begin{array}{c}\text { Stability / Permeability, Degradation, } \\
\text { Redox-tolerance }\end{array}$ \\
\hline
\end{tabular}




\section{Modeling}

Oxygen flux is proportional to logarithmic oxygen partial pressures as given by the equation,

$$
j_{O 2}=\frac{\sigma_{i} R T}{4 L n^{2} F^{2}} \ln \left(\frac{P_{O 2}^{\prime}}{P_{O 2}^{\prime \prime}}\right)
$$

where $j_{O 2}$ is the oxygen permeation rate, $R$ is the gas constant, $T$ is the absolute temperature, $\sigma_{\mathrm{i}}$ the oxide ionic conductivity, $F$ the Faraday constant, $L$ the thickness, and $p^{\prime}{ }_{\mathrm{O} 2}$ and $p{ }^{\prime}{ }_{\mathrm{O} 2}$ the partial oxygen pressures on feed and permeate side, respectively. This relationship assumes that the bulk diffusion is rate limiting. From this equation, it is clear that for high fluxes, high feed or very low permeate pressures are desirable, as well as small membrane thicknesses. Values for the partial oxygen pressure at the permeate side can be as low as $10^{-18}$ when partial or complete combustion of fuel takes place, i.e., in reactor mode [66].

The OCMR performance used in the present study is based on a 10 micrometer thick dense layer on a porous support. Performance is based on achieving a $15 \mathrm{ml} / \mathrm{cm}^{2}$-min flux at $850^{\circ} \mathrm{C}$ and with an oxygen pressure ratio of 20:1. Feed gases enter the OCMR at $800^{\circ} \mathrm{C}$ and exit at approximately $870^{\circ} \mathrm{C}$ when oxidation of the anode tail-gas is occuring. The reactor model is based in Excel and tied to ASPEN Plus ${ }^{\circledR}$.

\subsubsection{Carbon Capture System Results}

\subsubsection{Baseline system process description and performance}

Details of the baseline IGFC system with post-SOFC carbon capture are given in Figure 28. Approximately $290 \mathrm{MW}$ of Illinois \#6 coal enter the plant and after pulverization, it is pressurized in lockhoppers and then mixed with steam and oxygen in the gasifier. Syngas exits the gasifier and is cooled to $1000^{\circ} \mathrm{C}$ via $30 \%$ syngas recycle from downstream of the cyclone. After quench cooling, the syngas is stripped of halides (e.g., $\mathrm{HCl}$ ) then delivered to a warm-gas desulfurization unit where bulk $\mathrm{H}_{2} \mathrm{~S}, \mathrm{COS}, \mathrm{NH}_{3}$, and polishing of $\mathrm{HCl}$ to $<50$ ppbw occurs. $\mathrm{H}_{2} \mathrm{~S}$ polishing from $\sim 10 \mathrm{ppmv}$ to $<1$ ppmv occurs in a zinc oxide sorbent bed and is followed by elevated temperature mercury removal. As the SOFC operating pressure is 10 bar, the syngas is expanded down from 33 bars to 15 bars in a syngas expander that produces about $2.4 \mathrm{MW}$ of power. The clean syngas provides the necessary driving pressure for the anode gas ejector which recycles a fraction of the anode exhaust gas to achieve the necessary gas preheat and steam-tocarbon ratio at the anode inlet. The fuel gas enters the SOFC at about $650^{\circ} \mathrm{C}$ and 10.1 bars.

Both cathode and anode gas recycle are present in the SOFC periphery. For pressurized systems, cathode gas recycle via a high-temperature blower offers lower parasitic power penalty and can be advantageous in terms of avoiding expensive, high-temperature heat exchanger technology [67]. Cathode air supply is managed by the SOFC compressor which is connected to the SOFC expander. About 18.5 MW of net power is produced by the SOFC gas turbine spool and 100 
MW of ac power by the SOFC stack. Gas turbine exhaust flow is sent through a portion of the heat recovery steam generator for the bottoming steam cycle heat input before being vented from the IGFC system at $100^{\circ} \mathrm{C}$. Residual fuel in the anode outlet gas is oxidized with an oxygen stream from the ASU in the oxy-combustor.The products of oxy-combustor are expanded to produce about 14.5 MW of power. After water knockout and additional cooling, the captured $\mathrm{CO}_{2}$ is compressed in an intercooled $\mathrm{CO}_{2}$ compressor to the pipeline-ready sequestration pressure of 150 bar. The oxy-combustor expander produces enough power to operate the $\mathrm{CO}_{2}$ compressor, resulting in little $(<0.1 \mathrm{MW})$ net parasitic power in the carbon capture subsystem.

Oxygen for both the gasifier and oxy-combustion is supplied from a cryogenic ASU which consumes about $0.285 \mathrm{kWh}$ per kilogram of pure oxygen generated. Gasifier lockhopper pressurization is accomplished with a small $\mathrm{CO}_{2}$ bleed stream from a $\mathrm{CO}_{2}$ compressor stage. The steam bottoming cycle employs high, intermediate, and low-pressure turbines producing 32.5 MW of power. In total, the IGFC plant produces $138.4 \mathrm{MW}$ of net power at an overall system efficiency of $47.7 \%$ LHV including CCS.

A detailed plant energy balance summary is given in Table 10.

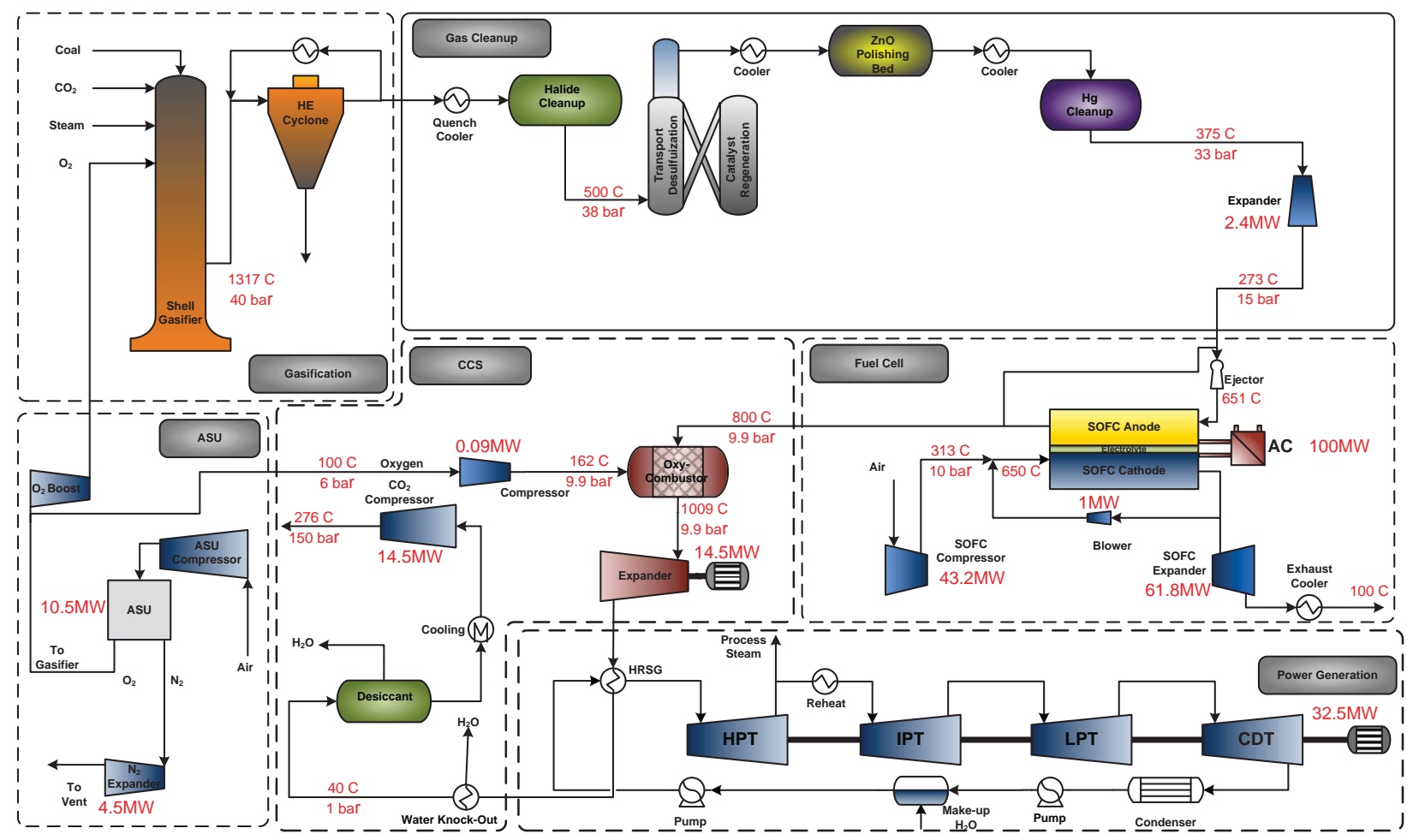

Figure 28. Baseline case: Post-SOFC CCS using oxy-combustion 


\subsubsection{Post-SOFC CCS System results}

\section{Case 1}

Figure 29 depicts the schematic diagram of the Case 1 IGFC power plant with post-SOFC CCS via a water-gas shift membrane reactor. In this plant concept, the essential features of the Baseline case are retained with the exception of the removal of the oxy-combustor and the associated oxygen supply from the ASU in favor of a hydrogen-air burner. The WGSMR is situated downstream of the anode tail-gas and operates at $400^{\circ} \mathrm{C}$ with a nearly 10 bar pressure differential between retentate and permeate streams. With the dilute anode exhaust gas, nearly $8700 \mathrm{~m}^{2}$ of membrane area is required. The system produces 133.2 MW of net power at an overall efficiency of $45.9 \%$ LHV.

A nearly two percentage point reduction in plant efficiency performance is realized compared with the Baseline case. The reduction in efficiency is primarily due to small reductions $(\sim 5$ MW) in gross power production from the expanders in the SOFC periphery while the overall plant auxiliary power requirements were nearly the same at 77.5 MW. Quantitative sub-system performance details of the Baseline and Case 1 systems can be found in Table 10.

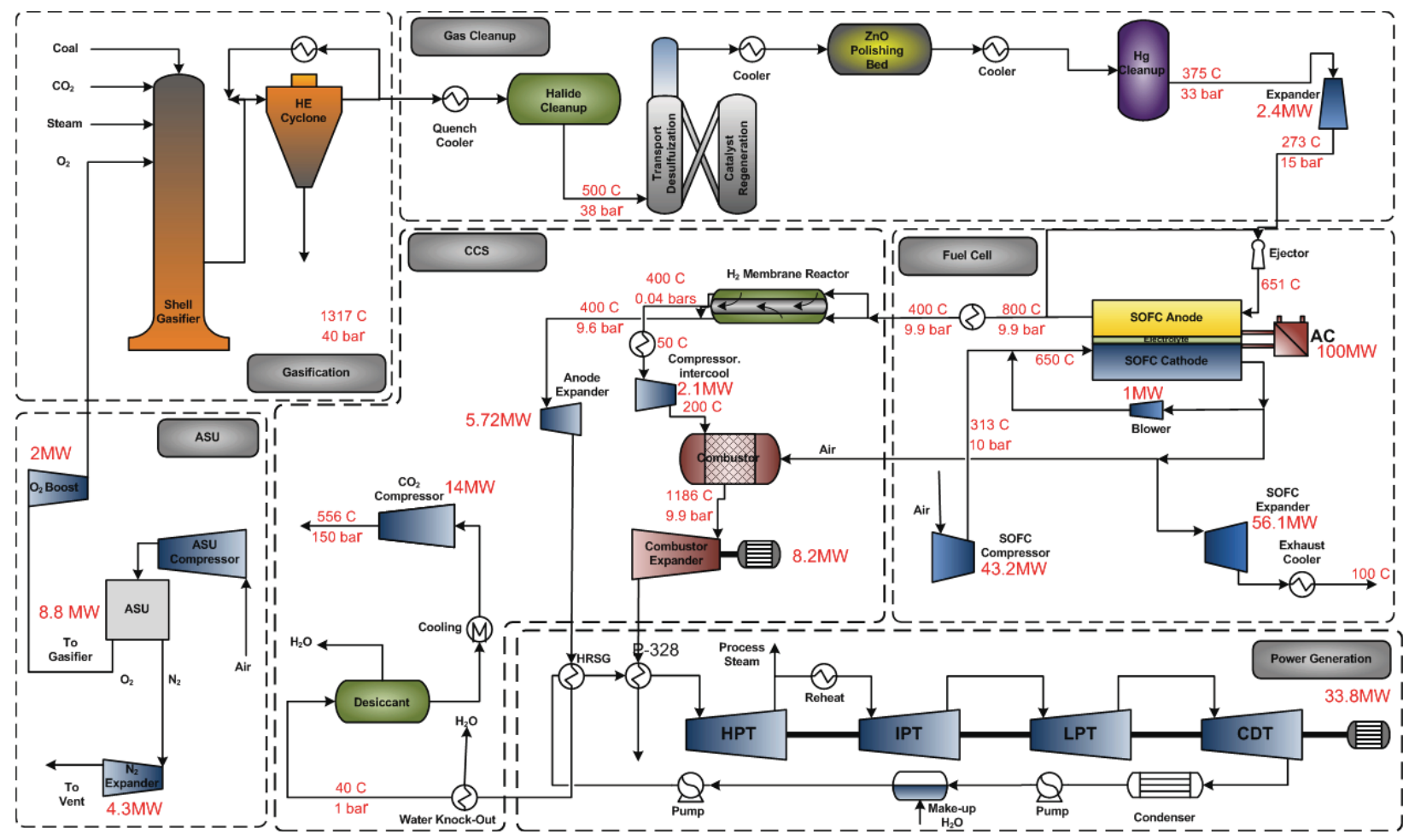

Figure 29. Case 1: Post-SOFC CCS using water-gas shift membrane reactor 
Table 10. IGFC Energy Balance Performance Summary

\begin{tabular}{|c|c|c|c|c|c|c|}
\hline \multirow[b]{2}{*}{ [all units = MW] } & \multicolumn{4}{|c|}{ Post-SOFC CCS } & \multicolumn{2}{|c|}{ Pre-SOFC CCS } \\
\hline & Baseline & $\begin{array}{c}\text { Case } 1 \\
\text { WGSMR } \\
\text { no sweep }\end{array}$ & $\begin{array}{c}\text { Case } 2 \\
\text { WGSMR } \\
\text { N2 Sweep }\end{array}$ & $\begin{array}{c}\text { Case } 3 \\
\text { OCM }\end{array}$ & $\begin{array}{l}\text { Case } 4 \\
\text { Selexol }\end{array}$ & $\begin{array}{c}\text { Case } 5 \\
\text { WGSMR }\end{array}$ \\
\hline Gasifier Input & 290 & 290 & 290 & 290 & 290 & 290 \\
\hline \multicolumn{7}{|l|}{ Plant Production } \\
\hline SOFC & 100.1 & 100.1 & 100.1 & 100.1 & 101.8 & 90.0 \\
\hline Syngas Expander & 2.4 & 2.4 & 2.4 & 2.4 & 2.5 & 1.8 \\
\hline Anode Expander & 14.5 & 5.7 & 5.8 & 11.5 & 19.3 & 40.8 \\
\hline Steam Cycle/ORC & 32.5 & 33.8 & 32.1 & 31.9 & 28.2 & 31.0 \\
\hline N2 Expander & 4.5 & 4.3 & 4.3 & 4.3 & 3.8 & 3.8 \\
\hline Cathode Expander & 61.8 & 64.3 & 68.5 & 66.5 & 45.3 & 27.8 \\
\hline Total & 215.7 & 210.6 & 213.1 & 216.6 & 200.9 & 195.2 \\
\hline \multicolumn{7}{|l|}{ Parasitics } \\
\hline Pumps/Misc & 0.3 & 0.4 & 0.4 & 0.4 & 0.6 & 0.4 \\
\hline CO2 Compressor & 14.5 & 14.2 & 14.3 & 14.1 & 5.7 & 2.4 \\
\hline Cathode Blower & 0.9 & 0.9 & 0.9 & 0.9 & 0.8 & 0.8 \\
\hline O2 Compressor & 2.0 & 2.0 & 2.0 & 2.0 & 2.0 & 2.0 \\
\hline $\begin{array}{l}\text { O2/Air } \\
\text { Compressor }\end{array}$ & 0.09 & 2.22 & 2.9 & - & 0.00 & 0.00 \\
\hline Air Compressor & 43.2 & 43.2 & 43.2 & 43.2 & 34.3 & 32.9 \\
\hline $\begin{array}{l}\text { Recycle } \\
\text { Compressor* }\end{array}$ & 0.02 & 0.02 & 0.02 & 0.02 & 0.02 & 0.02 \\
\hline ASU Duty & 10.5 & 8.8 & 8.8 & 8.8 & 8.8 & 8.8 \\
\hline $\begin{array}{l}\text { Cooling Tower + } \\
\text { Chiller }\end{array}$ & 3.7 & 3.7 & 3.6 & 3.6 & 3.5 & 1.4 \\
\hline Selexol Duty & - & - & - & - & 3.2 & - \\
\hline Misc & 2.0 & 2.0 & 2.0 & 2.0 & 2.0 & 2.0 \\
\hline Total & 77.3 & 77.5 & 78.2 & 75.0 & 60.9 & 50.8 \\
\hline Net Total & 138.4 & 133.2 & 134.9 & 141.6 & 139.9 & 144.4 \\
\hline $\begin{array}{l}\text { System Efficiency } \\
\text { (\%-LHV) }\end{array}$ & 47.7 & 45.9 & 46.5 & 48.8 & 48.3 & 49.8 \\
\hline $\begin{array}{l}\mathrm{CO}_{2} \text { capture } \\
\text { penalty }\end{array}$ & 5.01 & 4.89 & 4.94 & 4.84 & 3.07 & 0.84 \\
\hline
\end{tabular}

\section{Case 2}

The use of a WGSMR can require substantial membrane area due to reductions of the partial pressure driving force between retentate and permeate sides when a sweep gas is not employed. The large membrane area requirement that has been estimated for Case 1 translates into high capital cost for a palladium alloy membrane. Palladium is an expensive raw material and given DOE targets for operation on sulfur containing syngases, could include even more expensive alloying materials, such as gold to achieve flux goals on coal syngas. Thus, the use of a nitrogen 
sweep gas has been investigated in a Case 2 system concept as shown in Figure 30 . The nearly pure nitrogen sweep stream $\left(>98 \% \mathrm{~N}_{2}\right)$ is available from the ASU and as shown in Figure 30, its integration adds complexity to the plant in the form of two additional compressors, three heat exchangers, and one expander. Despite these component additions the system efficiency is actually increased by $0.6 \%$ while producing about $135 \mathrm{MW}$ of net ac power for an overall system efficiency of $46.5 \%$-LHV.

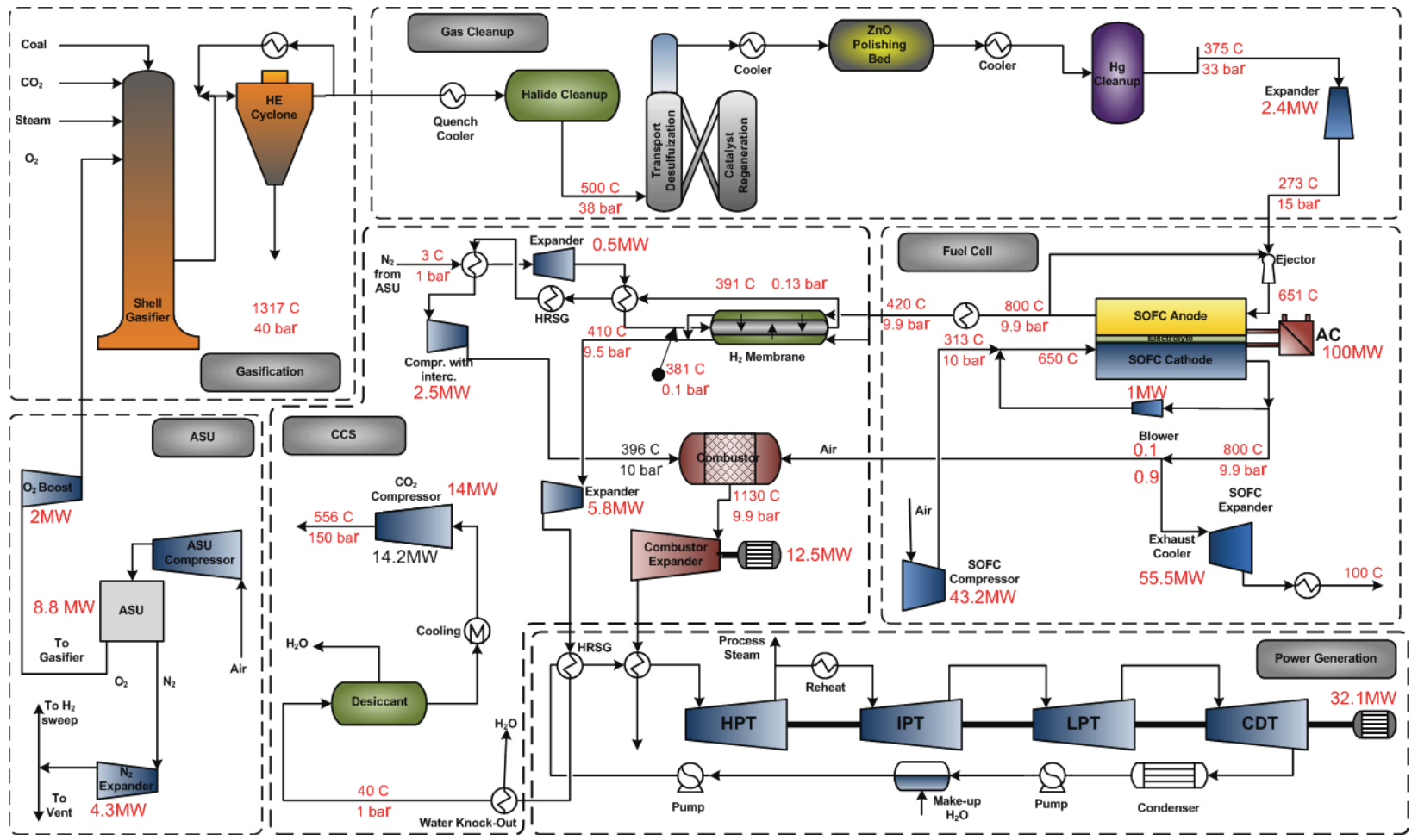

Figure 30. Case 2: Post-SOFC CCS using water-gas shift membrane reactor and sweep gas

As Figure 30 and Table 10 detail, a slight increase in the plant auxiliary power of less than 1 MW is realized for the integration of the sweep gas. The membrane area requirement is reduced by $34 \%$ from $8700 \mathrm{~m}^{2}$ to $5780 \mathrm{~m}^{2}$. Net plant power production is increased by nearly $2 \mathrm{MW}$ which increases the efficiency by $0.6 \%$ versus Case 1 . However, as will be shown in the economic evaluation below, the reduced membrane area produces a net decrease in plant capital cost and increases power plant efficiency performance due to higher expander power generation.

A close-up view of the membrane reactor integration in the SOFC periphery is shown in Figure 31(a) and (b). In these simplified diagrams, the power produced by the gas turbine includes the tail-gas combustor expander power. For example, in Figure 31(a), $64 \mathrm{MW}=56 \mathrm{MW}+8 \mathrm{MW}$. In Case 2, the nitrogen sweep gas lowers the rotor inlet temperature by $66^{\circ} \mathrm{C}$ but the increased mass flow through the turbine causes a net increase of $4 \mathrm{MW}$ of power generation. 


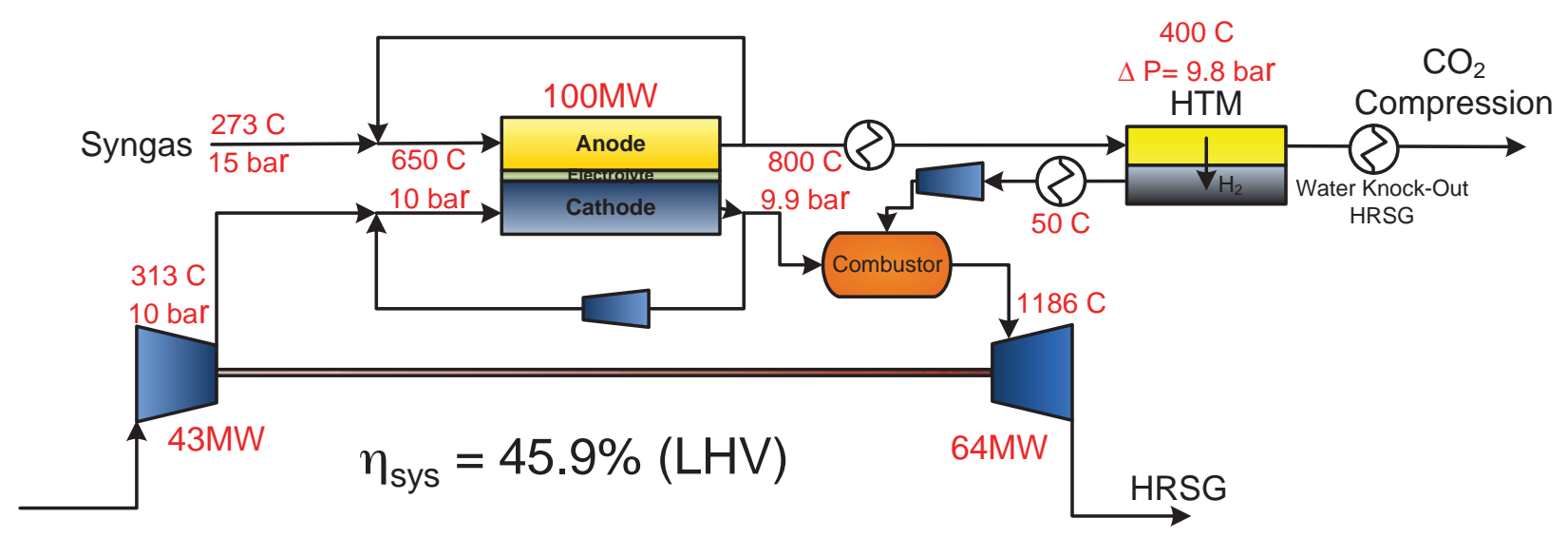

(a.) Simplified flow diagram for Case 1 post-SOFC CCS

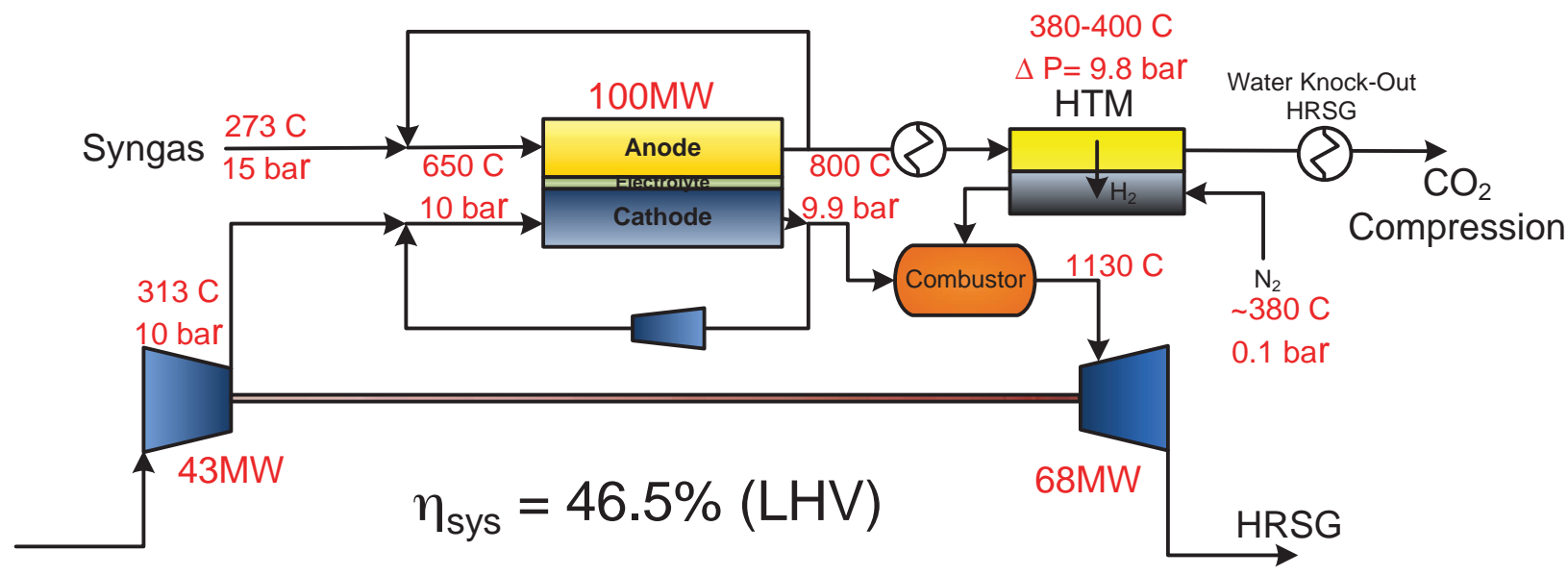

(b.) Simplified flow diagram for Case 2 post-SOFC CCS

Figure 31. Simplified diagram of SOFC periphery for (a.) Case 1 and (b.) Case 2 IGFC system

\section{Case 3}

Integrating an oxygen conducting membrane (OCM) into the cathode tail-gas offers another option for post-SOFC carbon capture. Note that 'oxygen conducting' and 'oxygen transfer membrane (OTM)' are used interchangeably in this document. As shown in Figure 32, the cathode exhaust gas is admitted into the oxygen conducting membrane reactor and oxygen from the depleted cathode gas is transported across the membrane where it mixes with the anode tail gas stream and oxidizes the residual $\mathrm{H}_{2}$ and $\mathrm{CO}$. An important feature of this configuration is that the bulk gas pressure on either side of membrane is roughly maintained constant, but the as the oxygen is consumed on the permeate side of the reactor, the partial pressure is very low $\left(\sim 10^{-}\right.$ ${ }^{18}$ ) and thus, a very large transport driving force is maintained which results in low membrane area. This has both cost and performance implications that make OCM technology attractive for future IGFC power plants. 


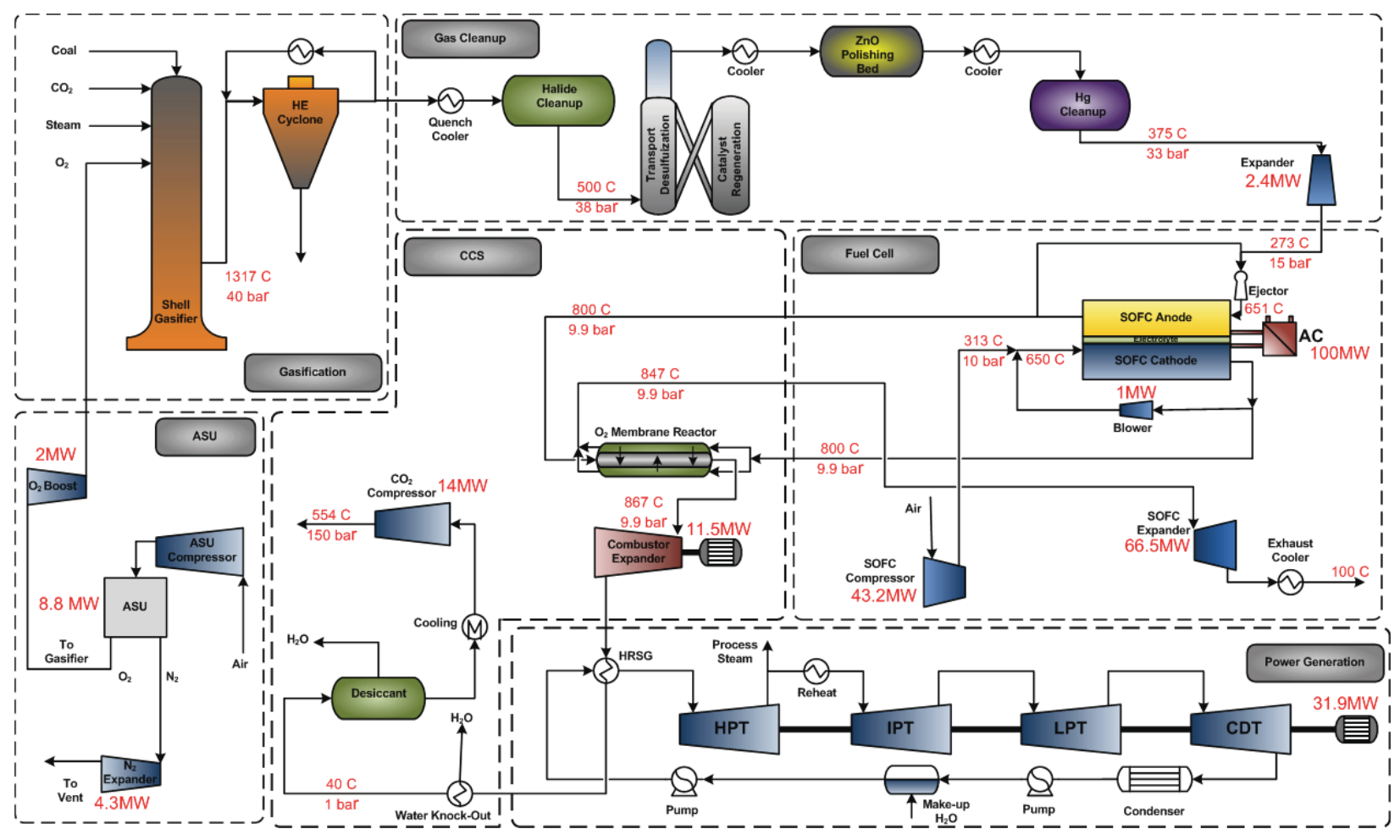

Figure 32. Case 3: Post-SOFC CCS employing an oxygen conducting membrane

The use of the OCM also enables a larger mass flow to the SOFC expander (than in either Case 1 or 2) which when combined with the expander downstream of the membrane reactor produces 78 MW of power as shown in Figure 33 and Table 10. The Case 3 plant concept generates nearly $142 \mathrm{MW}$ of power while achieving a net system efficiency of $48.8 \% \mathrm{LHV}$, a performance that is 1.1 percentage points higher than the Baseline case while producing $3 \mathrm{MW}$ additional power.

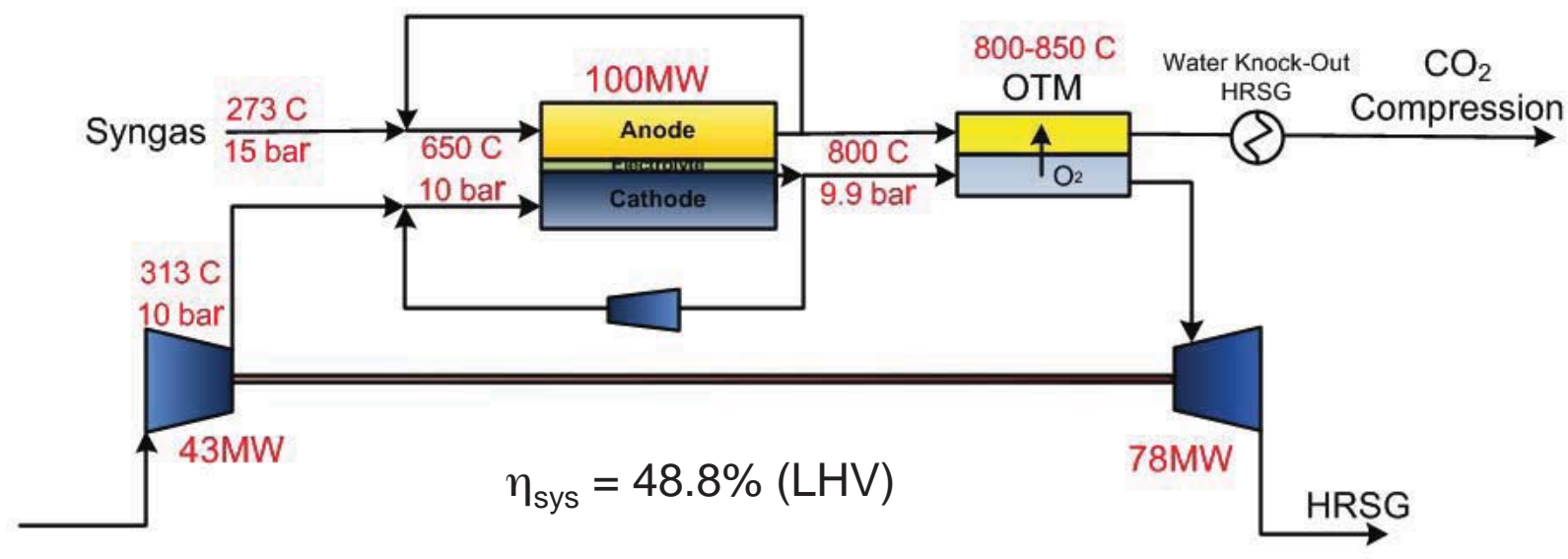

Figure 33. Case 3: Simplified diagram of OCMR in SOFC peripherary 


\subsubsection{Pre-SOFC CCS System Results}

\section{Case 4}

Figure 34 summarizes the plant concept for pre-SOFC carbon capture employing conventional Selexol acid gas removal technology. In this configuration, after halide and particulate removal, the syngas is supplied to a sour water-gas shift reactor that is capable of operating without degradation in the presence of high sulfur levels. Sulfur-tolerant water-gas shift catalysts have been developed by Haldor-Topsoe (e.g., type SSK commercial shift catalyst) specifically for coal syngases. The CO-shifted syngas is cooled to the temperature necessary for a 2-stage Selexol process $\left(60^{\circ} \mathrm{C}\right)$. Captured $\mathrm{CO}_{2}$ is then compressed from $\sim 5$ bar to 150 bar pipeline-ready sequestration conditions. The clean syngas is heated to $375^{\circ} \mathrm{C}$ for polishing of $\mathrm{H}_{2} \mathrm{~S}$ in a zincoxide sorbent bed down to sub-1 ppmv concentration levels. After mercury removal, the syngas is expanded down to the required anode ejector driving pressure of 15 bar. Note that in this configuration, anode gas recycle is still employed to preheat the reactants to $650^{\circ} \mathrm{C}$. The use of anode recycle in Pre-SOFC CCS configuration deserves further evaluation as it primarily serves as a high temperature preheat option, however its use dilutes the inlet fuel gas hydrogen concentration, driving up the number of cells required to obtain $100 \mathrm{MW}$ of dc power.

Two possible configurations for handling the SOFC tail-gases exist. The first is to retain the basic configuration of separated exhaust gases as previously done in the Baseline and Cases 1 thru 3. This option is the one shown in Figure 34 and Figure 35. Approximately $65 \mathrm{MW}$ of power are developed from the SOFC and combustion gas expanders. Parasitic power amounts to only $61 \mathrm{MW}$ with the primary reductions (as compared to Baseline and Cases 1-3), coming from the lowering of $\mathrm{CO}_{2}$ compression energy from 14.1 MW to 5.7 MW and a $9 \mathrm{MW}$ reduction in required air compression. The Selexol plant requires about $3.2 \mathrm{MW}$ of auxiliary electric power. The net power generated is nearly $140 \mathrm{MW}$ at a system efficiency of $48.3 \%$-LHV. This efficiency is slightly higher than the post-SOFC CCS Baseline case.

A second configuration for Case 4 allows the cathode and the anode tail-gases to mix and exhaust through one expander in a manner such as that shown previously in Figure 23(b). While not shown explicitly in a process diagram, the ASPEN Plus model of this re-configuration estimates a only a slight increase $(<0.3 \%)$ in overall system efficiency. Interestingly, it is slightly more effective to leave the tail-gases unmixed in terms of efficiency and there is little overall net cost difference compared to mixing of tail-gases, oxidizing the residual fuel, and expanding them in a single turbine. 


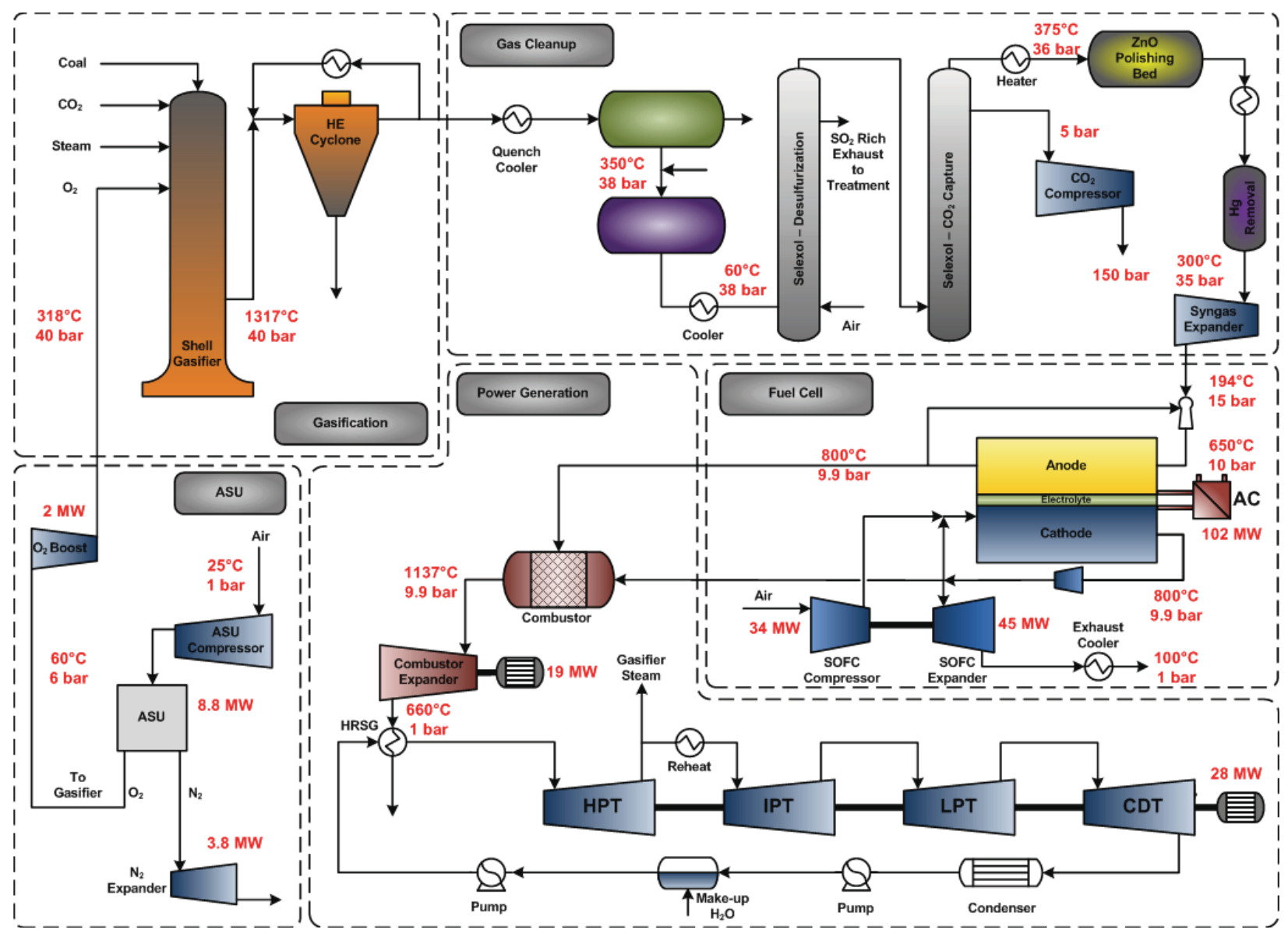

Figure 34. Case 4: Pre-SOFC CCS using Selexol acid gas removal technology

When the 2-stage Selexol acid gas removal plant is replaced by warm gas desulfurization and a water-gas shift membrane reactor, further improvements in system efficiency and cost are possible. The Case 5 plant concept that encompasses this approach is depicted in Figure 35. As shown, the WGSMR is positioned downstream of the mercury removal unit and operates at the same temperature $\left(350^{\circ} \mathrm{C}\right)$. Carbon monoxide is shifted to $\mathrm{CO}_{2}$ using the steam content already present in the syngas. In this pre-SOFC CCS configuration, the hydrogen flux rate is estimated at $68 \mathrm{scft} / \mathrm{hr} / \mathrm{ft}^{2}$ and the associated membrane area required is about $2870 \mathrm{~m}^{2}$ (which is 52 to $67 \%$ lower than Cases 3 and 2, respectively). The consumption of $\mathrm{H}_{2} \mathrm{O}$ in the WGSMR produces a drier gas that reduces the cooling load to achieve the required pipeline sequestration dewpoint. The retentate (primarily $\mathrm{CO}_{2}, \mathrm{H}_{2} \mathrm{O}$ ) exits the WGSMR at a pressure 1-bar lower than it entered and is cooled in a series of heat exchangers removing the water such that a $-40^{\circ} \mathrm{C}$ dewpoint in the pipeline gas is achieved. Compression from 33 bar to 150 bar requires about 2.3 MW of power. The pure hydrogen permeate stream exits the membrane reactor at 17 bar and is expanded down to the SOFC operating pressure of 10 bar. Over $144 \mathrm{MW}$ of power is produced at an overall efficiency of $49.8 \%$. 


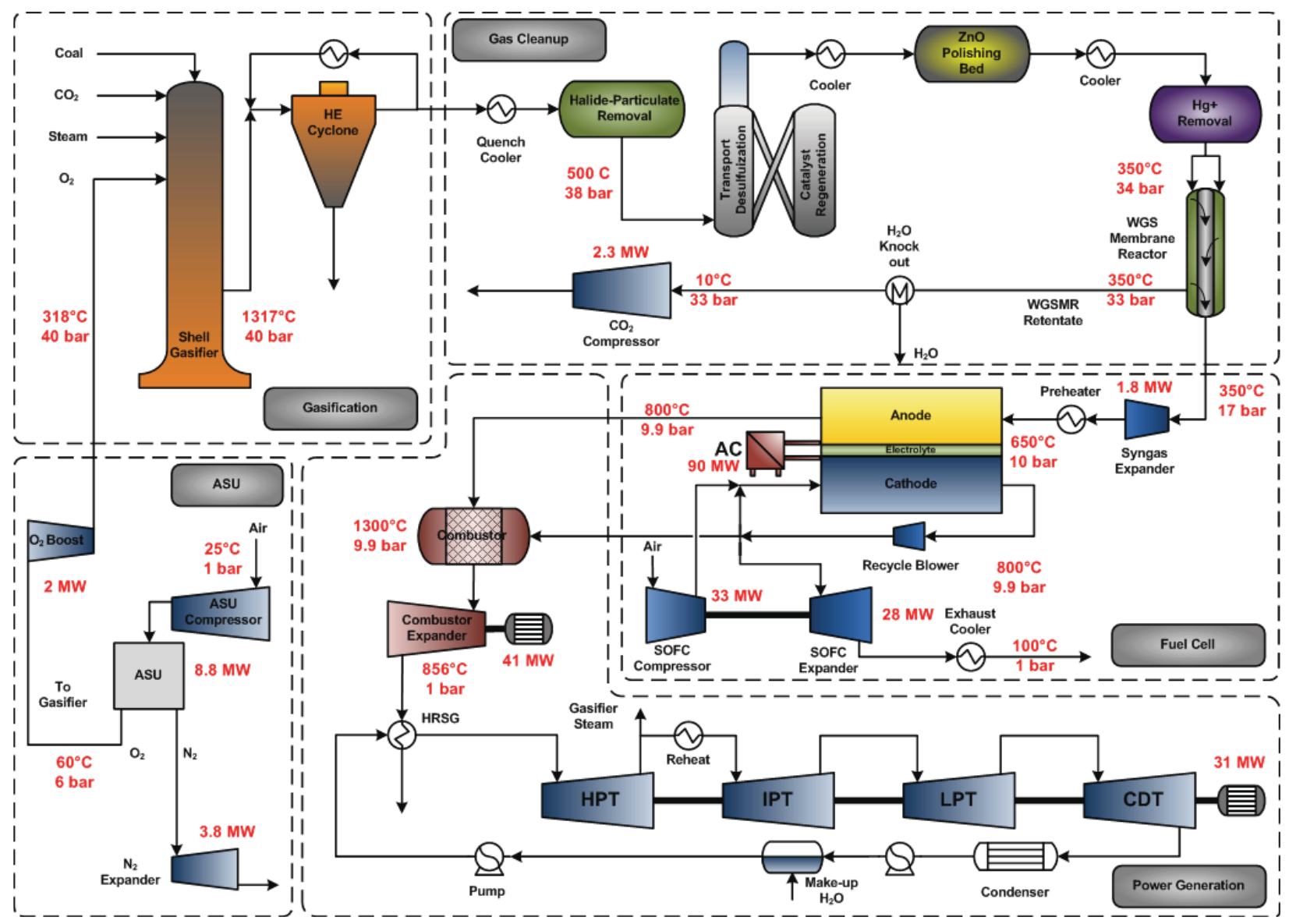

Figure 35. Case 5: Pre-SOFC CCS using water-gas shift membrane reactor technology

Compared to the Baseline Plant, auxiliary power in Case 5 is reduced from 77 MW to 51 MW ( $34 \%$ ) from reductions in the $\mathrm{ASU}, \mathrm{CO}_{2}$ compresssion, and cooling tower duty. Gross power is lowered by over $20 \mathrm{MW}$, but net power is increased from 138.4 to $144.4 \mathrm{MW}$. A summary comparison of the gross power generation and auxiliary power consumption in the Baseline and pre-SOFC CCS concepts is given in Figure 36. Changes in the SOFC power output are due to variations in the anode feed gas composition due to different gas cleaning steps for fixed fuel utilization, cell voltage, operating temperature and pressure, and plant fuel input.

Higher system efficiencies for the plant concepts presented in this report are conceivable as operating parameters were not optimized. For example, note that the per pass fuel utilization in Case 5 is higher than that of the Case 4 as anode recycle is not employed in Case 5. Focus Area (1) also recommended lower system fuel utilizations than the $80 \%$ employed here. Furthermore, the SOFC-GT power block operating pressure of 10-bars is lower than that of other studies (e.g., see Gerdes et al., [21]) and thus, further gains in plant efficiency than reported here are likely. 

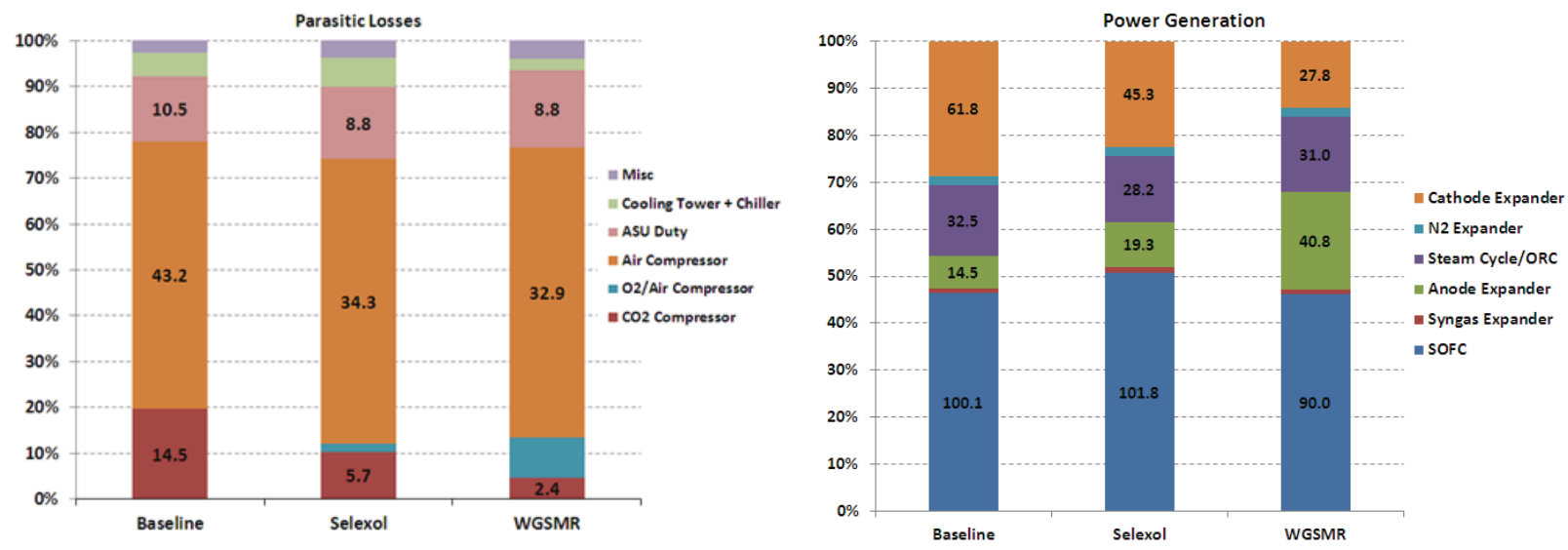

Figure 36. Comparison of auxiliary and gross power generation

\subsubsection{Preliminary Techno-economic Performance Comparisons}

IGFC plant efficiency and economic performance comparisons were made to gauge the overall effectiveness of the various carbon capture concepts. The economic analysis is preliminary in that hardware cost estimates were made for key sub-systems but a complete bottoms-up analysis was not performed. Instead, the gasifier and bottoming steam Rankine power generation cycle capital costs were assumed to be unaffected by changes in system configurations. The entrainedflow gasifier in each system operates with the same feedstock flows and at the same operating conditions. The Rankine power cycle operates within a $10 \%$ power level deviation across all configurations. The focus of economic performance comparisons was made to understand the impact on gas cleanup, SOFC and gas turbine power blocks, carbon capture, and air separation sub-systems.

Capital cost estimates for the targeted sub-sysems were established from the technical literature on IGCC and IGFC plant analyses [21, 43]. Target costs have been employed for SOFC [21] and membrane reactors (see Table 7 and Table 9). A summary of the capital cost reference data and scaling exponents employed to achieve an estimate in 2009 US\$ can be found in Table 11. The comparative results are displayed in the form of bar graphs in Figure 37 and Figure 38. As Figure 37 shows, the installed capital cost estimate (not including gasifier and bottoming Rankine cycle) for the Baseline oxy-combustion system that produces nearly $140 \mathrm{MW}$ of power is about $\$ 116$ million. When comparing the Baseline IGFC system to the post-SOFC CCS plants, capital cost increases nearly $20 \%$ in Case 1 and decreases by over $5 \%$ in Case 3 . Use of a 2 -stage Selexol plant in the pre-SOFC CCS configuration of Case 4 increases plant capital cost by about $46 \%$ with little efficiency performance increase. The parenthetical numbers in red are associated with Case 4 and 5 systems that allow tail-gas mixing. Thus, as Figure 38 shows, Case 5 achieves a $2.5 \%$ efficiency gain and a capital cost reduction of about $\$ 5$ million dollars $(\sim 4 \%)$. Thus, these results indicate that Post-SOFC CCS Case 3 with OCMR and Pre-SOFC CCS Case 5 with WGSMR are the most techno-economically attractive system concepts. 


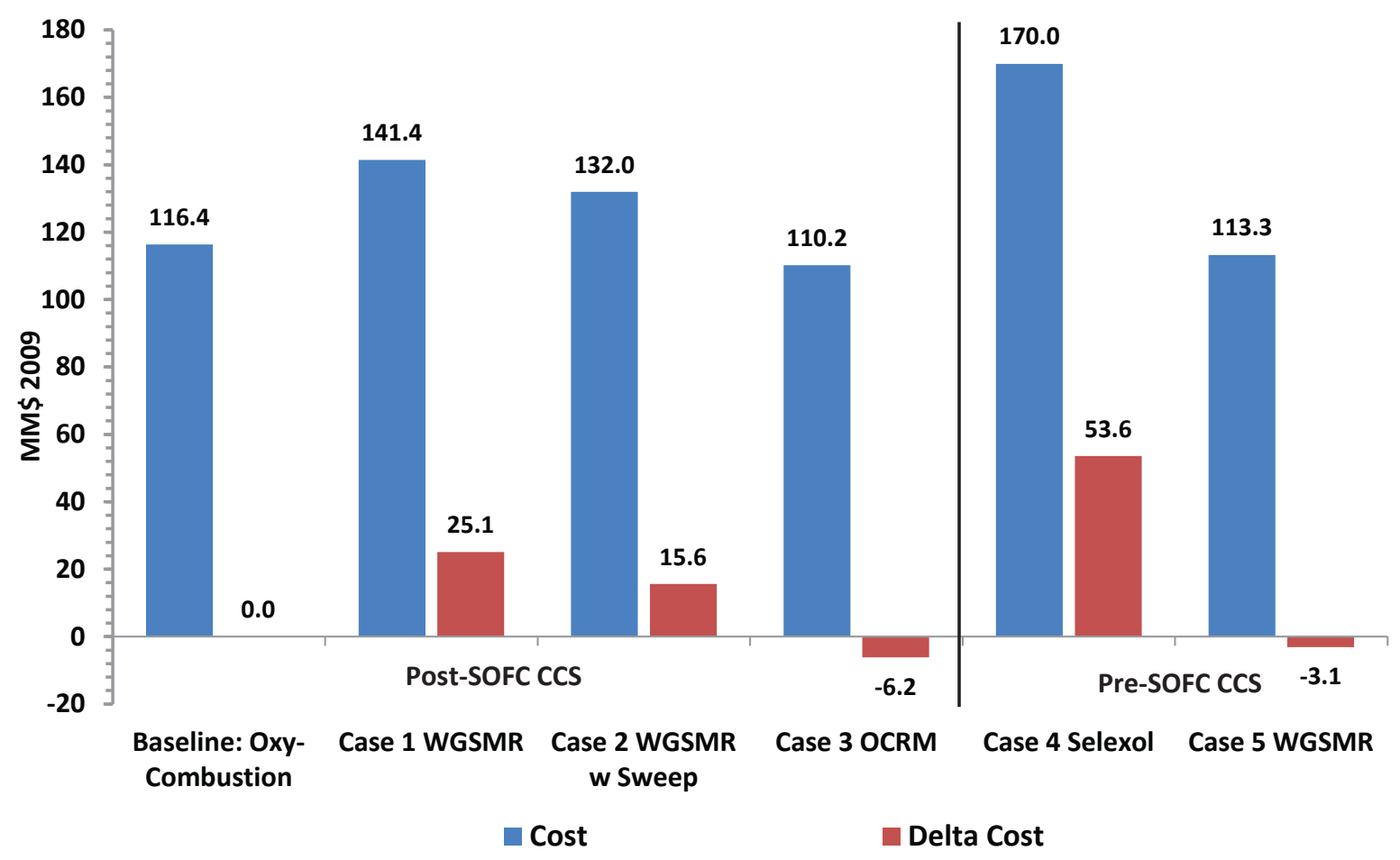

Figure 37. Comparison of IGFC system costs for the various CCS concepts

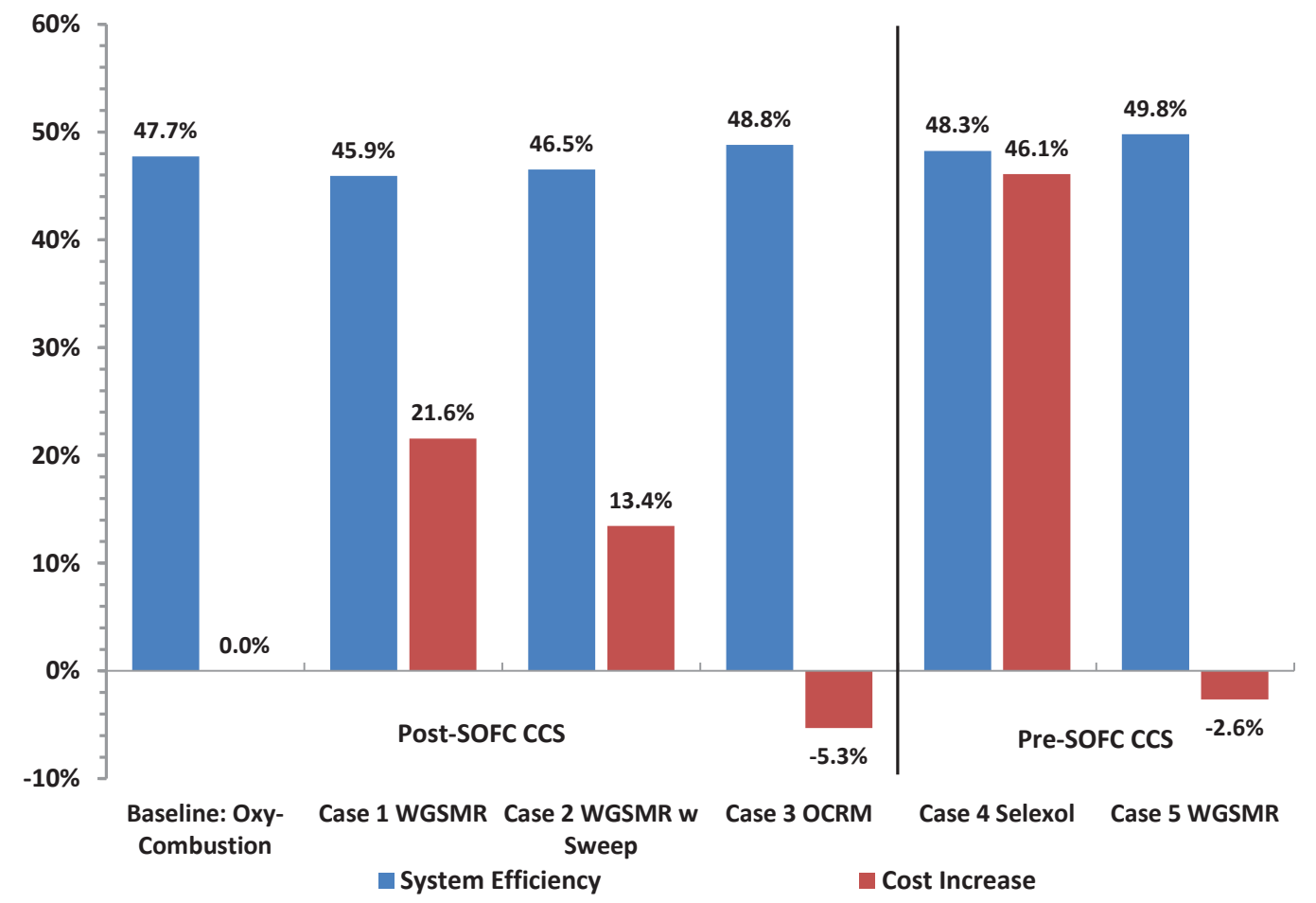

Figure 38. Comparison of IGFC system efficiency and percent cost change for CCS concepts 
Table 11. IGFC capital cost estimation data for each of the cases

\begin{tabular}{|c|c|c|c|c|c|c|c|c|c|c|}
\hline Baseline: Oxy-combustion & $\mathrm{C}_{0}$ & S & $\mathrm{S}_{0}$ & units & $\mathbf{n}$ & CEPCI & $\mathrm{CEPCl}_{0}$ & C & I.F. & Installed Cost \\
\hline WGDS & 4.158288 & 500 & 233.6 & $\mathrm{lb} / \mathrm{hr}$ & 0.7 & 521.9 & 381.7 & 9.69 & 1 & 9.69 \\
\hline ASU & 40.318 & 9.35 & 16.06 & $\mathrm{kgO} 2 / \mathrm{s}$ & 0.625 & 521.9 & 444.2 & 33.78 & 1 & 33.78 \\
\hline SOFC Stack & - & 100.05 & 466 & $\$ / \mathrm{kW}_{\mathrm{DC}}$ & - & 521.9 & 525.4 & 46.31 & 1 & 46.31 \\
\hline Oxy-Combustor & 5 & 17.5 & 69.7 & MW & 0.7 & 521.9 & 525.4 & 1.89 & 1 & 1.89 \\
\hline Syngas Expander & 2 & 2243 & 8375 & $\mathrm{~kW}$ & 0.67 & 521.9 & 525.4 & 0.82 & 1 & 0.82 \\
\hline Oxy-Combustor Expander & 2 & 12706 & 8375 & $\mathrm{~kW}$ & 0.67 & 1 & 1 & 2.64 & 1 & 2.64 \\
\hline $\mathrm{O}_{2}$-compressor & 11 & 65 & 17435 & $\mathrm{~kW}$ & 0.67 & 521.9 & 525.4 & 0.26 & 1 & 0.26 \\
\hline $\mathrm{CO}_{2}$ compressor & 36.121 & 203988 & 999,309 & Ibs/hr & 0.67 & 521.9 & 499.6 & 13.01 & 1 & 13.01 \\
\hline $\mathrm{HXs}$ & - & 79.53 & $100 \$ / \mathrm{kW}$ & MW & - & - & - & 7.95 & 1 & 7.95 \\
\hline Totals (MM 2009\$) & & & & & & & & 116.36 & & 116.36 \\
\hline
\end{tabular}

\begin{tabular}{|c|c|c|c|c|c|c|c|c|c|c|}
\hline Case 1: Post-SOFC CCS via WGSMR & $\mathrm{C}_{0}$ & s & $\mathrm{S}_{0}$ & units & $\mathrm{n}$ & CEPCI & $\mathrm{CEPCI}_{0}$ & C & I.F. & Installed Cost \\
\hline WGDS & 4.158288 & 500 & 233.6 & $\mathrm{lb} / \mathrm{hr}$ & 0.7 & 521.9 & 381.7 & 9.69 & 1 & 9.69 \\
\hline ASU & 35.84 & 9.35 & 16.06 & $\mathrm{kgO} 2 / \mathrm{s}$ & 0.625 & 521.9 & 444.2 & 30.03 & 1 & 30.03 \\
\hline SOFC Stack & $-\quad$ & 100.05 & 466 & $\$ / \mathrm{kW}_{\mathrm{DC}}$ & - & 521.9 & 525.4 & 46.31 & 1 & 46.31 \\
\hline WGSMR & & & & & & & & & 4 & 23.27 \\
\hline Combustor & 5 & 14.90 & 69.7 & MW & 0.7 & 521.9 & 525.4 & 1.69 & 1 & 1.69 \\
\hline Syngas Expander & 2 & 2243 & 8375 & $\mathrm{~kW}$ & 0.67 & 521.9 & 525.4 & 0.82 & 1 & 0.82 \\
\hline WGSMR Expander & 2 & 6005 & 8375 & $\mathrm{~kW}$ & 0.67 & 521.9 & 525.4 & 1.59 & 1 & 1.59 \\
\hline Anode Expander & 2 & 10323 & 8375 & kW & 0.67 & 521.9 & 525.4 & 2.29 & 1 & 2.29 \\
\hline $\mathrm{HXs}$ & - & 109.3 & $100 \$ / \mathrm{kW}$ & $\mathrm{MW}$ & \begin{tabular}{l|l|}
- \\
\end{tabular} & \begin{tabular}{l|l|}
- & \\
\end{tabular} & - & 10.93 & 1 & 10.93 \\
\hline $\mathrm{CO}_{2}$ compressor & 36.121 & 203988 & 999,309 & Ibs/hr & 0.67 & 521.9 & 499.6 & 13.01 & 1 & 13.01 \\
\hline H2 compressor & 11 & 1193 & 17,435 & & 0.67 & 521.9 & 525.4 & 1.81 & 1 & 1.81 \\
\hline Totals (MM 2009\$) & & & & & & & & 116.35 & & 141.44 \\
\hline
\end{tabular}

\begin{tabular}{|c|c|c|c|c|c|c|c|c|c|c|}
\hline Case 2: Post-SOFC WGSMR w Sweep & $\mathrm{C}_{0}$ & S & $\mathrm{S}_{0}$ & units & $\mathrm{n}$ & CEPCI & $\mathrm{CEPCl}_{0}$ & C & I.F. & Installed Cost \\
\hline WGDS & 4.158288 & 500 & 233.6 & $\mathrm{lb} / \mathrm{hr}$ & 0.7 & 521.9 & 381.7 & 9.69 & 1 & 9.69 \\
\hline ASU & 35.84 & 9.35 & 16.06 & $\mathrm{kgO} 2 / \mathrm{s}$ & 0.625 & 521.9 & 444.2 & 30.03 & 1 & 30.03 \\
\hline SOFC Stack & - & 100.05 & 466 & $\$ / \mathrm{kW}_{\mathrm{DC}}$ & - & 521.9 & 525.4 & 46.31 & 1 & 46.31 \\
\hline WGSMR & & & & & & & & & & 15.46 \\
\hline Combustor & 5 & 13.65 & 69.7 & $\mathrm{MW}$ & 0.7 & 521.9 & 525.4 & 1.59 & 1 & 1.59 \\
\hline Syngas Expander & 2 & 2243 & 8375 & $\mathrm{~kW}$ & 0.67 & 521.9 & 525.4 & 0.82 & 1 & 0.82 \\
\hline WGSMR Expander & 2 & 6005 & 8375 & Ibs/hr & 0.67 & 521.9 & 525.4 & 1.59 & 1 & 1.59 \\
\hline N2 Expander & 2 & 454 & 8375 & $\mathrm{lbs} / \mathrm{hr}$ & 0.67 & 521.9 & 525.4 & 0.28 & 1 & 0.28 \\
\hline Anode Expander & 2 & 10323 & 8375 & $\mathrm{lbs} / \mathrm{hr}$ & 0.67 & 521.9 & 525.4 & 2.29 & 1 & 2.29 \\
\hline $\mathrm{CO}_{2}$ compressor & 36.121 & 203988 & 999,309 & Ibs/hr & 0.67 & 521.9 & 499.6 & 13.01 & 1 & 13.01 \\
\hline $\mathrm{N} 2+\mathrm{H} 2$ compressor & 11 & 2500 & 17435 & kW & 0.67 & 521.9 & 525.4 & 2.97 & 1 & 2.97 \\
\hline HXs & - & 79.53 & $100 \$ / \mathrm{kW}$ & $\mathrm{MW}$ & - & - & - & 7.95 & 1 & 7.95 \\
\hline Totals (MM 2009\$) & & & & & & & & 105.60 & & 131.99 \\
\hline
\end{tabular}

\begin{tabular}{|c|c|c|c|c|c|c|c|c|c|c|}
\hline Case 3: OCMR & $\mathrm{C}_{0}$ & $s$ & $\mathrm{~S}_{0}$ & units & $\mathrm{n}$ & CEPCI & $\mathrm{CEPCl}_{0}$ & C & I.F. & Installed Cost \\
\hline WGDS & 4.158288 & 500 & 233.6 & $\mathrm{lb} / \mathrm{hr}$ & 0.7 & 521.9 & 381.7 & 9.69 & 1 & 9.69 \\
\hline ASU & 35.84 & 9.35 & 16.06 & $\mathrm{kgO} 2 / \mathrm{s}$ & 0.625 & 521.9 & 444.2 & 30.03 & 1 & 30.03 \\
\hline SOFC Stack & - & 100.05 & 466 & $\$ / \mathrm{kW}_{\mathrm{DC}}$ & - & 521.9 & 525.4 & 46.31 & 1 & 46.31 \\
\hline Syngas Expander & 2 & 2243 & 8375 & MW & 0.67 & 521.9 & 525.4 & 0.82 & 1 & 0.82 \\
\hline OTM Expander & 2 & 11039 & 8375 & $\mathrm{lbs} / \mathrm{hr}$ & 0.67 & 521.9 & 525.4 & 2.39 & 1 & 2.39 \\
\hline $\mathrm{CO}_{2}$ compressor & 36.121 & 203988 & 999,309 & Ibs/hr & 0.67 & 521.9 & 499.6 & 13.01 & 1 & 13.01 \\
\hline $\mathrm{HXs}$ & - & 79.53 & $100 \$ / \mathrm{kW}$ & $\mathrm{MW}$ & - & - & - & 7.95 & 1 & 7.95 \\
\hline Totals (MM 2009\$) & & & & & & & & 110.21 & & 110.21 \\
\hline
\end{tabular}


Table 11. IGFC capital cost estimation data for each of the cases (continued)

\begin{tabular}{|c|c|c|c|c|c|c|c|c|c|c|}
\hline Case 4: Pre-SOFC CCS via Selexol & $\mathrm{C}_{0}$ & $S$ & $\mathrm{~S}_{0}$ & units & $\mathbf{n}$ & CEPCI & $\mathrm{CEPCl}_{0}$ & C & I.F. & Installed Cost \\
\hline Water Gas Shift & 16.253 & 226616 & $1,714,460$ & Ibs/hr & 0.7 & 521.9 & 499.6 & 4.12 & 1 & 4.12 \\
\hline ASU & 40.318 & 7.746 & 16 & $\mathrm{kgO} 2 / \mathrm{s}$ & 0.625 & 521.9 & 444.2 & 30.03 & 1 & 30.03 \\
\hline 2-Stage Selexol & 172.48 & 226616 & $1,249,470$ & Ibs/hr & 0.7 & 521.9 & 499.6 & 54.54 & 1 & 54.54 \\
\hline SOFC Stack & - & 106 & 510 & $\$ / \mathrm{kW}_{\mathrm{DC}}$ & - & 521.9 & 525.4 & 53.70 & 1 & 53.70 \\
\hline Combustor & 5 & 44.4 & 69.7 & MW & 0.7 & 521.9 & 525.4 & 3.62 & 1 & 3.62 \\
\hline Syngas Expander & 2 & 2500 & 8375 & $\mathrm{~kW}$ & 0.67 & 521.9 & 525.4 & 0.88 & 1 & 0.88 \\
\hline Combustor Expander & 2 & 19300 & 8375 & $\mathrm{~kW}$ & 0.67 & 521.9 & 524.4 & 3.48 & 1 & 3.48 \\
\hline $\mathrm{CO}_{2}$ Compressor & 36.121 & 176043 & 999,309 & Ibs/hr & 0.67 & 521.9 & 499.6 & 11.79 & 1 & 11.79 \\
\hline $\mathrm{HX}$ & - & 78.107 & $100 \$ / \mathrm{kW}$ & MW & - & - & - & 7.81 & 1 & 7.81 \\
\hline Totals (MM 2009\$) & & & & & & & & 135.83 & & 169.98 \\
\hline
\end{tabular}

\begin{tabular}{|c|c|c|c|c|c|c|c|c|c|c|}
\hline Case 5: Pre-SOFC CCS via WGSMR & $\mathrm{C}_{0}$ & s & $\mathrm{S}_{0}$ & units & $\mathbf{n}$ & CEPCI & $\mathrm{CEPCl}_{0}$ & C & I.F. & Installed Cost \\
\hline WGDS & 4.158288 & 500 & 233.6 & Ibs/hr & 0.7 & 521.9 & 381.7 & 9.69 & 1 & 9.69 \\
\hline ASU & 40.318 & 7.746 & 16 & $\mathrm{kgO} 2 / \mathrm{s}$ & 0.625 & 521.9 & 444.2 & 30.03 & 1 & 30.03 \\
\hline SOFC Stack & & 93.46 & 352 & $\$ / \mathrm{kWDC}$ & & 521.9 & 525.4 & 32.68 & 1 & 32.68 \\
\hline WGSMR & 100 & 30827 & & $\mathrm{ft} 2$ & 1 & 521.9 & 521.9 & 3.08 & 2.5 & 7.71 \\
\hline Combustor & 5 & 65.7 & 69.7 & MW & 0.7 & 521.9 & 525.4 & 4.77 & 1 & 4.77 \\
\hline Syngas Expander & 2 & 1766 & 8375 & kW & 0.67 & 521.9 & 525.4 & 0.70 & 1 & 0.70 \\
\hline Combustor Expander & 2 & 27800 & 8375 & kW & 0.67 & 521.9 & 524.4 & 4.45 & 1 & 4.45 \\
\hline $\mathrm{CO}_{2}$ compressor & 36.121 & 199646 & 999,309 & $\mathrm{lbs} / \mathrm{hr}$ & 0.67 & 521.9 & 499.6 & 12.83 & 1 & 12.83 \\
\hline $\mathrm{HX}$ & - & 104.416 & $100 \$ / \mathrm{kW}$ & MW & - & - & - & 10.44 & 1 & 10.44 \\
\hline Totals (MM 2009\$) & & & & & & & & 36.26 & & 113.28 \\
\hline
\end{tabular}




\subsubsection{Focus Area (2) Summary and Conclusions}

Modeling in ASPEN Plus using target performance characteristics for IGFC system hardware was performed. The analysis focused on examination of pre-SOFC and post-SOFC CCS concepts at fixed fuel input and SOFC operating conditions of $10 \mathrm{bar}, 725^{\circ} \mathrm{C}$ (nominal) and an average single-cell voltage of 0.78 volt. Pre- and post-SOFC CCS concepts included the employment of emerging membrane separation technologies. Preliminary capital cost estimates were made to enable a more complete assessment of the attractiveness of one concept over another. Efficiency performance advantages from $-1.8 \%$ to $+2.1 \%$ points are observed over the Baseline case. However, it is also important to recognize these results have not employed an optimal selection of SOFC operating parameters (particularly pressure). The conclusions of the analysis for pre-SOFC and post-SOFC carbon capture concepts are given below.

\section{Post-SOFC CCS Summary}

- High efficiency IGFC system concepts employing membrane reactors in the SOFC tailgas achieve system efficiencies are comparable to those with oxy-combustion.

- Tail-gas WGS membrane reactors are unattractive due to large area requirements (and therefore, cost) from dilute $\mathrm{H}_{2}$ concentration in SOFC tail-gas.

- The usage of oxygen conducting membrane reactor indicates both a cost $(-\$ 5.3 \mathrm{M})$ and efficiency $(+1.1 \%)$ advantage in these preliminary studies.

\section{Pre-SOFC CCS Summary:}

- Efficiency gains in Pre-SOFC systems are largely associated with reduced auxiliary power in $\mathrm{CO}_{2}$ compression and air separation.

- Further, there is significant potential for SOFC stack cost reduction due to the higher $\mathrm{H}_{2}$ concentration in the feedgas which increases power density at the same design voltage (i.e., same stack efficiency).

- Cost reductions of $\sim 3 \%$ and efficiency increases of $2.1 \%$ may be possible with mature WGSMR technology.

- If pre-SOFC carbon capture is to be performed, these results suggest to do so with WGSMRs versus Selexol (for mature hydrogen transfer membrane technology) which allows for both capital cost reduction and efficiency performance increases $(2.1 \%)$.

- Mixing of tail-gases is not necessarily a preferred configuration from cost and efficiency performance standpoints, but deserves further exploration.

\subsubsection{Acknowledgements}

The co-PI's would like to thank John VonOsdol and Elaine Everitt for use of the NETL SOFC ASPEN Plus model. Additionally, we would like to thank Prof. Doug Way at CSM for helpful discussions on hydrogen transfer membrane design and performance. 


\section{Task I-C Summary and Future Work}

The project foci explored in this Task were motivated along two primary lines of investigation: (1) understanding IGFC performance when SOFCs are integrated with existing or capacityscaled commercial gas power generation and gas cleanup technologies; and (2) developing carbon capture concepts and quantifying the merit of the various capture strategies in IGFC systems. In particular, Focus Area (1) set out to evaluate the performance of IGFC systems that leverage existing or scaled, pre-commercial technologies where possible, with a focus on hardware integration strategies and system performance sensitivity to variations in SOFC operating parameter selection. The objective of Focus Area (2) was to explore IGFC systems that employ advanced membrane technologies in either pre-SOFC or post-SOFC CCS configurations and evaluate the carbon capture concepts on both technical and economic bases.

\subsection{Focus Area (1): IGFC Integration with Existing Technologies}

This study detailed the performance of a $100 \mathrm{MW}$-scale IGFC hybrid power plant that integrated a pressurized SOFC power block with the low-pressure turbine spool of the Pratt \& Whitney FT8-3 gas turbine and either a scaled-up, water-cooled version of the P\&W PureCycle ORC or the larger $\mathrm{P} \& \mathrm{~W}$ TurboDen product lines. The basic system concept included carbon capture via oxy-combustion followed by water knockout and $\mathrm{CO}_{2}$ compression to pipeline ready $\mathrm{CO}_{2}$ sequestration conditions. Performance results were reported that indicate:

- Hybrid SOFC systems could achieve electric efficiencies of $49 \%$ including CC\&S and as high as $67 \%$ when operating off a clean syngas and venting the $\mathrm{CO}_{2}$ to the atmosphere.

- The impact of integrating an ORC bottoming cycle was found to add as much as 8 percentage points of efficiency to the system. Use of a steam power cycle, in lieu of the ORC, could increase net plant efficiency by another 3.7\%.

- Additionally, the strategic use of gas expanders is particularly advantageous to offset carbon capture compression requirements or air separation unit auxiliary power requirements.

A study of system performance sensitivity to a variation in SOFC design parameters revealed the strongest influences are design cell voltage, SOFC fuel utilization, and system pressure. In particular:

- The net system efficiency can vary by as much as 3 percentage points over the range studied for changes to any of these parameters and thus, SOFC-GT-ORC system efficiency could top 52\%-LHV when optimal SOFC operating parameters are selected.

- Anode tail gas recycle ratio and cathode side design parameters, such as pressure drop and temperature rise, only mildly affect system efficiency; however, increasing the recycle ratio of anode tail-gas has the negative effect of decreasing SOFC power density and hence, increasing the number of cell-stacks required. 
- Depending on power density, two to three thousand 300-kW SOFC stacks are required to generate $115 \mathrm{MW}$ of dc power.

- It was also noted that additional analyses related to changes in the system design, such as ASU integration with the gas turbine or catalytic gasification could substantially improve the system performance beyond what is reported herein.

\subsection{Focus Area (2): Post- and Pre-SOFC CCS concept evalution using membranes}

The thrust of this focus area was to evalute the potential of emerging membrane separation technologies in IGFC hybrid power plants. A techno-economic analysis was carried out using ASPEN Plus software and evaluated concepts that employed either hydrogen or oxygen transfer membrane technologies strategically located upstream or downstream of the SOFC power block. In particular, the analysis focused on examination of pre-SOFC and post-SOFC CCS concepts at fixed fuel input and SOFC operating conditions of $10 \mathrm{bar}, 725^{\circ} \mathrm{C}$ (nominal) and an average single-cell voltage of 0.78 volt. Preliminary capital cost estimates were made to enable a more complete assessment of the attractiveness of one concept over another. Efficiency performance advantages from $-1.8 \%$ to $2.1 \%$ are observed over the Baseline case. The conclusions of the analysis for pre-SOFC and post-SOFC carbon capture concepts are as follows:

\section{Post-SOFC CCS Summary}

- High efficiency IGFC system concepts employing membrane reactors in the SOFC tailgas achieve system efficiencies are comparable to those with oxy-combustion.

- Tail-gas WGS membrane reactors are unattractive due to large area requirements (and therefore, cost) from dilute $\mathrm{H}_{2}$ concentration in SOFC tail-gas.

- The usage of oxygen conducting membrane reactor indicates both a cost (-\$5.3 M) and efficiency $(+1.1 \%)$ advantage in these preliminary studies.

\section{Pre-SOFC CCS Summary:}

- Efficiency gains in Pre-SOFC systems are largely associated with reduced auxiliary power in $\mathrm{CO}_{2}$ compression and air separation.

- Further, there is significant potential for SOFC stack cost reduction due to the higher $\mathrm{H}_{2}$ concentration in the feedgas which increases power density at the same design voltage (i.e., same stack efficiency).

- Cost reductions of $\sim 3 \%$ and efficiency increases of $2.1 \%$ may be possible with mature WGSMR technology.

- If pre-SOFC carbon capture is to be performed, these results suggest to do so with WGSMRs versus Selexol (for mature hydrogen transfer membrane technology) which allows for both capital cost reduction and efficiency performance increases $(2.1 \%)$. 
- Mixing of tail-gases is not necessarily a preferred configuration from cost and efficiency performance standpoints, but deserves further exploration.

\subsection{Future Work Recommendations}

Two areas for further investigation are recommended.

1. Techno-Economic Design Optimization Studies of IGFC Plants Considering Both Emerging Membrane Technologies and SOFC Degradation

- Motivation: Achieving aggressive economic and energetic performance of IGFC power plants requires multi-objective optimization of life cycle plant costs. Extending the foundation established thus far, many analyses require more than either efficiency or unit capital cost performance evaluations. Much of the recent work in the literature assumes several constant operating parameter specifications for the SOFC power block. In fact, the SOFC performance degrades with use and the rate of degradation depends on its operating conditions. SOFC life cycle costing of a variety of system configurations and operating parameter selection that is inclusive of voltage degradation would be valuable towards supporting current DOE SECA program goals.

- Objective: Perform operating parameter and system configuration optimization via minimization of life cycle costs and exergetic $\left(2^{\text {nd }}\right.$ Law $)$ analyses.

\section{Techno-Economic Design Optimization of IGCC/IGFC Plants with Biomass Commingling and Fuel Co-production}

- Motivation: When considering the production of fuels from gasification plants, the co-production of power is often crucial to the economic value proposition, especially for medium-sized gasification plants ( 2000-3000 tPD). However, what is the optimal distribution of fuel vs. power production? What are the most effective system configurations when fuel cell technology and carbon capture are incorporated? What are the implications of commingling biomass and coal on carbon capture, efficiency, and economic performance?

- Objective: Develop system models and optimize configurations that provide the most attractive value proposition for gasification systems that involve coproduction of fuels and power.

As a subset of either of the above efforts, CSM could also develop advanced ASPEN Plus models (SOFC, gasifier, combustors) and provide some benchmarking services for SOFC models developed at NETL. This could be valuable as non-conventional unit operation models such as gasifiers, etc are either not available in ASPEN or are of low fidelity (e.g., equilibrium). Furthermore, 3rd party benchmarking of models often provides useful feedback and discussion for model and system design developers. 


\section{References}

1. Klara, J.M., (2009), "The potential of advanced technologies to reduce carbon capture costs in future IGCC power plants," Energy Procedia 1:3827-3834.

2. Santin, M., Traverso, A., Massardo, A., (2008), "Technological aspects of gas turbine and fuel cell hybrid systems for aircraft: a review," The Aeronautical Journal, August, Vol. 112, No. 1134, pp. 459-467.

3. Costamagna, P., Magistri, L., Massardo, A., (2001), "Design and part-load performance of a hybrid system based on a solid oxide fuel cell reactor and a micro gas turbine," J. Power Sources, 96:352-368.

4. Roberts, R., Brouwer, J., Jabbari, F., Junker, T., Ghezel-Ayagh, H., (2006), “Control design of an atmospheric solid oxide fuel cell/gas turbine hybrid system: Variable versus fixed speeed gas turbine operation," J. Power Sources,161:484-491.

5. Traverso, A., Massardo, A., Roberts, R., Brouwer, J., Samuelsen, S., (2007), "Gas turbine assessment for air management of pressurized SOFC/GT hybrid systems," ASME Journal of Fuel Cell Science and Technology, 4:373-383.

6. Ferrari, M., (2011), "Solid oxide fuel cell hybrid system: control strategy for stand-alone configurations," J. Power Sources, 196:2682-2690.

7. Yang J.S., Sohn, J.L., Ro, J., (2007) "Performance characteristics of a solid oxide fuel cell/gas turbine hybrid system with various part-load control modes," J. Power Sources, 166:155-164.

8. Mueller, F., Gaynor, R., Auld, A., Brouwer, J., Jabbari, F., Samuelsen, G., (2008), "Synergistic integration of a gas turbine and solid oxide fuel cell for improved transient capability," J. Power Sources, 176:229-239.

9. Tucker, D., Lawson, L., and Gemmen, R., (2005), "Characterisation of air flow management and control in a fuel cell turbine hybrid power system using hardware simulation," ASME paper no. PWR2005-50127.

10. Research and Development Solutions, llc, (2007), Cost and Performance Baseline for Fossil Energy Plants, Vol. 1, Final Report, U.S. DOE, National Energy Technology Laboratory, DOE/NETL-2007/1281, August.

11. R.J. Braun, "Optimal Design and Operation of Solid Oxide Fuel Cell Systems in Small-scale Stationary Applications,” Ph.D. Thesis, University of Wisconsin-Madison (2002).

12. R.J. Braun, S.A. Klein, and D.T. Reindl, "Evaluation of system configurations for SOFCbased micro-CHP systems in residential applications," J.Power Sources 158, 1290-1305 (2006).

13. Zhu, H., Kee, R., Janardhanan, V., Deutschmann, O., Goodwin, D., "Modeling elementary heterogeneous chemistry and electrochemistry in solid-oxide fuel cells," J. Electrochem. Soc. 152, A2427-A2440 (2005).

14. Lobachyov, K., Richter, H.J., (1996). "Combined cycle gas turbine power plant with coal gasification and solid oxide fuel cell," J Energy Resources Tech; 118: 285-292. 
15. Kivisaari., T., Björnbom, P., Sylwan, C., Jacquinot, B., Jansen, D., de Groot, A., (2004), Chemical Engineering Journal; 100: 167-180.

16. Ghosh, S., De, S., (2006), "Energy analysis of a cogeneration plant using coal gasification and solid oxide fuel cell." Energy; 3: 345-363

17. Verma, A., Rao, A.D., Samuelsen, G.S., (2006), "Sensitivity analysis of a Vision 21 coal based zero emission power plant," J Power Sources; 158: 417-427.

18. Romano, M., Campanari, S., Spallina, V., Lozza, G., (2009), "SOFC-based hybrid cycle integrated with a coal gasification plant," ASME Turbo Expo: Power for Land, Sea, and Air, Paper no. ASME GT2009-59551.

19. Liese, E., (2010), "Comparison of preanode and postanode carbon dioxide separation for IGFC systems," J. Engineering for Gas Turbines and Power, June, Vol. 132 / 061703.

20. Siefert, N., Shekhawat, D. and Kalapos, T., (2010) "Integrating catalytic coal gasifiers with solid oxide fuel cells," Proceedings of the ASME $20108^{\text {th }}$ International Fuel Cell Science, Engineering, and Technology Conference, FuelCell2010-33206, June 14-16, Brooklyn, New York.

21. Gerdes, K., Grol, E., Keairns, D., and Newby, R., (2009), Integrated Gasification Fuel Cell Performance and Cost Assessment, a report prepared by the National Energy Technology Laboratory, Morgantown, WV, DOE/NETL-2009/1361, March.

22. Verda, V., (2008), "Solid oxide fuel cell system configurations for distributed generation," J. Fuel Cell Science and Technology, November, Vol. 5 / 041001.

23. Probstein, R.F., and Hicks, R.E., (2006), Synthetic Fuels, Dover Publications, Mineola, NY.

24. Spath et al., "Biomass to Hydrogen Production Detailed Design and Economics Utilizing the Battelle Columbus Laboratory Indirectly-Heated Gasifier”, NREL May (2005).

25. Nextant, Preliminary Feasibility Analysis of RTI Warm Gas Cleanup (WGCU) Technology. RTI International. June (2007).

26. Y. Ohtsuka, N. Tsubouchi, T. Kikuchi, H. Hashimoto. Recent progress in Japan on hot gas cleanup of hydrogen chlorine, hydrogen sulfide and ammonia in coal-derived fuel gas. Powder Technology (2009).

27. Xuepeng et al., "New Development of zinc-based sorbents for hot gas desulfurization", Fuel Processing Technology (2007).

28. D. Cicero, R. Gupta, B. Turk, D. Simbeck. A Review of Desulfurization in Gasification Systems, $20^{\text {th }}$ Annual International Coal Conference, Session 2.4 Gasification, Pittsburg, PA (2003)

29. Hydrocarbon Processing, (2002)

30. J. Patt, D. Moon, C. Phillips, L. Thompson. Molybdenum carbide catalysts for water-gas shift Catalysis Letters. 65 (2000)

31. D. Kubek, E. Polla. Purification and Recovery Options for Gasification UOP LLC (2000)

32. A. Kohl, R. Nielsen, Gas Purification, $5^{\text {th }}$ Edition, Gulf Professional Publishing (1997) 
33. Merichem Company LO-CAT® Process Spec Sheet available at http://www.gtpmerichem.com/products/lo-cat/process.php

34. P. Spath, A. Aden, T. Eggeman, M. Ringer, B. Wallace, J. Jechura. Biomass to Hydrogen Production Detailed Design and Economics Utilizing the Battelle Columbus Laboratory Indirectly-Heated Gasifier. National Renewable Energy Laboratory (2005) TP-510-37408

35. Nextant, Preliminary Feasibility Analysis of RTI Warm Gas Cleanup (WGCU) Technology. RTI International. June (2007).

36. R. P. Gupta, B.S. Turk, J.W. Portzer, and D.C. Cicero, Desulfurization of Syngas in a Transport Reactor, Environmental Progress (Vol.20, No.3), October (2001).

37. G. Henningsen, S. Katta, G. Mathur. Sorbent Testing and Commerciallization of Transport Reactors for Hot Gas Desulfurization. Proceedings of The Advanced Coal-Based Power and Environmental Systems '97 Conference, Pittsburg, PA (1997)

38. Current and Future IGCC Technologies. DOE/NETL-2008/1337. October (2008.)

39. S. Gangwal, J. Portzer. Advanced Sulfur Control Concepts. Proceedings of the Advanced Coal-Fired Power Systems '95 Review Meeting, Springfield, VA (1995) 622-630

40. Shelton, W., and Lyons, J., (2000), "Shell Gasifier IGCC Base Cases," PED-IGCC-98-002, prepared by EG\&G for the U.S. Department of Energy, Office of Fossil Energy, National Energy Technology Laboratory, Morgantown, WV, revised.

41. Pratt \& Whitney Power Systems, (2010), “Organic Rankine Cycle Technology," product brochure, PS-S0022.01.10, available from www.pw.utc.com.

42. Process Systems Enterprise, Ltd., (2009), http://www.psenterprise.com/gproms/index.html, as accessed on 11/15/2006.

43. Research and Development Solutions, llc, (2007), Cost and Performance Baseline for Fossil Energy Plants, Vol. 1, Final Report, U.S. DOE, National Energy Technology Laboratory, DOE/NETL-2007/1281, August.

44. Simbeck, D. R., Korens, N., Biasca, F. E., Vejtasa, S., and Dickenson, R. L., (1993), "Coal Gasification Guidebook: Status, Applications, and Technologies," Electric Power Research Institute Final Report No. TR-102034, Palo Alto, CA.

45. Chiesa, P., Consonni, S., Kreutz, T., and Williams, R., (2005), Int. J. Hydrogen Energy, 30, pp. 747-767.

46. West Virginia University Chemical Engineering Department. (2009), "Large-scale Process Design Projects: Air Separation into Oxygen, Nitrogen and Argon," http://www.che.cemr.wvu.edu/publications/projects/large_proj/air.PDF, Accessed June 1.

47. American Water Works Association, (1997), American Society of Civil Engineers. Water Treatment Plant Design. 3rd edition. New York: McGraw Hill.

48. Proceedings of the $9^{\text {th }}$ Annual Solid State Energy Conversion Alliance (SECA) Workshop, (2008), U.S. Department of Energy, National Energy Technology Laboratory, August 5-7.

49. Williford, R.E., Chick, L.A., Maupin, G.D., Simner, S.P., and Stevenson, J.W., (2003) Journal of The Electrochemical Society, 150 (8) A1067-A1072. 
50. Pratt \& Whitney Power Systems, (2010), “Organic Rankine Cycle Technology,” Product Brochure (PS-S0022.01.10), www.pw.utc.com.

51. GE Power, (2008), "GE combined cycle product line and performance," GE Power Product and Services Website Information, Publication document no. GER3574g.

52. Gas Turbine World, (2006), “2006 GTW Handbook,” Farmer, R., Editor, Pequot Publication, Southport, CT.

53. Carbon Capture and Sequestration Systems Analysis Guidelines, (2005), U.S. DOE, Office of Fossil Energy, NETL, April.

54. Probstein, R.F., and Hicks, R.E., (2006), Synthetic Fuels, Dover Publications, Mineola, NY.

55. Marsano, F., Magistri, L., Massardo, A., (2004), "Ejector performance influence on a solid oxide fuel cell anodic recirculation system," J. Power Sources, 129:216-228.

56. Wilson, D.G., (2003), "Regenerative Heat Exchangers for Microturbines, and An Improved Type," Proc. of ASME Turbo Expo 2003, June 16-19, Atlanta, Georgia, USA.

57. EG\&G Technical Services, Inc., (2004), Fuel Cell Handbook, $7^{\text {th }}$ Ed., prepared for the U.S. DOE Office of Fossil Energy, National Energy Technology Laboratory, Morgantown, WV.

58. Braun, R.J., (2010), “Techno-Economic Optimal Design of Solid Oxide Fuel Cell Systems for Micro-Combined Heat and Power Applications in the U.S.," ASME J. Fuel Cell Sci. and Tech., August, vol. 9.

59. DOE Hydrogen from Coal Program Multi-Year RD\&D Plan, September (2010).

60. S.C. Emerson, et al., "Experimental Demonstration of Advanced Palladium Membrane Separators for Central High-Purity Hydrogen Production," DE-FC26-07NT43055, DOE Annual Merit Review, May (2009).

61. J. Moe, "Design of water-gas shift reactors" Chemical Engineering Progress, 58-3 (1962) 33-36.

62. H. Luoa, Y. Weia, H. Jiang, W. Yuana, Y. Lva, J. Carob, H. Wanga, "Performance of a ceramic membrane reactor with high oxygen flux Ta-containing perovskite for the partial oxidation of methane to syngas," J. of Membrane Science, Vol. 350, Issues 1-2, 15 March (2010).

63. H.J.M. Bouwmeester, A.J. Burggraaf, "Dense ceramic membranes for oxygen separation," in: P.J. Gellings, H.J.M. Bouwmeester (Eds.), CRC Handbook of Solid State Electrochemistry, CRC Press, Boca Raton, FL, Chapter 14, (1997).

64. W. Yang, H. Wang, X. Zhu, L. Lin, 'Development and application of oxygen permeable membrane in selective oxidation of light alkanes," Topics in Catal. 35 (1-2) 155 (2005).

65. H. Lua, J. P. Kima, S. Hwan Sona, J. Parka, "Perovskite Co-free $\mathrm{La}_{0.6} \mathrm{Sr}_{0.4} \mathrm{M}_{0.2} \mathrm{Fe}_{0.8} \mathrm{O}_{3-\delta}(\mathrm{M}=$ $\mathrm{Cr}$ or Ti) mixed-conductors: Preparation and characterization," Materials Science and Engineering B 163 (2009) 151-156.

66. M.J. den Exter, W.G. Haije, and J.F. Vente , "Viability of ITM Technology for Oxygen Production and Oxidation Processes: Material, System, and Process Aspects," in Inorganic 
Membranes for Energy and Environmental Applications, A.C. Bose (ed.), DOI 10.1007/9780-387-34526-0 2, Springer, Science+Business Media, LLC (2009).

67. R.J. Braun, S. Kameswaran, J. Yamanis, and E. Sun, "Highly efficient IGFC hybrid power systems employing bottoming organic rankine cycles with optional carbon capture," ASME J. Engineering for Gas Turbines and Power, accepted for publication, August (2010). 


\title{
The design, fabrication, and evaluation of a ceramic counter-flow microchannel heat exchanger
}

\author{
Task II \\ Final Report
}

\author{
Robert J. Kee \\ 1610 Illinois Street \\ Engineering Division \\ Colorado School of Mines \\ Golden, CO 80401
}

\author{
Prepared for: \\ The U.S. Department of Energy \\ National Energy Technology Laboratory \\ 626 Cochrans Mill Road \\ Pittsburgh, PA
}

Under contract no.: DE-NT0005202

1 October 2011

\section{COLORADOSCHOOLOFMINES}

EARTH・ENERGY・ENVIRONMENT 


\section{Contents}

1 Executive summary $\quad 2$

2 Introduction $\quad 2$

3 Prior literature $\quad 4$

4 Nominal design $\quad 5$

5 Pressure drop in microchannels $\quad 6$

$\begin{array}{lll}6 & \text { Three-dimensional simulation } & 7\end{array}$

7 Traditional heat-exchanger analysis $\quad 9$

8 PLIS Fabrication $\quad 12$

9 Materials considerations $\quad 14$

10 Performance evaluation $\quad 15$

10.1 Inlet temperature . . . . . . . . . . . . . . . . 16

10.2 Flow rates . . . . . . . . . . . . . . . . . . 16

10.3 Unbalanced flow . . . . . . . . . . . . . . . . . . . . . . . . . . . . . . . . . .

10.4 Pressure drop . . . . . . . . . . . . . . . . . . 18

11 Summary and conclusions $\quad 20$

DE-NT0005202 II, p. 1 


\section{Executive summary}

This paper reports the model-based design and experimental performance evaluation of an allceramic compact counterflow microchannel heat exchanger. Ceramic materials enable high temperature operation that can exceed the capabilities of comparable metal heat exchangers. Additionally, ceramics may enable operation in harsh chemical environments in which metals cannot be used. Although the internal manifolds and channel layouts can be complex, a unique fabrication process called Pressure Laminated Integrated Structures (PLIS) facilitates low-cost manufacturing. The heat exchangers are tested using inlet air heated up to $750{ }^{\circ} \mathrm{C}$ on the hot side, room-temperature inlet air on the cold side, and flow rates up to $3 \times 10^{-3} \mathrm{~kg} \mathrm{~s}^{-1}$ (150 standard liters per minute of air). The paper reports measured performance of single units at the kilowatt scale for which heatexchanger effectiveness up to $70 \%$ has been achieved.

The text of this report is published as:

- R.J. Kee, B.B. Almand, J.M. Blasi, B.L. Rosen, M. Hartmann, N. P. Sullivan, H. Zhu, A.R. Manerbino, S. Menzer, W.G. Coors, J.L. Martin, "The design, fabrication, and evaluation of a ceramic counter-flow microchannel heat exchanger," Applied Thermal Engineering, 31:2004-1012 (2011).

\section{Introduction}

There is a vast literature that documents the performance advantages of microchannel heat exchangers, including integrated chemical processing [1-4]. A recent review by Sommers et al. discusses numerous applications that benefit particularly from ceramic heat exchangers [5]. The present paper documents the design, development, and performance evaluation of a ceramic counterflow microchannel heat exchanger. A new fabrication process (called Pressure Laminated Integrated Structures, PLIS) enables cost-effective manufacturing. Figure 1 is photograph showing the small heat exchanger that is the primary subject of this paper.

Ceramic materials offer potentially significant advantages compared to metal alternatives. A major advantage is the capability to operate at very high temperature. Ceramics are also much more tolerant to harsh chemical environments than metals. Because the oxide ceramics can tolerate strongly oxidizing environments, it may be possible to remove certain fouling deposits by intermittently introducing oxygen to burn deposits. The performance of counter-flow heat exchangers can be improved with low thermal conductivity materials that impede axial wall conduction [6]. Compared to some metals, ceramics offer low thermal conductivity.

In addition to heat exchangers alone, catalysts can be introduced into one or both sets of channels, thus extending capability as reactive heat exchangers. Ceramic materials offer potential advantages 


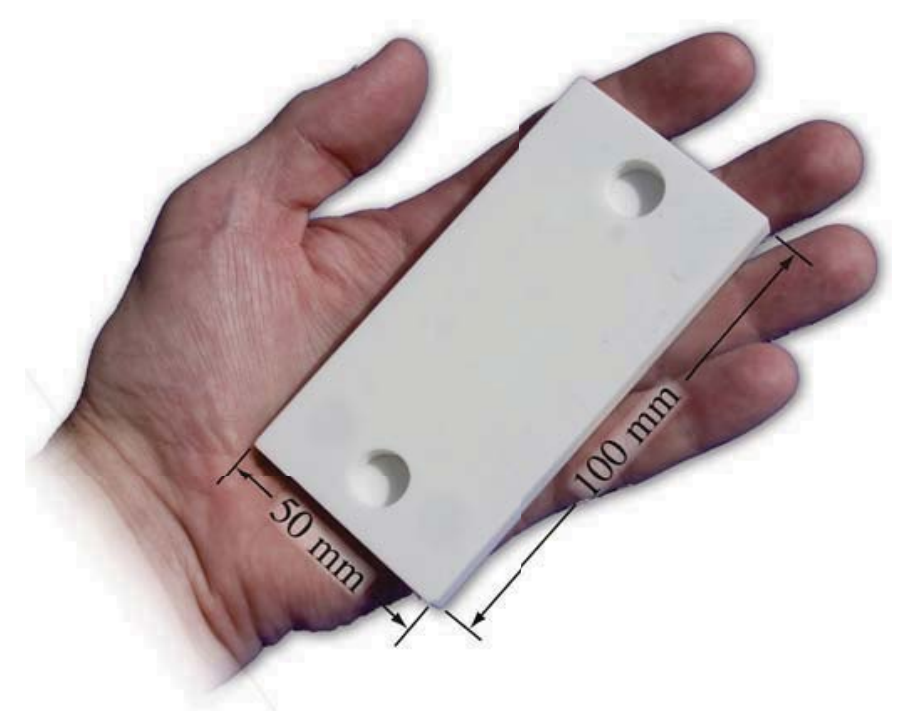

Figure 1: Photograph of a compact ceramic microchannel counter-flow heat exchanger. This view shows the hot and cold inlets, with the exhaust flow issuing from the under side.

in the application of ceramic-based catalyst washcoats. Even for applications for which metal microchannels are entirely appropriate, the ceramic alternative can deliver significant cost savings.

Although there are numerous possible applications, the effort reported here is motivated by cleanenergy applications that require high-temperature gas-gas heat exchangers. For example, oxy-fired combustion processes benefit by preheating air prior to entering oxygen-ion-transport membranes for oxygen separation (typically operating at temperatures around $900{ }^{\circ} \mathrm{C}$ ). In this application, hot nitrogen from the separation is used in a recuperator to preheat incoming air, thus improving overall process efficiency. Another application involves very-high-temperature gas-cooled nuclear reactors (VHTR). In this application the primary reactor coolant is helium that leaves the reactor at temperatures up to $950{ }^{\circ} \mathrm{C}$. A heat exchanger is used to transfer heat from the reactor coolant loop to helium that can deliver energy to a variety of downstream chemical processes. Efficient operation of solid-oxide fuel cell systems require recuperating heat exchangers that use waste heat from the anode exhaust to preheat incoming cathode air.

The present heat exchanger is classified generally as a compact laminar-flow primary-surface design. The performance of such systems can be qualitatively different from larger turbulent-flow extended-surface designs. Consequently, design and scaling strategies can be different. For example, primary-surface counter-flow heat exchangers can benefit by using low-conductivity materials. The present design is assisted by comprehensive three-dimensional simulation as well as traditional heat-exchanger analysis.

On a heat-transfer-to-pressure-drop basis, the microchannel design approaches a theoretical optimum for laminar flow, which exceeds the vast majority of heat exchanger surfaces, regardless of 


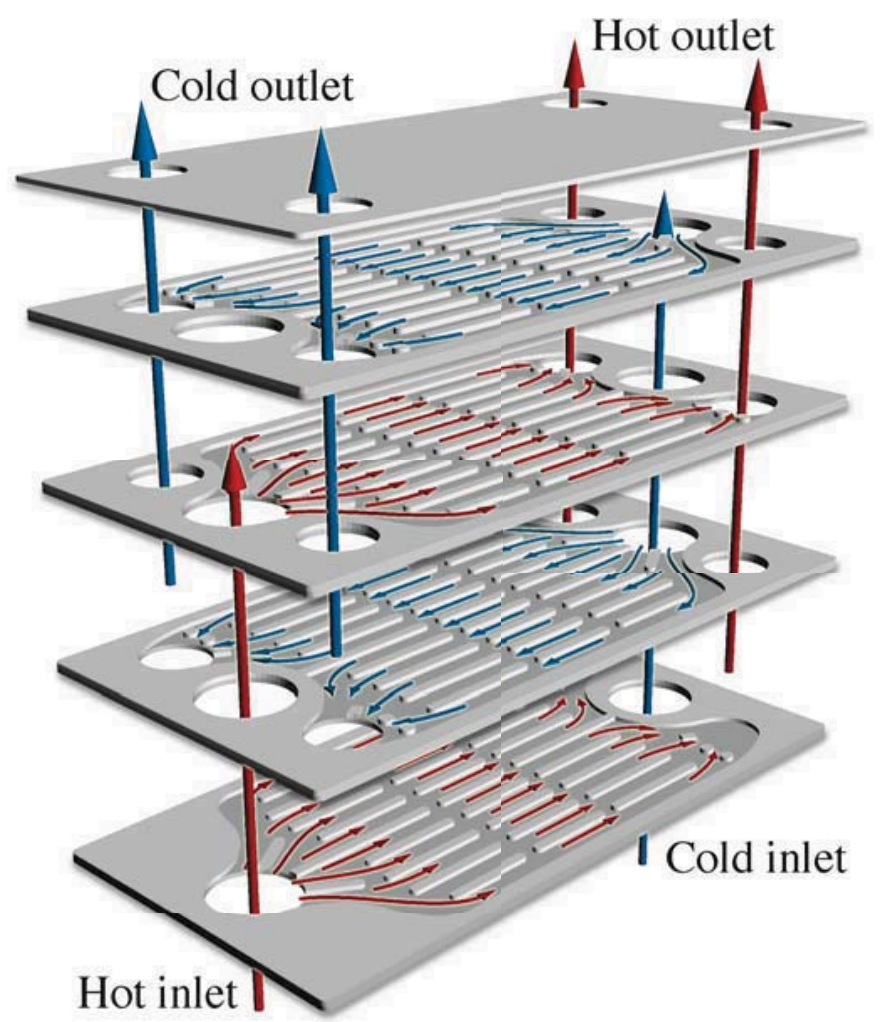

Figure 2: Exploded view showing internal manifold and channel structure.

Reynolds number. As discussed by Kays and London [7], if small smooth compact flow passages can be practically manufactured, "high performance" surfaces (e.g., interrupted fins and turbulent flow) no longer show an advantage, with simple smooth passages being preferred. The present design, with very high surface-area-to-volume ratio, high chemical inertness, and low-cost ceramics fabrication, provides the basis for a very high performance heat exchanger.

\section{Prior literature}

Only a few papers focus specifically on ceramic microchannel heat exchangers. Takeuchi, et al. [8] developed and applied three-dimensional models to assist the design of a silicon-carbide (SiC) heat exchanger for application to VHTR nuclear reactors. Schulte-Fischedick, et al. [9] designed and tested $\mathrm{SiC}$ plate-and-fin heat exchangers for applications in biomass conversion. Their design was also supported by detailed three-dimensional modeling of fluid flow and conjugate heat transfer. Alm, et al. [10] designed and fabricated small alumina microchannel counter-flow heat exchangers, and evaluated performance at low temperature using water as the working fluid. 
Especially in small high-performance counter-flow heat exchangers, it is well known that longitudinal conduction within the solid materials can play an important role in performance. Although the general formulation of longitudinal conduction is available in textbooks [6,7], more comprehensive analyses can be achieved via three-dimensional simulation of the fluid flow and conjugate heat transfer $[8,11,12]$.

Although correlations for fully developed, steady-state, laminar-flow, heat-transfer coefficients are readily available, details of the flow and heat transfer within microchannels depend upon channel and manifold geometry [13-16]. Brandner, et al. [17] explored opportunities for enhancing heat transfer within channels by using small obstructions that alter the flow patterns. Ciofalo explored the effects of spatial variations in the local heat-transfer coefficient on the longitudinal conduction [18].

There is a great deal of research in the direct coupling of microchannel heat exchangers with catalytic reactors [3, 16, 19-24]. In these cases, one of more sets of channels are catalytically active and such process intensification can produce highly effective chemical reactors. The approach for designing manifolds and microchannels has much in common with the design and analysis of heat exchangers alone.

\section{Nominal design}

Figure 2 illustrates the counter-flow heat-exchanger design, which has an overall footprint of 50 $\mathrm{mm}$ by $100 \mathrm{~mm}$. Each flow layer contains 10 microchannels that are approximately 550 microns high and $2.8 \mathrm{~mm}$ wide. The channel floors that separate the hot and cold streams are approximately 600 microns thick. The axial gaps in channel ribs serve three purposes. The first is to enable pressure equalization between channels. The axial pressure drop is approximately inversely proportional to the cube of the channel height, which means that small fabrication variations have a large impact upon flow distribution between channels (cf. Sec. 5). Thus, the gaps tend to improve flow distribution. The gaps serve a secondary purpose by tending to reduce potentially deleterious longitudinal wall conduction. Conduction along the channel floors and ribs (i.e., parallel to the flow direction) is known to degrade counterflow performance toward the lower performance of coflow heat exchangers, especially for high-effectiveness designs [6, 25]. A third beneficial effect of the rib gaps is to cause local entry-length boundary-layer behavior as the flow enters the microchannel sections, which serves to increase local heat-transfer coefficients.

As illustrated in Fig. 2 the hot and cold fluids enter through central holes from the bottom and exit via outboard holes at the top. Each of the internal layers is identical, but with alternating layers rotated $180^{\circ}$ relative to the underlying layer. The feed and exhaust manifolds at the ends of the layers are designed such that there is exact alignment upon layer rotation. Using identical layers reduces the manufacturing cost. One of flow directions can be reversed (i.e., inlet flow through the 
outboard holes), producing a co-flow configuration.

The heat exchangers to date have been fabricated with four flow layers (two hot and two cold), but are designed to accommodate more flow layers. The relatively large diameters of the central inlets and the outboard exhausts enable the use of many heat-exchanger layers. The large diameters also enable the staging of several heat exchangers without significant pressure drops in the connecting tubing .

The heat exchangers discussed in this paper are fabricated from $94 \%$ alumina. The specific alumina blend and the PLIS fabrication process are discussed in Sect. 8).

\section{Pressure drop in microchannels}

Assuming steady-state Hagen-Poiseuille flow within the channels [26-28], the pressure drop $\Delta p$ can be represented as

$$
\Delta p=\frac{\tau_{\mathrm{w}} P L}{A_{\mathrm{c}}},
$$

where $A_{\mathrm{c}}$ is the flow cross-sectional area, $\tau_{\mathrm{w}}$ is the wall shear stress, $P$ is the channel wetted perimeter, and $L$ is the channel length. The wall shear stress can be represented in terms of a dimensionless friction factor $f$ as

$$
f=\frac{\tau_{\mathrm{w}}}{\frac{1}{2} \rho u_{\mathrm{m}}^{2}},
$$

where $\rho$ is the fluid mass density and $u_{\mathrm{m}}$ is the mean fluid velocity. Assuming laminar flow, the product of the friction factor and Reynolds number is a constant that depends upon the channel aspect ratio (i.e., $\operatorname{Re} f=C$ ), where the Reynolds number is based upon the channel hydraulic diameter $D_{\mathrm{h}}$ as

$$
\mathrm{Re}=\frac{\rho u_{\mathrm{m}} D_{\mathrm{h}}}{\mu}, \quad D_{\mathrm{h}}=\frac{4 A_{\mathrm{c}}}{P},
$$

where $\mu$ is the dynamic viscosity. With the mass-flow rate through a channel being $\dot{m}=\rho A_{\mathrm{c}} u_{\mathrm{m}}$, it follows directly that

$$
\Delta p=\frac{1}{2} \operatorname{Re} f \frac{\mu^{2}}{\rho} \frac{P}{D_{\mathrm{h}}^{2} A_{\mathrm{c}}} L \operatorname{Re} .
$$

Assume a rectangular channel with height $H$ and width $W$. With the small dimension being $H$, the channel aspect ratio is $\alpha=H / W$. In this case,

$$
D_{\mathrm{h}}=\frac{2 H}{1+\alpha}, \quad P=2 H \frac{\alpha+1}{\alpha}, \quad A_{\mathrm{c}}=\frac{H^{2}}{\alpha}
$$

By rewriting Eq. 4 as

$$
\Delta p=\frac{1}{2} \operatorname{Re} f \frac{\mu^{2}}{\rho} \frac{(1+\alpha)^{3}}{2 H^{3}} L \operatorname{Re},
$$




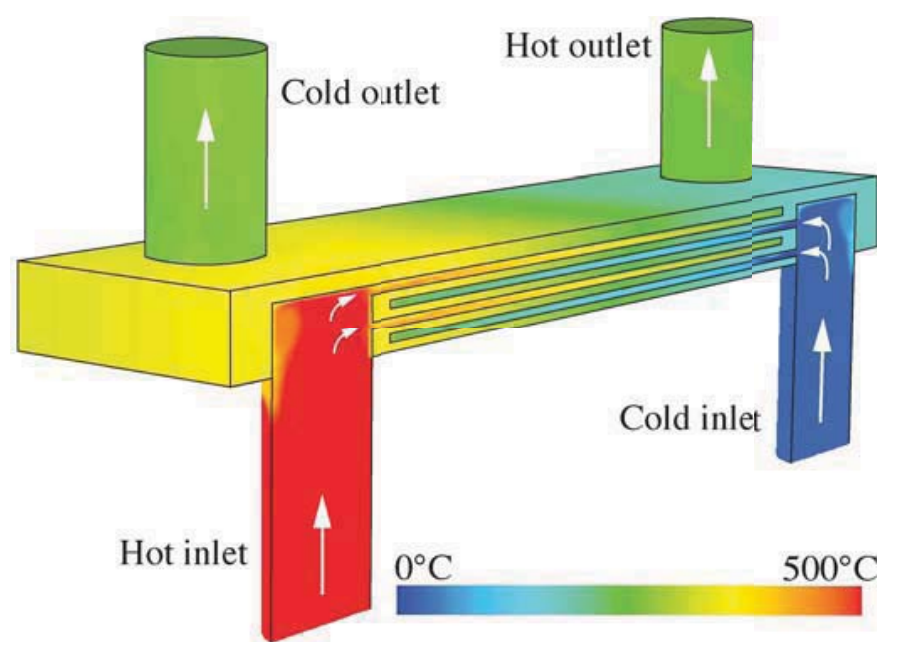

Figure 3: Vertical cut through a three-dimensional simulation, showing gas and solid temperature fields.

it is evident that pressure drop is inversely proportional to the cube of the channel height. This means that small changes in channel height affect pressure drop greatly.

\section{Three-dimensional simulation}

Figures 3 and 4 illustrate the results of three-dimensional simulations that predict both fluid and solid-body temperatures. These simulations are used to guide tradeoffs between heat-transfer performance and requirements of the fabrication process. In addition to fluid flow, the models predict the solid-material thermal fields. Local thermal gradients cause local strain through thermal expansion, which in turn can lead to failure of the ceramics. The current design is in its fifth generation, with each generation improving performance and manufacturability. The design is based upon simulation using three-dimensional computational fluid dynamics (CFD), including the conjugate heat transfer between fluids and solid materials. The CFD models are implemented in FLUENT ${ }^{\circledR}$ [29]. Temperature-dependent properties are used for air and for alumina.

The results in Figs. 3 and 4 are for balanced air flow (i.e., the same mass flow rates through both the hot and cold inlets). The hot air enters at $500{ }^{\circ} \mathrm{C}$ and the cold flow enters at $30{ }^{\circ} \mathrm{C}$. The simulations are based upon assuming that all external surfaces are perfectly insulated. The results in Fig. 3 are for flow rates of $1.58 \times 10^{-3} \mathrm{~kg} \mathrm{~s}^{-1}$ (80 standard liters per minute of air, slm) and Fig. 4 is for flow rates of $4.93 \times 10^{-4} \mathrm{~kg} \mathrm{~s}^{-1}(25 \mathrm{slm})$. Both air streams enter from below, flow in opposite directions through the microchannels, and then exhaust through tubes at the top. Figure 3 shows predicted temperature fields on a vertical cut near the heat-exchanger centerline, in the middle of the first flow channel away from the heat-exchanger centerline. Figure 4 shows temperature fields 


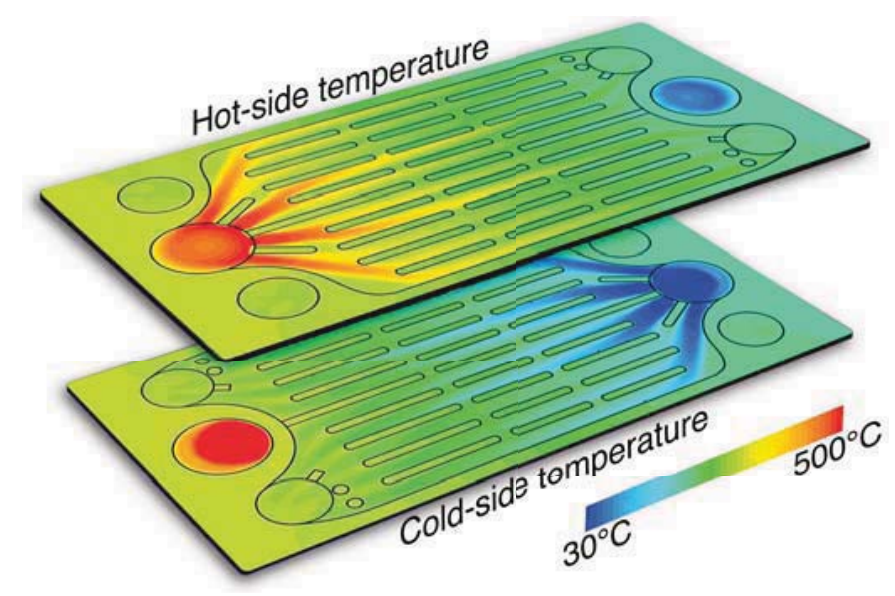

Figure 4: Three-dimensional simulation showing gas and solid temperature fields on a hot and cold layer.

at the mid-planes of a hot and a cold layer.

The design process is assisted greatly by three-dimensional simulations that are used to predict quantitatively the influence of manifold and channel geometry on heat-exchanger performance. For example, there are practical tradeoffs between increased heat-transfer performance and increased pressure drop. Manufacturing processes also introduce practical tradeoffs that must be considered. For example, the small pedestals around the exhaust manifolds (Fig. 2) are required to carry compression load and thus achieve uniform layer-to-layer contact during green-layer lamination $^{1}$. These features introduce some added pressure drop. The angled channel ribs radiating from the inlet manifolds are used to direct the flow and to carry lamination load during fabrication.

It is evident from both Figs. 3 and 4 that the axial temperature variations are essentially onedimensional (i.e., varying primarily in the axial direction with little variation across the short dimension). This is a desired result, leading to similar heat-transfer performance within all channels. Figure 3 shows that the floor layer (i.e., between hot and cold flows) is nearly uniform in the vertical direction and essentially at the average temperature between the local mean temperatures of the hot and cold air. Again, this is a desired result, indicating relatively little heat-transfer resistance through the layer floors.

\footnotetext{
${ }^{1}$ The term "green," which is standard nomenclature in ceramics processing, means the composite structure made of ceramic powders and binders prior to firing.
} 


\section{Traditional heat-exchanger analysis}

Even with comprehensive three-dimensional model in hand, analytic models provide great value in understanding performance tradeoffs and interpreting results. Of course, the relatively simpler models rely on significant approximations.

In compact primary-surface heat exchangers, the dominant heat transfer is between the hot and cold flow streams directly across the separating wall, without the influence of extended surfaces such as fins. The overall conductance $U A$ between hot and cold streams can be represented in terms of contributing thermal resistances as

$$
(U A)=\left[\left(\frac{1}{h A_{\mathrm{s}}}\right)_{\text {hot }}+\left(\frac{t}{k A_{\mathrm{s}}}\right)_{\text {wall }}+\left(\frac{1}{h A_{\mathrm{s}}}\right)_{\mathrm{cold}}\right]^{-1},
$$

where $h$ is the heat-transfer coefficient between fluid and wall, $A$ is the primary surface area, $k$ is the thermal conductivity of the wall, and $t$ is the wall thickness. In optimized primary-surface heat exchangers the conductive heat flux across the walls is relatively low and the conduction distance is small (i.e., the wall thickness). Consequently the thermal resistance of the wall $t /\left(k A_{\mathrm{s}}\right)$ can be small relative to the convective resistance even when low-conductivity wall materials are used. In contrast to extended-surface heat exchangers designs, which are often fabricated with high-conductivity materials (e.g., copper or aluminum), the following analysis shows that compact primary-surface heat exchangers do not necessarily benefit from the use of high-conductivity materials.

As a limiting case, assume steady, fully developed, laminar flow in high-aspect-ratio channels the Nusselt number is constant (i.e., independent of Reynolds number) at [30]

$$
\mathrm{Nu} \equiv \frac{h D_{\mathrm{h}}}{k_{\mathrm{f}}} \approx 8
$$

where $D_{\mathrm{h}}$ is the channel hydraulic diameter and $k_{\mathrm{f}}$ is the thermal conductivity of the fluid. It is interesting to compare the relative thermal resistances of the convection and conduction. Assuming air as the fluid and a hydraulic diameter of $D_{\mathrm{h}}=500 \mu \mathrm{m}$, the convective heat-transfer coefficient is $h \approx 550 \mathrm{~W} \mathrm{~m} \mathrm{~K}^{-2} \mathrm{~K}^{-1}$. Assuming an average thermal conductivity of $10 \mathrm{~W} \mathrm{~m}^{-1} \mathrm{~K}^{-1}$ (alumina at around $250{ }^{\circ} \mathrm{C}$ ) and a wall thickness of $t=500 \mu \mathrm{m}$, the ratio of conductive thermal resistance offered by the wall and the total thermal resistance (i.e., conduction and convection) is

$$
\frac{R_{\mathrm{cond}}}{R_{\mathrm{tot}}} \approx 0.01
$$

In other words, even with low-conductivity ceramics, the influence of conduction across the wall is very small.

Although conduction across the wall (i.e., normal to the flow directions) does not contribute significantly to performance, longitudinal heat conduction (i.e., parallel to the flow directions) can 
significantly degrade counter-flow heat-exchanger performance. The effect of longitudinal conduction can be particularly important in compact heat exchangers with short distances $L$ between inlet and outlet ports. The dimensionless longitudinal conduction parameter [6]

$$
\lambda=\frac{k_{\mathrm{wall}} A_{\mathrm{c}}}{L C_{\min }}
$$

can be used to estimate the effect of longitudinal conduction on performance. In this equation, $A_{\mathrm{c}}$ is the longitudinal cross-sectional area of the wall and $C_{\min }=\dot{m} c_{p}$ is the minimum capacity rate ( $\dot{m}$ is the mass flow rate and $c_{p}$ is the heat capacity of the fluid). The present design has a cross-sectional area (including floors between layers and channel-separation ribs) of $A_{\mathrm{c}} \approx 2.8 \times 10^{-4} \mathrm{~m}^{2}$. The length between inlet and outlet ports is $L \approx 64 \mathrm{~mm}$. With balanced flow rates of $1.58 \times 10^{-3} \mathrm{~kg} \mathrm{~s}^{-1}$ (80 slm), the minimum capacity rate is $C_{\min } \approx 1.6 \mathrm{~W} \mathrm{~K}^{-1}$. With an alumina thermal conductivity of $10 \mathrm{~W} \mathrm{~m}^{-1} \mathrm{~K}^{-1}, \lambda \approx 0.028$. The room temperature thermal conductivity of alumina is $22.4 \mathrm{~W}$ $\mathrm{m}^{-1} \mathrm{~K}^{-1}$, but decreases greatly as a function of temperature.

Evaluating effectiveness depends upon the "number of transfer units," defined as $[6,7,30]$

$$
\mathrm{NTU}=\frac{U A}{C_{\min }} .
$$

For counter-flow heat exchangers with balanced flow, considering the effect of longitudinal conduction, the effectiveness can be written as [6]

$$
\varepsilon=1-\left[1+\mathrm{NTU} \frac{1+\lambda \Phi}{1+\lambda \times \mathrm{NTU}}\right]^{-1}
$$

where

$$
\Phi=\sqrt{\frac{\lambda \times \mathrm{NTU}}{1+\lambda \times \mathrm{NTU}}} .
$$

When $\lambda=0$ longitudinal conduction vanishes, leading to $\varepsilon=\mathrm{NTU} /(1+\mathrm{NTU})$.

For high-effectiveness designs with small $\lambda$ (i.e., $\lambda<0.05$ ), the reduction in heat-exchanger effectiveness due to longitudinal conduction $\Delta \varepsilon$ is given as [6]

$$
\frac{\Delta \varepsilon}{\varepsilon} \approx \lambda,
$$

where $\varepsilon$ is the effectiveness calculated without longitudinal conduction.

Assuming the nominal design with $500 \mu \mathrm{m}$ alumina walls, the heat-exchanger performance depends significantly upon flow rates. Figure 5 shows predicted effectiveness as a function of balanced flow rates for two different channel hydraulic diameters with all other geometric parameters fixed at the nominal design conditions. Predictions are based upon including and neglecting longitudinal conduction. At low flow rates where the effectiveness is high, the longitudinal conduction 
plays a significant role, causing the effectiveness to be maximum at flow rates around $1.97 \times 10^{-4}$ $\mathrm{kg} \mathrm{s}^{-1}(10 \mathrm{slm})$. Neglecting longitudinal conduction would lead to predicting unrealistically high effectiveness at low flow rates. Reducing the channel height (hydraulic diameter) generally increases effectiveness, with the largest influence at relatively higher flow rates and lower effectiveness.

Continuing to assume the nominal design, longitudinal conduction is relatively unimportant at flow rates greater than about $9.87 \times 10^{-4} \mathrm{~kg} \mathrm{~s}^{-1}(50 \mathrm{slm})$. Thus, at high flow rates, reducing the thermal conductivity of the wall materials or using thinner walls produces little benefit. However, at low flow rates performance could be improved by reducing $\lambda$, either through the use of thinner walls or lower-conductivity materials. With the current PLIS process, reducing wall thickness below about $500 \mu \mathrm{m}$ is difficult. However, lower conductivity materials can be used. For example, cordierite has a significantly lower thermal conductivity of $k \approx 3 \mathrm{~W} \mathrm{~m}^{-1} \mathrm{~K}^{-1}$ compared to alumina at $k \approx 10$ $\mathrm{W} \mathrm{m}{ }^{-1} \mathrm{~K}^{-1}$.

Because reducing the thermal conductivity adversely affects the overall conductance $U A$, but beneficially affects the axial conduction factor, there is an optimal thermal conductivity for particular designs and operating circumstances. To make the present example concrete, consider the design and operating circumstances illustrated in Fig. 5a at around $3 \times 10^{-4} \mathrm{~kg} \mathrm{~s}^{-1}(15 \mathrm{slm})$. In this case reducing wall conductivity below $k=1.5 \mathrm{~W} \mathrm{~m}^{-1} \mathrm{~K}^{-1}$ reduces the effectiveness. At around $1 \times 10^{-3} \mathrm{~kg} \mathrm{~s}^{-1}$ (50 slm), the optimal thermal conductivity is about $k=5 \mathrm{~W} \mathrm{~m}^{-1} \mathrm{~K}^{-1}$, but the effectiveness is reduced very little even with much a lower thermal conductivity of around $k=1$ $\mathrm{W} \mathrm{m} \mathrm{m}^{-1} \mathrm{~K}^{-1}$.

For the nominal design with floor and channel height at $500 \mu \mathrm{m}$, balanced flow at $1.58 \times 10^{-3} \mathrm{~kg}$ $\mathrm{s}^{-1}(80 \mathrm{slm})$, the number of transfer units is estimated to be NTU $\approx 0.96$, which leads to an effectiveness of $\varepsilon \approx 49 \%$. Under these circumstances, the longitudinal conduction has a relatively small influence. However, because the dominant thermal resistance between hot and cold flow streams is convective and because the Nusselt number is essentially independent of the channel height, reducing the channel height provides a significant performance benefit. Reducing the channel height to $300 \mu \mathrm{m}$, increases the heat-transfer coefficient from $h \approx 500 \mathrm{~W} \mathrm{~m}^{-2} \mathrm{~K}^{-1}$ to $h \approx 800 \mathrm{~W} \mathrm{~m}^{-2}$ $\mathrm{K}^{-1}$ and consequently increases the effectiveness to $\varepsilon \approx 60 \%$.

At high flow rates the effectiveness decreases as flow rates increase. All other things being equal, high effectiveness is desirable. However, the net heat transferred decreases as the flow rates decrease. Thus, depending upon application requirements, there may be benefits to operating at relatively high flow rates, but with lower effectiveness.

At Reynolds numbers above around 2300 the flow can become turbulent, increasing the heattransfer coefficients compared to those predicted from Eq. 8. The heat transfer coefficients can also be higher in the entry regions of the channel before the flow is fully developed. For the heat exchanger reported in the present paper, the channel Reynolds numbers exceed 2300 at flow rates above about $100 \mathrm{slm}$, depending upon the temperatures (i.e., higher temperatures increase 


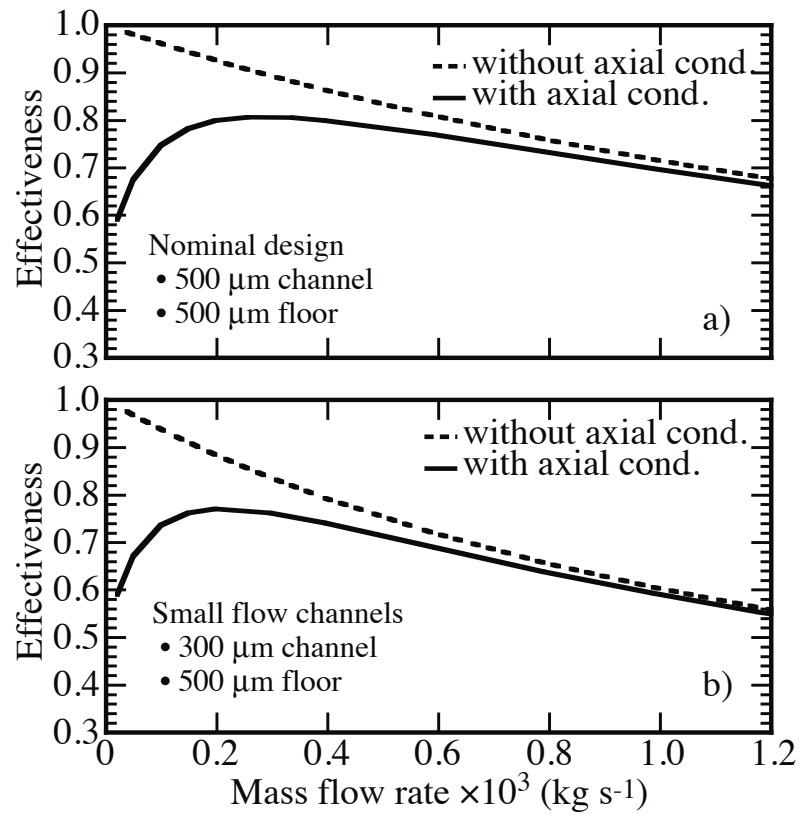

Figure 5: Heat-exchanger effectiveness as a function of balanced flow rates for two different channel hydraulic diameters.

gas-phase viscosity, reducing Reynolds numbers). Even for situations with higher heat-transfer coefficients (e.g., turbulent flow), axial conduction tends to degrade performance. Although the quantitative details would be different without fully developed laminar flow, axial conduction plays an important role in the performance of small, high-performance, counter-flow heat exchangers.

\section{PLIS Fabrication}

The PLIS fabrication begins by mixing ceramic powders with appropriate binders. In production, the green (i.e., unfired) layers that incorporate manifold and channel geometry are formed using custom dies and high-pressure hydraulic presses. However, to avoid the expense of fabricating production dies, prototype designs are machined from pressed green-state blocks. In preparation for laminating together in a hydraulic press, green layers are oriented and assembled as shown in Fig. 2. After laminating the layers in a press, the assembled part is fired. As illustrated by the scanning electron microscope (SEM) images in Fig. 6, the fired part becomes a single polycrystalline ceramic piece with essentially no evidence of the bond lines between initially laminated layers.

The PLIS manufacturing process depends upon relatively complex interactions among ceramic powders and binders, layer formation pressures, and layer lamination pressures. For example, excessive pressures during lamination can damage or crush channel ribs, while insufficient pressure 


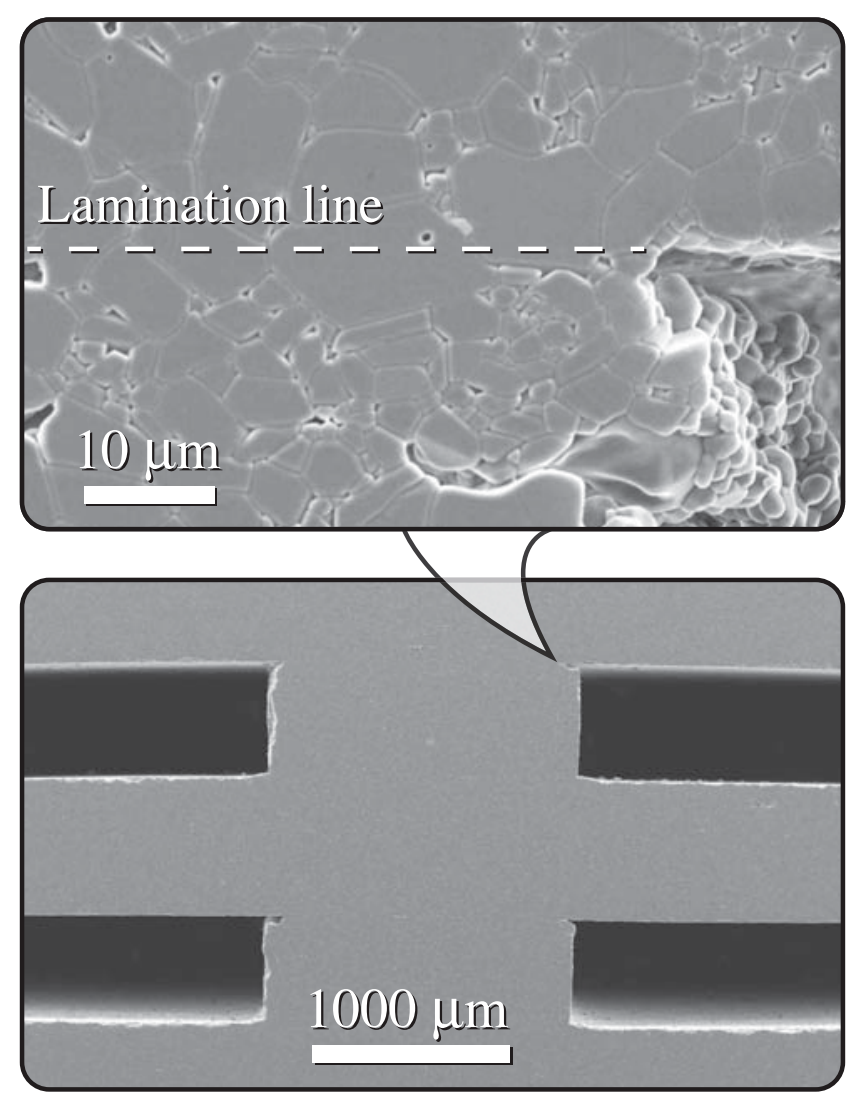

Figure 6: Scanning electron microscope images showing channel structures, with high resolution at a channel corner.

can cause poor bonding between layers. During development, a careful design of experiments process was used to determine best material combinations and processing conditions.

Figure 6 is microscopic image that shows essentially perfect polycrystalline joining between layers. In fact, the layers are not "bonded" together. Rather, after sintering the resulting part is a single polycrystalline ceramic. Prior to heat-exchanger testing, the finished parts are leak tested to an internal pressure of $3 \mathrm{~atm}$, assuring no external leaks between layers or to the outside.

The sintered ceramic yields perfect "sealing" between the hot and cold layers. However, there is usually a need at some point to join the ceramic heat exchanger to metal inlet and outlet plumbing, which may require some sort of metal-ceramic bonding and sealing. Our current heat-exchanger testing uses a metal tubing manifold and graphite compression seals between the metal manifold and the ceramic heat-exchanger body (Fig. 7). While this is a viable solution in the laboratory and for some applications, it is not a viable solution for all applications. For some applications a high-performance brazing process can be viable. Hermetic refractory-metal ceramic-to-ceramic and ceramic-to-metal braze seals have proven to be effective in non-oxidizing environments. 
The PLIS fabrication technology promises low-cost manufacturing of a high-performance system. The green (unfired) layers are produced to near net shape, thus significantly reducing complexity compared with building up structures from multiple individually tailored thin sheets. The ceramic processing can be much less costly than similar metal-based assemblies that use diffusion bonding or brazing as bonds between layers.

\section{Materials considerations}

Because they can operate at high temperature and are chemically inert, ceramics offer some significant advantages. However, ceramics also come with some potential problems. Ceramics are usually brittle, and subject to breakage at sufficiently high thermal-mechanical stress. The heat exchangers discussed in this paper, which are fabricated from 94\% alumina, are demonstrated to be robust with nominally balanced air flows at hot and cold inlet temperatures of approximately $750{ }^{\circ} \mathrm{C}$ and $30{ }^{\circ} \mathrm{C}$, respectively, and with flow rates up to $2.96 \times 10^{-3} \mathrm{~kg} \mathrm{~s}^{-1}(150 \mathrm{slm})$. Failures are usually caused by stresses associated with thermal gradients, with the absolute temperature not being too important. Temperature differences of approximately $700{ }^{\circ} \mathrm{C}$ are suitable for many applications.

The CoorsTek AD-94 Alumina material is dominantly $\mathrm{Al}_{2} \mathrm{O}_{3}$, but contains other oxides and glassy phases. Specifically, the composition is nominally $93 \% \mathrm{Al}_{2} \mathrm{O}_{3}, 4 \% \mathrm{SiO}_{2}, 0.12 \% \mathrm{Fe}_{2} \mathrm{O}_{3}, 0.25 \%$ $\mathrm{CaO}, 0.7 \% \mathrm{MgO}, 0.8 \% \mathrm{BaO}, 0.12 \% \mathrm{Na}_{2} \mathrm{O}$, and $0.7 \% \mathrm{ZrO}_{2}$. At room temperature, the material has a mass density of $3.7 \mathrm{~g} \mathrm{~cm}^{-3}$, tensile strength of $193 \mathrm{MPa}$, thermal conductivity of 22.4 $\mathrm{W} \mathrm{m}{ }^{-1} \mathrm{~K}^{-1}$, heat capacity of $880 \mathrm{~J} \mathrm{~kg}^{-1} \mathrm{~K}^{-1}$, and thermal expansion coefficient of $8.2 \times 10^{-6}$ $\mathrm{K}^{-1}$. The maximum use temperature is approximately $1500^{\circ} \mathrm{C}$.

The designs and processing are suitable to ceramics other than alumina. Being stronger than alumina, silicon carbide ( $\mathrm{SiC}$ ) can offer advantages. Cordierite is not as strong as $\mathrm{SiC}$ or alumina, but has a very low thermal-expansion coefficient. Thus, it can withstand high temperature gradients with acceptable thermal stresses. Ongoing efforts are directed toward developing appropriate binder formulations and processing parameters for both $\mathrm{SiC}$ and cordierite.

Some applications demand high internal pressures. Thus, in addition to thermally induced stresses, the system must also withstand pressure-induced stresses. The intimate bonding between layers forming a monolithic ceramic body provides great strength. However, the current heat exchangers have been tested to only $0.3 \mathrm{MPa}(3 \mathrm{~atm})$ at room temperature. 


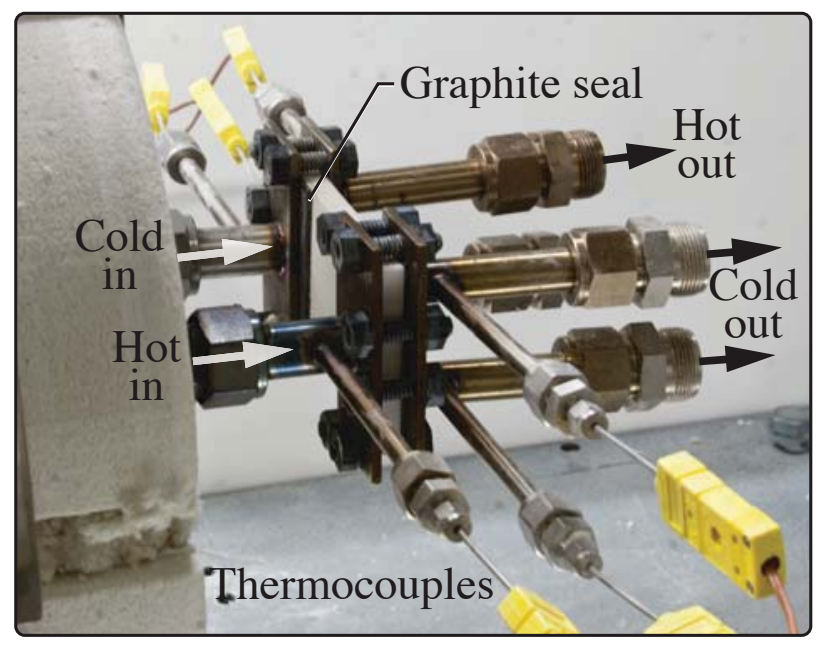

Figure 7: Heat exchanger in test stand with metal fixture and graphite compression seals. During testing, the entire assembly is wrapped in thick fiberglass insulation.

\section{Performance evaluation}

A relatively straightforward test stand has been developed to measure heat-exchanger performance. Mass flow controllers are used to specify hot and cold inlet air flow rates. The mass-flow controllers (Alicat Scientific MCR-500SLPM) have specified accuracy of $\pm 0.8 \%$ of reading plus $0.2 \%$ of full scale, corresponding to approximately \pm 2.2 standard liters per minute at 150 standard liters per minute. Type-K thermocouples are used to measure temperatures of the inlet and outlet air. The thermocouples (Omega KMQSS-062U-6) have specified accuracy to within $2.2{ }^{\circ} \mathrm{C}$ or $0.75 \%$ of measured temperature, corresponding to about $5.6^{\circ} \mathrm{C}$ at $750{ }^{\circ} \mathrm{C}$. Hot-side air is heated by passing room-temperature air through multiple small tubes that are positioned within a large hightemperature furnace. The hot inlet temperature is varied by changing the electrical input to the tube furnace. The settling time associated with changing inlet temperature by $50{ }^{\circ} \mathrm{C}$ is approximately 15 minutes; data is taken after waiting 30 minutes. Once the steady inlet temperatures are achieved, the standard deviation temperature variation is less than $\pm 0.5^{\circ} \mathrm{C}$. The mass-flow controllers and the furnace, as well as data collection, are coordinated through a LabVIEW ${ }^{\circledR}$ computer $^{\circ}$ interface.

Figure 7 shows an assembly that is being prepared for testing. Inlet and exhaust flows are supplied to the heat exchanger body through a stainless steel manifold. Graphite gaskets are used to provide a seal between the steel manifolds and the ceramic heat exchanger body. The graphite is compressed using molybdenum bolts. Molybdenum is chosen because it has low thermal expansion, thus tending to retain compression at high temperature. Thermocouples are positioned at the centerline of the inlet and outlet tubes, just upstream and downstream of the heat-exchanger itself. Prior to testing, thick fiberglass insulation is packed around the assembly (heat exchanger 
and manifold). Although heat loss through the insulation is not directly measured, the heat transfer from the hot flow is always measured to be within a few percent of the heat transferred to the cold stream.

In addition to reporting inlet and outlet temperatures, the net heat transferred and heat-exchanger effectiveness are also evaluated. The maximum heat that can possibly be transferred is given as [30]

$$
Q_{\max }=C_{\min }\left(T_{\text {hot,in }}-T_{\text {cold,in }}\right),
$$

where $C_{\min }$ is the minimum capacity rate and $T_{\text {hot,in }}$ and $T_{\text {cold,in }}$ are the hot and cold inlet temperatures, respectively. The capacity rates are evaluated as $C=\dot{m} c_{p}$, where $\dot{m}$ and $c_{p}$ are the mass flow rate and heat capacity of the inlet flows. The heat exchanger effectiveness is defined as

$$
\varepsilon=\frac{Q}{Q_{\max }},
$$

where $Q$ is the actual heat transferred. The actual heat transferred is evaluated in terms of the enthalpy change between inlet and outlet flows. That is

$$
\begin{gathered}
Q_{\text {hot }}=\dot{m}_{\text {hot }}\left(h_{\text {hot,out }}-h_{\text {hot,in }}\right), \\
Q_{\text {cold }}=\dot{m}_{\text {cold }}\left(h_{\text {cold,out }}-h_{\text {cold,in }}\right),
\end{gathered}
$$

where $h$ is the enthaply. If the heat exchanger has no external losses, $Q_{\text {hot }}$ and $Q_{\text {cold }}$ must be equal and opposite. Because of small external losses through the insulation, the magnitude of $Q_{\text {hot }}$ is slightly greater than $Q_{\text {cold }}$. For example, using data for the six experiments shown in Fig. 8, the heat loss averaged about $15 \mathrm{~W}$, corresponding to an average heat loss of about $3 \%$. For all experiments reported, the heat losses were always less than 5\% of the net heat transferred. The effectivenesses reported in this paper are evaluated based upon the heat transferred to the cold flow.

\subsection{Inlet temperature}

Figure 8 illustrates measured heat-exchanger performance as a function of hot-side inlet temperature with hot- and cold-side flow rates fixed at $1.97 \times 10^{-3} \mathrm{~kg} \mathrm{~s}^{-1}(100 \mathrm{slm})$. In all cases the cold-side inlet temperature is approximately $40{ }^{\circ} \mathrm{C}$. As the hot-side inlet temperature increases, heat transfer within the the metal manifolds can increase the cold-side inlet temperature by a few degrees. At the highest inlet temperature of $750{ }^{\circ} \mathrm{C}$, the net heat transferred is approximately 750 $\mathrm{W}$ and the effectiveness is nearly constant at approximately $55 \%$. The outlet temperatures and net heat transferred are nearly linear functions of the hot inlet temperature.

\subsection{Flow rates}

Figure 9 illustrates measured performance as a function of balanced inlet flow rates, with the hotand cold-side inlet temperatures fixed at $500{ }^{\circ} \mathrm{C}$ and $40{ }^{\circ} \mathrm{C}$, respectively. At low flow rates, the 


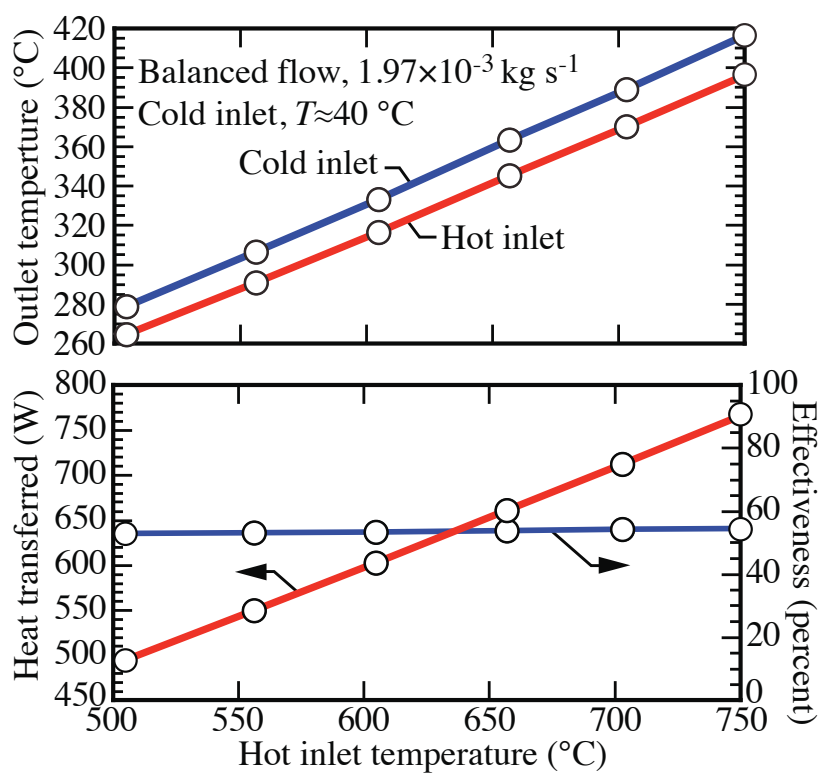

Figure 8: Measured heat-exchanger performance as a function of hot-side inlet temperature.

differences between inlet and outlet temperatures is high. As the flow rates increase, the hot-side outlet temperature increases, the cold-side outlet temperature decreases, and there is a net increase in heat transferred. The effectiveness decreases from approximately $70 \%$ at low flow rates of $4.93 \times 10^{-4} \mathrm{~kg} \mathrm{~s}^{-1}(25 \mathrm{slm})$ to approximately $50 \%$ at the highest flow rates of $150 \mathrm{slm}$.

\subsection{Unbalanced flow}

Figure 10 illustrates performance with unbalanced flow. In this case, the hot inlet flow is fixed at $700{ }^{\circ} \mathrm{C}$ and $1.58 \times 10^{-3} \mathrm{~kg} \mathrm{~s}^{-1}(80 \mathrm{slm})$, while the cold inlet flow rate varies from $1.18 \times 10^{-3}$ $\mathrm{kg} \mathrm{s}^{-1}$ to $1.97 \times 10^{-3} \mathrm{~kg} \mathrm{~s}^{-1}$ (60 slm to $100 \mathrm{slm}$ ). Both the hot- and cold-side outlet temperatures decrease as the cold-side flow rate increases. According to heat-exchanger theory (cf., [30]), the effectiveness is minimum when the ratio of inlet capacity rates (i.e., product of mass flow rate and specific heat, $C=\dot{m} c_{p}$ ) is unity. In the experiments shown in Fig. 10, the mass flow rates are controlled by mass flow controllers. However, because the specific heat of air varies with temperature (for air at $700{ }^{\circ} \mathrm{C}, c_{p} \approx 1140 \mathrm{~J} \mathrm{~kg}^{-1} \mathrm{~K}^{-1}$; at $50{ }^{\circ} \mathrm{C}, c_{p} \approx 1008 \mathrm{~J} \mathrm{~kg}^{-1} \mathrm{~K}^{-1}$ ) and the average temperatures are different on the two sides, the capacity rates are not equal when the massflow rates are equal. Thus, the capacity rates are approximately equal at a cold-flow mass-flow rate of $1.8 \times 10^{-3} \mathrm{~kg} \mathrm{~s}^{-1}(90 \mathrm{slm})$, which is the point of minimum effectiveness shown in Fig. 10. 


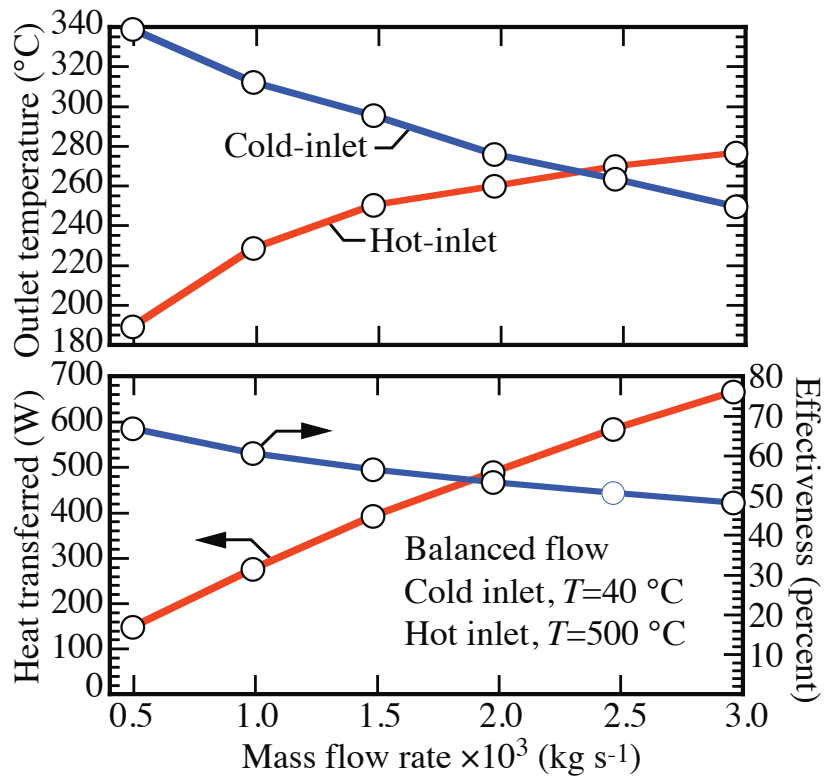

Figure 9: Measured heat-exchanger performance as a function of inlet flow rates.

\subsection{Pressure drop}

Figure 12 shows measured pressure drop under room-temperature conditions and pressure drop predicted by the three-dimensional CFD model. Up to about $2 \times 10^{-3} \mathrm{~kg} \mathrm{~s}^{-1}$ (100 slm), the model and measurements are in excellent agreement. At higher flow rates there may be transition to turbulent flow, which is possibly the cause of some disagreement between model and measurement.

The current experiment is not configured to measure pressure drop during high-temperature operation. However, the pressure drop scales with fluid viscosity, which, according to kinetic theory, scales approximately as $T^{0.65}$ [27]. Given good agreement for room-temperature operation, the CFD model, which considers temperature-dependent properties, is expected to provide accurate pressure predictions for high-temperature operation.

Generally speaking, all other performance measures being equal, pressure drop should be as low as possible. Importantly, however, "high" and "low" pressure drop must be understood in a relative context. The ratio of heat transfer to friction loss is often an important performance parameter. Microchannel heat exchangers are designed to achieve excellent heat-transfer performance relative to pressure drop, and the present design is very good in this regard. Pressure drop can be reduced, but only at the expense of making the heat exchanger significantly larger. The present design, which is ideally sized for mass-flow rates below $3 \times 10^{-4} \mathrm{~kg} \mathrm{~s}^{-1}(20 \mathrm{slm})$, incorporates a relatively large heat-transfer surface area into a small volume. At these flow rates, the effectiveness is high and the pressure drop is quite low for the NTUs delivered. Indeed, achieving these attributes is a 


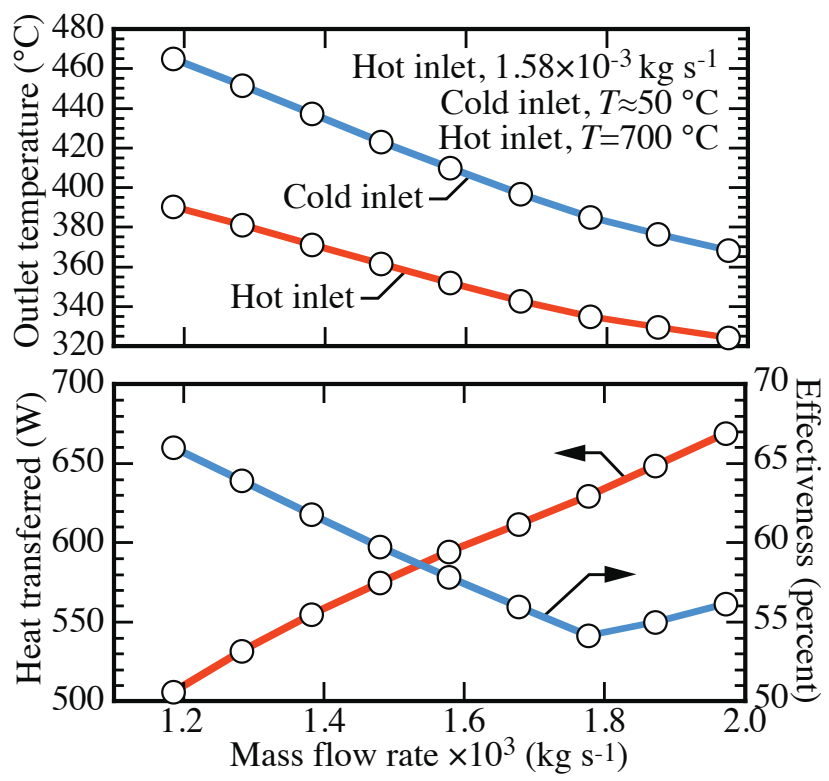

Figure 10: Measured performance as a function of cold-side inlet flow rate with hot-side inlet temperature and flow rate fixed.

primary objective of compact heat exchangers.

Following an analysis introduced by Kays and London [6, 7, 26], the "friction power per unit of surface area" can be represented as

$$
E=\frac{\Delta p}{\Delta A_{\mathrm{s}}} \frac{\dot{m}}{\rho}=\frac{\Delta p}{\Delta A_{\mathrm{s}}} u_{\mathrm{m}} A_{\mathrm{c}}=\frac{\Delta p}{\Delta A_{\mathrm{s}}} \dot{V},
$$

where $\Delta p$ is the pressure drop, $\Delta A_{\mathrm{s}}$ is the heat-transfer area, $u_{\mathrm{m}}$ is the mean fluid velocity, and $A_{\mathrm{c}}$ is the channel cross-sectional area. The pumping power is $\Delta p \dot{V}$, where $\dot{V}$ is the volumetric flow rate. For a rectangular channel with height $H$ and width $W$, the heat-transfer surface area is $\Delta A_{\mathrm{s}}=W L$ (i.e., the floor area between the hot and cold fluids). The heat-transfer coefficient $h$, which can be interpreted as the "heat transfer power per unit of surface area for one degree of temperature difference," can be evaluated from the Nusselt number as

$$
h=\frac{\mathrm{Nu} k}{D_{\mathrm{h}}} .
$$

Assuming a channel width of $W=5 \mathrm{~mm}$ and properties of air at $T=600 \mathrm{~K}$, Fig. 11 shows the ratio $E / h$ as a function of Reynolds number for three channel heights. Both the heat transfer and the pumping losses increase greatly as functions of increasing Reynolds number. At low Reynolds number, the heat transfer dominates (i.e., $E / h \ll 1$ ). However, at high Reynolds number the pumping losses can greatly exceed the heat transfer (i.e., $E / h \gg 1$ ). 


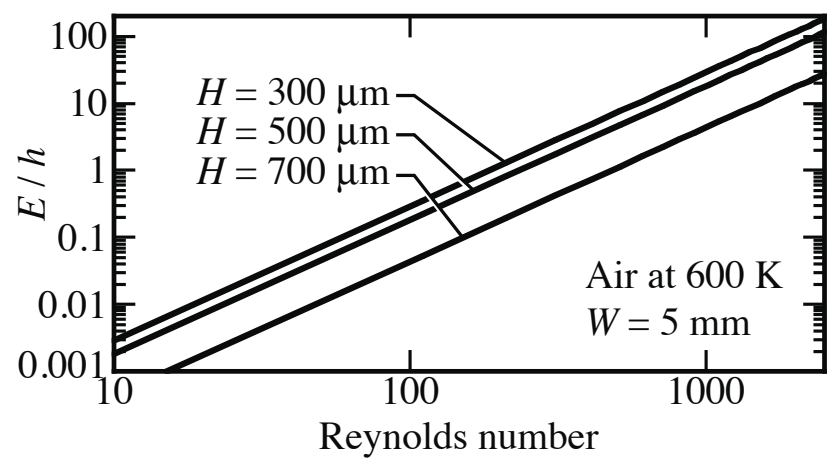

Figure 11: Ratio of friction loss $E$ and heat transfer $h$ as a function of Reynolds number for three rectangular channel aspect ratios.

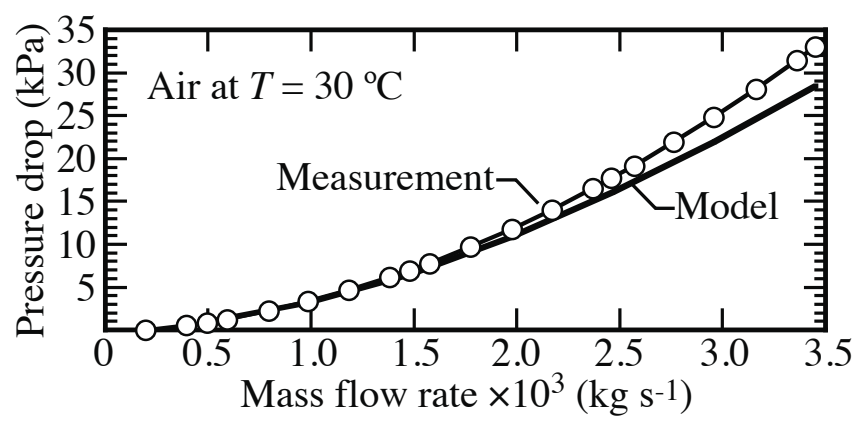

Figure 12: Measured and predicted pressure drop as a function of room-temperature air flow rate.

Another relevant measure of heat-exchanger performance is the "surface area goodness factor," which can be represented as the ratio [6]

$$
\frac{\mathrm{StPr}^{2 / 3}}{f}=\frac{\mathrm{Nu}}{\operatorname{Pr}^{1 / 3} \operatorname{Re} f},
$$

where St is the Stanton number and $f$ is the friction factor. Assuming fully developed flow in rectangular channels, this measure is a function of the channel aspect ratio. The present microchannel design, with an aspect ratio of $\alpha \approx 0.18$ produces a surface-area goodness factor of about 0.35 , which is quite good.

\section{Summary and conclusions}

An all-ceramic compact counterflow microchannel heat exchanger has been designed, fabricated, and evaluated. The design process is assisted by three-dimensional simulation of the fluid flow 
and conjugate heat transfer behavior as well as traditional heat-exchanger theory. A manufacturing process called PLIS enables cost-effective fabrication of relatively complex internal manifolds and microchannels. Ceramic materials enable applications at high-temperature and in harsh chemical environments that may be difficult to achieve with metal heat exchangers.

In addition to expanding operating space with ceramics, the PLIS process has the potential to reduce manufacturing costs relative to a comparable metal heat exchanger. Compared to approaches in which layers are fabricated by diffusion bonding multiple thin metal shims, the PLIS approach requires fabricating and handling far fewer parts. However, because metal wall thicknesses and channel dimensions can be much thinner than is possible with ceramics, metal heat-exchangers may be able to achieve higher performance.

Scaling from the current kilowatt-scale systems to much larger capacities presents some significant challenges. The current system is a four-layer design with a footprint of $50 \mathrm{~mm}$ by $100 \mathrm{~mm}$. With available processing equipment the system can be scaled to a ten-layer stack with a $100 \mathrm{~mm}$ by $200 \mathrm{~mm}$ footprint, improving heat-transfer capacity by roughly a factor of ten. The manifold design enables layering up with negligible effect on pressure drop. However, further scaling probably requires serial staging of multiple units. Serial staging of thermally isolated small units in a counter-flow configuration can improve overall effectiveness. However, because the microchannel flow length is increased, serial staging also increases pressure drop.

\section{References}

[1] S.G. Kandlikar, S. Garimella, D. Li, S. Colin, and M.R. King. Heat Transfer and Fluid Flow in Minichannels and Microchannels. Elsevier, Amsterdam, 2006.

[2] L.P. Yarin, A. Mosyak, and G. Hetsroni. Fluid flow, heat transfer and boiling in microchannels. Springer, Berlin, 2009.

[3] Z. Anxionnaz, M. Cabassud, C. Gourdon, and P. Tochon. Heat exchanger/reactors (HEX reactors): Concepts, technologies: State-of-the-art. Chem. Eng. Process., 47:2029-2050, 2008.

[4] R.K. Shah, B. Thonon, and D.M. Benforado. Opportunities for heat exchanger applications in environmental systems. Appl. Therm. Eng., 20:631-650, 2000.

[5] A. Sommers, Q. Wang, X. Han, C. T'Joen, Y. Park, and A. Jacobi. Ceramics and ceramic matrix composites for heat exchangers in advanced thermal systems-A review. Appl. Therm. Eng., 30:1277-1291, 2010.

[6] R.K. Shah and D.P. Sekulić. Fundamentals of Heat Exchanger Design. Wiley, Hoboken, NJ, 2003. 
[7] W.M. Kays and A.L. London. Compact Heat Exchangers. Krieger Publishing Company, Malabar, FL, third edition, 1998.

[8] Y. Takeuchi, C. Park, K. Noborio, Y. Yamamoto, and S. Konishia. Heat transfer in SiC compact heat exchanger. Fusion Eng. Des., in press:doi:10.1016/j.fusengdes.2010.03.017, 2010 .

[9] J. Schulte-Fischedick, V. Dreißigacker, and R. Tamme. An innovative ceramic high temperature plate-fin heat exchanger for EFCC processes. Appl. Therm. Eng., 27:1285-1294, 2007.

[10] B. Alm, U. Imke, R. Knitter, U. Schygulla, and S. Zimmermann. Testing and simulation of ceramic micro heat exchangers. Chem. Engr. J., 135S:S179-S184, 2008.

[11] A.G. Fedorov and R. Viskanta. Three-dimensional conjugate heat transfer in the microchannel heat sink for electronic packaging. Int. J. Heat Mass Trans., 43:399-415, 2000.

[12] T. Dang, J.T. Teng, and J.C. Chu. A study on the simulation and experiment of a microchannel counter-flow heat exchanger. Appl. Therm. Eng., 30:2163-2172, 2010.

[13] P.X. Jiang, M.H. Fan, G.S. Si, and Z.P. Ren. Thermal-hydraulic performance of small scale micro-channel and porous-media heat-exchangers. Int. J. Heat Mass Trans., 44:1039-1051, 2001.

[14] Z.Y. Guo and Z.X. Li. Size effect on microscale single-phase flow and heat transfer. Intl. J. Heat Mass Trans., 46:149-159, 2003.

[15] M.I. Hasan, A.A. Rageb, M. Yaghoubi, and H. Homayoni. Influence of channel geometry on the performance of a counter flow microchannel heat exchanger. Int. J. Therm. Sci., 48:16071618, 2009.

[16] E.V. Rebrov, J.C. Schouten, and M.H.J.M. de Croon. Single-phase fluid flow distribution and heat transfer in microstructured reactors. Chem. Eng. Sci., in press:doi:10.1016/j.ces.2010.05.044, 2010.

[17] J.J. Brandner, E. Anurjew, L. Bohn, E. Hansjosten, T. Henning, U. Schygulla, A. Wenka, and K. Schubert. Concepts and realization of microstructure heat exchangers for enhanced heat transfer. Exp. Therm Fluid Sci., 30:801-809, 2006.

[18] M. Ciofalo. Local effects of longitudinal heat conduction in plate heat exchangers. Int. J. Heat Mass Trans., 50:3019-3025, 2007.

[19] A.M. Moreno and B.A. Wilhite. Autothermal hydrogen generation from methanol in a ceramic microchannel network. J. Power Sources, 195:1964-1970, 2010.

[20] H. Zhang, L. Wang, S. Weng, and M. Su. Performance research on the compact heat exchange reformer used for high temperature fuel cell systems. J. Power Sources, 183:282-294, 2008. 
[21] K.P. Brooks, J. Hu, H. Zhu, and R.J. Kee. Methanation of carbon dioxide by hydrogen reduction using the sabatier process in microchannel reactors. Chem. Engr. Sci., 62:11611170, 2007.

[22] P. Pfiefer, K. Schubert, and G. Emig. Preparation of copper catalyst washcoats for methanol steam reforming in microchannels based on nanoparticles. Appl. Catal. A: General, 286:175$185,2005$.

[23] I. Aartun, H.J. Venvik, A. Holmen, P. Pfiefer, O. Görke, and K. Schubert. Temperature profiles and residence time effects during catalytic partial oxidation and oxidative steam reforming of propane in metallic microchannel reactors. Catal. Today, 110:98-107, 2005.

[24] S.R. Deshmukh and D.G. Vlachos. CFD simulations of coupled, countercurrent combustor/reformer microdevices for hydrogen production. Ind. Eng. Chem. Res., 44:4982-4992, 2005.

[25] J.E. Hesselgreaves. Compact Heat Exchangers. Elsevier, Amsterdam, 2001.

[26] W.M. Kays and M.E. Crawford. Convective heat and mass transfer. McGraw Hill, New York, NY, 1987.

[27] R.J. Kee, M.E. Coltrin, and P. Glarborg. Chemically Reacting Flow: Theory and Practice. John Wiley, Hoboken, NJ, 2003.

[28] R.J. Kee, P. Korada, K. Walters, and M. Pavol. A generalized model of the flow distribution in channel networks of planar fuel cells. J. Power Sources, 109:148-159, 2002.

[29] Fluent software package, Version 13.0, ANSYS, inc. Lebanon, NH. see also www.ansys.com.

[30] F.D. Incropera, D.P. DeWitt, T.L Bergman, and A.S. Lavine. Fundamentals of Heat and Mass Transfer. John Wiley and Sons, Hoboken, NJ, 6th edition, 2007. 